\title{
Erster Beratungsgegenstand: Gesetzgebung im Rechtsstaat
}

1. Bericht von Professor Dr. Kurt Eichenberger, Basel*)

\section{Inhalt}

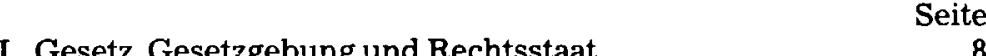

I. Gesetz, Gesetzgebung und Rechtsstaat . . . . . . . . . 8

1. Die Offenheit des Rechtsstaatsbegriffs. . . . . . . . 8

2. Der ,neue" Gesetzgebungsstaat. . . . . . . . . . 9

3. Die rechtsstaatliche Legitimation von Gesetz und Gesetzgebung durch Sachqualität und Demokratie-

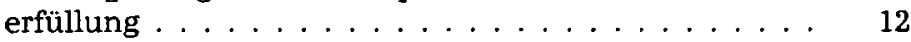

II. Kritiken an der Gesetzgebung. . . . . . . . . . . . . . 13

1. Leiden des Gesetzes und der Gesetzgebung. . . . . . . . 13

2. Ausschnitte aus der Mängelliste. . . . . . . . . . . . 15

a) Normenflut. . . . . . . . . . . . . . . . . 15

b) Strukturmängel . . . . . . . . . . . . . . . 16

c) Inhaltliche Unrichtigkeiten . . . . . . . . . . . 16

d) Kommunikative Unkorrektheiten . . . . . . . . . 17

e) Situation der Gesetzgebungsorgane . . . . . . . . 17

3. Die Brüchigkeit der Legitimation der Gesetzgebung. . . 18

III. Eine generalisierende Lagebeurteilung . . . . . . . . . . . . 19

1. Hinreichende Gesetzgebung. . . . . . . . . . . . . 19

2. Kompensationen bei mangelhafter Gesetzgebung . . . . 19

3. Sanierungsräume . . . . . . . . . . . . 20

IV. Zur Beherrschung der Normierungsmasse . . . . . . . 21

1. Bleibende Normierungsbedürfnisse . . . . . . . . . 21

2. Die Hoffnung auf entlastendes Verfahrensrecht . . . . 22

3. Notwendigkeitsprüfungen. . . . . . . . . . . . 2 23

V. Zur Verteilung der Rechtsetzungsaufgabe . . . . . . . 25

1. Die gegenwärtige Situation . . . . . . . . . . . . 25

2. Entwicklungslinien. . . . . . . . . . . . . . 26

vI. Zur legitimierenden Qualitätssicherung der Inhaltsgestaltung . . . . . . . . . . . . . 28

1. Die Vielheit der Beteiligten an der Gesetzgebung . . . . 28

2. Die tragende Präparation. . . . . . . . . . . . . 29

3. Die Konvergenz der Rechtsetzung bei der Exekutive . . 32

4. Orientierungspunkte . . . . . . . . . . . . . 33

*) Wegen des limitierten Raumes für Anmerkungen beschränke ich mich auf wenige Nachweise von unmittelbaren Übernahmen. 


\section{Gesetz, Gesetzgebung und Rechtsstaat}

\section{Die Offenheit des Rechtsstaatsbegriffs}

Das Gesetz hat eine dominante Position in der westlichen Staats- und Rechtswelt bisher behauptet. Von seinem verbliebenen, obwohl verbleichenden Glanze ist auch die Gesetzgebung noch angestrahlt, verstanden als das geordnete Verfahren herausgehobener Organe, mit dem Parlament im Zentrum, aus dem in Form des Gesetzes vorwiegend rechtsetzende Geltungsanordnungen hervorgehen. Auf das Gesetz zielt ein Großteil der politischen Aktivitäten ab, und zur Gesetzgebung drängt hin, wer staatliche Macht und Wirkung hat oder sucht. Wenn wir hier und heute nach der „Gesetzgebung im Rechtsstaat" fragen, so wird verallgemeinert, nicht die positivrechtliche Situation der Bundesrepublik, Österreichs oder der Schweiz unmittelbar und vergleichend angesprochen. Doch mit der Verknüpfung wird das unübersehbare Problemfeld des Rechtsstaates betreten. Die „Wertidee des Rechtsstaates“ (Werner Kägi/Hans Huber) ist nämlich dermaßen weit, offen und wandlungsbereit, daß sie für eine Gesetzgebung schlechthin ganz wenige präfixierte Gestaltungen und überdauernde Festlegungen zu treffen vermag. Die Idee des Rechtsstaates, die in der Menschenwürde und mit der Freiheit im Anliegen der Machtbegrenzungen gründet, erlangt ihre Konturen und verdichtet sich zum staatsprägenden Strukturprinzip (Klaus Stern) von relativ gesichertem Inhalt weitgehend erst in der einzelnen Verfassung und - wir müssen diesen Umstand deutlich betonen - mit der Gesetzgebung. Der Rechtsstaat, selbst mit der erststufigen Konkretisierung in der Verfassung, ist also inhaltlich keine vorgegebene Gewissheit, an die sich die Gesetzgebung determiniert halten könnte, sondern wird in besonderen "hermeneutischen Zirkeln" laufend ermittelt. Deswegen hat die Frage nach der "Gesetzgebung im Rechtsstaat" immer zugleich die weite Problematik von Idee und Prinzip des Rechtsstaates überhaupt auf dem Tisch. Also müßten wir uns auch ausgiebig über den Rechtsstaat unterhalten.

Unter dem Zwang der Begrenzung übe ich mich jedoch in Auslassungen und in der Willkür von punktuellen Auslesen. Ich schiebe namentlich die Rechtsstaatsproblematik möglichst beiseite und setze hier, wie beim Gesetz ebenfalls, als bekannt voraus, was in der Bundesrepublik und in Österreich dazu in den letzten Jahren ausgiebig und geistreich erörtert wurde. Ferner suche ich Sie tunlichst zu verschonen von Sonderheiten der schweizerischen Referendumsdemokratie, in der unser Gegenstand allerdings prononcierte Züge annimmt, ohne aber 
darnit anderen westlichen Staaten sichere Ausrichțungen bieten zu können.

\section{Der „neue" Gesetzgebungsstaat}

Immerhin verweile ich einen Augenblick bei jenen allgemeinen Beziehungen von Rechtsstaat, Gesetz und Gesetzgebung.

a) Das Rechtsstaatsprinzip wird zur begrifflichen Erfassung und praktischen Ausschöpfung gerne in „Elemente“, „Bestandteile“, „Grundpostulate“, „Folgerungen“, „Gebote“ ausgegliedert. Theodor Maunz zählt acht auf, Klaus Stern breitet sieben aus, Ulrich Scheuner erwähnt elf, Werner Kägi bringt es auf neun ${ }^{1}$ : Darunter figuriert immer das weit gedeutete Legalitätsprinzip mit seinen Begehren, daß staatliche Tätigkeiten prinzipiell vom Gesetze getragen und - freilich different - davon bestimmt oder doch begrenzt seien. Die Forderung der Gesetzmäßigkeit gibt - vollends allerdings erst mit weiteren „Bestandteilen", insbesondere mit der Gewaltenteilung, dem Rechtsschutz, der Gleichheitsforderung, der Grundrechtsverwirklichung und den rechtlichen Verantwortlichkeiten - dem Gesetz eine doppelte rechtsstaatliche Begründetheit: Es ist selbst ein derartiges Rechtsstaatselement und verkörpert damit einen eigenständigen rechtsstaatlichen Zielwert; es ist rechtsstaatlicher Sinn für sich und Aufgabe an sich. Daneben aber ist es Instrument. Es ist maßgeblich beteiligt, wenn weitere Rechtsstaatselemente geformt, gefördert, gestaltet, institutionalisiert werden. Bleibt es als Mittel aus oder versagt es qualitativ, kommen die anderen rechtsstaatlichen Bestandteile nicht oder nur rudimentär zum Tragen. Die zweifache Sinngebung des Gesetzes aber hebt die Gesetzgebung zum kritischen Angelpunkt realisierbarer Rechtsstaatlichkeit.

b) Diese Verknüpfung verstärkt sich durch das Demokratiegebot. Für Werner Kägi, dem ein größerer Teil der schweizerischen Lehre hierin folgt, ist Demokratie meist selbst und direkt dem Rechtsstaat essentiell zugehörig; sie macht gerade$\mathrm{zu}$ einen Rechtsstaatsbestandteil aus ${ }^{2}$. Andere Auffassungen

1 Theodor Maunz, Deutsches Staatsrecht, 23. Aufl., 1980, S. 74f.; Klaus Stern, Das Staatsrecht der Bundesrepublik Deutschland, I, 1977, S. $411 \mathrm{ff}$; Ulrich Scheuner, Die neuere Entwicklung des Rechtsstaats in Deutschland, in: „Staatstheorie und Staatsrecht", Gesammelte Schriften, 1978, S. $208 \mathrm{ff}$; Werner Kägi, Zur Entwicklung des schweizerischen Rechtsstaates seit 1848, ZSR 71 (1952) I, S. $174 \mathrm{ff}$.

"Werner Kägi (Anm.1), S. $197 \mathrm{f} ., 205 \mathrm{ff}$; Richard Bäumlin, Die rechtsstaatliche Demokratie, 1954, S. $90 \mathrm{ff}$; ders., Der schweizerische Rechtsstaatsgedanke, ZBJV 101 (1965), S. $81 \mathrm{ff}$. 
verstehen Demokratie als selbständiges Strukturprinzip des Staates, ordnen es aber regelmäßig dem Rechtsstaat zu und weisen unlösliche Verflechtungen nach. Für unsere heutige Erörterung mag der unterschiedliche Ansatz belanglos sein, wenn nur die gleichbleibende Rolle des Gesetzes beachtet wird: Demokratie erfüllt sich wesentlich in Gestalt der Gesetzgebung, und müssen Rechtsstaatlichkeit und Demokratieprinzip zueinander gebracht werden, so ist das Gesetz die Klammer, die Gesetzgebung als Prozeß die zusammenführende Garantin. Anders gewendet: Rechtsstaatliche Demokratie verwirklicht sich entscheidend in und mit zureichender Gesetzgebung. Sie ist, wenn wir die heiklen Worte neu und behutsam wagen: Gesetzesstaat und Gesetzgebungsstaat, das heißt ein Staat als volitiver „Macher", der sich herausnimmt, sich und seine Rechtsordnung nach den Vorstellungen der legiferierenden Menschen zu gestalten.

c) Rechtsstaat als Gesetzgebungsstaat wird elementar erweitert durch die Sozialstaatlichkeit. Der Sozialstaat, trotz seinen weitläufigen und stellenweise divergenten Umschreibungen, ist voll und kräftig gegenwärtig, und der westliche Staat bekennt sich durchwegs zu einem sozialstaatlichen Strukturprinzip. Dieses aber geht, ähnlich wie die Demokratie, zunehmend in den Rechtsstaat ein oder sucht die unlösbare Zuordnung ${ }^{3}$. In gesteigertem Ausma $ß$ findet der Sozialstaat

${ }^{3}$ Die Unsicherheit wächst wieder, ob der Begriff des Sozialstaats tauglich gefaßt, begrenzt und für die politisch-staatsrechtliche Verwendung operational gemacht werden kann. Die Verknüpfung mit der Rechtsstaatlichkeit beruhigt vorerst und garantiert die Beurteilungen unter Gesichtspunkten des Maßes und der rechtlichen Zusammenhänge. Allein, die Rechtsstaatlichkeit ist ihrerseits offen und wird mitgeprägt durch die einfließenden Gebote sozialer Gerechtigkeit, für die das tradierte rechtsstaatliche Begriffs- und Vorstellungsarsenal nicht hinreicht und offensichtlich nicht erheblich erweitert werden kann. Die Problematik der Verknüpfung von Rechts- und Sozialstaat scheint sich bei den sozialen Grundrechten einzupendeln, was indessen Sicht und Möglichkeit verengt.

Zur Problematik vgl. das von Hans Huber verfaßte Kapitel über die Menschenrechte im Schlußbericht der Arbeitsgruppe für die Vorbereitung einer Totalrevision der Bundesverfassung (Arbeitsgruppe Wahlen), VI, 1973, S. $62 \mathrm{ff}$., insb. S. $180 \mathrm{ff}$; Jörg P. Müller, Soziale Grundrechte in der Verfassung?, ZSR 92 (1973) II, S. $758 \mathrm{ff}$., $825 \mathrm{ff}$., $899 \mathrm{ff}$. und $921 \mathrm{ff}$; Josef Isensee, Verfassung ohne soziale Grundrechte, Ein Wesenszug des Grundgesetzes, in: Der Staat 19 (1980), S. $367 \mathrm{ff}$.; Karl Doehring, Sozialstaat, Rechtsstaat und freiheitlich-demokratische 
und dann der soziale Rechtsstaat wie Ulrich Scheuner und Peter Badura es in der neuen Festschrift für Hans Huber unübertrefflich geschildert haben, im Gesetz das zugkräftige Mittel zu seiner Ausgestaltung, Ausstattung und Durchführung. Die jetzt vorwiegend instrumentale Funktion des Gesetzes nimmt die Steuerungs-, Leistungs- und Ausgleichsfunktionen auf und hebt die Gesetzgebung in den bewegenden Mittelpunkt der politisch-staatlichen Sozialgestaltung. So diffus und zukunftsträchtig das sozialstaatliche Strukturprinzip sich ausnimmt, so sicher steht fest, daß der soziale Rechtsstaat Gesetzes- und Gesetzgebungsstaat sein muß. Und er ist es gesteigert, freilich zugleich alteriert und sonderbar hingewandt zu verwaltungsstaatlichen und justizstaatlichen Faktoren ${ }^{5}$.

d) Der potenzierte Gesetzes- und Gesetzgebungsstaat der Gegenwart ist nicht mehr derjenige gleichen Namens aus der Zeit rings um den Positivismus, der dem Gesetzgeber ohne materiale Bindungen an Verfassung, Grundrechte und Zielanweisungen fast ganz freie Hand gelassen hat, also in der Periode der sozusagen naiven Gesetzesgläubigkeit, der die damaligen Rechtsstaatsauffassungen kaum Bedenken eingepflanzt haben. Ernst-Wolfgang Böckenförde hat die bewegte Geschichte dargelegt ${ }^{6}$. In der zweiten Hälfte unseres Jahrhunderts beste-

Grundordnung, in: Zweimonatsschrift für Fragen der Zeit 23 (1978), Sonderheft, passim; ders., Alternativen des Sozialstaats, in: Detlef Merten/Rudolf Morsey (Hrsg.), 30 Jahre Grundgesetz, 1979, S. $125 \mathrm{ff}$; ders., Staatsrecht der Bundesrepublik Deitschland, 2. Aufl., 1980, S. $252 \mathrm{ff}$.

- Ulrich Scheuner, Die Funktion des Gesetzes im Sozialstaat, in: „,Recht als Prozeß und Gefüge“, (II.) Festschrift für Hans Huber, 1981, S. $127 \mathrm{ff}$; Peter Badura, Planung durch Gesetz, ebenda, S. $15 \mathrm{ff}$.

${ }_{5}^{5}$ Der Sozialstaat ist ein kumulierter Funktionenstaat. Er fordert alle staatlichen Tätigkeiten zu Spitzenleistungen heraus, gibt jedoch je nach dem Blickwinkel den Eindruck wieder, die eine oder andere Funktion prävaliere. Letztlich bleibt die Priorität bei der dirigierenden Gesetzgebung, auf die der aufgabenreiche Flächenstaat - selbst und gerade bei weit getriebener Dezentralisation - nicht verzichten kann. Wegen der Gefahr der Effektivitätsauflösung und Unregierbarkeit des modernen Staats wird die derzeitige Umkehrung in eine Suprematie der Justiz sich schwerlich halten können; dieser Vorrang verkennt Bedeutung und Auftrag der Gesetzgebung. Die Augsburger Tagung hat etliche Aspekte sichtbar gemacht: VVDStRL 34 (1976) mit den Eerichten G. Roellecke/C. Stark und R. Scholz/E. Schmidt-Aßmann.

- Ernst-Wolfgang Böckenförde, Gesetz und gesetzgebende Gewalt, 2. Aufl., 1981; ders., Entstehung und Wandlung des Rechtsstaatsbegriffs, jetzt in: „Staat, Gesellschaft, Freiheit“, Studien zur Staatstheorie und zum Verfassungsrecht, 1976, S. $65 \mathrm{ff}$. 
hen kraft erweckter rechtsstaatlicher Gebote solche Einbindungen des Gesetzgebers, und daß sie beachtet werden, kann etlichen, wiewohl begrenzten Kontrollen unterliegen?. Quantitativ und qualitativ aber haben sich jedenfalls, bis an die Wurzel gehend, die Ansprüche an das Gesetz und an den Gesetzgeber verschoben. Auf dem hundertjährigen Gang vom bürgerlich-liberalen zum demokratischen und sozialen Rechtsstaat haben sich die Beziehungen zwischen Gesetz, Gesetzgebung und Rechtsstaat verändert. Heute, meine ich, entfaltet sich ein gewandelter, eine Art „neuer" Gesetzes- und Gesetzgebungsstaat, potenziert, wie gesagt, komplex, ein mit den herkömmlichen Typisierungen schwer faßbares Leitbild, das wirklichkeitsnah und staatsgestaltend-programmatisch auftritt.

\section{Die rechtsstaatliche Legitimation von Gesetz und Gesetzge-} bung durch Sachqualität und Demokratieerfüllung

Sind Gesetz und Gesetzgebung den Rechtsstaat gestaltende und darstellende Institutionen, können und dürfen sie insoweit nicht beliebig aussehen, weder substantiell noch in der Form. Ihre rechtsstaatliche Funktion erfüllen sie vielmehr in einer offenen Rückbindung: Sie haben sich auszuweisen, daß sie die rechtsstaatlichen Dienste zu leisten imstande sind, daß sie verdienen, im Kontext rechtsstaatlicher Staatsbetätigung zu gelten. Sie haben also ihrerseits hinzutreten vor ein Forum rechtsstaatlich geprägter Maßgeblichkeiten.

Man mag es auch so ausdrücken: Gesetz und Gesetzgebung brauchen rechtsstaatliche Legitimation. Die Verfahrensweise liefert zwar Rechtfertigungen, genügt dafür allein aber nicht, sondern es bedarf zugleich und vorzüglich der materialen, sachgerechten und gerechtigkeitsbezogenen Konstitution von Rechtsnorm und Erlaß. Deshalb werden zwei Fundamentalpostulate erhoben: die Sachqualität der Gesetzgebung einerseits, die Demokratieerfüllung andrerseits.

Bei der Sachqualität der Gesetzgebung geht es darum, unter der Führung der Rechtsidee, welche zuvorderst Rechtsfriede und Gerechtigkeit in den ausgedehnten Wertzusammenhängen des sozialen Rechtsstaates anstrebt, fortwährend die mögli-

${ }^{7}$ Konrad Hesse, Funktionelle Grenzen der Verfassungsgerichtsbarkeit, in: „Recht als Prozeß und Gefüge“, (II.) Festschrift für Hans Huber, 1981, S. $261 \mathrm{ff}$., insb. S. $267 \mathrm{f}$; die Innsbrucker Berichte von Karl Korinek/Jörg P. Müller/Klaus Schlaich zur Verfassungsgerichtsbarkeit im Gefüge der Staatsfunktionen, VVDStRL 39 (1981), S. 40 ff., $87 \mathrm{ff} ., 106 \mathrm{ff}$. 
chen Versuche zu richtigem Recht zu unternehmen. Dafür ist regelmäßig eine Vielzahl normprägender Vorgegebenheiten zu eritdecken und zu beachten, z.B. soziologische Realien, Naturgesetzlichkeiten, anthropologische Erfahrungen, sozialwirksame Prognosen, politische Bedingungen, fortbestehende Normierungen $^{8}$. Daneben waltet ein gewisses Maß schöpferischer Freiheit - ein gewisses Maß nur, was besagt, daß Gesetzgebung, entgegen den verbreiteten Vorstellungen von den unbegrenzten Kreationsmöglichkeiten, eine beengte Funktion darstellt. Sie ist oft mehr das anspruchsvolle Gewerbe des Einfügens und Einpassens als die freie Kunst des großen Schaffens?. Der Demokratieaspekt sodann will, daß der qualifizierte Gehalt nach dem demokratischen Strukturprinzip des gerade legiferierenden Staates zustandekommt und sich mit solchen Werten anreichert und solche Interessen- und Sozialausgleiche herbeiführt, auf die sich das konkrete Gemeinwesen integrierend zu stützen vermag. Frankreich oder Italien haben hier andere Leitvorstellungen als die Niederlande oder Großbritannien.

\section{Il. Kritiken an der Gesetzgebung}

\section{Leiden des Gesetzes und der Gesetzgebung}

Die hohe Bedeutung und die erhebliche Ausdehnung von Gesetz und Gesetzgebung scheinen auf einem ungeheuren Vertrauen und Zutrauen zum Gesetzgeber zu beruhen. Im demokratischen und sozialen Rechtsstaat glaubt man offenbar immer noch weitherum an beinahe unbegrenzte Fähigkeiten und an die gesicherte Bonität der gesetzgebenden Organe,

${ }^{8}$ Der zureichende Umgang mit „Vorgegebenheiten“ macht essentiell Aufgabe, Wissenschaft und Kunst der Rechtsetzung aus. Vorgegebenheiten sind wechselnde Größen, deren Erfassung nicht aus der Verantwortung des Rechtsetzers entlassen werden kann. Vgl. u.a. Alexander Ruch, Sachkunde und Entscheidungskompetenz in der Rechtsetzung, in: Eichenberger/Buser/Métraux/Trappe (Hrsg.), Grundfragen der Rechtsetzung, 1978, S. 205 ff. m.w.L.

${ }_{9}$ Peter Noll, Gesetzgebungslehre, 1973, S. $98 \mathrm{ff}$; Georg Müller, Die Einführung neuer Rechtsnormen in die bestehende Rechtsordnung, in dem in Anm. 8 zitierten Sammelband, S. 369 ff. Vor dem Ansturm des Verwaltungsrechts auf die Gesetzgebung im 20. Jahrhundert war Legiferierung noch „Feiertag des Juristen“ (Walther Burckhardt), und die Kodifikationen haben diese Dignität unterstrichen. Zum Alltagsgeschäft einer fast permanent tätigen Organgruppe geworden, hat Gesetzgebung anderen staatlichen Handlungen wenig mehr an Sublimität voraus, und das schmälert ihre Autorität. 
voran an die des Parlaments als der unmittelbaren Volksrepräsentation. Daran braucht die Einrichtung der verfassungsgerichtlichen Normenkontrolle in der Staatspraxis vorerst wenig zu ändern. Denn die Kontrollinstitution bestätigt ursprünglich die gehobene Stellung des Gesetzes und ist insoweit eine mit dem Individualrechtsschutz gekoppelte objektive Fehlerberichtigung, die keine grundsätzliche politische Aktionsbeschränkung des Gesetzgebers zu implizieren brauchte.

Der demokratische und soziale Rechtsstaat nimmt fast unbekümmert Aufgabe um Aufgabe auf, dehnt seine Wirkungskreise aus, verstärkt seine Intensität, perfektioniert seine Tätigkeiten, indem er auf das Gesetz und die Gesetzgebung baut. Er mutet diesen zu, die erwartete substantielle Effizienz des Modernen Staates zustandezubringen, dies aber nicht beliebig und irgendwie, sondern auf dem komplizierten Wegnetz der „volkssouveränen Partizipationen" mit dem Anspruch, darauf zum richtigen Recht zu gelangen.

An diesen Erwartungen und Zumutungen ist im positiven Recht und in der Staatspraxis des demokratischen und sozialen Rechtsstaates - außer in Frankreich mit der Verfassungsgebung vom 28 . September $1958^{10}-$ nicht grundlegend gerüttelt worden. Die Zuständigkeitsordnungen für die Gesetzgebung sind geblieben. Der Gesetzgeber ist weder strukturell merklich umgebaut noch auf gänzlich andere Arbeitsweisen verwiesen worden. Einschneidende rechts- und staatstheoretische Umdeutungen mit praktischen Auswirkungen haben nicht stattgefunden. Offenbar herrscht einige oder ganze $\mathrm{Zu}$ friedenheit mit den angelegten Einrichtungen und der Gewichtsverteilung im großen.

Dem steht nun entgegen, daß Wehklagen über den tatsächlichen Zustand der Gesetzgebung beinahe alle Rechtsstaaten durchziehen. 1952 sprach Hermann Jahrreiss außer von der Größe auch von der Not der Gesetzgebung ${ }^{11}$. Trotz der respektablen Erneuerung und Kräftigung von Rechtsstaatlichkeiten,

${ }^{10}$ Die Rechtsetzungsfunktion ist verfassungsunmittelbar zwischen Parlament, Staatspräsident und Regierung aufgeteilt, und die Erlasse der Exekutivgewalt sind insoweit nicht an vorangehende Gesetze gebunden. Udo Kempf, Das politische System Frankreichs, Eine Einführung, 2. Aufl., 1980, S. 74 ff.; Christian A. L. Rasenack, Gesetz und Verordnung in Frankreich seit 1789, 1967, S. $260 \mathrm{ff}$; André Haurioul Jean Gicquel, Droit constitutionnel et institutions politiques, 7. Aufl., 1980, S. 999, 1022, 1105 ff.; Georges Burdeau, Droit constitutionnel et institutions politiques, 19. Aufl., 1980, S. 601 ff.; Jacques Cadrat, Institutions politiques et droit constitutionnel, II, 2. Aufl., 1979, S. $1105 \mathrm{ff}$.

${ }^{11}$ Hermann Jahrreiss, Größe und Not der Gesetzgebung, jetzt in: „Mensch und Staat", 1957, S. 17 ff. 
die die letzten 30 Jahre heraufgeführt haben, brechen in bezug auf die Gesetzgebung die Niedergangsdiagnosen nicht ab: Die Gesetzgebung stecke in Leiden. Sie sei krank. Sie genüge nicht. Das Gesetz, sein Zustandekommen, seine Erzeuger, seine Verwirklichung seien nicht, wie sie sein sollten. Demzufolge sei der Rechtsstaat nicht das, was er sein könnte.

Die Mängelliste füllt Bände. Und sie ist offensichtlich nicht einfach unreflektierte Wiedergabe der sozialwissenschaftlichen Negierungsmanie und Krisenfreude. Es können wirklich Mängel und Bedrohlichkeiten dahinter stecken. Und denkbar ist, daß gewisse Korrekturen möglich wären, die bisher unterlassen worden sind, weil man vielleicht vertrauensselig oder träge oder resigniert die angetroffene Lage hinnimmt.

\section{Ausschnitte aus der Mängelliste}

Aus der Mängelliste, in der Phänomene, Ursachen und Wirkungen ineinanderlaufen, wollen wir ein paar Anprangerungen herausgreifen.

a) Die geläufigsten Rügen treffen den verwirklichten Sachverhalt, der mit ,Normenflut" oder „Gesetzesinflation" gekennzeichnet wird ${ }^{12}$. Die quantitative Ausweitung bis ins Übermaß heißt, daß die Normen erheblich vermehrt werden, daß sie zunehmend mehr Regelungsgebiete erfassen, die Regelungen dichter machen, den Rechtsstoff erweitern und einer ausufernden Verrechtlichung den Boden bereiten. Die Wirkungen werden mit der zunehmenden Erschwerung beschrieben, das Recht zu überblicken, es zu befolgen oder durchzusetzen, den Standard zureichender Inhalte und Normstrukturen aufrechtzuerhalten, die Sorgfalt in der Rechtsetzung und später in der Rechtsanwendung aufzubringen, schließlich die Ordnungsfunktion des Rechts sicherzustellen, das Rechtsbewußtsein zu hegen und Rechtsmüdigkeit abzuwenden. Unter den vielfältigen Ursachen sticht der wesensgemäß ausgeweitete Regelungsbedarf des sozialen Rechtsstaats hervor, begleitet von Tendenzen des gesellschaftlichen und behördlichen Per-

1: Unter dieser Bezeichnung werden gelegentlich die Beanstandungen schlechtweg zusammengefaßt: Man knüpft am quantitativen Bild an und vermag dann, weniger ursächlich als in den Wirkungen, qualitative Mängel darzustellen. Vgl. Daniel Boerlin/Gottlieb Andreas Keller:Christophe Zumstein, Die Normenflut als Rechtsproblem, in dem in Anm. 8 zitierten Sammelband, S. $295 \mathrm{ff}$; Reinhold Hotz, Methodische Rechtsetzung, Eine Aufgabe der Verwaltung, St. Galler Habil. Schrift 1981, im Druck, \$ 5 mit Rechtsvergleichungen. Vgl. auch Rüdiger Voigt (Hrsg.), Verrechtlichung, 1980, insbes. S. 14 ff. m.w.L. 
fektionismus, der Sekuritätsbedürfnisse, der Übersteigerung des Legalitätsprinzips. Aber auch Zügellosigkeiten und sachfremde Geltungsbegehren der Gesetzgebungsorgane sind im Spiel.

b) Einen zweiten Block von Unzulänglichkeiten kann man unter dem Stichwort der Strukturmängel des Gesetzes herausheben. Gemeint sind verfehlte und unzureichende Normstrukturen, Vernachlässigungen und Fehler beim begrifflichen und systematischen Aufbau sowohl der Institute und Erlasse als auch von ganzen Hauptteilen der Rechtsordnung, logisch und sachlich unvollständige oder umgekehrt überdosierte Festlegungen. Darin sind eingeschlossen disproportionierte Verteilungen der Regelungslast unter die verfügbaren Rechtsetzungsformen, namentlich Disharmonien zwischen Gesetz und Verordnung. Schließlich gehört in diese Aufreihung, daß immer wieder entbehrliche Regelungen getroffen werden, andrerseits für Mensch, Staat und Gesellschaft dringliche Rechtsetzungen unterbleiben oder auf der langen Bank eintrocknen. Die Wirkungen schlagen sich nieder in politischen Ungleichgewichten und machen sich bemerkbar vor allem bei der Normvollziehung, wo überdehnte Auslegungen, unausfüllbare Normierungslöcher oder gegenteils Verdrängung von Freiräumen des Rechtsanwenders, Undurchführbarkeiten oder schikanöse Rechtsfolgen auftreten. Das Gesetz büßt wegen struktureller Fehlanlagen an Glaubwürdigkeit und an rationaler Steuerungskraft ein. Zurückgeführt wird das vor allem auf eine erhebliche Verminderung methodischen und systematischen Gestaltens, auf Nachlässigkeiten in der begrifflichen Durchformung, auf Hast und Gleichgültigkeit der Rechtsetzungsorgane.

c) Eine dritte Ansammlung erfaßt inhaltliche Unrichtigkeiten auf vielerlei Ebenen. Einbußen an Bezügen zu rechtsethischen Grundwerten, Vernachlässigungen fundamentaler materialer Grundsätze und Richtlinien, schiefe Interessenwertungen, übersteigerte oder permissive Anordnungen mit Normativitätsverlusten, Mißachtung von determinierenden Vorgegebenheiten des realisierungsfähigen Rechts, Nichtberücksichtigung von außerrechtlichen Normgefügen und politischen Rahmenbedingungen, die das Recht ergänzen, stärken und durchdringen könnten. Die Wirkungen sind einschneidend: Inhaltliche Verbiegungen und Fehlbeträge, die nur höchst begrenzt durch Verwaltung und Justiz behoben oder gemildert werden können, zerstören auf die Dauer die innere Begründung und damit das Ansehen von Gesetz und Recht, erodieren die Rechtsordnung, führen zu Auflehnungen gegen das Recht und 
seine Bewahrer, münden aus in Staatsverdrossenheit und schließlich Staatsverneinung. Die Ursachen ortet man vornehmlich bei sachlichem Unvermögen der Rechtsetzungsorgane, bei der Überwucherung der Bauprinzipien richtigen Rechts durch niedere Politik und simples Taktieren, bei Deformationen der überlegenen Rechtsetzung durch den hemmungslosen Zugriff partikulärer Interessen und machtbewußter: Massenmedien auf die Gesetzgebung, die darob der Ausmittlung des Gemeinwohls verlustig geht.

d) In vierter Linie werden sogenannte kommunikative Unkorrektheiten aufgeführt, die freilich schon bei der Normenflut und bei den Strukturmängeln erfaßt werden können. Gemeint ist insbesondere die unzureichende Aufbereitung des Gesetzes für seine Kommunikation mit den Normadressaten. Beanstandet werden der Schwund an präziser Begrifflichkeit und die Verwilderung der Sprache. Klarheit, Einfachheit, Verständlichkeit verlaufen. Dazu treten Komplikationen mit Verweisungen, Wiederholungen, Auslassungen und Vielstufigkeiten der Regelungsgefüge. Über alles lagert sich die wachsende Schwierigkeit der sinnvollen Kundmachung, der verläßlichen Kenntnisnahmen, des sicheren Zugangs zum "Law in action" mit Einschluß seiner Dogmatik. Wirkungen sind, daß das gesetzte Recht nicht ausreichend verstanden, die freiwillige Befoigung gefährdet, die gesicherte Durchsetzung erschwert wird. Ursächlich liegt bei der Kommunikationsbedürftigkeit ein einfacher Sachverhalt vor: Die Gesetzgebungsorgane lassen es an Einsatz und Bemühen fehlen, und kommen trotz Anstrengung die korrekten Formungen nicht zustande, so mangelt es an Elementarbildung und -ausbildung. Daß freilich auch bei den Adressaten ein Niveau der Aufnahmekapazität und des guten Willens zum Verstehen aufgrund des umfassenden Loyalitätsgebots vorauszusetzen ist, sollte jeweilen nicht verschwiegen werden.

e) In einer fünften Gruppe schließlich sammeln sich Mängel, die der strukturellen Eigenart, der funktionellen Betätigung und der personalen Situation der Gesetzgebungsorgane und Organwalter zugerechnet werden. Derartige Mängel sind vorhin zum Teil bereits als Ursachen unzulänglicher Gesetze erwähnt worden. Sie treten jetzt als Schädigungsphänome der Ge:setzgebung auf. Es stehen voran das überladene Pensum aller an der Gesetzgebung Beteiligten, die begrenzte Sachkompetenz der Entscheidungsorgane, ihre denaturierenden $\mathrm{Ab}$ hängigkeiten von außerparlamentarischen Kräften, die schwerfälligen Arbeitsweisen, die Trennung von inhaltsgestaltender Präparation und verbindlichkeitsschaffender Endent- 
scheidung, immer wieder und immer neu die führende Stellung der Regierung und die unerlässliche Beteiligung der Verwaltung an jeder Rechtsetzung, der Druck schließlich zu gruppenpolitischen Kalkulationen bei der Ermittlung der Gesetzesinhalte. Im Wege stehen namentlich dem Parlament die reduzierte Fähigkeit zur Konzentration auf das Wesentliche, die Abneigung gegenüber dem Denken in Alternativen, die Lust an der Betriebsamkeit und die Unlust zur Vertiefung, so vor allem der Vertiefung in das Recht, seine Methodik und wesensgemäßen Begrenzungen ${ }^{13}$. Mittelbar und unmittelbar wirken sich die institutionellen und personellen Unzulänglichkeiten des Gesetzgebers in den erwähnten Gesetzesmängeln aus. Dazu gesellen sich in einer Spiralwirkung die zunehmenden Autoritätsminderungen der Gesetzgebungsorgane. Die Kritiken an der Gesetzgebung, welche Verluste an der Sachqualität und an der Demokratieerfüllung registrieren, weisen am augenfälligsten die Ursachen an dieser fünften Mängelgruppe nach und verengen sich dann freilich mit Vorliebe zu einer blassen oder sarkastischen Parlamentskritik.

\section{Die Brüchigkeit der Legitimation der Gesetzgebung}

Ich will die Auflistung abbrechen und abgekürzt ein erstes Ergebnis festzuhalten versuchen. Entwickeln und halten sich in der Tat die geschilderten und weitere Mängel, baut sich die Funktion des Gesetzes als Ausdruck und zur Realisation des Rechtsstaates $a b$, und die rechtsstaatliche Legitimation der Gesetzgebung wird brüchig. Es hilft nichts, daß etliche der

${ }^{13}$ Dieser Sachverhalt sollte alarmieren: Das gesetzgebende Parlament - auch wo es nicht „Arbeitsparlament“ zu sein vorgibt - muß Recht schaffen, hat aber die Elementarkenntnisse des Rechts nur bescheiden präsent. Daraus entsteht entweder die deformierende Abhängigkeit von juristischen Experten oder die überhebliche Vernachlässigung des Juristischen als lästige formale Beigabe. Die Rechtswissenschaft hat im Gesetzgebungsvorgang nicht die Stellung anderer Wissenschaften, die man partiell um ihre Erkenntnisse angehen kann (vgl. Anm. 8), sondern es läuft ein eigentlicher rechtswissenschaftlicher Proze $\beta$ ab, bei dem sich juristischer Sachverstand und Entscheidungspflicht letztlich identifizieren. Ein Parlament aus lauter juristischer Halbbildung bei einiger rechtstechnischer Geschicklichkeit wünscht man sich erst recht nicht. Trotzdem fragt sich, ob der Rechtswissenschaft nicht aufgegeben sei, adäquate Fundierungen der Abgeordneten für Gesetzgebung bereitzustellen. Das wäre wohl ein aliud gegenüber der aufkommenden Gesetzgebungslehre und Legistik (vgl. unten Anm. 24). 
Miß3stände, z.B. die Gesetzesflut oder Fehlleistungen des Gesetzgebers, gerade aus der Rechtsstaatsbezogenheit hervorgehen und von ihr angetrieben werden können. Der Rechtsstaat provoziert seine eigene Stillegung, wenn er übertreibenden, aber fachlich oder politisch schwachen oder undisziplinierten Gesetzgebern in die Hände gerät. Der behauptete Glaube an Gessetz und Gesetzgebung ist also dürftig eingepflanzt, der potenzierte, der „neue“ Gesetzes- und Gesetzgebungsstaat im Lichte der Rechtsstaatlichkeit noch nichts Verläßliches.

Eine Gesamtbeurteilung ist allerdings nicht eindeutig, und die Forschung hat noch zu wenig zutage gefördert, als daß man rechtsstaatlich präzise verfassungspolitische Empfehlungen formulieren könnte. Bei einer vorläufigen Grobbetrachtung wird man etwa drei Sachverhalte unterscheiden.

\section{Eine generalisierende Lagebeurteilung}

\section{Hinreichende Gesetzgebung}

Einmal ist festzuhalten, daß Gesetz und Gesetzgebung keineswegs und überall dermaßen darniederliegen, wie die vorhin skizzierten Bilder es verbreiten. Es gibt gute bis vorzügliche Gesetze in beachtlicher Zahl, und gesetzgeberische Tätigkeiten können oft und lang einwandfrei ablaufen. Es steht auch nicht zu befürchten, daß Fähigkeiten zu tüchtiger Gesetzgebung versiegten. Mit einem Stock funktionsgerechter Gesetze uncl mit einem Kernbestand fähiger Gesetzgeber darf und soll man weiterhin rechnen. Das System, mit Gesetzen den Rechtsstaat auszugestalten und rechtsstaatlich Gesetzgebung zu betreiben, ist noch nicht zerbrochen und die prognostischen Folgerungen, die düster stimmen, sind nicht allgemeingültig. $\mathrm{Da} 3$ mit den geschilderten Verbiegungen Fäulnisherde ermittelt sind, die anstecken können, wird damit nicht bestritten. Aber es besteht auch die Möglichkeit, daß sich am Beispiel der zureichenden Funktion Sanierungen ermutigten.

\section{Kompensationen bei mangelhafter Gesetzgebung}

Als nächstes ergibt sich, daß eine von Mißständen bedrohte Gesetzgebung mit kompensatorisch-komplementären Funktionen und Organen umgeben werden kann. Das ist in der Tat im Gange. So springt allenthalben das Verfassungsrecht in Breschen. Es hat sich materiell geweitet, ist in einzelnen Staaten in der Geltung gestärkt, übernimmt da vom unruhig und 
wetterwendisch gewordenen Gesetz Aufgaben der Stabilität, der Kontinuität und selbst der direkten langfristigen Sozialgestaltung. Ferner werden aus der Idee des Rechtsstaates zusätzliche dirigierende Grundsätze und Leitprinzipien abseits der gesetzlichen Positivierung gewonnen und in die Rechtsverwirklichungsprozesse eingeschleust. Sodann steht die Justiz, bevorzugt der Verfassungsrichter, im Begriffe, ihre Wirksamkeit auszuweiten und zu verstetigen. Mit Normenkontrollen behebt sie einzelne inhaltliche Unrichtigkeiten der Gesetze und hält punktuell die Gesetzgebungsverfahren in geordneten Bahnen, während sie mit Interpretation und Rechtsfindung gewissen Übernormierungen und Lücken zu begegnen imstande ist. Die Regierung und die Verwaltung besitzen mit der ordentlichen Rechtsanwendung, mit der Ermessenshandhabung, mit Planungen, mit der Haushaltsführung und mit Staatsverträgen Instrumentierungen, dank derer sie mit etlichen Erfolgsaussichten gesetzgeberische Fehldispositionen auszugleichen fähig sind. Und ein Seitenblick auf die Schweiz zeigt, daß selbst Initiativrechte aus der Mitte des Volkes den müßigen Gesetzgeber ersetzen oder mitunter zu besserer Leistung zu treiben vermögen.

Kompensierende Institutionen und komplementäre Funktionen bieten freilich nie vollwertigen Ersatz. Sie künden Sozialsteuerungen aus oft ungewollten Quellen an, die die rechtsstaatliche Entscheidkonzeptionen mit verantwortlicher gesetzgeberischer Aktivität dereinst aus den Angeln heben könnten. So geht beispielsweise dauernd das Gespenst um, der Sozialstaat würde sich allein durch die Exekutive in Bewegung halten, umgeben von bescheidenen richterlichen Kontrollen, insgesamt aber beschwichtigt durch die Deklaration, es finde ein rechtsstaatlich alles heilender unmittelbarer Verfassungsvollzug statt.

\section{Sanierungsräume}

Ein erheblicher Bestand von Mängeln mit gesetzesauflösenden Auswirkungen schließlich wird ohne Kompensationen bestehen bleiben. Da fragt sich, ob zur Erneuerung und Festigung von Gesetz und Gesetzgebung Sanierungen und innovatorische Überholung eingeleitet werden sollen. Sollen setzt Können voraus. Was läßt sich willentlich und institutionell unternehmen, gefragt immer unter dem Vorbehalt, daß man rechtsstaatliche Gesetzgebung überhaupt beibehalten will? Die institutionelle Änderung bleibt dann ein rechtsnormatives Thema, solange das Recht und der Staat die eigene 
Erzieugung, Realisation und Überwachung bestimmen. Gibt es Chancen für sanierende Normierungen zugunsten der gefährdeten Gesetzgebung? Ich greife drei Fragmente heraus, in denen sich derzeit im demokratischen und sozialen Rechtsstaat Probleme normativer Korrekturen aktualisiert haben, närnlich Fragen der Herrschaft über die Normierungsmaße, der Regelungsverteilung und der Qualitätssicherung der Inhaltsgebung.

Gemeinsam ist diesen Ausschnitten, daß sich hier eine harte Staatswirklichkeit gewissen positivrechtlichen Regelungen oder Regelungsvoraussetzungen entgegenstellt, die ihrerseits in verhärteten Rechtsstaatsbestandteilen ruhen können. Soll eine zeitgemäße Gesetzgebung, im potenzierten, im „,neuen“ Gesetzesstaat zustandekommen und überleben, braucht es die Konfrontation mit derartigen Tatsachen und schließlich Anpassungen. Wer aber soll sich wem anpassen? Es gibt in bezug auf die Gesetzgebung Sachverhalte, die hochgradig resistent gegen korrigierende Normierungen sind, z.B. das Faktum, daß Parlamente genuin schwerfällig, dilettantisch und taktischopportunistischen Zufälligkeiten ausgesetzt sind. Muß das Normative sich fügen, so ist aber sogleich das Rechtsstaatliche im Spiel: Es kann auch geboten sein, nicht bloß positives Recht zu verbessern, sondern auch Auffassungen der konkretisierten Rechtsstaatsidee zu verändern, zu erweitern, dafür umzudenken.

\section{Zur Beherrschung der Normierungsmasse}

\section{Bleibende Normierungsbedürfnisse}

Der überbordenen Normierungsmasse solle man durch rigorose Beschränkung aller Rechtsetzung wieder Herr werden. Mit der Kanalisierung aber würden sich die gerügten Mängel verlaufen. Derartige Rufe sind ebenso zahlreich wie bisher offenkundig wirkungslos. Erfolge mit einem "self-restraint" des Gesetzgebers sind wohl nur denkbar bei gehöriger Differenzierung, also mit der Einsicht, daß damit rechtsstaatsrelevante Maßfragen in polyvalenten Bezugssystemen gestellt sind und durch vielschichtige Wertungen beantwortet werden müssen ${ }^{14}$. Um nicht den Ansatz schon im Utopischen zu wäh-

14 Mit der Gesetzgebungskompetenz sind Handlungsverpflichtungen auferlegt, die nicht einfach linear gekürzt werden können, was gegenüber den ,großen Vereinfachern“, die geringere Gesetzgebungstätigkeit durchzusetzen trachten, gelegentlich betont werden muß. 
len, wird man eingestehen, daß der soziale Rechtsstaat, der die demokratische Komponente nicht zurückdrängen möchte, ein geradezu gigantisches Normierungsbedürfnis behalten wird.

Es sprudelt fortzu aus den dynamisierten Soziallagen und zudem aus dem rechtsstaatlichen Druck, die beschleunigte Überalterung der geltenden Rechtsordnung durch laufende Revisionen aufzufangen. Daß zusätzlich Technik, Planungsmöglichkeiten, Wohlstandsbegehren und Wissenschaft antreibende Kräfte sind, ist nicht zu bestreiten. Aber es ist auch die Rechtsidee in rechtsstaatlichen Ausgliederungen selbst, die zur Gesetzgebung herausfordert. Denn die sozialgestaltenden Vorkehren und eine Menge der angeblich „nur-technischen" Anordnungen können und müssen mit rechtsideellen Gehalten durchdrungen werden. Daß in Gestalt der Gesetzgebung wesentliche politische Auseinandersetzungen und Ausgleiche des Sozialstaats stattfinden, befreit nicht von der Abwicklung der legislativen Verfahren und von der Einfügung von Rechtswertbezügen ${ }^{15}$. Für die gesellschaftspolitische Funktion der Gesetzgebung kann nur beschränkt auf andere Staatsakte und Vorgänge ausgewichen werden.

\section{Die Hoffnung auf entlastendes Verfahrensrecht}

Die übliche Hoffnung für Verbesserungen in der Gesetzgebung wirft sich bislang nicht auf die Parlamentsstruktur und

Gemeint ist vielmehr die Disziplinierung aus einer Gesamtsichtung der Lage der Rechtsordnung und der anstehenden Gestaltungsbedürfnisse. Die Parlamente vermögen die dafür nötige Übersicht aber offensichtlich nur zu gewinnen, wenn entweder ein eigener Gesetzgebungsdienst oder die Exekutive sie bereitstellen. Vgl. meine Bemerkungen in: „Der Staat der Gegenwart“, 1980, S. $312 \mathrm{ff}$., $123 \mathrm{ff}$.

15 Seit man inne wird, daß in und mit der Gesetzgebung hochpolitische Prozesse ablaufen (am deutlichsten wohl ermittelt von Ulrich Scheuner, so schon in: Der Bereich der Regierung, in [I.] Festschrift für Rudolf Smend, 1952, S. 273 f.), verbreitet sich eine Neigung, zu trennen und diesen politischen Akten eine Eigenständigkeit losgelöst von rechtsetzenden Gestaltungsmaximen zuzuschreiben. Das ist nur ganz begrenzt möglich und ruft dann die alte Frage neu hervor, ob man besondere Einkleidungen für nicht-rechtsetzende Parlamentsakte und die Ausschaltung des nur-formellen Gesetzes für staatsleitende Entscheidungen vorsehen soll. Zur signifikanten Entwicklung in der Schweiz: Alfred Kölz, Reform der Volksrechte im Kanton Solothurn, in: Festschrift 500 Jahre Solothurn im Bund, 1981, S. 41 ff. Vgl. ferner Georg Müller, Die Parlamentsverordnung, in: Festschrift für Hans Nef, 1981, S. 231 ff.; Siegfried Magiera, Parlament und Staatsleitung in der Verfassungsordnung des Grundgesetzes, 1979, insb. S. $174 \mathrm{ff}$., $210 \mathrm{ff}$. 
das Regierungssystem, sondern vorwiegend auf parlamentarische Verfahrensordnungen. Es gibt unzählige Empfehlungen, die parlamentarischen Verfahren zu straffen, zu vereinfachen und inhaltlich anzureichern, die Arbeitshilfen für die Abgeordneten zu verstärken, bei Mehrkammersystemen das Zusammenwirken zu erleichtern, die außenstehende Sachkunde bereitzustellen, die Beziehungen zwischen Regierung und Parlament und zwischen Mehrheit und Opposition von entbehrlichem Ballast zu reinigen. Die Empfehlungen erweisen sich vielfach als betrieblich-technische Aushilfen und können soweit tauglich sein, als sie dem Parlament den Repräsentationsund den Deliberationsauftrag nicht rauben, sondern stützen ${ }^{16}$. Insbesondere ist unverzichtbar, im Gesetzgebungsvorgang zumindest die spiegelbildliche Realrepräsentation des pluralistischen Interessengefüges unterzubringen, nachdem man idealistische Ganzheitsrepräsentationen nicht mehr erwartet ${ }^{17}$. Ob aber Verfahrensreformen $z u$ echter gesetzgebungsstaatlicher Mäßigung und Konzentration vordringen, ist abhängig davon, was die beteiligten Organe aus ihnen machen, und das zielt in praxi nicht immer auf die Optimierung der gesetzgeberischen Qualität. Die erreichte Entlastung wird vielmehr häufig aufgeschluckt durch zusätzliche neue Geschäftigkeiten. Die Hoffnung auf Verfahrensreformen sind deswegen gedämpft. Die Frage bleibt immerhin gestellt, und der Appell an Disziplin, Maß und sachliches Bemühen der Abgeordneten, worin ein erhebliches Stück sanktionsloser Erwartung liegt, möchte sich dennoch partienweise institutionell umkleiden lassen.

\section{Notwendigkeitsprüfungen}

Von den mannigfachen konkreten Vorschlägen derartiger normativer Aufrüstungen hebe ich einen hervor: Den gesetz-

${ }^{16}$ Die verfahrensrechtlichen Parlamentsreformen tendieren in der Regel zu einseitig zu Straffungen und Beschleunigungen, die dem Deliberationsauftrag des Parlaments rasch zuwider sind: ausgreifende Erörterung, Hin und Her, Verweisen und Zögern, Aufzeigen von Positionen, allmähliches Heranreifen von Lösungen bleiben parlamentsrelevant. Damit erfüllt sich zugleich Repräsentation, die die Explikation und die Gewinnung von Distanz erfordert, und zwar auch da, wo man sich mit Volksvertretung zufriedengibt. Vgl. Schlußbericht der Studienkommission der Eidgenössischen Räte ,Zukunft des Parlaments“, 1978 , S. $31 \mathrm{ff}$.

${ }_{17}$ Wie die Bielefelder Tagung über das parlamentarische Regierungssystem des Grundgesetzes aufgrund der Berichte Hans Meyer/ Thomas Oppermann deutlich machte: VVDStRL 33 (1975) S. 43 ff. 
gebenden Organen sei aufzuerlegen, eine gesonderte stringente Prüfung der Notwendigkeit oder, wenn man das Wort in Anlehnung an das Verhältnismäßigkeitsprinzip vorzieht, Erforderlichkeit jedes Gesetzgebungsvorhabens vorzunehmen. Das ist etwas anderes als die üblichen Eintretensbeschlüsse in den Parlamentsverfahren.

Es ist die separierte und eindringliche Frage danach, ob die intendierte rechtliche Regelung nötig und ob sie in der vorgeschlagenen Ausgestaltung proportioniert sei. Gefragt wird im Ob und Wie zwar auch nach quantitativer Aussiebung, letztlich aber nach einer vertieften problemorientierten Qualitätsprüfung der Rechtsetzung, z. B. ob das konkrete Regelungsbegehren durch Rechtsnormen überhaupt erfüllt werden könne, ob Sozialnormen oder rechtsfreie Bereiche nicht sinnvollere $\mathrm{Zu}$ stände verhießen, ob, falls Rechtsnormen angezeigt wären, weniger Festlegungen, insbesondere mit geringeren $\mathrm{Be}-$ stimmtheiten zuträglicher wären, ob anstatt öffentlich-rechtlicher Regelungen Raum der Privatautonomie und dem dispositiven Zivilrecht zu überlassen wäre, ob es andere staatliche Handlungsformen gäbe, mit denen die politischen Ziele der Initianten zu erreichen wärén? Eine streng methodische Durchleuchtung ist Voraussetzung solcher Ermittlungen, freilich bald gefolgt von freien Wertungen ${ }^{18}$.

Daß die Prüfung im Parlament im Spiel von Mehrheit und Opposition oder in der parlamentarischen Courtoisie der Gegenseitigkeiten untergehen könnte, ist nicht zwingend. Die Prüfung einem Drittorgan zu übertragen, mag bestechen. Sie würde aber beim Verfassungsrichter oder beim Staatsoberhaupt zu einer heiklen politischen Vetokompetenz, die einschneidender die Gewaltenrelationen träfe als die gewohnten Normenkontrollen. Ein Consilium von Ephoren, Zensoren oder geharnischten Staatsräten für diese und allenfalls weitere

${ }^{18}$ Die amtlichen Anweisungen für die methodische Gesetzgebung enthalten mitunter diese Fragestellung (vgl. Reinhold Hotz, Anm. 12; Harald Kindermann, Ministerielle Richtlinien der Gesetzestechnik, 1979), doch werden die Zusammenhänge des Rechts mit sozialen Festlegungen wenig betont. Dazu Paul Trappe, Außerrechtliche Normsysteme, in dem in Anm. 8 zitierten Sammelband, S. 149 ff.; ders., Zur Situation der Rechtssoziologie, 1968, passim; Niklas Luhmann, Rechtssoziologie, 1972, S. $190 \mathrm{ff}$.; Julius Stone, Lehrbuch der Rechtssoziologie, III, 1966/76, S. 264 ff. 
gesetzgeberische Voraus- und Verfahrensentscheidungen einzusetzen, dürfte in unserer organisationsrechtlich phantasielosen und stagnierenden Epoche ein müßiger Gedanke sein. Es empfiehlt sich letztlich die institutionalisierte Selbstprüfung durch den Gesetzgeber, die sich, je nach Regierungssystem, verknüpfen ließe mit einer ratschlagenden Begleitverpflichtung der Regierung, sich ihrerseits zur Notwendigkeit einläßlich auszusprechen. Schließlich müßte die Prüfung der Notwendigkeit in den Rahmen von mittelfristigen Rechtsetzungsprogrammen (Rechtsetzungsplänen) gestellt werden. Diese bilden das Kernstück einer effizienten politischen Planung, in der die Staatsleitung die gesetzgeberischen Aktivitäten ermittelt und mit einer politischen Selbstbindung kundtut.

\section{Zur Verteilung der Rechtsetzungsaufgabe}

\section{Die gegenwärtige Situation}

Die meisten rechtsstaatlichen Verfassungen, selbst neuere, geben den Eindruck wieder, die Rechtsetzung sei Gesetzgebung. Und wo sie Verordnungsrecht der Exekutive anerkennen, wird es - von Verwaltungsverordnungen abgesehen, die wir hier außer acht lassen - mit Delegations- und neuerdings Eindämmungsklauseln an ein vorangehendes formelles Gesetz gebunden. Verordnungsrecht hat das Odium des Irregulären und Unerwünschten trotz der jetzt durchgreifenden Überwölbung durch das Kontrollparlament - außer in Frankreich - beibehalten und mit den neueren Demokratisierungsströmungen noch verstärkt. Nicht gerade laut, aber unüberhörbar schlägt immer wieder der Ton an vom Totalvorbehalt des Gesetzes und vom Universalitätsauftrag des Gesetzgebers, weil sich so erst demokratische Rechtsstaatlichkeit runde. Die Verordnung hat, mit dauernden Reprisen altrechtsstaatlicher Argumentationen, die Stellung des minderen Hintersassen, was die Staatspraxis freilich nicht hindert, sie ausgiebig einzusetzen.

Nun ist es schlicht und völlig ausgeschlossen, den Modernen Staat auszugestalten, zu leiten und aufrechtzuerhalten ohne die Masse generell-abstrakter Anordnungen. Aber die bestehenden und selbst die überprüften Normierungsbedürfnisse können nicht zureichend von einer einzigen Organgruppe zentral und konzentriert gesättigt werden. Ganz praktisch und erdnah: Die tatsächliche Regelungslast kann der singuläre 
Gesetzgeber nicht allein tragen; sie muß verteilt werden. Rechtsetzung im sozialgestaltenden Staat ist nur noch dekonzentriert und dezentralisiert zustandezubringen. Die gegenwärtige Verteilungsproblematik aber überschreitet die Beziehung Gesetz - Verordnung. Die bundesstaatliche und die regional-kommunale Dezentralisation entlastet zunächst, bringt im rechtsetzenden Gesamtzusammenhang allerdings auch komplizierende Häufungen von Normierungen. In die Normierungsaufgaben des sozialstaatlichen Gemeinwesens treten ferner die Sozialpartner ein, wenn sie mit den Tarifverträgen den staatlichen Organen politisch und sachlich lästige Entscheidungen abnehmen, an denen Parlamente heutigen Zuschnitts wohl scheitern müßten. Seit einiger Zeit treten private Rechtsetzer mit technischen Normungen von noch unsicherer, aber faktisch respektierter Allgemeinverbindlichkeit auf, z.B. die DIN-Normungen, die den Staat davon entheben, zusätzlich hochspezialisiertes technisches Wissen bereitzuhalten. Es gibt weitere Arten der Verteilung, die allesamt davor bewahren, die gesetzgeberischen Entscheidungskörbe zu überfüllen. Die nichtgesetzlichen Normierungen aber sind derzeit nur teilweise Beiwerk, das in der rechtlichen, politischen oder sozialen Bedeutung dem Gesetze nachsteht. Im übrigen können von ihnen soziale Gestaltungen der industrialisierten und technisierten Gesellschaft mit primärem Geltungsanspruch in die normative Gesamtordnung einfließen. $\mathrm{Ob}$ in der heutigen Rechtsetzungspluralität, die sich ohne Methode und ohne Überblick entfaltet, jedoch eine harmonisierende Symmetrie und Kohärenz der Rechtsregelungen tatsächlich noch zustandekommen - Gleichgewichtiges in gleichen Formen und gleicher Dichte, Ausgewogenheit der Regelungsbereiche untereinander, Wertkonkordanz, rechtslogischer Zusammenhang - ist zweifelhaft, und die „Einheit der Rechtsordnung“ ist formal und material angegriffen. Soll und kann es so weitergehen?

\section{Entwicklungslinien}

Dem drängenden Verteilungsproblem werden positivrechtliche Gesetzbegriffe offensichtlich nicht Meister, und tradierte Rechtsstaatsbestandteile geben keine begrifflich faßbaren und nuancierten Antworten. Mit der Mechanik der Delegation vom Gesetz zur Verordnung ist nicht beantwortet, was ins Gesetz und was in die Verordnung gehört. Man hält deshalb Ausschau nach sinnvollen und praktikablen Aufschlüsselungen. Mit den differenzierbaren Begriffen der Wesentlichkeit oder der Wich- 
tigkeit sind von deutscher wie von schweizerischer Seite Versuche dafür vorgelegt worden ${ }^{19}$. Es soll abgestellt werden auf die bestimmungsmäßige Struktur, Leistungsfähigkeit und Akze:ptationsverschaffung der rechtsetzenden Organe, sodann auf die staatliche und soziale Bedeutung der Norm in ihrer erwarteten Wirkung und endlich auf die Eigenarten der Regelungsgegenstände mit ihren Randbedingungen, z.B. mit den finanziellen Auswirkungen und dem organisatorischen Aufwand. Das Gesetz soll das Grundlegende, Belangvolle, Gewichtige, Gefestigte bringen, wo möglich auch das Dauerhafte und Stabilisierende, schließlich das, was in der politisch-demokratischen Wertung den nahen Volksbezug als nötig ausweist. Man mag weitere Merkmale beifügen, entscheidend bleibt, daß nach Wert und Geltungsanspruch Gehobenes hervorgeht, das in der Obhut eines spezifisch autorisierten Organs zu stehen verdient. Anderes dann läßt sich verlegen, darf in anderen Verfahren und Formen unterkommen.

Bei dieser Sicht werden freilich Gesetz und Gesetzgebung nicht länger als monopolistische Emanationen wahrer Rechtsstaatlichkeit begriffen, sondern man stellt, ohne Blockierung durch Gewaltenteilungsdogmen und durch demokratische Überdehnungen des Legalitätsprinzips, unbefangen neu die Fiage in den Raum: Mit welchen Rechtsetzungsorganen, -verfahren und -formen sollen die Regelungsbedürfnisse so erfüllt werden, daß rechtsstaatliche Sinngebungen erhalten, geschützt und gestärkt werden? Sofort wird aber deutlich, daß auch dem Rechtsstaatsprinzip Modifikationen aufgegeben wären. Es wird, namentlich mit seinen Demokratiekomponenten, sowohl die mehrfache Verteilung endlich klar und grundsätzlich anerkennen, als auch allmählich Gehalte entwickeln müssen, denen die kompetentiell-funktionellen Zuweisungen den Sinnbezug zu den Fundamenten der Menschenwürde, Freiheit und Machtbegrenzung entnehmen können. Im Verbund mit positivem Verfassungsrecht würden sich dann für den konkreten Staat die sinnvollen Verteilungsordnungen herausbilden lassen. Das ist ein langer Marsch, der eben erst zaghaft begonnen hat, aber die Staatsrechtswissenschaft sollte nicht überhören, daß sie zum Schrittmacher aufgerufen ist.

${ }^{19}$ Siegfried Magiera, Allgemeine Regelungsgewalt (,Rechtsetzung“) zwischen Parlament und Regierung, in: Der Staat 13 (1974), S. $1 \mathrm{ff}$;; Georg Müller, Inhalt und Formen der Rechtsetzung als Problem der demokratischen Kompetenzordnung, 1979, S. $107 \mathrm{ff}$; Christian Starck, Der Gesetzesbegriff des Grundgesetzes 1970, S. 172 ff.; Klaus Stern, Das Staatsrecht der Bundesrepublik Deutschland, II, 1980, S. $572 \mathrm{ff}$., $644,659 \mathrm{f}$., m.w.L. 


\section{Zur legitimierenden Qualitätssicherung der Inhaltsge- staltung}

\section{Die Vielheit der Beteiligten an der Gesetzgebung}

An der rechtsstaatlichen Gesetzgebungsqualität mit der Demokratieerfüllung festzuhalten und die Mängel zu verringern, erfordert hohe rechtsetzende Fähigkeiten, politische Lenkungskraft und demokratisch optimierte Konsensherstellung, die über die einfache Dezision mit parlamentarischen Mehrheiten hinauswächst. Daß ein auf sich selbst gestelltes Parlament - kraft seiner rational faßbaren Struktur und einer irrationalen Erleuchtung vorwiegend aus dem Volksbezug - derartigen Erwartungen eo ipso nachkäme, ist eine getreu gehegte Vorstellung. Und das positive Recht und mit ihm auch die Staatsrechtswissenschaft pflegen mit Vorliebe die öfentlichparlamentarischen Tätigkeiten, als ob sich das Gesetze-Geben gerade nur hier abspiele ${ }^{20}$. Die Wirklichkeit geht längst eigene und weitere Wege. So werden an der formellen Gesetzgebung weitere Gewalten, insbesondere Regierung und Verwaltung, sowie legislativ geeignete Sozialkräfte, insbesondere Parteien und Verbände, ausgiebig beteiligt; es geschieht, um Qualität und politische Akzeptationen mit legitimierenden Konnexen beizubringen. Dazu kommt die ununterbrochene Einwirkung der Massenmedien auf ein entstehendes Gesetz, verbunden mit dem Druck von sozialen Wirksamkeiten unbestimmter Organisationsgrade, die ihre Machtmöglichkeiten kräftig nut-

${ }^{20}$ Dabei ist deutlich hervorzuheben: Die Öffentlichkeit und schließlich die Verbindlichkeit herstellende Endentscheidung im wohlgeordneten Parlamentsverfahren haben ihre juristische Relevanz und legitimierende Wirkung durchaus behalten. Indessen geht die Anregung dahin, andere Stadien der Rechtserzeugung in ihrem spezifischen staatsrechtlichen Gewicht mit gleicher Umsicht einzubeziehen. Vgl. einerseits Norbert Achterberg, Die parlamentarische Verhandlung, 1979, passim; Friedrich Schäfer, Der Bundestag, 3. Aufl., 1977, insb. S. 86 ff.; Leo Kissler, Der Deutsche Bundestag, JöR 26 (1977), insb. S. 53 ff.; Hans Trossmann, Der Bundestag: Verfassungsrecht und Verfassungswirklichkeit, JöR 28 (1979), insb. S. $30 \mathrm{ff}$.; andrerseits Klaus Stern (Anm. 19), S. $615 \mathrm{ff}$; Günther Winkler, Gesetzgebung und Verwaltungsrecht, in Günther Winkler/Bernd Schilcher (Hrsg.), Gesetzgebung, 1981, S. $125 \mathrm{ff}$; Jacques-Michel Grossen, L'organisation des travaux préliminaires de législation, ZSR 93 (1974) II, S. 349 ff.; Walter Buser, Die Organisation der Rechtsetzung, ebenda, S. $377 \mathrm{ff}$.; Hans Huber, Die Anhörung der Kantone und der Verbände im Gesetzgebungsverfahren, jetzt in: „Rechtstheorie, Verfassungsrecht, Völkerrecht", Ausgewählte Aufsätze, 1971, S. 387 ff.; Kurt Eichenberger, Die oberste Gewalt im Bunde, 1949, S. $132 \mathrm{ff}$. 
zen. Das überlieferte Leitbild zersetzt sich, wonach Gesetzgebung die hoheitlich-einseitige Anordnung durch eine interessendistanzierte, exklusiv gemeinwohlorientierte Autorität von wahldemokratischer Abstützung sei. In den konsensualen A.ushandlungen mit sozial wirksamen Organisationen und im aufmerksamen Hinhören auf wie auch immer geäußerte Stimmen aus der Öffentlichkeit realisiert sich seit Jahrzehnten und immer stärker eine spezifische Vertrags- und eine diffuse Verhandlungsdemokratie, und zwar auch im parlamentarischen Regierungssystem. Aus ihren mühevollen informellen Konkordanzverfahren erwächst allmählich Gesetzesinhalt. Der langwierige und konfigurierte Gesetzgebungsprozeß der pluralen Teilhaber aber kann nicht länger die Gewißheit fingieren, unfehlbar zum Richtigen hinzuführen. Vielmehr wird jetzt kritisch und beharrlich gefragt: Wo und wie kommt der Inhalt der Gesetze eigentlich zustande, wo sind die materiellen Regelungsgewalten (Normierungspotenzen) angesiedelt, wo liegt die substantielle Verantwortung für die legitimierende Qualität der Gesetze?

\section{Die tragende Präparation}

Die materiell tragende Phase der Gesetzgebung ist offensichtlich die Präparation. Sie erstreckt sich von der substantiellen Impulsgebung bis zur förmlichen Einbringung einer Vorlage in das Parlament. Ihre Aufgabe ist es, den parlamentstauglichen Gesetzesentwurf zu erarbeiten.

a) Dieser Gesetzesentwurf ist in den meisten Fällen nicht Skizze oder alternatives Konzept zuhanden fortführender Kreationsakte, sondern abgeschlossenes Werk, das steht und mit dem stillen oder lauten Anspruch auftritt, als gut befunden und angenommen zu werden. Später noch ausfeilen, ergänzen, am Rande modifizieren, neu auftretende Konsensbedürfnisse befriedigen - das wird eingerechnet, dem Parlamente zugemutet und zugeschieden. Aber weder Parlamentsausschüsse noch Plenum sind die eigentlichen Inhaltsgeber und Formpräger. Das kann wesensgemäß gar nicht ihre Aufgabe sein. Denn sie sind nach Größe, Beschickung, Sendung und praktischen N.öglichkeiten daraufhin nicht angelegt. Es gehört denn zu den gehüteten Irrtümern und ideologiebesetzten Überforderungen, dem Parlamente die Inhaltsgebung ab ovo bis zur Marschfähigkeit zuzuschreiben, um dann, wenn es sich dieser Aufgabe entschlägt, sein Ungenügen oder eine unlautere Beihilfe durch Dritte zu verkünden. Das ist fortgesetzter Parlamentsrufmord. Oder, falls das Parlament selbst von seinem Vermö- 
gen und Unvermögen nicht Kenntnis nehmen will, wie das in der Schweiz vielfach der Fall ist, die perpetuierte Selbsttäuschung. Gewiß, man könnte einschneidend umgestalten, wirkliche - nicht nur, wie heute, so titulierte - Arbeitsparlamente von eigenständiger Gestaltungskapazität aufzuziehen trachten. Allein, das wären nicht mehr isolierbare Transformationen einer einzelnen Organgruppe, sondern Umstrukturierungen der kohärenten Staatsorganisation und ihren politisch stützenden Grundlagen. Soweit will bis jetzt, wie angedeutet, keine rechtsstaatliche Reform gehen. Dann aber muß Rechtsstaatlichkeit vernünftigerweise die gesonderte Vorbereitung der Gesetze anerkennen. Die Präparatoren schaffen in breit angelegten und erstreckten Verfahren die sachliche Vertretbarkeit und die politische Tragfähigkeit der Vorlage. Das ist weit mehr als Hilfsdienst, als Formulierungshilfe. Das ist der kreative Vorgang in fortlaufenden informellen Vorabentscheidungen, beladen mit allen Verantwortungen für qualitative und politische Zulänglichkeit des Projektes.

b) Dieses materielle Kernstück der Gesetzgebung liegt nun auch und gerade im demokratischen und sozialen Rechtsstaat vorwiegend in der Hand der Exekutive, verstanden als Regierung und Verwaltung, die unter sich wieder differente Positionen einnehmen, ohne daß ich ihnen hier nachgehen kann. Das war schon immer so; aber es nimmt nun bei der gewaltigen Regelungsproduktion der Gegenwart eine qualitativ veränderte Bedeutung an. Zwar könnten einzelne Abgeordnete, parlamentarische Arbeitsgruppen, vom Parlament bestellte Sachbearbeiter mit den Hilfsdiensten, Fraktionssekretariate, außenstehende Sachkundige die präparative Aufgabe teilweise übernehmen, und sie tun es auch. Doch die Regel ist es nicht, und selbst da, wo aus der Mitte des Parlaments die Entwürfe eingebracht werden, ist in Wahrheit oft die Exekutive der Urheber oder zumindest der Mitautor. Das Regierungssystem und die Parteienordnung sind wahrscheinlich von geringem Einfluß: Die Exekutive nimmt, wenn auch mit Unterschieden, die präparative Obliegenheit im parlamentarischen, im präsidentiellen und im gemischten (schweizerischen) System wahr. Die Gründe dafür liegen vereint in den politisch-faktischen Grundbeziehungen von Parlament und Regierung, wie Ernst Friesenhahn sie aufgewiesen hat ${ }^{21}$, und in der bisher unübertroffenen Eignung der Exekutive zur rechtsetzenden Arbeit. Die Exekutive hat das Know-how für die Rechtsetzung:

${ }^{21}$ Ernst Friesenhahn, Parlament und Regierung im modernen Staat, VVDStRL 16 (1958), S. 9 ff., insb. S. $41 \mathrm{ff}$. 
- Sie verfügt über die umfassende Sachkunde, namentlich für die Rechtsetzung im Verwaltungsrecht, die den Hauptanteil heutiger Gesetzgebung ausmacht.

- Sie hat die vielen Instrumente leicht greifbar, ohne die eine zeitgemäß-qualifizierte Legiferierung nicht auskommt, insbesondere Rechtsstandsübersicht, Fakteninformation, Rechtsvergleichung, Meinungsstand, Nebenfolgeprognosen.

- Sie entdeckt, im Gegensatz zu vielen weiteren Impulsträgern, die wirklichen Regelungsnotwendigkeiten und vermag praktikable Problemlösungen aufzuzeigen.

- Sie hat für die Rechtsetzung geeignetes Personal und größere Personalreserven als jede andere Organgruppe.

- Sie beherrscht die Koordinations- und Kooperationsmethoden staatsintern und gegenüber den intermediären Gewalten. Wenn schon jemand unter den Staatsorganen, so ist es meistens allein die Exekutive, die die Zugriffe der sozialen Mächtigkeiten auf die Entscheidungsprozesse zu zügeln imstande ist.

- Sie hat sicheres Verfahrenswissen, kennt die personellen Sonderheiten der Stunde und findet die erleichterten „Zugänge zu den Machthabern" im Staats- und Sozialgefüge.

- Sie bringt insgesamt die Zusammenführung von Sachverstand und politischem Verstand in den Gesetzgebungsvorgang ein.

Der Erfolg der Exekutive als Präparator ist durchschlagend: Die geltende Rechtsordnung ist materiell weitgehend ihr entsprungen, ungeachtet dessen, wer nominell initiiert haben mag. Damit allerdings trägt auch vorwiegend sie die Schuldenlast der Gesetzesmängel, in der Bilanz vielleicht verringert um die unzähligen Eingriffe, mit denen sie im Parlamente Fehler verhindert oder Vorlagen von Abgeordneten Verbesserungen verschafft hat.

c) Wer als Präparator dergestalt amtet, kann nicht abbrechen, wenn der Entwurf ins Parlament gelangt. Er wird unentbehrlich. Der Präparation folgt nahtlos die Lenkung oder Leitung von Gesetzgebungsarbeiten im Parlament durch die Exekutive, allerdings auf vielerlei Gängen, mit vielerlei Hinderungen und geteilten Führungsansprüchen. Insgesamt aber behält im parlamentarischen Verfahren die Exekutive eine lenkende Obliegenheit bei, auf die Gefahr hin, daß sonst sachlich unzureichend oder infolge politischer Zerfahrenheit überhaupt nicht legiferiert wird. 


\section{Die Konvergenz der Rechtsetzung bei der Exekutive}

Betrachtet man den enormen Anteil der Exekutive an der Gesetzgebung, schlägt man dazu, daß das ausgedehnte Verordnungsrecht weitgehend Domäne der Exekutive bildet, so ist unabweisbar: Es entsteht eine Konvergenz der Rechtsetzung bei der Exekutive, und zwar in quantitativer und mehr noch in substantieller Hinsicht. Demzufolge leuchtet ein, daß, zumal vor dem Hintergrund der allgemein expandierenden Verwaltung im Modernen Staat, von radikalen Gefährdungen des Rechtsstaates gesprochen wird. Die verbreiteten Vorstellungen der Gewaltenteilung werden an der empfindlichsten Stelle getroffen, das Legalitätsprinzip büßt an Glaubwürdigkeit ein, die Grundrechtsbehütung wird fraglich, die Machtkonzentration bei der Exekutive kulminiert. Man kann bedrängende Behauptungen beifügen: Das Recht werde sub specie der Exekutive und der Verwaltungsressorts gestaltet, und die Häufung der Gesetzesmängel fuße weniger an der Überforderung des Parlaments als in der rundum aktivierten Exekutive, die ihre Verantwortung für die Gesamtrechtsordnung nicht aufnehme und sich für die eigene Legiferierungsaufgabe unter dem Blickwinkel richtigen Rechts zu wenig bemühe ${ }^{22}$.

Angesichts dessen scheint Rechtsstaatlichkeit darauf zu brennen, gerade die rechtsetzende Exekutive zu bannen, die Sanierungen bei ihr und gegen sie anzusetzen. Alle Änderungsbemühungen, die über Kosmetik hinausgehen möchten, laufen indessen regelmäßig an der gleichen Klippe auf: Es gibt keine praktikablen Alternativen. Die in der Gesetzgebung präparierende und leitende Exekutive kann offensichtlich nicht ersetzt werden. Es ist niemand da, und es kann niemand glaubwürdig hergerichtet werden, der ihre Rollen übernähme. Korrigiert man, bleibt es wirkungsarm, oder die Exekutive

${ }^{22}$ Wenn die Bemühungen um eine umfassende Regelungstheorie, die die Unterscheidung von Norm und Einzelakt mit der Differenzierung von Rechtsetzung und Rechtsanwendung problematisieren, keineswegs die Funktion Rechtsetzung im staatsrechtlichen Bereich preisgeben, so wirken sich ihre vorläufigen Feststellungen, gleichsam vereinfacht und verfrüht, gern als Stärkung der Entscheidungsgewalt der Exekutive und der Judikative aus. Man wird deshalb wohl bald die praktischen staatsrechtlichen Konsequenzen einer umfassenden Regelungstheorie $\mathrm{zu}$ erfassen und allenfalls klarzustellen haben. Vgl. René A. Rhinow, Rechtsetzung und Methodik, Rechtstheoretische Untersuchungen zum gegenseitigen Verhältnis von Rechtsetzung und Rechtsanwendung, 1979, insb. S. $244 \mathrm{ff}$; J. Rödig, Zum Begriff des Gesetzes in der Rechtswissenschaft, in ders. (Hrsg.), Theorie der Gesetzgebung, 1976, insb. S. $46 \mathrm{ff}$. 
betritt durch Hintertüren die Regieräume doch wieder. Recht, Politik und Wissenschaft stehen deshalb immer noch und immer wieder vor der bedrängenden Frage, wie sie sich einzustellen, was sie vorzuschlagen haben. Wollen sie die Grundentscheide nicht umstürzen, werden sie sich an etwa vier Richtpunkten orientieren.

\section{Orientierungspunkte}

a) Wie schon bei der Gesetzeskritik ergeben realitätsbezogene Sichtungen im allgemeinen gemilderte Ergebnisse zugunsten des Parlaments. Es ist nicht einfach sanktionierende Passage, nicht nur öffentlicher Umschlagplatz für wohlvorbereitete Entwürfe zu verbindlichen Akten, nicht nur Stätte gruppenpolitischer Darstellungen um des politischen Betriebes willen. Derartiges ist es auch. Aber noch weit mehr. In bezug auf den Gesetzesinhalt kann das Parlament kräftige Vorauswirkungen entwickeln: Die Präparationsverfahren stellen sich auf seine Verhaltensweisen, Empfänglichkeiten und Zielvorstellungen ein und bemühen sich, genehme Inhalte vorzuschlagen. Im anschließenden parlamentarischen Verfahren bleiben Rückweisungen, Änderungen durch Ausschüsse und durch das Plenum und schließlich Ablehnungen der Vorlagen denkbar. Der Auftrag des Parlaments kann nicht die tatsächliche Inhaltsgebung sein, sondern - und zwar auch im parlamentarischen Regierungssystem - eine immer offene Potentialität, mit dem Entwurf so zu verfahren, wie es ihm selbst letztlich zusiagt. Rücken solche Möglichkeiten nahe an die Aktualisierungsfähigkeit heran, so daß die Exekutive ernsthaft mit ihnen zu rechnen hat, ist für Sinn und Auftrag des gesetzgebenden Parlaments Entscheidendes gewonnen. Es hebt sich dann über eine kontrollierende Gewalt hinaus, und seine Teilhabe ist ebenso unentbehrlicher wie qualifizierter Bestandteil gehobener Rechtsetzung. Die Gesetzgebung kann zu einer echt kocperativen Funktion werden ${ }^{23}$. Jede Organgruppe ist auf die andere angewiesen. Voraussetzung für ausgewogenes Teilhaben ist freilich, daß einerseits die Volksvertretung Selbstverantwortlichkeiten für ihre Tätigkeit aufnimmt und da $\beta$ andrerseits die Exekutive das staatsrechtliche Respektierungsgebot loyal innehält: Sie soll das Parlament in seiner legislativen Aufgabe achten, seine Beurteilungs- und Entscheidungsmöglichıkeiten fördern, die eigenen Entfaltungsfähigkeiten nicht rücksichtslos ausnutzen. Derartige Voraussetzungen nehmen sich von Staat zu Staat verschieden aus, und im parlamentari-

${ }^{23}$ Karl Meier, Kooperation von Legislative und Exekutive bei der Rechtsetzung im Bunde, 1979, insb. S. $79 \mathrm{ff}$. 
schen System mit zwei Hauptparteien stellen sie sich mühevoller ein als anderswo. Gesamthaft beurteilt, darf man die Parlamente aber bis heute nicht als Versager in der rechtsstaatlichen Gesetzgebungsaufgabe hinstellen.

b) In zweiter Linie fragt es sich, ob die Präparation durch geschriebenes Recht erfaßt werden soll, z. B. wem sie im einzelnen obliege, wie zu verfahren sei, wer Zutritt habe, wer wie aushandle, ob und wo Publizität geboten sei. Seit 20 Jahren wird in der Schweiz diskutiert, ob Verfassung, Gesetz und Verordnung dieses sogenannte Vorverfahren ordnen sollen. Man hat es bis jetzt zu einer gesetzlichen Markierung und zu einigen Verwaltungsverordnungen mit gewissen Außenwirkungen gebracht, scheut aber die Verdichtung und die stufenmäßige Hebung, um die politischen und sachlichen Mobilitäten im weichen Stadium der Gesetzesschöpfung keinesfalls zu beengen, mehr aber wohl noch deswegen, weil man sich bei der Präparation noch außerhalb des Rechtsraumes wähnt. Das letzte Wort zur Normierung der Normierung in der materiellen Schwergewichtsphase des legislativen status nascendi ist noch nicht gesprochen. Tradierte rechtsstaatliche Überlegungen aber geben keine Ratschläge: Die bisherigen Rechtsstaatselemente schweigen.

c) In dritter Linie fügen sich Postulate zusammen, die auf die Sicherung gesetzgeberischer Arbeitsqualität gerichtet sind, adressiert an Präparatoren und an das Parlament, darüber hinaus an alle auf die Gesetzgebung einwirkenden Kräfte. Es sind legislatorische Grundsätze und Rechtsetzungsmaximen, die erleichtern möchten, zureichendes Recht in der rechtsstaatlichen Einbettung zu formen. Darin liegt weit mehr als das gewohnte Gebot, bei der Rechtsetzung höherrangiges Recht zu respektieren. Es ist die Verpflichtung, die Versuche zum richtigen Recht schlechtweg zu optimieren. Dafür soll unter anderem einer Gesetzgebungsmethodik gefolgt werden, in der zeitgemäße Gesetzestechnik mit tragfesten Arbeitsunterlagen Hilfen bietet ${ }^{24}$. Die Anweisungen sollten allerdings das Betriebstechnische und Schulhafte hinter sich lassen und von rechtsstaatlichen Grundüberlegungen getragen sein, wie sie etwa Konrad Hesse angestellt hat und an die mit den Stichworten vom Primat des Rechtes im staatlichen Handlungssystem, von

${ }^{24}$ Positiv zum Aufbau von Gesetzgebungslehren: Peter Noll (Anm. 9), passim; Klaus Stern (Anm.9), S. $643 \mathrm{ff}$; Ulrich Scheuner (Anm. 4), S. $141 \mathrm{f}$; Werner Maihofer, Gesetzgebungswissenschaft, in: Günther Winkler/Bernd Schilcher (Hrsg.), Gesetzgebung, 1981, S. 3 ff.; Jürgen Rödig, Vorstudien zu einer Theorie der Gesetzgebung, 1975, passim. 
der Verstetigung und Kontinuität des Rechts, von der Rationalisierung des offentlichen Gesamtzustandes durch rechtsrichtige Gestaltung erinnert werden $\operatorname{mag}^{25}$. In welche Gestaltungsform und -stufe die Anweisungen zu setzen wären, ist ungelöst. Wesentlicher ist vorderhand, zu fordern, daß materiell zeitgemäße Rechtsstaatlichkeit in ihnen zum Ausdruck gebracht wird.

d) In vierter Linie wird erwogen, ob die vielfältigen Bemühungen um gesetzgeberische Qualität Fremdkontrollen zu unterwerfen seien. Obgleich ,optimale Methodik der Gesetzgeburig als Verfassungspflicht" (Gunther Schwerdtfeger) charakterisiert werden $\mathrm{mag}^{26}$, so sind derzeit etwa verfassungsgerichtliche Kontrollen über Gesetze und Gesetzgebungsverfahren, die über die Messung an Grundrechten, namentlich der Rechtsgleichheit hinausgingen, nur schwer praktikabel zu machen und im Gewaltengefüge kaum unterzubringen. Doch damit münde ich ein in Fragestellungen, die an der letztjährigen Tagung in Innsbruck zur Diskussion gestanden haben und dort als längerfristig aufgegeben erkannt worden sind. Man wird für die Qualitätssicherung weiterhin und vornehmlich der Verantwortung der kooperierenden Gewalten, nämlich Parlament und Exekutive, anheimgeben müssen.

Ich beende den kursorischen Gang. „Gesetzgebung im Rechtsstaat" weist darauf hin, daß alle drei Größen: Gesetz Gesetzgebung - Rechtsstaat aufeinander bezogen sind und einander wechselseitig bestimmen. Jede dieser Größen ist Wandlungen ausgesetzt, so daß die Relationen ihrerseits in Bewegung sind. Wenn vielfach Mängel gerügt werden, so ist vorwiegend die Gesetzgebung angeklagt, und wenn Sanierungen gesucht werden, so wird zuerst sie angesprochen. Das ist einsieitig. Dem sozialen und demokratischen Rechtsstaat sollten Begrifflichkeit und Zugänglichkeit so fortgebildet werden, daß Gesetz und Gesetzgebung an ihm zeitgemäße Orientierungen erlangen und die Legitimierung in seinem Dienste erwerben können. Dieser Rechtsstaat vermöchte dann in Gesetz und Gesetzgebung - als Ausdruck des Versuchs zu richtigem

${ }^{25}$ Konrad Hesse, Der Rechtsstaat im Verfassungssystem des Grundgesetzes, in: „Staatsverfassung und Kirchenordnung“, (II.) Festgabe für Fludolf Smend, 1962, S. $71 \mathrm{ff}$.

${ }^{26}$ Gunther Schwerdtfeger, Optimale Methodik der Gesetzgebung als Verfassungspflicht, in: „Hamburg - Deutschland - Europa“, Fest:schrift für Hans Peter Ipsen, 1977, S. $173 \mathrm{ff}$. Vgl. auch Günther Winkler (Anm. 20), S. $130 \mathrm{ff}$. 
Recht $^{27}$ - erneut Gestalt zu gewinnen und Verwirklichung zu finden.

${ }^{27} \mathrm{Zu}$ dem für die Rechtsetzung zentralen Begriff des richtigen Rechts: Karl Larenz, Richtiges Recht, Grundzüge einer Rechtsethik, 1979, passim; Hans Ryffel, Grundprobleme der Rechts- und Staatsphilosophie, 1969, passim; Walther Burckhardt, Methode und System des Rechts, 1936, S. $121 \mathrm{ff}$., $241 \mathrm{ff}$; ders., Die Organisation der Rechtsgemeinschaft, 2. Aufl., 1944, S. $234 \mathrm{ff}$. und passim; Rudolf Stammler, Die Lehre vom richtigen Rechte, 2. Aufl., 1926, passim. 
Leitsätze des 1. Berichterstatters über:

\section{Gesetzgebung im Rechtsstaat}

1. Gesetz, Gesetzgebung und Rechtsstaat stehen in komplexen Wechselbeziehungen, und sie wandeln sich für sich und in ihren Relationen.

2. Das Gesetz ist „Rechtsstaatselement" und damit eigenständiger Zielwert, zudem Instrument zur Verwirklichung weiterer „Rechtsstaatselemente“ (z.B. Gewaltenteilung, Rechtsschutz, Gleichheitsforderung, Grundrechtsverwirklichung, Verantwortlichkeiten). Die Gesetzgebung wird zum kritischen Angelpunkt realisierbarer Rechtsstaatlichkeit. Der Staat der moderner Aufgabenfülle, der demokratischer und sozialer Rechtsstaxt sein will, ist ein potenzierter (,neuer") Gesetzes- und Gesetzgebungsstaat. Er hebt sich wegen rechtsstaatlich-materialer Zügelungen und Lenkungen vom ungebundenen Gesetzes. und Gesetzgebungsstaat des späteren 19. und der ersten Hälfte des 20. Jahrhunderts ab.

3. Die dafür notwendige rechtsstaatliche Legitimation erlangen Gesetz und Gesetzgebung mit ihrer Sachqualität und Denokratieerfüllung. Es wird die Schaffung richtigen Rechts auf Wegen, die das demokratische Strukturprinzip des einzelnen Staates angibt, angestrebt.

4. Obwohl der Gesetzgebung die erwartete hohe Leistungsfähigkeit normativ zugeschrieben bleibt, werden ihr - in offenbar zunehmendem Ausmaß - Mängel nachgewiesen, die die Legitimation von Gesetz und Gesetzgebung und damit Rechtsstaatlichkeit beeinträchtigen. Die Rügen betreffen insbesondere eine ,Normenflut", Strukturmängel, inhaltliche Unrichtigkeiten, kommunikative Unkorrektheiten der Gesetze, funktionelle und personale Unzulänglichkeiten des Gesetzgebers.

5. Eine generalisierende Lagebeurteilung räumt immerhin ein, daß einerseits hinreichende Legiferierungen erwartet werden können und andererseits kompensatorisch-komplementäre Mängelausgleiche (so durch Verfassungsrecht, Rechtsgrundsätze, Funktionen der anderen Gewalten) stattfinden. Doch stellt sich für einen erheblichen Bestand von Mängeln die rechtsnormative Frage, ob institutionelle Sanierungen möglich und er- 
wünscht seien. Es gibt darunter Sachverhalte, bei denen sich die Staatswirklichkeit tradiert-normativen Lenkungen widersetzt und das Problem auftritt, ob und gegebenenfalls wie weit positives Recht, aber auch „Rechtsstaatselemente“ und Institutionen-Deutungen sich anzupassen, insbesondere sich schmiegsam fortzubilden und zu differenzieren hätten.

6. Ohne einschneidende Änderungen der staatlichen Fundamentalvoraussetzungen wird sich das Normierungsbedürfnis nicht grundlegend verringern. Rechtsstaatliche Perfektion der Rechtsordnung sowie sozialstaatliche politische Auseinandersetzungen in demokratischen Prozessen erfordern ausgreifende gesetzgeberische Aktivitäten. Entlastungen durch reformierendes Verfahrensrecht bleiben begrenzt. $Z u$ erwägen sind gesonderte Prüfungen der Notwendigkeit (Erforderlichkeit) von gesetzgeberischen Vorhaben.

7. Die Rechtsetzung tendiert von demokratisch-rechtsstaatlichen Ansätzen aus zur Ausweitung der (formellen) Gesetzgebung, die die Regelungslast jedoch nicht meistert. Es finden Dezentralisierungen und Dekonzentrationen statt, die mangels methodischer Handhabung die Einheit der Rechtsordnung gefährden. Eine geordnetere Verteilung der Rechtsetzungsaufgaben drängt sich auf. Sie kommt über die herkömmlichen Gesetzesbegriffe und Delegationsklauseln nicht zustande. Sie hat sich vielmehr nach differenzierbaren Wertungskriterien (z.B. Wesentlichkeit, Wichtigkeit) zu richten. Rechtsstaatlichkeit sollte dazu Hilfen bieten, indem sie eigene Dogmatisierungen (z.B. bei Aspekten der Gewaltenteilung) auflöst und sich um neue Verbindungen zu ihren konstitutiven Grundwerten bemüht.

8. Die (formelle) Gesetzgebung muß wegen der Qualitätsforderung, des Demokratiegebots und der konsensualen Akzeptationsverschaffung eine Vielheit von Beteiligten in konfigurierten Abläufen zulassen. Die Inhaltsgestaltung kommt dabei vorwiegend in einem dem parlamentarischen Verfahren vorgelagerten Präparativproze $\beta$ zustande, der maßgeblich von der Exekutive (Regierung und Verwaltung) getragen und geführt wird. Bei der Exekutive stellt sich angesichts der Gesetzesvorbereitung und der Verordnungsgebung eine materielle Konvergenz der Rechtsetzung ein. Zur Ablösung der Exekutive aus dieser rechtsstaatlich beanstandeten Stellung sind bisher keine durchschlagenden Alternativen aufgewiesen worden. Mildernd wirkt sich aus, daß sich die Gesetzespräparation auf das Parlament ausrichtet, solange diesem eine Entscheidungspotentialität und der Gesetzgebung die Natur einer substantiell kooperativen Funktion gesichert werden kann. Es fragt sich, ob 
präparative Verfahren rechtlich geregelt werden sollen. Daß legislatorische Grundsätze und Rechtsetzungsmaximen die Rechtsetzungsarbeiten methodisch lenken und läutern sollen, wird allmählich anerkannt, doch sind ihr Gehalt und die Kontrollen ihrer Beachtung noch offene Probleme. 
2. Bericht von Professor Dr. Richard Novak, Graz

\title{
Gesetzgebung im Rechtsstaat
}

\author{
Inhalt
}

I. Von der Notwendigkeit zur "Not der Gesetzgebung“.

Seite

Einleitung und Gliederung . . . . . . . . . . . . . 40

1. Gesetzgebung im Zwielicht . . . . . . . . . . . . . 40

2. Die qualitative und die quantitative Dimension. . . . . . 42

II. „Rechtsstaat und Gesetzesstaat - Konsequenz oder

Alternative?" Qualitative Bestimmungsgründe. . . . . . . . 44

1. Der Gesetzmäßigkeitsgrundsatz . . . . . . . . . . . 44

2. Formelles Rechtsstaats-Verständnis . . . . . . . . . . . 48

3. Gewaltenteilung im Wandel . . . . . . . . . . . . . . . 49

4. Reform der Verordnungsdelegation . . . . . . . . . . 51

5. Eigenverantwortung der Verwaltung. . . . . . . . . . 53

III. „Rechtsstaat - ein Widerspruch in sich?"

Quantitative Bestimmungsgründe ............ 56

1. Die Fragestellung . . . . . . . . . . . . . . . . . . . . 56

2. Konstante Größen. . . . . . . . . . . . . . . . . . 57

3. Variable Größen und Unbekannte der Gleichung . . . . 58

\section{Von der Notwendigkeit zur „Not der Gesetzgebung““. Ein- leitung und Gliederung}

1. Gesetzgebung im Zwielicht

Das zur Erörterung gestellte Thema drückt einen evidenten, historisch festgefügten Zusammenhang aus; und zugleich eine latente Spannungslage der Gegenwart. Vor wenigen Jahren noch hätten an der Richtung, in die sich die Untersuchung zu bewegen hat, kaum Zweifel sein können. Das Problem der „Gesetzgebung im Rechtsstaat" wäre als Frage nach der Reichweite des Gesetzesvorbehalts und als Appell zu seiner Ausdehnung und Vertiefung zu verstehen gewesen. Gesetz und gesetzgebende Gewalt konnten als „Achse der rechtsstaatlichen

\footnotetext{
${ }^{1}$ In Anlehnung an Hermann Jahrreiß, Größe und Not der Gesetzgebung (Vortrag 1952), in: Mensch und Staat, 1957, 17.
} 
Verfassung“ und als „Drehscheibe des modernen demokratischen Rechtsstaates" bezeichnet werden. ${ }^{2}$

Heute kann man es auch anders hören. Der „Niedergang des Gesetzgebungsverfahrens", die „Inflation im Recht",, ausufernde Massenhaftigkeit bei abnehmender Durchschaubarkeit und innerer Überzeugungskraft der Normproduktion sind Klagen, die die Szene beherrschen. Die „Gesetzesflut" ist zu einem beliebten Punkt in den Tagesordnungen juristischer Fachkongresse aufgerückt. Auch die einschlägige Literatur ist unterdessen zu einer beträchtlichen Woge angeschwollen. ${ }^{4}$ Fast möchte es scheinen, als wäre das Gesetz selbst zum Feind des Rechtes und des Rechtsstaates geworden.

Oder hat man es bei dem weithin aufgebrochenen Unbehagen doch nur mit einer wissenschaftlich verbrämten Form gesellschaftspolitischer Wehleidigkeit zu tun, die vor Zwangsläufigkeiten des sozialen Prozesses die Augen schließt; noch schlimmer: diese aus ideologischer Voreingenommenheit nicht wahrhaben will? Ist einfach die derzeitige Situation der Gesetzgebung, bei all ihren Mängeln, ,nichts anderes als die Normalität einer demokratisch verfaßten Industriegesellschaft"??

Nun sind es gewiß nicht Schlagworte und Redewendungen, mit denen die Krise heraufbeschworen oder gebannt werden kann. Die Symptome sind deutlich genug. In knapp einem Jahrzehnt hat eine neue Disziplin, die Gesetzgebungslehre, einen wahren Siegeszug angetreten und mit dem anspruchsvollen Programm der Planung, Methodik und Evaluierung der Rechtssetzung die bescheidenen Anfänge auf dem Gebiet der Gesetzestechnik und Rechtsbereinigung längst hinter sich ge-

${ }^{2}$ Ernst-Wolfgang Böckenförde, Entstehung und Wandel des Rechtsstaatsbegriffs, in: FS Arndt 1969, 53 (58), bzw. Hans R. Klecatsky, Was verlangt der Rechtsstaat heute?, ÖJZ 1967, 113.

${ }^{3}$ Vgl. Hans Schneider, Der Niedergang des Gesetzgebungsverfahrens, in: FS Müller 1970, 421; Georg Berner, Inflation im Recht, BayVBl. 1978, 617.

${ }^{4}$ Auf eine nähere Dokumentation und Würdigung mußte, dem Wunsch des Vorstandes der Vereinigung folgend, verzichtet werden. Dies gilt insb. auch für die jüngst zum Thema erschienenen Arbeiten von Christoph Degenhart und Hermann Hill, DÖV 1981, 477 und 487, Christian Pestalozza, NJW 1981, 2081, und Walter Leisner, DVBl. 1981, 849.

${ }^{5}$ So Friedrich Kübler, Kodifikation und Demokratie, JZ 1969, 645 (651). 
lassen. ${ }^{6}$ In ihrem Sog erlebt - wieder einmal - die Kritik an Bürokratie und Bürokratisierung eine Hochkonjunktur. ${ }^{7}$ Ursache oder Wirkung, mehr Täter oder Opfer der Normierungssucht, das allenfalls bleibt umstritten. Forderungen nach Entstaatlichung, Privatisierung und gesellschaftlicher Selbstorganisation greifen noch weiter und verraten prinzipielle Skepsis gegenüber den Kapazitäten öffentlicher Aufgabenbewältigung. Nicht zu vergessen schließlich die Verwendungszusagen und beginnenden Bemühungen seitens der praktischen Politik, es in Hinkunft besser machen zu wollen.

Das Bild der diagnostizierten Abnützungserscheinungen und der angebotenen Therapien ist also ein vielschichtiges und buntes. Entsprechend streng hat im gegebenen Rahmen die Auswahl zu sein.

\section{Die qualitative und die quantitative Dimension}

Man nehme: ,. . . Regelungsdichte und Bürgerohnmacht beklagen“, gemessen in Zentimetern Bundesgesetzblatt; ,... an die eigene Brust klopfen (wir Politiker/Beamte/Bürger haben auch dazu beigetragen)“; dann „eine einzelne absurde Vorschrift zitieren (möglichst aus dem Bereich der Europäischen Gemeinschaft)"; endlich Aufstellung der These, daß eine sorgfältige Überprüfung zur Abschaffung eines je nach politischem Standort variablen Prozentsatzes der Rechtsmasse führe - so etwa wurde im Schrifttum das gängige Muster der Auseinandersetzungen um die Normenfülle charakterisiert oder, besser gesagt, karikiert. ${ }^{8}$

Im folgenden soll versucht werden, dieses Rezept nicht anzuwenden, obwohl es, namentlich was die verfügbaren Beispiele anlangt, verlockend und auch geeignet wäre, manche nationale Besonderheit zum Vorschein zu bringen. Man

${ }^{6}$ Der Anschluß an die entsprechenden schweizerischen und deutschen Forschungen ist nunmehr auch in Österreich hergestellt. Vgl. insb. Günther Winkler - Bernd Schilcher (Hrsg.), Gesetzgebung, 1981, Hans R. Klecatsky - Norbert Wimmer (Hrsg.), Sozialintegrierte Gesetzgebung, o.J. (1981), und Theo Ohlinger (Hrsg.), Methodik der Gesetzgebung, 1982.

7 Treffend diese Zusammenhänge bei Frido Wagener, Vom Neubau zur Pflege - wohin entwickelt sich unser Verwaltungssystem? in: Zukunftsaspekte der Verwaltung, 1980, 21 (22 f.), und bei Rainer Wahl, Die bürokratischen Kosten des Rechts- und Sozialstaats, Die Verwaltung 1980, 273.

\& Vgl. Rudolf Dieckmann, Aktuelle Problemfelder bei der Umsetzung von Bundesgesetzen, VuF 1980, 155. 
braucht bloß an eine Verordnung der Bundesregierung über die „Beistellung von Dienstkleidern und Dienstabzeichen an das aktive reitende Personal der Spanischen Reitschule" zu denken; ${ }^{9}$ eine Regelung, die sich, zudem in illustrierter Form, vom Zweispitz über die Hirschlederhose bis zu den Stulpenstiefeln und Sporen erstreckt. Ganz zu schweigen von einer anderen, auf das Lebensmittelgesetz gestützten Verordnung mit dem lapidaren Titel „Extrawurst“. Im übrigen hat - und das gehört unmittelbar zum Thema - vor genau einem Jahr der Verfassungsgerichtshof (VfGH) diese „Extrawurst“ wieder als gesetzwidrig aufgehoben. ${ }^{10}$

Aber um derlei Versatzstücke aus dem juristischen Kuriositätenkabinett soll es gerade nicht gehen. Die bisherige Diskussion läßt auch Grundsätzlicheres erkennen. Sie ist, wenngleich nicht immer klar auseinandergehalten, auf zwei unterschiedlichen Ebenen verlaufen. Knüpft man nochmals an die reichlich strapazierten Etikettierungen „Gesetzesflut" und „Normeninflation" an, so ist mit der ersten, beim Namen genommen, ein qualitatives Kriterium angesprochen. Gefragt wird, über Postulate der legistischen Gestaltung selbstverständlich hinaus, nach der angemessenen Rechtssatzform und der sachgerechten Aufteilung der Regelungsbefugnisse zwischen Legislative und Exekutive. Anders ausgedrückt, das Interesse gilt den verfassungs-endogenen Gründen oder Hauptgründen vermehrter Gesetzgebung und den rechts- und rechtsstaatsimmanenten Reformüberlegungen. Dagegen zielt das Stichwort "Normeninflation“ auf die quantitative Seite des Problems, auf die Ausmaße des Rechtsstoffes als solchen und die außerhalb des Verfassungssystems, im gesellschaftlichen Vorfeld wurzelnden Kräfte seines Wachstums.

$\mathrm{Daß}$ die beiden Gesichtspunkte nicht völlig trennscharf sind, sich überschneiden können, ist einzuräumen. Im Phänomen der Gewaltenteilung fließen rechtliches Gebot und politische Realität aufs engste ineinander. Sozialstaatsklausel und sozialstaatliche Deutung der Grundrechte markieren einen erheblichen Abstand zwischen der deutschen und der österreichischen Verfassungslage. Aber das ist das Schicksal jeder Schematisierung, daß sie nur eine ungefähre Zuordnung erlaubt und nicht fugenlos paßt.

\footnotetext{
${ }^{9}$ BGBl. 1976/635.

${ }_{10}$ BGBl. 1977/89 bzw. Erkenntnis (Erk.) des VfGH 10. 10. 1980, V 36/ 77.
} 


\section{II. „Rechtsstaat und Gesetzesstaat - Konsequenz oder Al- ternative?'11 Qualitative Bestimmungsgründe}

\section{Der Gesetzmäßigkeitsgrundsatz}

„Worauf es ankommt ist: die von der Verfassung gezogene Grenze zwischen der Kompetenz der Gesetzgebung und der Verordnung zu wahren. ... Verordnungen dürfen nur aufgrund oder im Rahmen der Gesetze erlassen werden, Verordnungen können nur Gesetze durchführen, aber nicht abändern. Damit überhaupt von einer näheren Durchführung eines Gesetzes gesprochen werden kann, muß dieses Gesetz nicht nur die Bestimmung enthalten, daß überhaupt irgendwelche Maßnahmen getroffen werden - in diesem Falle läge nur eine formalgesetzliche Delegation vor -, sondern das Gesetz muß auch bestimmen, welche Maßnahmen zu treffen sind, wenn es auch die nähere Durchführung dieser Maßnahmen der Verordnung überläßt. Damit ein Gesetz durch Verordnung überhaupt durchführbar sei, muß es im Sinne der Bundesverfassung inhaltlich hinreichend bestimmt sein, müssen schon aus dem Gesetz allein - und ohne daß es der Heranziehung der Durchführungsverordnung bedarf - alle wesentlichen Momente der beabsichtigten Regelung ersehen werden. Nicht nur das , $\mathrm{Ob}^{6}$, sondern auch das ,Wie' der Normierung muß in Gesetzesform bestimmt sein. Dabei läßt sich allerdings die Grenze zwischen bloß formalgesetzlicher Delegation und materiellrechtlicher Bestimmung nicht scharf ziehen. Es muß stets Fälle geben, bei denen die Entscheidung: Ob noch ,formalgesetzliche Delegation' oder schon ,materiellrechtliche Bestimmung' zweifelhaft sein kann. Hier muß das wohlerwogene Ermessen des Gerichtes die Grenze ziehen."

Das Zitat könnte durchaus der Rechtsprechung des BVerfG entlehnt sein und als Variation auf die sogen. „Wesentlichkeitstheorie“ - „Theorie" unter Anführungszeichen gesetzt gelten. ${ }^{12}$ Das Urheberrecht gebührt aber dem österreichischen VfGH. Das wiedergegebene Erkenntnis stammt aus dem Jahr 1923. ${ }^{13}$ Es hat die Weichen für die weitere Entwicklung gestellt; eine Entwicklung, die dann freilich mit jener unter dem GG nicht nur insgesamt, sondern oft bis in Details augenfällige Parallelen zeigt.

${ }^{11}$ Titel des Beitrages von Joachim Kormann in: FS Fröhler 1980, 23.

12 Die Ähnlichkeit der Formulierungen in BVerfGE 7, 282 (301 f.), die dem eigentlichen Durchbruch zur "Wesentlichkeits"-Judikatur in BVerfGE 33, 125 (155ff. - Fachärzte) und 303 (338ff. - numerus clausus), voranliegt, ist nicht $\mathrm{zu}$ übersehen.

${ }^{13}$ Amtl. Sammlung (Slg.) 1923/176. 
Der VfGH hat seine Linie nach 1945 von neuem aufgenommen und er hat sie erklärtermaßen verschärft. Die verfassungswidrige „formalgesetzliche Delegation“ ist in dieser Zeit zu einem echten Schreckgespenst des Gesetzgebers avanciert. ${ }^{14}$ Doch nicht genug. Hand in Hand mit der Steigerung der inhaltlichen Anforderungen ist die Basis des Legalitätsprinzips verbreitert worden. Der Gedanke strenger gesetzlicher Determinierung der Vollziehung, bisher aus der speziellen Norm des Art. 18 Abs. 2 der Bundesverfassung, dem Gegenstück zu Art. 80 Abs. $1 \mathrm{GG}$, abgeleitet und auf die Verordnung beschränkt, wurde auf den individuellen Verwaltungsakt übertragen und $\mathrm{zu}$ einem allgemeinen Bestimmtheitsgebot ausgebaut. Der Gesetzgeber darf Ermessen einräumen. Aber wenn er das tut, dann ist er zugleich verpflichtet, der Behörde den Sinn, in dem das Ermessen ausgeübt werden soll, mit auf den Weg zu geben; "schrankenloses Ermessen“ ist mit der Verfassung unvereinbar. ${ }^{15}$ Wiederum kann sich der VfGH dabei auf eine Sonderregelung, und zwar auf Art. 130 Abs. 2 des Bundes-Verfassungsgesetzes (B-VG) berufen.

Schließlich hat er in einem ergänzenden Schritt den unbestimmten Rechtsbegriff ins Visier genommen. Auch bei seiner Verwendung müsse das Gesetz, müsse namentlich eine gesetzliche Strafvorschrift noch einer „Objektivierung“ zugänglich, die Auslegung durch die Verwaltungsbehörde müsse „,vorhersehbar" sein. Die Ordnung des Rechtsstaates habe dem Bürger die Möglichkeit zu geben, ,sich dem Rechte gemäß zu verhalten“, und seine Freiheitssphäre durch eine „,deutliche Grenzziehung" vom Bereich des Unerlaubten zu trennen. Ansonsten liege ein Widerspruch zu Art. 18 Abs. 1 der Bundesverfassung vor, der verlange, „daß die Rechtmäßigkeit jeglichen Vollziehungsaktes am Gesetze gemessen werden kann, was zur Voraussetzung hat, daß der Inhalt des Gesetzes hinreichend bestimmt ist". - Die abstrakte Aussage dürfte überzeugender sein als die konkrete Entscheidung. Anlaß waren das, nach Ansicht des Gerichtshofes verfassungswidrige, Verbot in einem Kinogesetz, Bilder vorzuführen, die u.a. geeignet sind, das „sittlich-religiöse“" Empfinden zu verletzen, und ein darauf gestützter Strafbescheid. ${ }^{16}$ Es ist - aber das nur in Parenthese - nicht der Film „Eva im Abendkleide" gewesen, dem wir ja bekanntlich die grundlegenden Forschungen zur Subven-

14 Vgl. die mit Slg. 3754/1960 eingeleitete Rechtsprechung.

${ }_{15}$ Erstmals Slg. 3317/1958 und dann insb. Slg. 5240/1966. Letzteres Erk. ist BVerfGE 20, 150 (154ff. - Sammlungsgesetz) eng verwandt.

${ }^{16}$ Vgl. Slg. 4037 und 4039/1961. 
tionsverwaltung verdanken; sondern, ganz im Gegenteil, ein Kunstwerk namens „Die Nackte und der Satan“.

Die klassischen Weichzonen der Gesetzesbindung, Verordnung, Ermessen und unbestimmter Rechtsbegriff, waren damit in den Bannkreis eines strikten Legalitätsdenkens gezogen. Mittlerweile lag eine weitere Bastion der Verwaltung schon unter Beschuß; nämlich das, in Österreich angeblich gar nicht existierende oder mindestens lange Zeit im Schatten einer scheinbar alles überstrahlenden Gesetzmäßigkeit verborgene, besondere Gewaltverhältnis. Der VfGH ist hier nicht so abrupt mit der Tür ins Haus gefallen wie das BVerfG in seinem Beschluß zur Gefangenenpost. ${ }^{17}$ Er ist eher nach der Methode verfahren: Steter Tropfen höhlt den Stein. Das Ergebnis war aber letztlich das Gleiche, ein Strafvollzugsgesetz, das im Jahr 1970 die bisher anstaltsinternen Regelungen abgelöst hat. ${ }^{18}$ Und in ähnlicher Weise hat die Judikatur Geburtshilfe beim Schulunterrichtsgesetz von 1974 geleistet, mit dem der Gesetzesvorbehalt in die innere Schulordnung hineingetragen worden ist. ${ }^{19}$ Dies in einem Maße freilich, daß von „Vorbehalten" des Gesetzgebers eigentlich kaum die Rede sein kann.

So ist es, im ganzen gesehen, bloß ein, wenn auch fundamental wichtiges Gebiet, auf dem die Dinge unverändert in Fluß sind; jenes der nichthoheitlichen Verwaltung oder, auf österreichisch - horribile dictu -, der sogen. „Privatwirtschaftsverwaltung“. In dieser Arena vor allem ist der Meinungsstreit um den Gesetzmäßigkeitsgrundsatz entbrannt. Er hat viel Staub aufgewirbelt, hat Lehre und Rechtsprechung in mehrere Lager gespalten und ist bis heute nicht endgültig entschieden. ${ }^{20}$ Unentschieden nämlich vom Prinzip her, von der Geltung, Nichtgeltung oder differenzierten Anwendung des Art. 18 der Bundesverfassung; weniger was die rechtspolitische Handhabung anlangt. Zwar gibt es nach wie vor die lediglich etatbezogene Subventionierung. Aber seit einigen Jahren ist die Tendenz zur sondergesetzlichen Ausformung unverkennbar. Wobei allerdings hinzugefügt werden muß, daß das Flickwerk dieser Förderungs- oder „Selbstbindungsgesetze“ - ein Anklang an

17 BVerfGE 33, 1 (9ff.).

18 BGBl. 1969/144.

19 BGBl. 1974/139.

${ }^{20}$ Vgl. z.B. Heinz Schäffer, Die sogenannte Privatwirtschaftsverwaltung und das Gesetz, in: Allgemeines Verwaltungsrecht, 1979, 253; Richard Novak, Divergenzen in der Rechtsprechung der Gerichtshöfe des Öffentlichen Rechts - ein unbewältigtes Problem, in: FS Klecatsky 1980, 655 (669ff.). 
die Thematik von morgen - ihre fragwürdige rechtsstaatliche Substanz nur notdürftig zu verschleiern vermag. Darauf ist noch zurückzukommen. Schließlich sollen uns gewisse trübe Erfahrungen jüngeren Datums, über die der Mantel des Schweigens gebreitet sei, demnächst sogar eine gesetzliche Regelung auf dem Sektor der öffentlichen Aufträge in Gestalt eines Vergabegesetzes bescheren. ${ }^{21}$

Weitere Einzelheiten, den Niederschlag des Auf und Ab der Legalitätsvorstellungen im Schrifttum darzulegen, die ursprünglich unverhohlene Sympathie, dann auch die wachsende Sorge, mit der man die Entwicklung beobachtet hat, all das ist weder möglich noch erforderlich. ${ }^{22}$ Auf den kürzesten Nenner gebracht: Am Anfang war der "Normenhunger" der Verwaltung; ${ }^{23}$ der Gesetzgeber hat sich dieser Mangellage mit Eifer angenommen; er hat - zum Teil wenigstens - des Guten zuviel getan; und der Katzenjammer, genannt "Gesetzesflut", ist auf dem Fuße gefolgt.

Es scheint, daß auch den VfGH selbst, der in dieser Beziehung die tonangebende Rolle verkörpert, eine Art von Bangigkeit ergriffen hat. Die Aufhebung unscharfer gesetzlicher Ermächtigungen an die Verwaltung, in den 60er Jahren gang und gäbe, ist neuerdings zur seltenen Ausnahme geworden. Das Bestimmtheitserfordernis dürfe, insb. in wirtschaftsrechtlichen Belangen, „nicht überspannt" werden, heißt es. ${ }^{24}$ Der Prognose-Spielraum des Gesetzgebers und seine Befugnis, ihn der Vollziehung zu delegieren, wird unterstrichen. Nicht zuletzt hat auch das Theorem von der bloß ,finalen“ Determinierung im Planungsbereich den erklärten Segen der Judikatur empfangen. ${ }^{25}$ Stets wird dabei die Fassade der ständigen Rechtsprechung aufrechterhalten. Doch dahinter und über unvermeidliche Schwankungen hinaus, zeichnen sich größere Bruchflächen ab.

${ }^{21}$ Die Regierungsvorlage $996 \mathrm{BlgNR} 15$. GP ist ein zweiter Versuch nach der gescheiterten Vorlage von 1969 (1246 BlgNR 11. GP).

${ }^{22}$ Die Wende wird deutlich bei Günther Winkler, Gesetzgebung und Verwaltung im Wirtschaftsrecht, 1970.

${ }^{23}$ Ernst Forsthoff, Lehrbuch des Verwaltungsrechts (I) ${ }^{10}, 1973,136$.

${ }_{24}$ Z.B. Slg. 8203/1977, 8813/1980.

${ }^{25}$ Zum Prognoseproblem vgl. etwa Slg. 8212/1977 (Einführung des Bonus-Malus-Systems) und 8389/1978; zur „finalen“ Determinierung Slg. 8280 und 8330/1978. 


\section{Formelles Rechtsstaats-Verständnis}

Nun kann es mit einem solchen Lagebericht sicherlich nicht sein Bewenden haben. Zwar ist der berühmte Art. 18 Abs. 1 BVG österreichischerseits auch in diesem Forum immer gerne vorgezeigt worden. Aber der Rechtsstaat, nicht eines seiner Elemente ist in Betracht zu ziehen. Indessen hat die bisher verkürzte Perspektive wieder ihre Gründe. Der Kelsen-Merklsche Standpunkt, daß jedweder Staat logisch zwingend auch Rechtsstaat ist, mag wenig beweisen. Er ist rechts- oder, wenn man will, rechtsstaats-theoretisch gemeint. ${ }^{26}$ Das Dogma ist freilich signifikant; ebenso wie der Umstand, daß der Grundsatz an sich in der Bundesverfassung nicht ausdrücklich aufscheint. Rechtsstaat ist, folgt man der traditionellen Anschauung, ,der Staat mit einer dem Justizrecht ebenbürtig entwikkelten Verwaltungsrechtsordnung“, der Staat, „dessen Verwaltung gesetzlich gebunden ist " ${ }^{27}$ Die Definitionen verflüchtigen sich in Gesetzmäßigkeit; wie ehedem, bei O. Mayer, im "Staat des wohlgeordneten Verwaltungsrechts". ${ }^{28}$

Die bemerkenswerte Feststellung des VfGH, daß eine Vorschrift, ,zu deren Sinnermittlung subtile verfassungsrechtliche Kenntnisse, qualifizierte juristische Befähigung und Erfahrung und geradezu archivarischer Fleiß vonnöten sind", keine verbindliche Norm sei, ${ }^{29}$ ist rasch zu einem geflügelten Wort geworden. Sie bildet ein äußerstes Korrektiv gegenüber mißbräuchlichen Verweisungspraktiken des Gesetzgebers. Aus dem Rechtsstaatsgedanken wird, auch mangels gesetzlicher Regelung, die Kundmachungspflicht bei Verordnungen erschlossen. ${ }^{30}$ Aber derartige Ableitungen verbleiben fast durchwegs im Bereich des Formalen und Technischen. Was weitgehend fehlt oder bestenfalls in spärlichen Ansätzen fruchtbar wird, sind Folgerungen inhaltlicher Natur, wie Übermaßverbot und Vertrauensschutz. In diesem materiellen Sinn ist der Begriff bei uns nie wirklich heimisch geworden.

${ }^{26}$ Vgl. dazu Hans Kelsen, Allgemeine Staatslehre, 1925, 44, $90 \mathrm{f}$. und 109; ders., Reine Rechtslehre ${ }^{2}, 1960,314 \mathrm{f}$. und 319f.; Adolf Merkl, Allgemeines Verwaltungsrecht, 1927, 74.

${ }^{27}$ Adolf Merkl (FN 26), 68 und 77, bzw. Walter Antoniolli, Allgemeines Verwaltungsrecht, $1954,50 \mathrm{f}$.

${ }^{28}$ Otto Mayer, Deutsches Verwaltungsrecht $I^{3}, 1924,58$.

${ }^{29}$ Slg. 3130/1956 (bestätigt in Slg. 7098/1973).

30 Z.B. Slg. 5722/1968, 8351/1978. 
Die Formel lautet heute, der Rechtsstaat müsse „Verfassungsstaat", „Gesetzesstaat" und „Rechtsschutzstaat" sein. ${ }^{31}$ Nach wie vor ist jedoch in dieser Dreieinigkeit das mittlere Glied das stärkste. Die Grundrechte führen ein entstehungsgeschichtlich geprägtes Eigendasein im „,iberalen Prinzip“ der Bundesverfassung und geben dem "Verfassungsstaat" nur schwache Konturen. Der „Rechtsschutzstaat“ ist infolge seines engen Zuschnittes auf den Verwaltungsakt Rechtsformenstaat, Rechtsstaat der hoheitlichen Handlungsform. Daran, an dieser Blindheit gegenüber den Proportionen der modernen Verwaltung, krankt unsere Verfassungsstruktur. Und daher rührt der Glaube an die Omnipotenz des Gesetzgebers.

\section{Gewaltenteilung im Wandel}

Systembedingt hat sich dieses Credo auch nahezu ungehemmt ausleben können. Dem formellen Rechtsstaats-Verständnis entspricht die Gewaltenteilung als bloßes Organisationsmodell; und diesem ein reiner Formbegriff des Gesetzes. Zum mindesten gilt das für die ursprüngliche Konzeption der Bundesverfassung von 1920. Man wollte damals den Trennungsgrundsatz in der Beziehung Legislative und Exekutive einem radikal-parlamentarischen Gewaltenmonismus bewußt zum Opfer bringen; und ungeachtet wesentlicher Änderungen der Folgezeit wirkt diese Entscheidung nach. Es hat des Konfliktes um die Rückkehr eines exilierten Kaisersohnes bedurft, $u m$ in der Lehre eine Wiederbesinnung auf inhaltliche Schranken der Rechtsetzung in die Wege zu leiten..$^{32}$ Gesichert ist ferner, daß die Schaffung von Berufstiteln, wie „Kommerzialrat" oder „Ökonomierat“, eine Prärogative des Bundespräsidenten und der Kompetenz des Gesetzgebers entzogen ist. ${ }^{33}$ Das sind Austriaca. Aber immerhin war es ja auch eine brisante Frage, die im Kalkar-Beschluß des BVerfG zu einer Art

${ }^{31}$ Robert Walter, Österreichisches Bundesverfassungsrecht, 1972, $112 \mathrm{f}$. Vgl. aber auch das Bemühen um eine Neubestimmung bei Edwin Loebenstein, Der Rechtsstaat, in: Herbert Schambeck (Hrsg.), Das österreichische Bundes-Verfassungsgesetz und seine Entwicklung, 1980, 253.

${ }^{32}$ Gemeint ist die sogen. „causa Habsburg“ des Jahres 1963. Dazu insb. Hans Spanner, Überforderte Gerichtsbarkeit, JZ 1963, 671; Gustav E. Kafka, Der Fall Dr. Otto Habsburg, AöR 1963, 451. Im allgemeineren Zusammenhang Günther Winkler, Das österreichische Konzept der Gewaltentrennung in Recht und Wirklichkeit, Der Staat 1967, 293, und zuletzt Manfried Welan, Die Gewaltenteilung, in: Herbert Schambeck (Hrsg., FN 31), 481.

${ }^{33}$ Vgl. Art. 65 Abs. 2 lit. b. B-VG und VfGH Slg. 5242/1966. 
Neuentdeckung der Gewaltenteilung geführt hat. ${ }^{34}$ Der österreichische VfGH hat sich von dergleichen Erwägungen, ob Habsburg oder Kernkraft, wenig beirren lassen. Er hält daran fest, daß das Einzelfallgesetz, das „Individualgesetz“, wie er es ausdrückt, unter rechtsstaatlichen Aspekten keinen Bedenken begegnet. ${ }^{35}$

Zweifellos stärker noch als die Einebnung der rechtlichen Grenzen hat der Wandel der politischen und gesellschaftlichen Faktoren die Austauschbarkeit der Staatsfunktionen beschleunigt. Der Antagonismus von einst zwischen Volksvertretung und monarchischer Regierung ist durch die Polarität zwischen Mehrheitspartei und oppositioneller Minderheit abgelöst - und abgeschwächt - worden. Ein Spannungsverhältnis, in das wieder das Subsystem der organisierten Interessen vielfach hineinverflochten ist. Es genügt, das schlicht zu konstatieren. Ebenso unbestritten ist, daß bei diesen Umschichtungen das Parlament, trotz oder gerade wegen der forcierten Legalitätsansprüche, nicht unbedingt günstig abgeschnitten hat. Der formelle Kompetenzzuwachs mußte mit einer faktischen Einbuße an Steuerungs- und Kontrollfähigkeit erkauft werden. Der Verlierer scheint also festzustehen. Aber wer ist eigentlich der Gewinner gewesen?

Das ist der Punkt, an dem, nach der "Gesetzesflut", die Bürokratiekritik die Bühne betritt. Nicht darum geht es, daß im Durchführungsbereich „Anwendungsgewalt" durch sektorale Auswahl aus dem Rechtsmaterial geübt wird und geübt werden muß ${ }^{36}$ Diese Gefahr - nach Wagener die „Not der Selbstbestimmung durch Regelungsüberlastung ${ }^{637}$ - ist nicht von der Hand zu weisen. Das Gesetz wird zum Monument des politischen Wirkens, unbekümmert um seine spätere Pflege. Aber auch „Lust der Selbstbestimmung" und, ihre Ausgeburt, die Gesetzgebung als „technokratische Selbstprogrammierung der Verwaltung ": ${ }^{38}$ Solche Umschreibungen erwecken den Eindruck, daß die Exekutive zugleich Motor der Normfülle ist, die sie nicht zu bewältigen vermag. Das Bild dürfte

${ }^{34}$ BVerfGE 49, 89 (124ff.). Ebenso BVerwGE 60, 162 (181 f. - NDRVertrag).

${ }_{35}$ Slg. 3118/1956 und 6697/1972.

${ }^{36} \mathrm{Vgl}$. Walter Leisner, Rechtsstaat - ein Widerspruch in sich?, JZ 1977, 537 (539).

${ }^{37}$ Frido Wagener, Der öffentliche Dienst im Staat der Gegenwart, VVDStRL 37 (1979), 215 (244).

${ }^{38}$ Der erstgenannte Passus bei Frido Wagener (FN 37), 238; der zweitgenannte bei Helmut Widder, Die Gesetzgebung, in: Herbert Schambeck (Hrsg., FN 31), 349 (421). 
erheblich überzeichnet sein. Im allgemeinen wenigstens ist die Rollenverteilung denn doch eine andere. Die treibende Kraft ist in den Partei- und Verbandshierarchien zu suchen; und in deren gemeinsamem Mißtrauen gegenüber einer politisierten oder der Politisierung verdächtigten Bürokratie.

Gewiß bleibt jede Erklärung aus einer einzigen Ursache unbefriedigend. Die genannten rechtlichen Prämissen behalten ihre Bedeutung. Die Vorgegebenheiten der Verfassung und die Vorgaben des Verfassungsgerichts haben dem Parlament einen hohen Grad an Normierungsdichte abverlangt. Es war genötigt, sein Gesetz ,gerichtsfest“ "zu gestalten. ${ }^{39}$ Den Rest hat die Eigendynamik des Parteien- und Verbändestaates besorgt; das Bestreben, den im Gesetz errungenen Kompromi 3 und nicht minder den politischen Alleingang auch und zuerst administrationsfest zu machen. Der technische Schliff mag auf das Konto der Bürokratie gebucht - mitunter wohl gutgebucht - werden.

\section{Reform der Verordnungsdelegation}

Hält man Umschau nach Wegen, die aus dem Dilemma herausführen können, so fällt der Blick erneut auf die Verordnung. Die Enquete-Kommission Verfassungsreform hat in ihrem Schlußbericht von 1976 bekanntlich eine Änderung des Art. 80 Abs. 1 GG in dem Sinn empfohlen, die Schrankentrias dieser Bestimmung auf ein Moment, den "Zweck" der Ermächtigung zu reduzieren. Damit solle ein ,deutliches Zeichen“" grünes Licht also für eine freizügigere Handhabung der Verordnungsdelegation gesetzt werden. ${ }^{40}$

Derselbe Gedanke ist wenig später auch in Österreich aufgetaucht. Nur die sprachliche Form wäre verschieden gewesen. Man hat überlegt, zur Stammfassung des Art. 18 Abs. 2 B-VG - Erlassung von Verordnungen „im Rahmen“ statt, wie seit 1925 , , auf Grund“ der Gesetze - zurückzukehren. Die Diskussion ist auf politischer Ebene kurz entflammt und inzwischen, wie es scheint, dort wieder versandet. Sie hat aber doch Spuren in der Rechtsentwicklung hinterlassen. Zunächst 1978, in einer Novelle zum Rohstofflenkungsgesetz, und jetzt im Versorgungssicherungsgesetz von 1980 - typischerweise in wirtschaftslenkenden Instrumenten - wird dem zuständigen Bun-

${ }^{39}$ So bereits Fritz Scharpf, Die politischen Kosten des Rechtsstaats, $1970,55$.

${ }^{40}$ Beratungen und Empfehlungen zur Verfassungsreform.(I), Zur Sache $3 / 76,192 \mathrm{f}$. 
desminister durch Verfassungsbestimmung eine weitgespannte Verordnungsermächtigung erteilt. Ihre Ausübung ist an die Zustimmung des Hauptausschusses des Nationalrats gebunden. Der Beschluß bedarf einer Zweidrittel-Mehrheit. ${ }^{41}$

Die Regelung erlaubt, so spezifisch ihr Sachbezug ist, eine Reihe grundsätzlicher Folgerungen. Der naheliegende Einwand, mit dem die verstärkte Delegierung von Rechtsetzungsbefugnissen an die Vollziehung zu rechnen hat, nämlich die Preisgabe der demokratischen Legitimations- und Öffentlichkeitsfunktion der Gesetzgebung, geht in dieser Verallgemeinerung fehl. Er ist vordergründig; darauf wurde schon hingewiesen. Denn gerade die routinehafte Normproduktion oder eigentlich Ratifikation von vorgefertigten Normentwürfen ist es ja, die die politische Führungsaufgabe des Parlaments an den Rand gedrängt hat. Seine Entlastung ist demgemäß nicht die falsche Flagge, unter der ein prinzipieller Demokratieaffekt segelt.

Zum anderen aber bedeutet Herausverlagerung aus dem Gesetzgebungsproze $ß$ nicht notwendig Ausschaltung des gesetzgebenden Organs. Das Minus an inhaltlicher Vorausbestimmung der Verwaltung kann durch ein Plus an Mitwirkung und Kontrolle aufgefangen werden. Diese Kontrolle schließlich ist, soll sie effektiv sein, unter den realen Bedingungen der Parteiendemokratie nicht vom Parlament als solchem, d.h. von der einfachen Parlamentsmehrheit, sondern nur von der politischen Opposition zu erwarten. Auch insofern trifft das erwähnte Gesetz ins Ziel. ${ }^{42}$

Die Vorschrift soll keineswegs zum großen Wurf erklärt werden, der aus höherer staatsrechtlicher Eingebung gelungen ist. Sie ist das Resultat eines handfesten Kompromisses der Sozialpartner; und sie hat singulären Charakter. Eine weiter gesteckte Neuordnung könnte nicht beim Hauptausschuß des Nationalrates stehen bleiben, sie müßte die parlamentarischen Fachausschüsse miteinbeziehen. Der Entlastungsgewinn wäre ansonsten gering. Aus dem gleichen Grund darf das Zustimmungserfordernis nicht verabsolutiert werden. Die Durchführungsverordnung wird ihren traditionellen Platz behalten. Dann aber, wenn der Opposition im Ergebnis ein Vetorecht eingeräumt ist, wäre konsequenterweise auch an die Anfechtungsbefugnis einer entsprechend qualifizierten Minderheit

${ }^{41}$ Jeweils Art. I der genannten Gesetze in BGBl. 1978/274 bzw. 1980/ 282.

${ }^{42} \mathrm{Vgl}$. in diesem Sinn bereits die eingehenden Überlegungen bei Gunter Kisker, Neue Aspekte im Streit um den Vorbehalt des Gesetzes, NJW 1977, 1313 (1319f.). 
beim VfGH zu denken. Das Muster der Fraktionsanfechtung von Gesetzen seit 1975 bietet sich an. ${ }^{43}$

Doch wie immer eine Reform im einzelnen aussehen mag der Ansatz bei Art. 18 Abs. 2 B-VG und bei Art. 80 Abs. 1 GG ist jedenfalls flexibel genug, um der Überbeanspruchung des formellen Gesetzes vorzubeugen, ohne deshalb durchschlagenden Bedenken aus dem Demokratieprinzip begegnen zu müssen. Die Lösung hätte zudem den beachtlichen Vorzug, die ehrlichere zu sein. Denn sie würde zum Teil nur die Tendenz der jüngeren verfassungsgerichtlichen Rechtsprechung einholen; oder, besser gesagt, die bei unverändertem Verfassungstext sich abzeichnende Tendenzwende der Judikatur offenlegen. Davon war früher die Rede.

\section{Eigenverantwortung der Verwaltung}

Die Verordnungsdelegation ist bloß ein Beispiel, das die Gemeinsamkeit der rechtspolitischen Diskussion veranschaulicht. Letztlich ist damit das Verhältnis von Gesetzgebung und Vollziehung auf breiter Front aufgerollt. Der Wind hat sich in dieser Beziehung spürbar gedreht. Nicht mehr gesetzesstaatliche Aufforstung, sondern „Entfeinerung", „Ausdünnung"," Vereinfachung und Verallgemeinerung der Rechtsordnung ist die Parole. Von Perfektionismus und Kasuistik, vom Druck fortwährender Änderung zurück also zur geschmeidigeren und beständigeren Vorschrift, zu einer „Renaissance des Ermessens"45 und zur Generalklausel.

Es liegt auf der Hand, daß auch dieser Weg keine Einbahn sein kann. Die geschlossene, ins Detail gehende, die ,kasuistische" Norm eben, hat zweifellos ihren Nutzen; ja sie ist unausweichlich, wenn man es mit der massenhaften Erledigung gleichförmiger Sachverhalte zu tun hat, wie im Abgaben-, Besoldungs- und Sozialrecht. Nur sie erlaubt den Einsatz von minder ausgebildetem Personal bis hin zum Verzicht auf menschliche Arbeitskraft und Interpretationskunst in der automatisierten Verwaltung. Allein dieser Umstand verbietet es, das eine Extrem gegen das andere einzutauschen. Ausgewogen, aufgabenadäquat und vollzugsorientiert soll die Regelung

43 Art. 140 Abs. 1 B-VG i.d.F. BGB1. 1975/302.

${ }_{44} \mathrm{Vgl}$. Frido Wagener, Der öffentliche Dienst im Staat der Gegenwart (FN 37), 254, bzw. Klaus Lange, Kriterien für die Wirksamkeit von Instrumenten und Programmen des Verwaltungshandelns, DÖV 1981 , $73(80)$.

${ }^{45}$ Rainer Wahl, Die bürokratischen Kosten des Rechts- und Sozialstaats (FN 7), 286, der aber vor schematischen Lösungen warnt. 
sein. Dort allerdings, wo es auf die differenzierte Entscheidung gerade des Einzelfalles ankommt - und auf diesen Bereich beschränkt sich die Debatte in Wahrheit -, dort wird der Gesetzgeber gut beraten sein, der Verwaltung und ihrer Eigenverantwortung, auch ihrem Sachverstand und den Selbstgesetzlichkeiten - und Tücken - der Materie größere Bewegungsfreiheit als bisher zuzuerkennen. ${ }^{46}$

Freilich geht es nicht nur um die angemessene Zuordnung öffentlicher Funktionen und um Grundsätze objektiven Rechts. Aus der Sicht des einzelnen stellt sich von neuem ein Problem. Berechenbarkeit des staatlichen Handelns und in dem Sinn Rechtssicherheit ist unbestreitbar der Basiswert, der das Legalitätsprinzip trägt. Müßte diese Forderung nicht auf der Strecke bleiben? Aber, anders gefragt, ist sie denn heute erfüllt, ist sie überhaupt erfüllbar? Eine der ersten Studien, die sich in Österreich der Thematik gründlicher angenommen hat, steht unter dem Titel "Rechtskenntnis und Gesetzesflut"; bezeichnenderweise gerichtet auf eine Umdeutung des $\$ 2$ ABGB, wonach sich mit der Unkenntnis des Gesetzes niemand entschuldigen kann - die „lächerlichste aller Fiktionen“ nach dem Zeugnis Anton Mengers. ${ }^{48}$ Das Postulat der Rechtssicherheit entpuppt sich daher, wie früher jenes der Demokratie, als halbes Scheinargument. Was eigentlich, welche Informationen erwartet der Bürger wirklich vom Recht? Sein Interesse ist kein theoretisches, sondern ein praktisches; es ist nicht auf jeden möglichen, sondern auf den jeweils tatsächlichen Kontakt und Konflikt mit der Verwaltung bezogen. Damit verschiebt sich aber der Blickwinkel von der abstrakten und ohnehin zumeist illusionären Vorhersehbarkeit auf die Plausibilität der Entscheidung im konkreten Fall. Anders ausgedrückt: von dem Mehr oder Weniger an materieller Bestimmtheit des Gesetzes auf die verfahrensrechtliche Gewähr sowohl innerhalb der Verwaltung als auch im Rahmen der gerichtlichen Verwaltungskontrolle. Der Gedanke des Grundrechtsschutzes durch Organisation und Verfahren, den das BVerfG zunehmend betont hat, liegt auf dieser Ebene ${ }^{49}$ Und ähnliche Bestrebungen lassen sich für Österreich feststellen. Einmal in

${ }^{46} \mathrm{Vgl}$. zuletzt Günther Winkler, Gesetzgebung und Verwaltungsrecht, in: Gesetzgebung (FN 6), 100 (115 ff.).

47 Theo Mayer-Maly, Rechtskenntnis und Gesetzesflut, 1969.

48 Das bürgerliche Recht und die besitzlosen Volksklassen, 1890, 20.

${ }_{49}$ Dazu insb. BVerfGE 53, 30 (62 ff. - Mülheim-Kärlich); 56, 216 (235ff. - Asyl). Vgl. auch Konrad Hesse, Bestand und Bedeutung der Grundrechte in der Bundesrepublik Deutschland, EuGRZ 1978, 427 (434 ff.). 
einer längerfristigen Entwicklung der verwaltungsgerichtlichen Rechtsprechung, die übrigens auch zum Teil im Licht der Europäischen MRK zu sehen ist; ${ }^{50}$ und ferner in einer geplanten Novellierung der Verwaltungsverfahrensgesetze. ${ }^{51}$

Lockerung übermäßiger Bindung und Einengung heißt also nicht, daß der Gesetzgeber die Zügel schießen läßt. Es ist auch nicht nur an ihm, den Stellenwert der Verwaltung zu festigen. Die intensivierte Schulung des Personals ist eine selbstverständliche Voraussetzung. Noch dringender dürfte der Nachholbedarf an „vertrauensbildenden“, oder vielleicht: mißtrauensabbauenden Maßnahmen in der Beziehung zur politischen Spitze sein. Mit rein rechtlichen Mitteln wird man da wenig ausrichten können. Immerhin hat aber die Dienstrechtsreform von 1979 in Österreich dem Beamten die Befugnis und Verpflichtung gebracht, gegen eine Weisung, die er für gesetzwidrig hält, zu remonstrieren. Die Weisung gilt als zurückgezogen, wenn sie nicht schriftlich wiederholt wird..$^{52}$

Ein letzter Aspekt betrifft gleichfalls die besondere Lage und Dogmatik des österreichischen Verwaltungsrechts. Aus ihr heraus gewinnt nämlich die zunächst etwas unverbindliche Chiffre „Verallgemeinerung“ der gesetzlichen Regelung noch eine ganz andere Dimension. Es ist nicht bloß eine bestimmte inhaltliche Gestaltung und technische Aufbereitung einzelner Rechtsgebiete damit gemeint. Vielmehr zielt der Anspruch gerade auf Überwindung fachspezifischer Grenzen und namentlich auf die Durchbrechung der unseligen Trennung von öffentlichem und privatem Recht. ${ }^{53}$ Gegenwärtig steht bei uns die Regierungsvorlage eines Zustellgesetzes in parlamentarischer Verhandlung, mit dem die diversen Vorschriften verwaltungs-, zivil- und strafprozessualer Herkunft vereinheitlicht

${ }^{50}$ Genannt seien, mit Bezug auf die Nachprüfung des von der Verwaltungsbehörde angenommenen Sachverhalts, VwSlg. 8619 A/1974 und $9723 \mathrm{~A} / 1978$.

51 So soll die Änderung des AVG (Regierungsvorlage 160 BlgNR 15. GP) z.B. eine Manuduktionspflicht der Behörde, die Erweiterung der Akteneinsicht und eine Verbesserung der Rechtsmittelbelehrung bringen.

${ }_{52} \S 44$ Abs. 3 Beamten-Dienstrechtsgesetz 1979 BGBl. 333.

${ }_{53}$ Der Gedanke wurde grundlegend erarbeitet von Martin Bullinger, Öffentliches Recht und Privatrecht, 1968, insb. $75 \mathrm{ff}$. Er ist in Österreich vorerst von Franz Bydlinski und Robert Walter, in: Zur Erneuerung der Struktur der Rechtsordnung, o.J. (1970), 15 (29ff.) bzw. 49 (60f.), und jüngst wieder von Bernd Schilcher, Gesetzgebungstheorie und Privatrecht, in: Gesetzgebung (FN 6), 35 ( $47 \mathrm{ff}$.), aufgegriffen worden. 
werden sollen..$^{54}$ Das Beispiel mag nicht das eindrucksvollste sein. Überzeugender sicherlich ist die schon erwähnte Situation der leistenden Verwaltung. Sie wird nach wie vor weitgehend in privatrechtlichen Formen abgewickelt; kann auch nach geltendem Verfassungsrecht nur so konstruiert sein. Und die Grundrechte sind, zum mindesten in der durchschnittlichen Einschätzung der ordentlichen Gerichte, ein arcanum des öffentlichen Rechts und seiner Frühgeschichte. In diesem Bereich vor allem tut sich die Kluft zwischen „Verfassungs-", „Gesetzes-“ und „Rechtsschutzstaat" auf. Hier könnte „Verallgemeinerung" zum Brückenschlag werden; ebenso wie es die Zweistufentheorie, der Begriff des Verwaltungsprivatrechts und das Institut des öffentlich-rechtlichen Vertrages geworden sind. Denn daran, an der Verfassungsbindung und ihrer Garantie fehlt es in erster Linie. Nicht an den vielen, nur allzuvielen Einzelregelungen in Gesetzesform und mit Alibifunktion.

\section{III. „Rechtsstaat - ein Widerspruch in sich?" ${ }^{455}$ Quantitative Bestimmungsgründe}

\section{Die Fragestellung}

Eine Neubemessung der Aufgaben zwischen Gesetzgebung und Vollziehung ist sinnvoll und möglich, ohne das System aus dem Gleichgewicht zu bringen. Sie kann die verfassungsrechtlichen Rahmenbedingungen, demokratisches Prinzip, individuelle Rechtssicherheit und Grundrechtsschutz, wahren; ja sieht man genauer $\mathrm{zu}$, ihnen förderlich sein.

Es bleibt indessen ein Einwand, der in der Gliederung des Referates bereits angelegt ist. Zwar werden Regelungsbefugnisse verlagert, nicht aber Regelungsbedürfnisse verneint. $\mathrm{Zu}$ rückdrängung des formellen Gesetzes auf das „Wesentliche“ oder ,Allgemeine“ bedeutet, gesamthaft betrachtet, noch nicht Reduktion des Rechtsstoffes als solchen. Hat man es nicht bloß mit einem Ausweichmanöver zu tun, das - um so ärger vom Regen der Gesetze in die Traufe der Verordnungen und Präjudizien hineinführt? Gibt es also zum Gesetz nur eine Alternative, das bessere Gesetz? ${ }^{56}$

Das ist die zweite Seite der Frage, jene nach den verfassungsexternen Wurzeln rechtlicher Normierung und Übernormie-

\footnotetext{
${ }^{54} 162$ BlgNR 15. GP.

${ }^{55}$ Nach Walter Leisner, JZ 1977, 537.

${ }^{56}$ So Theo Öhlinger, Das Gesetz als Instrument gesellschaftlicher Problemlösung und seine Alternativen, in: Methodik (FN 6), 17 (49).
} 
rung. Dazu können wenige Bemerkungen genügen. Denn es handelt sich um notorische Tatsachen. Zudem ähnelt das Problem fatal der Quadratur des Kreises, des ,circulus vitiosus der Verrechtlichung", wie in der Literatur auch gemeint wurde. ${ }^{57}$

\section{Konstante Größen}

Eine erste handgreifliche Erscheinung dieser Art ist die fortschreitende Internationalisierung der Normproduktion. Im selben $\mathrm{Ma} B$, in dem die Welt kleiner geworden ist, nach der banalen Weisheit, ist die rechtliche Verflechtung der Staaten gewachsen; und sie wird weiter wachsen. Von der Wiege bis zur Bahre Verwaltung und Verwaltungsrecht, das ist bekannt: Aber heute eben auch internationales Verwaltungsrecht. Bis zum Grabe, im wahrsten Sinn des Wortes. 1978 hat Österreich des Europäische Übereinkommen über die Leichenbeförderung ratifiziert - samt Beilage noch dazu ${ }^{58}$ Die sogen. „Gesetzesflut", die im Bundesgesetzblatt zu Buche schlägt, ist in erheblichem Umfang auch ein Strom von Staatsvertragsrecht. ${ }^{59}$ Nicht zufällig hat es der Verfassungsgesetzgeber im Jahr 1972 unternommen, einiges davon in Nebenkanäle abzuleiten. Die Bundesverfassung wurde dahin ergänzt, daß Staatsverträge oder Teile von solchen nicht im Gesetzblatt, sondern ,in anderer zweckentsprechender Weise" kundgemacht werden können. ${ }^{60}$ Die Regelung hat im einzelnen höchst fragwürdige Konsequenzen gezeitigt. Aber wie dem auch sei, die Tendenz selbst ist irreversibel; mehr noch, sie ist die zwangsläufige Folge einer im ganzen positiven Entwicklung.

Nicht anders steht es mit der rapiden Technisierung der Lebensbedingungen. Der „Staat der Industriegesellschaft“" ist zum Paradigma dieses Wandels geworden, wie zuvor die „Verwaltung als Leistungsträger" und die Sozialstaatsbestimmung. ${ }^{61}$ Der zivilisatorische Aufschwung hat den Umweltschutz als Staatsaufgabe aus sich herausgesetzt; und diese das Umweltschutzrecht. Der steigende Energiebedarf und die Unsicherheit seiner Deckung aus konventionellen Reserven waren Impuls für das Atomrecht. Die Technik der Datenverarbei-

\footnotetext{
57 Walter Leisner, Rechtsstaat - ein Widerspruch in sich? (FN 55), 540 .

${ }^{58}$ BGBl. 1978/515.

${ }^{59}$ Für 1980 ergibt sich eine Zahl von 63 - allein gesetzesrangigen Staatsverträgen, die 107 formellen Bundesgesetzen gegenüberstehen.

${ }^{60}$ Art. 49 Abs. 2 B-VG i.d.F. BGBl. 1972/105.

${ }^{61} \mathrm{Vgl}$. die frühen, hellsichtigen Analysen von Ernst Forsthoff, Die Verwaltung als Leistungsträger, 1938, und in: Der Staat der Industriegesellschaft ${ }^{2}, 1971$.
} 
tung bedingt den Datenschutz. Daß hier Vernunft zum Unsinn und Wohltat zur Plage werden kann, ist gar nicht zu leugnen. Was das österreichische Datenschutzgesetz $z^{62}$ anlangt, besteht wenigstens in dieser einen Hinsicht die schönste Übereinstimmung der Meinungen. Schon in der parlamentarischen Plenardebatte, die der Beschlußfassung vorausgegangen ist, war man sich der Notwendigkeit einer späteren Änderung bewußt. Ein drastischer Beweis für die Behauptung, daß das Gesetz von heute zum Experiment und die praktischen Erfahrungen erst hinterher zur Novelle gemacht werden. ${ }^{63}$ Dennoch, das ist immer die Frage des ,Wie“, auch des „Wieviel“; es ist kaum eine Frage des „Ob“ gesetzlicher Regelung - oder des „Daß nicht“, wenn man an die Kernenergienutzung in Österreich denkt. ${ }^{64}$

Der Rückzug in die Idylle des Rechtsstaates liberaler Prägung, sollte er eine solche je gewesen sein, wird auch auf diesem Gebiet nicht gelingen. Im Gegenteil, die rechtspolitische Dynamik, die es entfaltet, hat jene der sozialen Zweckverwirklichung längst eingeholt. Eher scheint dort der Sättigungsgrad erreicht, wenn nicht überschritten zu sein und mancher Abschied von wohlfahrtsstaatlichen Hypertrophien bevorzustehen. Das Kappen der „sozialen Hängematten“ oder die „Schlankheitskur für den Staat" ${ }^{65}$ das sind hübsche Bilder; notabene bei der Abmagerung der öffentlichen Haushalte. Aber diese „Entstaatlichung“ wird zumeist wieder nicht Ent-Rechtlichung, sondern Rechtsänderung bedeuten. Ebensooft mindestens dürfte die Rechnung auch umgekehrt stimmen, daß nämlich, je weniger Geld, desto mehr Vorschriften zu verwalten sind.

\section{Variable Größen und Unbekannte der Gleichung}

Es zeigt sich somit, daß der Spielraum der frei verfügbaren Rechtssetzung von vornherein schmal ist. Hier kann zunächst die schillernde Vokabel „Demokratisierung“ eingereiht werden; verstanden als Übergangszone, in der der ominöse „Normenhunger" nicht aus Gründen des internationalen oder des technischen Prozesses, sondern aus ideologischen Motiven heraus gestillt, oder erst einmal geweckt wird. Der Bildungsbereich ist diesbezüglich zum bevorzugten Exerzierfeld geworden. Nicht um die gesetzliche Regelung der inneren Schul-

\footnotetext{
${ }^{62}$ BGBl. 1978/565.

${ }^{63}$ So Theo Mayer-Maly, Die vielen Gesetze und der Einzelne, in: Zur Erneuerung (FN 53), 39 (46).

${ }^{64} \mathrm{Vgl}$. das sogen. „Atomsperrgesetz“ BGBl. 1978/676.

${ }^{65}$ Unter diesem Titel die Beiträge in: Hubertus Zuber (Hrsg.), 1979.
} 
ordnung an sich geht es dabei. Sie war zweifellos ein notwendiger Schritt gegenüber dem älteren Erlaßwesen und -unwesen. Auch liegt es nicht so sehr daran, daß das Schulunterrichtsgesetz von 1974 weit über das Ziel hinausgeschossen und den Verwaltungsakt im Schulbetrieb zur Potenz erhoben hat. Es ist der Fluch der bösen Tat gewesen, daß man mit einer Novelle alsbald wieder etwas Wasser in den vermeintlich rechtsstaatlichen Wein gießen mußte. ${ }^{66}$ Wohl aber gehört in diesen Zusammenhang die liebevolle Detailmalerei, die der Gesetzgeber der Mitverwaltung der Schüler und Erziehungsberechtigten hat angedeihen lassen; und ihre Fortschreibung im Schülervertretungs-Gesetz $1981^{67}$ - Stichwort: ,überbetriebliche Mitbestimmung". Gemeint ist ferner das reiche Anschauungsmaterial, das die Universitätsreform von 1975 bietet ${ }^{68}$ Nach Einzelheiten ist kein Bedarf. Aber daß der Rektor der Universität Wien in den Studienjahren 1979/81 quasi vom Verwaltungsgerichtshof inauguriert worden ist, das spricht doch für sich..$^{69}$

An diesem Punkt ist allerdings Verrechtlichung nicht nur, wie stets, ein Problem des legistischen Könnens, sondern auch und primär des politischen Maßes. Letzten Endes aber ein solches der Verläßlichkeit rechtstranszendenter gesellschaftlicher und individueller Normvorstellungen. Das „Wesentliche“, das der Gesetzgeber zu regeln hat - so ein Vorschlag in der Lehre -, ist, neben der Grundrechtsrelevanz, das ,politisch Kontroverse ". ${ }^{70}$ Der Gedanke kann weitergeführt werden: Die Kontroverse beginnt, wenn die genannten außerrechtlichen Wertbezüge in Verlust geraten. Doch wo wäre das nicht der Fall?

Die Wissenschaft steht an der Schwelle der medizinischen und biologischen Manipulierbarkeit des menschlichen Lebens. Vor knapp drei Jahren hat ein Strafverfahren die Gemüter in Österreich bewegt. Angeklagt war die Organentnahme an einem Verunglückten ohne Einwilligung seiner Angehörigen. Die Lösung mußte konkret zwischen dem Deliktstypus

${ }_{66}$ BGBl. 1977/231.

${ }^{67} \mathrm{BGBl} .56$.

${ }^{68}$ Sie beruht auf dem Universitäts-Organisationsgesetz BGBl. 1975/ 258. Auch bei ihm hat sich rasch die Notwendigkeit von Novellierungen herausgestellt; vgl. BGBl. 1978/443.

${ }^{69}$ Dazu das Erk. VwSlg. 9881 A/1979.

${ }^{70}$ Gunter Kisker, Neue Aspekte im Streit um den Vorbehalt des Gesetzes (FN 42), 1318. Einschränkend jedoch BVerfGE 49, 89 (126Kalkar). Um eine Rationalisierung des „Wesentlichen“ oder „Wichtigen" bemüht Georg Müller, Inhalt und Formen der Rechtssetzung als Problem der demokratischen Kompetenzordnung, 1979, $110 \mathrm{ff}$. 
„Störung der Totenruhe ${ }^{\text {"71 }}$ und dem übergesetzlichen Notstand gesucht werden. Von völliger Rechtsfreiheit ist also auch hier nicht die Rede. Die Frage ist bloß, ob auf Dauer der grobe Klotz des Strafgesetzbuches genügt und die Feinsteuerung gleichsam ethischen Standards anvertraut bleiben kann. Der erste Ruf war jedenfalls der nach dem Gesetzgeber, nach einem Transplantationsgesetz. - Nicht nur in Österreich. Der Bundestag wird ja in dieser Legislaturperiode schon den zweiten Anlauf nehmen. Und wie werden wir es mit der Sterbehilfe, mit der künstlichen Insemination und der Gentechnologie halten?

Der „Niedergang des Rechts“ und die „Krise des Rechtsstaates", nach der frühen Feststellung von Hans Huber, ${ }^{72}$ sind dann nicht mehr als äußere Anzeichen eines tiefer sitzenden Leidens. $\mathrm{Zu}$ übertriebenem Optimismus dürfte kaum Anlaß bestehen. Jedes Volk hat die Regierung, die es verdient, sagt man. Offenbar hat jedes Volk auch die Rechtsordnung, die es verdient.

${ }^{71} \S 190$ Abs. 1 Strafgesetzbuch BGBl. 1974/60.

72 In: FS Giacometti 1953, 59. 
Leitsätze des 2. Berichterstatters über:

\section{Gesetzgebung im Rechtsstaat}

$I$.

1. Gesetz und Gesetzgebung als notwendige Steuerungsmittel des Rechtsstaates sind ins Zwielicht geraten. Ihr Bild schwankt zwischen Schlagworten wie "Gesetzesflut" einerseits und ,Normalität einer demokratisch verfaßten Industriegesellschaft" andererseits. Der Vormarsch der Gesetzgebungslehre, eine neue Welle der Bürokratiekritik und Entstaatlichungs-Postulate sind Anzeichen tieferliegender Funktionsverluste.

2. Das Problem ist in zwei verschiedenen Richtungen, als solches der Qualität und als solches der Quantität zu erörtern. In der ersten Beziehung geht es um die rechtsstaats-immanente Aufteilung der Regelungsbefugnisse zwischen Legislative und Exekutive. In der zweitgenannten Hinsicht ist nach den außerhalb des Verfassungssystems wirksamen Ursachen der Rechtsvermehrung zu fragen.

\section{II.}

3. Unter den qualitativen Bestimmungsgründen hat sich der Gesetzmäßigkeitsgrundsatz (Art. 18 Abs. 1, 2 B-VG) als stärkster Motor der Normproduktion erwiesen. Seine Entfaltung in der Judikatur des österreichischen VfGH zeigt, namentlich auch mit der jüngeren Tendenz einer flexiblen Handhabung, deutliche Parallelen zur "Wesentlichkeits"-Rechtsprechung des BVerfG. Vergleichbar unentschieden ist ferner die Frage des Gesetzesvorbehalts für die sog. „Privatwirtschaftsverwaltung“.

4. Vom Legalitätsprinzip abgesehen, ist der Rechtsstaatsbegriff in Österreich schwach konturiert. Seiner formellen Prägung entspricht das Gefälle zum „Gesetzesstaat"; dem organisatorischen Verständnis der Gewaltenteilung die Zulässigkeit des Maßnahmegesetzes.

5. Die realen Gegebenheiten des Parteien- und Verbändestaates und die ihm gemäße Logik des Mißtrauens gegenüber der Bürokratie haben den Druck der Regelungsdichte erhöht. Das Gesetz muß nicht nur (verfassungs-)gerichtsfest, es soll auch administrationsfest sein. 
6. Der der deutschen und der österreichischen Reformdiskussion gemeinsame Gedanke einer Lockerung der Verordnungsdelegation begegnet keinen grundsätzlichen Einwänden aus dem demokratischen Prinzip. Er wäre durch parlamentarische Mitwirkungs- und Kontrollbefugnisse, speziell in Form von Minderheitsrechten, abzustützen.

7. „Entfeinerung" der Rechtsordnung bedeutet nicht zwangsläufig Rechtsunsicherheit. Die Zurücknahme inhaltlicher Determinierungsgebote kann durch verfahrensrechtliche Garantien aufgefangen werden. Für das Sonderproblem der Privatwirtschaftsverwaltung in Österreich müßte ,Verallgemeinerung" des Rechts zunächst den Weg zur Verfassungs- und Grundrechtsbindung frei machen.

\section{III.}

8. Im Rahmen der quantitativen Bestimmungsgründe der Rechtsetzung sind konstante und variable Größen zu unterscheiden. Die zunehmende Internationalisierung der Normerzeugung und der Normierungsbedarf hochtechnisierter Lebensbedingungen sind irreversibel. Entstaatlichung der Erfüllung öffentlicher Aufgaben dürfte eher Rechtsänderung denn Rechtsverminderung zur Folge haben.

9. Hingegen verweist das Stichwort „Demokratisierung“ auf variable, d.h. politik-abhängige Faktoren. Als Unbekannte der Gleichung erscheint die Tragfähigkeit außerrechtlicher Werthaltungen. Diesbezüglich könnte der Grenzbereich zu Medizin und Biologie die Probe aufs Exempel bringen. 
3. Bericht von Professor Dr. Michael Kloepfer, Trier

\section{Gesetzgebung im Rechtsstaat}

\section{Inhalt}

A. Seite

A. Distanz durch Rechtsstaat und Gesetz . . . . . . . . . . 65

I. Rechtsstaat und Distanz . . . . . . . . . . . . 65

II. Gesetz als Distanzgewähr . . . . . . . . . . . . . 66

III. Distanz in der demokratischen Gesetzgebung $\ldots \ldots \ldots \ldots$

IV. Verlust an gesetzgeberischer Distanz $\ldots \ldots \ldots \ldots \ldots \quad 67$

B. Zur Übernormierung . . . . . . . . . . . . . . . . 68

I. Nachteile der Übernormierung . . . . . . . . . . . . . . 68

II. Vorteile von Gesetzen und Gesetzesänderungen . . . . . . . 69

III. Ursachen . . . . . . . . . . . . . . . . . . 70

1. Ausdehnung von Staatsaufgaben . . . . . . . . . 70

2. Gesetz als politisches Instrument . . . . . . . . . . 71

3. Institutionelle Gründe . . . . . . . . . . . . . . 73

4. Rechtliche Gründe . . . . . . . . . . . . . . 73

IV. Politische Abhilfemöglichkeiten . . . . . . . . . . 75

1. Regelung nur des Normierbaren . . . . . . . . . . 76

2. Gesetzgebungsentlastung durch private Rechtsetzung 77

V. Rechtliche Abhilfemöglichkeiten. . . . . . . . . . . . 78

1. Distanzverlust als Ausgangsposition . . . . . . . . . . 78

2. Rechtsgrenzen der inneren und äußeren Übernormierung . . . . . . . . . . . . . . . . . . 79

3. Rechtsgrenzen von Gesetzesänderungen . . . . . . . 81

a) Ausgangsposition . . . . . . . . . . . . 81

b) Schutzansätze . . . . . . . . . . . . . . . . . . 82

c) Gesetzesänderung und Widerruf von Verwaltungsakten. . . . . . . . . . . . . . . 84

d) Gesetzesänderung und verfassungsgeschützte Kontinuität. . . . . . . . . . . . . . . . . 86

e) Arten der Gesetzesänderung. . . . . . . . . . . . . . 87 
C. Verbesserung der Gesetzesqualität. . . . . . . . . . 88

I. Verbesserung der gesetzgeberischen Entscheidungsfindung. . . . . . . . . . . . 88

1. Ausgangsposition . . . . . . . . . . . . . 89

2. Verbesserung gesetzgeberischer Diagnose und Prognose . . . . . . . . . . . . . . . . . . 90

II. Gesetzgebungsexperimente . . . . . . . . . . . . . 91

1. Abgrenzung . . . . . . . . . . . . . . . . . 91

2. Ursachen ....................... 92

3. Verfassungsrechtliche Voraussetzungen ........ 93

D. Ausblick .......................... 96 


\section{A. Distanz durch Rechtsstaat und Gesetz}

\section{Rechtsstaat und Distanz}

Der Rechtsstaat ist eine Staatsform der Distanz. Er schafft Abstand z.B. zwischen Interesse und staatlicher Entscheidung ${ }^{1}$, zwischen Gesetzeshervorbringung und Gesetzesvollzug $^{2}$, zwischen Ermächtigung und Ermächtigungsgebrauch, zwischen politischem Wollen und rechtlicher Verbindlichkeit ${ }^{3}$, zwischen Straftat und Verurteilung. Der Rechtsstaat distanziert zwischen staatlichen Gewalten ${ }^{4}$, zwischen Staat und Gesellschaft und schließlich - gewissermaßen privatgerichtet zwischen den Bürgern selbst, soweit deren soziale Kontakte als Rechtsbeziehungen aufgefaßt werden ${ }^{5}$. Rechtsstaatliche Verfahrensanordnungen und Zuständigkeitsaufteilungen, Unparteilichkeitsgebote und verbürgte Grundrechte gegen den Staat: alles dies erzeugt oder ermöglicht Distanz. In diesen vielfältigen Distanzgehalten steht der Rechtsstaat in einem spezifischen Gegensatz zum Sozialstaat, dem gewissermaßen die Nähe, die Stiftung von Mitmenschlichkeit und Solidarität aufgegeben ist. Freilich muß der Sozialstaat - und hier liegt eines seiner Schlüsselprobleme - diese aufgegebene Nähe in rechtlicher Distanz erstellen. Die Deutung des Rechtsstaats als Staatsform der Distanz macht Juristen zu Dienern der Distanz und entspricht in besonderer Weise der abstanderzeugenden Art juristischen Denkens ${ }^{6}$ durch dessen Beschränkung auf Subsumierbarkeit unter Rechtsnormen, d.h. auf rechtliche Relevanz eines Lebenssachverhalts.

1 Zu den institutionellen Distanzierungen gegenüber konkreten Interessiertheiten mit Hilfe rechtsstaatlicher Figuren siehe Zippelius, Das Wesen des Rechts, 4. Aufl. 1978, S. 127 f.; ders., Rechtsphilosophie, 1982, S. 143; ders., ARSP $1981,90 \mathrm{ff}$.

2 Eine Legalenteignung statt einer Administrativenteignung verringert diese rechtsstaatliche Distanz zwischen Gesetz und Gesetzesvollzug mit der Folge z. B. von Rechtsschutzverkürzungen, weshalb BVerfGE 24, 367 (398ff.); 45, 297 (331, 333) zutreffend die Legalenteignung nur in eng begrenzten Fällen für zulässig hält.

3 Zur „Distanz schaffenden Funktion des Gesetzgebungsverfahrens" Degenhart, DÖV 1981, 479. - Zur andersartigen „normativen Distanz" zwischen alten und neuen Regelungen R. Schweizer, Rödig-Gedächtnisschrift, 1978, S. 67.

4 Eine „soziale Distanz . . . als Basis für die Gewaltenteilung“ fordert Jarass, Politik und Bürokratie als Elemente der Gewaltenteilung, 1975, S. 79.

5 Vor dieser Distanzierung zwischen Menschen durch Verrechtlichung persönlicher Beziehungen warnt am Beispiel familienbezogener Normierungen Wei $\beta$, DÖV 1978, 605.

6 Allgemein zur Distanz durch wissenschaftliche Tiefe Scheuner, VVDStRL 31, 11; „Distanz von den Dingen und Menschen“ fordert für den Politiker $M$. Weber, Der Beruf zur Politik (abgedruckt in: DIE ZEIT vom 1. 1. 1982, S. 14). 
Die rechtsstaatliche Distanz ist nicht ziel- und funktionslos: sie soll Freiheit und Gerechtigkeit sichern. Die Sichtweise des Rechtsstaats als Distanzgewähr erschließt zwar nicht das gesamte Wesen der Rechtsstaatlichkeit. Sie zeigt aber ein essentielles rechtsstaatliches Wesensmerkmal, das inbesondere zur Klärung des Verhältnisses zwischen Rechtsstaat und Gesetz ${ }^{7}$ beitragen kann.

\section{Gesetz als Distanzgewähr}

Das Gesetz ist das klassische Instrument zur Erstellung von Distanz: Distanz etwa im und durch das Gesetzgebungsverfahren - zwischen Gesetzesimpuls ${ }^{\mathbf{z}}$, Gesetzesinitiative und Gesetzesbeschlu 3 -, zwischen Entscheidungsträgern und Betroffenen sowie zwischen Interessen und Staatsgebot. Das demokratische Gesetzgebungsverfahren - mit der Notwendigkeit der Mehrheitsfindung - führt regelmäßig zu einer inhaltlichen Distanz durch die mit der Mehrheitsfindung notwendige Ablösung von Sonderinteressen. Hinzu kommt vor allem der Abstand zwischen abstrakter Gesetzesentscheidung und konkreter Gesetzesanwendung. Dies ermöglicht nicht nur Distanz zwischen Gesetzesformulierern und Gesetzesanwendern, sondern auch eine zeitliche Entfernung des konkreten Gesetzesvollzugs vom Gesetzesanlaß. Seine notwendige Zukunftsoffenheit löst das Gesetz von der Augenblickssituation der Gesetzesentstehung. Durch ihre abstrakte und generelle Fassung rückt die gesetzliche Regelung von Interessen und Gegebenheiten des Einzelfalles ab. Weil typischerweise viele von einem DistanzGesetz betroffen sind, kann sich gegen eine solche Norm auch kollektiver Widerstand bilden. Die Ermöglichung von Belastungen grundrechtlicher Freiheit soll so eine der höchsten politischen Barrieren überschreiten, die es in unserem Gemeinwesen gibt: die Durchsetzung gegenüber den Interessen, Mitgestaltungsansprüchen und Einwänden der gesellschaftlichen, politischen und parlamentarischen Gruppen sowie der öffentlichen Meinung. Die politische Selbstgefährdung staatli-

\footnotetext{
${ }^{7}$ Obwohl das Gesetz eine zentrale Bedeutung für den Rechtsstaat hat (vgl. z.B. Böckenförde, Staat, Gesellschaft, Freiheit, 1976, S. 69; Merten, Rechtsstaat und Gewaltenmonopol, 1975, S. 11), scheidet seine einfache Indienstnahme für rechtsstaatliche Zwecke aus, zumal essentielle Bezüge des Gesetzes zu den anderen Staatsstrukturprinzipien bestehen. Das Gesetz ist eine eigenständige Verfassungsfigur, die auch eine Blockierung der Gesetzgebung durch Überdehnung zu stark begrenzender rechtsstaatlicher Gehalte hemmt.

${ }^{8}$ Siehe dazu Hill, DÖV 1981, $487 \mathrm{ff}$., m.w.N.
} 
cher Entscheidungen durch Gesetzesdistanz kann so die Freiheit vieler sichern.

Distanz durch Gesetz schützt aber gerade auch den einzelnen. Wird nur dieser durch ein staatliches Gebot betroffen, sind kollektive Einwände nicht oder kaum zu erwarten'. Die Diskriminierung einzelner ist deshalb politisch relativ leicht zu bewerkstelligen. Dies zu verhindern und Gesetzesentwürfe typischerweise möglichen kollektiven Einwänden auszusetzen, ist heute der eigentliche politische Sinn des Verbots des distanzarmen Einzelfallgesetzes.

\section{Distanz in der demokratischen Gesetzgebung}

Die Findung der bindenden politischen Entscheidung in Distanz öffnet zugleich die entscheidende Verbindung zum Gedanken der demokratischen Gesetzgebung. Das Gesetz ist ja ein Stützpfeiler, auf dem nicht nur das rechtsstaatliche, sondern auch das demokratische Gewölbe ruht. Das parlamentarische Gesetzgebungsverfahren in einem materiellen Sinn ist zu einem wesentlichen Teil Erprobung und Erstellung der Mehrheitsfähigkeit eines Gesetzes im Parlament und damit zugleich auch vor der Öffentlichkeit und ihren Einflüssen. Gesetzgeberischer Abstand von betroffenen Interessen wird nicht nur durch die abstrakte und generelle Form eines Gesetzes, sondern in einer repräsentativen Demokratie auch durch die Nicht-Identität von Repräsentanten und Repräsentierten geschaffen. Die Interessendistanz zwischen Repräsentierten und Repräsentanten darf aber nicht zu groß werden, soll die demokratische Legitimität von Gesetzen ungefährdet bleiben.

\section{Verlust an gesetzgeberischer Distanz}

Die moderne Gesetzgebung ist nun geprägt durch den Verlust an rechtsstaatlicher und demokratischer Distan $z^{10}$. Kennzeichnend ist zunächst der Verlust der durch das Gesetzgebungsverfahren erzeugten Distanz zwischen Gesetzesimpuls und Gesetz durch überhastete und inhaltsarme Gesetzesberatungen ${ }^{11}$. Schwer wiegt aber auch der verringerte Abstand der

\footnotetext{
${ }^{9}$ Kloepfer, Gleichheit als Verfassungsfrage, 1980, S. 47.

10 Siehe schon Lerche, Übermaß und Verfassungsrecht, 1961, S. 54, 75.

11 Vgl. dazu etwa H. Schneider, G. Müller-Festschrift, 1970, S. $423 \mathrm{ff}$., sowie Kloepfer, Der Staat 1974, 462ff.; Schenke, Die Verfassungsorgantreue, 1977, S. $112 \mathrm{ff}$.
} 
Gesetzgebung von den jeweils betroffenen Interessen durch das Aushandeln von Gesetzen mit mächtigen Verbänden oder durch den Verfall politischer Moral bei Lobby-Abgeordneten. Typisch ist vor allem der Verlust an Distanz des Gesetzgebers gegenüber der von ihm geregelten Situation durch Anlaß-oder Maßnahmegesetze ${ }^{12}$ sowie durch stark individualisierende Normen. Fehlender zeitlicher Abstand des Gesetzgebers von der jeweiligen Regelungssituation zeigt sich an den Zeitgesetzen und vor allem an den vielen Gesetzesänderungen, die häufig übereilt auf veränderte Außendaten reagieren.

\section{B. Zur Übernormierung}

\section{Nachteile der Übernormierung}

Das Unbehagen an verlorener Distanz des Gesetzes sowie an verlorener Distanz des Staates gegenüber dem Bereich der Gesellschaft ist ein wesentlicher Punkt in der laufenden Debatte um die Übernormierung, $d$.h. um die steigende Zahl von Gesetzen und Gesetzesänderungen ${ }^{13}$. Dabei ist die äußere Übernormierung durch zu viele Gesetze (insbesondere wegen der Vergesetzlichung immer neuer Lebensbereiche) von der inneren Übernormierung durch zu starke Detailliertheit von Gesetzen, durch deren intensivierte Bezogenheit auf Einzelfallgruppen zu unterscheiden ${ }^{14}$. Die ökonomischen und vor allem politischen Kosten der Übernormierung sind beträcht-

\footnotetext{
${ }^{12}$ Grundlegend Forsthoff, Rechtsstaat im Wandel, 2. Aufl. 1976, S. 105 ff.; siehe dazu zuletzt etwa G. Müller, Inhalt und Formen der Rechtsetzung als Problem der demokratischen Kompetenzordnung, 1979, S. 96 ff; ; trotz der von BVerfGE 25, 371 (396) vertretenen These der verfassungsrechtlichen Irrelevanz des Begriffs des Maßnahmegesetzes findet bei dieser Gesetzeskategorie das Übermaßverbot wegen der präzisen Abgrenzbarkeit des Ziels von Maßnahmegesetzen besonders griffige Prüfungsansätze.

${ }^{13}$ Aus der Schriftenflut zur Normenflut vgl. neben Jahrreiß, Größe und Not der Gesetzgebung, 1953, zuletzt nur etwa Berner, BayVBl. 1978, $617 \mathrm{ff.;}$;öhret/ Hugger, Der Praxistest von Gesetzesentwürfen, 1980, S. 13 ff.; Heldrich, Zweigert-Festschrift, 1981, S. 811 ff.; 'Herzog, in: Geißler, Verwaltete Bürger-Gesellschaft in Fesseln, 1978, S. 83 ff.; Honsell, Vom heutigen Stil der Gesetzgebung, 1979, S. 7 ff.; Kloepfer, in: Denkschrift zum 450jährigen Bestehen der PhilippsUniversität zu Marburg, 1977, S. 259 f.; Kormann, Fröhler-Festschrift, 1980, S. $23 \mathrm{ff}$; $K$. Lange, DVBl. 1979, 532 ff.; Leisner, DVBl. 1981, 849 ff.; Maassen, NJW 1979, 1473 ff.; Sendler, ZRP 1979, 227 ff.; Starck, ZRP 1979, 209 ff.; Stern, Das Staatsrecht der Bundesrepublik Deutschland, Bd. II, 1980, S. 689 ff.; $H$. Vogel, JZ 1979, 321 ff.; Weiß, DOV 1978, 601 ff.; Gesetzesflut und Gesetzesperfektionismus, Sitzungsbericht Q, 53. DJT, 1980.

${ }_{14}$ Kloepfer, ZfU 1979, 148; vgl. auch die Unterscheidung bei Weiß, DÖV 1978, 602, zwischen Dynamisierung und Detaillierung der Gesetzgebung.
} 
lich $^{15}$. Für den Bürger, die rechtsanwendenden Gewalten, aber auch für den Gesetzgeber selbst führt die Vielzahl von Gesetzen und Gesetzesänderungen gleichermaßen zu schwerwiegenden Uberforderungen und zur Abschwächung der individuellen und gesellschaftlichen Selbstverantwortung. Rechtsbrüche - sei es aus Unkenntnis oder aus Gesetzesverdrossenheit - durch den normenüberschütteten, aber nicht mehr normengeborgenen Bürger, Vollzugsverweigerungen durch die gesetzlich gegängelte und in ihren Initiativen gelähmte Verwaltung ${ }^{16}$, Überforderungen der Gerichte ${ }^{17}$ und oberflächliche Beratungen durch den überlasteten Gesetzgeber sind die gefährlichen Folgen ${ }^{18}$. Das schnelle Tempo von Gesetzesänderungen überfordert die Wandlungsfähigkeit des Rechtsbewußtseins, nimmt dem Recht den Anspruch des Dauerhaften und unterhöhlt so seine Autorität $t^{19}$. Eine Fülle heutiger Gesetze von Experten für Experten sind für Nicht-Experten häufig weder rechtsbewußtseinsfähig noch vollzugsfähig und für den durchschnittlichen Abgeordneten auch kaum noch beratungsfähig. Das Erfolgsrezept guter Gesetzgebung, Legalität trotz fehlender Rechtskenntnis der Bürger aus ihrem Rechtsgefühl zu erzeugen ${ }^{20}$, muß hier versagen. So bedroht die Übernormierung insgesamt den Verfassungswert des Gesetzes ${ }^{21}$, die Legalität der Normunterworfenen und die Legitimität des Rechts.

\section{Vorteile von Gesetzen und Gesetzesänderungen}

Gegenüber diesen beträchtlichen Nachteilen der Übernormierung dürfen natürlich nicht die gewichtigen - und heute vielleicht bisweilen schon zu selbstverständlich erscheinenden - Vorteile der Gesetze und Gesetzesänderungen übersehen werden. Die zunehmende Politisierung der Übernormie-

${ }_{15} \mathrm{Zu}$ den Gefahren der Normenflut zuletzt Leisner, DVBl. 1981, $850 \mathrm{ff}$.

${ }^{16}$ Siehe z. B. K. Lange, DVBI. 1979, 535; - die Gesetzmäßigkeit der Verwaltung bedeutet nicht die Entmündigung der Verwaltung mit dem Mittel des Gesetzes. Umgekehrt kann die Übernormierung auch zu erheblichem Bürokratiewachstum führen.

17 Dazu etwa Sendler, ZRP 1979, $227 \mathrm{ff}$.

${ }_{18}$ Siehe z. B. Weiß, DÖV 1978, 603; - die Überlastung des Parlaments führt nicht nur zu Qualitäts- und Legitimationsverlusten der Gesetze, sondern verstärkt auch die Macht der Exekutive bei der Gesetzesvorbereitung; Degenhart, DÖV $1981,482$.

19 Vgl. Wermer, Recht und Gericht in unserer Zeit, 1971, S. 210.

${ }^{20}$ Siehe dazu zuletzt Schilcher, in: Winkler/Schilcher, Gesetzgebung, 1981, S. 43.

${ }^{21}$ Vgl. Scheuner, Staatstheorie und Staatsrecht, 1978, S. 219. 
rungsdebatte hat jedenfalls die Differenzierungsfähigkeit bei der Problembewältigung abnehmen lassen und scheint bisweilen die juristischen Fortschritte durch rechtssichernde und entscheidungsrationalisierende Vergesetzlichungen sowie durch fortschritts-, anpassungs- und flexibilitätsermöglichende Gesetzesänderungen zu vergessen.

Überhaupt ist Besonnenheit bei Behandlung des gegenwärtig politisch so aufgeheizten Themas der Übernormierung als Rechtsstaatsgefährdung geboten. Waren da nicht eben noch die Einwände gegenüber zu viel Richtermacht oder gegenüber der allmächtigen Verwaltung und über deren Herrschaftsbastionen der unbestimmten Rechtsbegriffe und Ermessensräume? Nach dem Richterstaat und dem Bürokratenstaat wird nun der Gesetzesstaat auf die Anklagebank der öffentlichen Meinung gezerrt und als Bedrohung des Rechtsstaates und der Demokratie dargestellt. Das hindert natürlich eine aufgeregte Öffentlichkeit nicht, fast unverbunden daneben z.B. über zuviel Demokratie und zuviel Rechtsstaat - also wohl insgesamt über zuviel Verfassung - zu lamentieren. Und woher nehmen eigentlich einflußreiche Stimmen ihre Legitimation zur ätzenden Kritik an der Unstetigkeit des Gesetzgebers, wo sie doch eben noch die angeblich bleierne Erstarrung unseres politischen Systems beklagten?

\section{Ursachen}

Die Ursachen der Übernormierung sind überaus mannigfaltig.

\section{Ausdehnung von Staatsaufgaben}

Die steigende Zahl der Gesetze und Gesetzesänderungen hat zunächst und vor allem ihren Grund in der Expansion staatlicher Aktivitäten, die ihrerseits freilich nicht nur auf staatliche Machtbegehrlichkeit, sondern auch auf eine Anspruchsinflation auf seiten der Bürger ${ }^{22}$ zurückzuführen ist. Primär mit seinen wirtschafts- und soziallenkenden sowie technikkontrollierenden Aktivitäten dringt der Staat in neue Bereiche ein, deren komplexe Sachverhalte zudem schnell wechseln und notwendig zu vermehrten Gesetzesänderungen führen ${ }^{23}$. Ge-

\footnotetext{
${ }^{22}$ Siehe etwa $\mathrm{Hug}$, Rödig-Gedächtnisschrift, 1978, S. 4.

${ }^{23}$ Siehe z. B. Leisner, DVBl. 1981, 853; Scheuner, H. Huber-Festschrift, 1981, S. 128.
} 
setze können insoweit Reaktionen des Staates auf neue Regelungsprobleme und gesellschaftliche Konflikte sein, deren Lösung er nicht mehr den - vielfach in der Tat versehrten gesellschaftlichen Selbststeuerungskräften ${ }^{24}$ überlassen will und kann.

\section{Gesetz als politisches Instrument}

Eine weitere wichtige Ursache der Übernormierung ist die Benutzung des Gesetzes als - distanzverringertes - politisches Lenkungsmittel ${ }^{25}$. Verfassungsrechtlich bedenklich wird die Instrumentalisierung des Gesetzes als Lenkungsmittel wegen Funktionsverschiebung im Verfassungsgefüge vor allem dann, wenn es faktisch zum eher punktuell ansetzenden Handlungsinstrument der Regierung wird. Die Regierung muß handeln - ein Gesetz muß her; dieser Satz wird bezeichnenderweise von der Öffentlichkeit kaum noch als Widerspruch gesehen.

Mit der Funktion des Gesetzes als politisches Lenkungsmittel wird deutlich, daß das Gesetz gerade auch Instrument des politischen Kampfes sein kann ${ }^{26}$. Durch Gesetze können parlamentarische Mehrheiten versuchen, ihre zeitlich begrenzte Macht über das Ende einer Legislaturperiode hinaus zu verlängern. Wollen neue parlamentarische Mehrheiten ihre Gesetzgebungsabsichten durchsetzen, müssen sie dann die gewöhnlich unbefristeten früheren Gesetze erst ändern. Daran werden sie jedoch nicht selten wegen begrenzter Gesetzgebungskapazitäten, aber auch wegen politischer Ursachen (bei belastenden Änderungen) und nicht zuletzt aus rechtlichen Gründen (z. B. durch Schaffung von Besitzständen) gehindert sein. Demokratie ist bezüglich irreversibler Gesetze und Entscheidungen eben nicht nur zeitlich begrenzte Macht. Insgesamt können also Gesetze politische Macht konservieren.

Gesetze dienen der Machterhaltung auch insoweit, als sie schnelle und publizitätsträchtige Verbesserungen politischer Erfolgsbilanzen versprechen. Die öffentliche Meinung verkennt häufig die Bedeutung der Gesetzesakzeptanz und des Gesetzesvollzugs. Deshalb erliegt sie nicht selten dem Irrtum, das erlassene Gesetz als solches würde bereits die in ihm

\footnotetext{
24 Siehe etwa Starck, ZRP 1979, 212.

25 Wichtiges Beispiel ist das Steuerungsgesetz; vgl. dazu besonders Häberle, VVDStRL 30, 51; $M$. Schröder, Planung auf staatlicher Ebene, 1974, S. 25 ff.: zum „Gesetz als Auftrag der Verwaltung" Scheuner, DÖV 1969, $585 \mathrm{ff}$.

26 Dazu etwa Maihofer, in: Winkler/Schilcher, Gesetzgebung, 1981, S. 23.
} 
geregelten politischen, wirtschaftlichen und sozialen Probleme lösen.

Gesetze können gerade auch der persönlichen politischen Profilierung von Ministern und Ministerialbürokraten dienen: das Gesetz als Ministerdenkmal oder als Instrument der Karriereverbesserung für Beamte ${ }^{27}$. Schließlich vermag ein Gesetzgebungsverfahren auch Entscheidungsschwächen der Regierung oder der Verwaltung $\mathrm{zu}$ tarnen, indem man das, was als exekutiver Staatseingriff an sich bereits legal wäre, als ein gesetzgeberisches Regelungsproblem bezeichnet und dann angekündigte Gesetzgebungsverfahren nicht einleitet oder doch nur schleppend betreibt. In Verleugnung seiner dienenden Funktion kann das Gesetzgebungsverfahren ${ }^{28}$ fast zum politischen Selbstzweck werden, bei dem dann das Gesetz eher eine unwichtige Folge denn eigentliches Ziel des politischen Bemühens ist. Das zeigt sich z. B. dann, wenn das Gesetzgebungsverfahren primär als Mittel zur politischen Selbstdarstellung oder zur politischen Selbstvergewisserung, zur Integration des eigenen politischen Lagers bzw. zur Desintegration des Gegners dienen soll.

Nicht nur als Konsequenzen veränderter Lebensumstände, sondern vorrangig politisch sind auch viele der überstürzten Gesetzesänderungen zu erklären. Dabei fällt freilich die naheliegende Deutung der Gesetzesänderungen als Konsequenz parlamentarischer Mehrheitswechsel im wesentlichen aus. In der Vergangenheit sind unter gleichen politischen Mehrheiten - d.h. ohne wesentliche parlamentarische Mehrheitsverschiebungen - vielfältigste Änderungen durchgesetzt worden. Wichtige politische Gründe dafür dürften die Kurzatmigkeit und die Konzeptionslosigkeit des Gesetzgebers sein. Er hat zu wenig Distanz von Fragen der Tagesaktualität und läuft nur zu schnell kurzlebigen politischen Moden der öffentlichen Meinung hinterher ${ }^{29}$. Der Verlust eines Konsenses über einheitsstiftende politische Grundwerte läßt den Gesetzgeber Stetigkeit und Richtung verlieren. Statt langsame gesellschaftliche, soziale und wirtschaftliche Selbstheilungsprozesse abzuwarten, verführt die permanente Angst vor der jeweils nächsten Wahl - irgendwo in der Bundesrepublik - häufig zu übereilten Gegensteuerungen durch gesetzliche Maßnahmen.

\footnotetext{
${ }^{27}$ Hierzu z. B. auch Maassen, NJW 1979, 1477; Wilke, VVDStRL 37, 298.

${ }^{28}$ Auch im Straf- und Verwaltungsprozeßrecht leugnet das Verfahren zunehmend seine dienende Funktion zur Findung und Durchsetzung des materiellen Rechts und wird nicht selten zur Verhinderung der Realisierung materiellen Rechts mißbraucht.

${ }^{29}$ Zur gesetzgeberischen Wankelmütigkeit Kloepfer, DOV 1978, 225 f.
} 


\section{Institutionelle Gründe}

Institutionelle Gründe für die Übernormierung sind unverkennbar. Gewaltige Gesetzgebungsressourcen - vor allem in der Ministerialbürokratie, aber natürlich auch im Parlament sowie im davorgelagerten Parteien- und Lobbybereich - drängen im Rahmen des rechtlich und politisch Machbaren ständig auf neue Normierungen. Die Gesetzgebungsmaschine ist da, also produziert sie.

Ein weiterer wichtiger institutioneller Grund für die Vielzahl von Gesetzen sind die dezentralisierte Rechtserzeugung und die gestufte Rechtsordnung in der Bundesrepublik Deutschland mit den hieraus folgenden Notwendigkeiten vielfältiger normativer Verzahnung. Überflüssig normvermehrend ist dabei freilich die verbreitete Unsitte der Normwiederholungsgesetzgebung in der jeweils niederrangigen Norm (z. B. die wörtliche Wiederholung von Verfassungsbestimmungen im einfachen Gesetz).

Angesichts des dichten Netzes der heutigen Rechtsordnung ist schließlich davon auszugehen, daß viele Gesetzesänderungen in Form von juristischen Kettenreaktionen eine Fülle von anpassenden Folgeänderungen in anderen Gesetzen nach sich ziehen $^{30}$. Die Änderung einer Vorschrift muß nicht nur in ein Gesetz, sondern auch in die Rechtsordnung selbst eingepaßt werden $^{31}$.

\section{Rechtliche Gründe}

Damit kommen die rechtlichen Gründe der Übernormierung in Sicht. Zu denken ist dabei zunächst an internationalrechtliche und EG-rechtliche Vorschriften, die mannigfaltige Aus- und Durchführungsregelungen erforderlich machen und ihr vielfach schnelles Änderungstempo auf die nationalen Rechtsordnungen übertragen. Auch die Gesetzgebungsaufträge, Differenzierungs-, Detaillierungs- und Anpassungsgebote der Verfassung und die hieran teilweise anknüpfenden Appellentscheidungen des Bundesverfassungsgerichts können normenvermehrend und änderungserzwingend wirken ${ }^{32}$.

${ }^{30}$ Dazu Hill, DÖV 1981, 489; H. Müller, DÖV 1964, 231.

${ }^{31}$ Eichenberger, Der Staat der Gegenwart, 1980, S. 341; G. Müller, in: Eichenberger, Grundfragen der Rechtsetzung, 1978, S. 369 ff;; Noll, Gesetzgebungslehre, 1973 , S. $104 \mathrm{ff}$.

${ }^{32}$ So auch Hill, DÖV 1981, $493 \mathrm{ff}$; - auch die Differenzierungsgebote des Übermaßverbots haben stark normenvermehrend gewirkt; vgl. Starck, ZRP 1979, 211; siehe auch Wahl, Die Verwaltung 1980, $280 \mathrm{f}$. 
Eine erhebliche rechtliche Ursache für den Normenzuwachs stellen - etwa bei Ablösung der besonderen Gewaltverhältnisse - die grundrechtlichen Gesetzesvorbehalte und vor allem der allgemeine Gesetzesvorbehalt ${ }^{33}$ dar. Die insbesondere vom Bundesverfassungsgericht hierfür derzeit angebotene Wesentlichkeitstheorie ${ }^{34}$, die wegen der Ungewißheit über das Wesentlichkeitskriterium freilich bisher eher eine Theorieskizze ist, führt im Ergebnis wohl zu einer Ausweitung des Vorbehalts des förmlichen Gesetzes. Werden bloß potentiell gefährdende Zugriffe auf Grundrechtsgrundlagen und Grundrechtsvoraussetzungen ${ }^{35}$ mit den klassischen Grundrechtseingriffen gleichgestellt, so folgt hieraus notwendigerweise eine gewisse Ausdehnung des Gesetzesvorbehalts (z. B. bezüglich der friedlichen Nutzung der Kernenergie ${ }^{36}$ oder hinsichtlich der Einführung privaten Rundfunks $\mathrm{s}^{37}$ ).

Demgegenüber finden bislang die inneren Grenzen des Gesetzesvorbehalts wenig Beachtung. Dieser gilt jedenfalls etwa dort nicht, wo lediglich Bagatelleingriffe - wie z.B. bei vielen sog. Informationseingriffen oder bei entfernten Umweltbelastungen - vorliege ${ }^{38}$. Auch da, wo so schnelle oder so einzelfallbezogene Regelungen erforderlich sind, daß ein gesetzgeberisches Einschreiten zu spät käme oder wegen zu intensiver Detaillierung tatsächlich oder rechtlich unmöglich wäre, kann der Gesetzesvorbehalt nicht gelten. Hier muß die Exekutive quasi im Sinne eines Verwaltungsvorbehalts - freilich auf der Grundlage vorausschauender allgemeiner Gesetze - handeln.

${ }^{33}$ Zusammenfassend Stern, Das Staatsrecht der Bundesrepublik Deutschland, Bd. I, 1977, S. 635 ff., m.w. N.

${ }^{34}$ Siehe insbes. BVerfGE 34, 165 (192f.); 40, 237 (248ff.); 41, 251 (259); 45, 400 (417f.); 47, 46 (78ff.); 48, 210 (221); 49, 89 (126ff.); 53, 30 (56 f.); 56, 1 (13); BVerfG, JZ 1981, 581 (582f.); - vgl. auch BVerwGE 47, 194 (197f.); 47, 201 (203f.); 56, 31 (40); 56, 155 (157); 57, 360 (363); 60, 162 (181); -- aus dem Schrifttum vgl. z.B. Kisker, NJW 1977, 1313 ff.; Nevermann, VerwArch. 1980, 246 ff.; Oppermann, 51. DJT, Bd. I, 1976, C $48 \mathrm{ff}$; Wilke, Zeugnisreform als Erziehungsreform, 1980, S. 34ff.; zuletzt etwa Scholz/Bismark, DJT, Schule im Rechtsstaat, Bd. II, 1981, S. $110 \mathrm{ff}$;; Lerche, Bayerisches Schulrecht und Gesetzesvorbehalt, 1981, bes. S. $11 \mathrm{ff}$.

${ }^{35}$ Siehe dazu Kloepfer, Grundrechte als Entstehenssicherung und Bestandsschutz, 1970, S. 15 ff.; sowie BVerfGE 33, 303 (332); Starck, BVerfG-Festgabe, Bd. II, 1976, S. 481 ff.; T. Würtenberger, Staatsrechtliche Probleme politischer Planung, 1979, S. $379 \mathrm{ff}$.

${ }_{36}$ BVerfGE 49, 89 (127ff.).

${ }^{37}$ BVerfG, NJW 1981, 1774 (1776).

38 Zur fehlenden Grundrechtsrelevanz von Bagatellbelastungen: Kloepfer, BVerfG-Festgabe, Bd. II, 1976, S. 415; ders., Zum Grundrecht auf Umweltschutz, 1978, S. 20; ders., Datenschutz als Grundrecht, 1980, S. 25. 
Insgesamt wäre es falsch, in dem Gesetzesvorbehalt den entscheidenden Grund für die Übernormierung zu sehen. Diese hat primär politische, nicht rechtliche Gründe. Heute jedenfalls trägt die angestrengte Debatte um den Gesetzesvorbehalt angesichts einer allenthalben beklagten Normenflut für viele Rechtsbereiche ohnehin manchmal leicht absurde Züge. Die weitaus meisten Gesetze sind gegenwärtig - was bisweilen übersehen wird - schon längst die Änderungsgesetze, für die nicht der Gesetzesvorbehalt, sondern der derivative Gesetzesänderungsvorbehalt gilt, wenn und weil in die normative Substanz eines alten Gesetzes eingegriffen wird ${ }^{39}$.

\section{Politische Abhilfemöglichkeiten}

Die Frage nach Abhilfemöglichkeiten gegen die primär politisch verursachte Übernormierung hat zunächst politisch anzusetzen $^{40}$. Sicherlich ist deshalb die politische Problematisierung des Umfangs und des Geschwindigkeitsrausches gesetzgeberischer Aktivitäten ein richtiger, freilich - hinsichtlich seiner Erfolgsaussichten - ungewisser Ansatz zur Abhilfe. Die verstärkte Rückbesinnung des Staates auf gesellschaftliche Selbststeuerungskräfte sowie auf Möglichkeiten der Herrschaft durch geistigen Einflu $\beta^{41}$ und durch politische Initiierung sozialer Prozesse ist unerläßlich. Dies und die verstärkte Nutzung nichtgesetzlicher Handlungsinstrumente des Staates (z.B. Verträge ${ }^{42}$ ), die Rückgewinnung gesetzgeberischer Di$\operatorname{stanz}(z . B$. durch die angemessene Entfeinerung von Gesetzen $^{43}$ ) sowie die gesonderte Prüfung der Erforderlichkeit von Normen ${ }^{44}$ stellen grundsätzliche Möglichkeiten zur Eindäm-

\footnotetext{
${ }^{39}$ Siehe auch Leisner, DVBl. 1981, 851, mit der Beobachtung, daß „ein Gesetz zum nächsten zwingt".

${ }^{40}$ Siehe dazu z. B. Schreckenberger, Schäfer-Festschrift, 1980, S. $76 \mathrm{ff}$.

${ }^{41}$ Zur Lenkung durch Überzeugung Kloepfer, UPR 1981, 44 f.; zur Lenkung durch Information ders., Information als Intervention in der Wettbewerbsaufsicht, 1973.

${ }^{42}$ Zu normersparenden Selbstbeschränkungsabkommen vgl. zuletzt Kloepfer, in: Gutzler, Umweltpolitik und Wettbewerb, 1981, S. $81 \mathrm{ff}$., $88 \mathrm{ff}$; - zur Normsetzung durch Vereinbarung siehe Kirchhof, BVerfG-Festgabe, Bd. II, 1976, S. $90 \mathrm{f}$; Stern, Anm. 13, S. 587; zu Normenverträgen zwischen Staat und Bürger H. Krüger, NJW 1966, 622.

${ }^{43}$ Siehe dazu Wagener, VVDStRL 37, 254 ff.; zur verstärkten Wiederbenutzung gesetzlicher Generalklauseln zuletzt Leisner, DVBl. 1981, 854, m.w.N.

${ }_{44}$ Vgl. hierzu besonders $R$. Schweizer, Anm. 3, S. 66 ff. sowie etwa Pestalozza, NJW 1981, 2083; siehe auch die richtungsweisenden Kriterien für die Wichtigkeit einer Norm von Eichenberger, Anm. 31, S. 343 f. FN 22.
} 
mung der Übernormierung dar. Die Figur des Parlamentsvorbehalts zeigt schließlich, daß eine fehlende Vergesetzlichung nicht zwingend den Verlust parlamentarischer Entscheidungsteilhabe $-z$. B. bei der sog. politischen Planung ${ }^{45}$ - bedeuten muß.

Ein konkreter Abbau der Übernormierung könnte zunächst durch einen verstärkten Normenabgang in Form vorsichtig

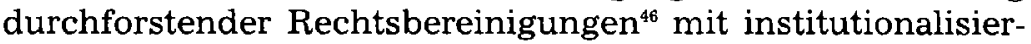
ten Prüfungen der Noch-Erforderlichkeit von Gesetzen erfolgen $^{47}$. Bloße Aufhebungsgesetze ohne ersetzende Neuregelungen haben bisher ausgesprochen Seltenheitswert. Wichtig ist zur Zurückdämmung der Normenflut vor allem eine Drosselung des Normenzuwachses.

\section{Regelung nur des Normierbaren}

Vorrangig ist dabei eine gesetzgeberische Besinnung auf das wirklich Normierbare. Ambitionierte Versuche, durch Gesetz volkswirtschaftliche Theorien mit normativer Kraft auszustatten und hieraus rechtliche Handlungsanweisungen für die Globalsteuerung zu entnehmen, überfordern - wie sich am Stabilitätsgesetz gezeigt hat - die instrumentellen Möglichkeiten der Gesetzgebung.

Angesichts der in Eingangsbestimmungen häufig auftauchenden politischen Paragraphenpoesie - wie z. B. im Raumordnungsgesetz und anderen Planungsgesetzen - ist daran zu erinnern, daß Gesetze nicht zum Ergötzen, sondern zum Befolgen da sind. Die Grenze zwischen politischen Erklärungen und Rechtsgeboten, zwischen verbindlichen Regelungen, Drohgesetzen (Ausbildungsplatzförderungsgesetz bezüglich der Berufsausbildungsabgabe), konkretisierungsbedürftigen Gesetzesprinzipien, sanktionsfreien Empfehlungsgesetzen (Autobahn-Richtgeschwindigkeits- $\mathrm{VO}^{48}$ ) und normativen Posen

45 Dazu insbes. Böckenförde, Der Staat 1972, 429 ff.; Brünner, Politische Planung im parlamentarischen Regierungssystem, 1978; Vitzthum, Parlament und Planung, 1978; T. Würtenberger, Anm. 35.

46 Dazu etwa Mock, in: Winkler/Schilcher, Gesetzgebung, 1981, S. 167 ff.; Brande, daselbst, S. $173 \mathrm{ff}$.

47 Durchgängige Befristungen von Gesetzen - etwa nach dem Vorbild von Polizeiverordnungen - könnten derartige Prüfungen zu bestimmten Zeitpunkten erzwingen (siehe dazu auch Hellstern/Wollmann, ZfParl. 1980, 557f., mit Hinweis auf die US-amerikanische ,sunset-legislation"). Dem stehen freilich erhebliche Nachteile (drohendes Rechtsvakuum, weitere Belastung des Gesetzgebers etc.) gegenüber. Kritisch auch Göbel, in: Böhret, Gesetzgebungspraxis und Gesetzgebungslehre, 1980, S. 79 f.

${ }^{48}$ vom 21. November 1978 (BGBl. I, S. 1824). 
(z.B. strafrechtlichen Symbolgesetzen ${ }^{4 y}$ ) verschwimmt, die gestalterische Eigengesetzlichkeit der Rechtsetzung wird nicht gewahrt. Eher vertonungs- als vollziehungsfähige Eingangsbestimmungen dienen häufig weniger dem in Gesetzesbegründungen erwähnten Zweck der Auslegungs- und Ermessensleitung, sondern vielmehr der Errichtung von Kompromißfassaden zur Erreichung öfentlicher Zustimmung und parlamentarischer Mehrheiten.

Ein wesentlicher Grund für diese bisweilen weitgehende Entrechtlichung von Gesetzesvorschriften durch überzogene Politisierung liegt vor allem darin, daß viele Gesetze (z.B. das Bundesdatenschutzgesetz ${ }^{50}$ ) auch als Mittel der politischen Bewußtseinsbildung dienen sollen. Der pluralistische Staat kann heute - getragen von einer permissiven Grundhaltung nicht mehr mit dem ungebrochenen Gesetzesgehorsam seiner Bürger rechnen, zumal er selbst nicht selten geltendes Recht zur bloß taktischen Größe politischen Handelns verkommen läßt. Da er nicht bereit oder (z.B. wegen begrenzter Vollzugskapazitäten) nicht in der Lage ist, die Rechtsbindung der Bürger mit Mitteln staatlichen Zwanges durchzusetzen, wird die Weckung und Erhaltung des Gesetzesbefolgungswillens um so wichtiger: Die Gesetzgebung wird so zur Befolgungsmotivation durch politische Überredung in Gesetzesform. Legitimationsverluste des Rechts können dadurch freilich kaum beseitigt, sondern eher erzeugt werden, wenn z.B. Laien der notwendigerweise vertrauenszerstörenden Illusion nachhängen, politische Parolen in Gesetzesform seien vollzugsfähiges Recht.

\section{Gesetzgebungsentlastung durch private Rechtsetzung}

Eine wesentliche Entlastung der staatlichen Gesetzgebung könnte sich - jedenfalls zur Abwehr neuer Gesetze - durch eine private Rechtsetzung ergeben, die zugleich die gesellschaftlichen Selbststeuerungskräfte stärken und zur stabilisierenden Formierung des Gemeinwesens nutzen könnte. Das Tarifvertragswesen, das sog. selbstgeschaffene Recht der Wirtschaft und das Normungswesen der Technik sind Beispiele für im wesentlichen gelungene Formen gesellschaftlicher QuasiRechtsetzung. Da diese allerdings wesensmäßig Quasi-Nor-

49 Siehe dazu Amelung, ZStW 92 (1980), 54 ff.; zu „Plakatgesetzen“ vgl. Hill, DŐV 1981, $489 \mathrm{f}$.

${ }^{50}$ Dazu Kloepfer, Datenschutz als Grundrecht, 1980, S. 15. 
mierungen aus geringer Distanz zu den formulierenden Interessen sind, erweisen sie sich bisweilen als nicht hinreichend gemeinwohlorientiert. Deshalb kann hier auf staatliche Rahmenregelungen und Kontrollen häufig nicht ganz verzichtet werden. Die staatliche Abwehr von Gruppenübermacht, die Sicherung der Chancen- und Waffengleichheit und die Gewährleistung der angemessenen Beteiligung betroffener Gruppen, können dabei ausgewogene Entscheidungen mit einer Mindest-Distanz von den formulierenden Interessen ermöglichen.

Bei einer Übernahme privater Rechtsetzung in staatliches Recht ist aber der direkte staatliche Einfluß zur Sicherung des Gemeinwohls - durch konkrete, nicht pauschale staatliche Rezeptionsentscheidungen ${ }^{51}$ (etwa in Verordnungsform) - unverzichtbar, weil der demokratische Staat das Monopol verbindlicher Gemeinwohlbestimmung besitzt. Gruppenmäßig besetzte Sachverständigenparlamente, Dritte Kammern etc. mit staatlicher Rechtsetzungsmacht sind deshalb abzulehnen $^{52}$, zumal sich in derartigen Gremien vorwiegend Sachverständige mit gruppenspezifischem Kampfauftrag, d.h. mit geteilter Loyalität zum Sachverstand, sammeln würden.

\section{Rechtliche Abhilfemöglichkeiten}

\section{Distanzverlust als Ausgangsposition}

Die Frage nach rechtlichen Abhilfemöglichkeiten gegen die Übernormierung hat zunächst von dem geschilderten Distanzverlust der modernen Gesetzgebung als einem entscheidenden Grund für die Vielzahl und Unstetigkeit von Gesetzen auszugehen. Die Distanzarmut von Gesetzen führt zwar - außer beim Einzelfallgesetz - regelmäßig noch nicht zu deren Verfassungswidrigkeit. Erforderlich sind aber - gewissermaßen kompensierend - verschärfte Verfassungssicherungen, weil distanzarme Gesetze nicht selten näher an der individuellen Freiheitssphäre siedeln, eingriffsnäher, freiheits- und gerechtigkeitsgefährdender sind als die allgemeinen und distanzierten Rechtsgesetze.

\footnotetext{
${ }^{51}$ Zur Verweisung staatlichen Rechts auf private Normierungen vgl. zuletzt Schenke, Fröhler-Festschrift, 1980, S. 87 f., 108 ff.; zur Rezeption technischer Normen durch staatliches Recht grundlegend Breuer, AÖR 101 (1976), $46 \mathrm{ff}$;; Marburger, Die Regeln der Technik im Recht, 1979, S. $379 \mathrm{ff} ., 387 \mathrm{ff}$., $390 \mathrm{ff}$., jeweils m.w.N.

${ }_{52}$ Zutreffend Breuer, Anm. 51, S. 51.
} 


\section{Rechtsgrenzen der inneren und äußeren Übernormierung}

Ob durchgehend wirksame verfassungsrechtliche Abhilfen gegen die innere und äußere Übernormierung bestehen, ist zweifelhaft. Die Grundrechte schützen nur wenige Bereiche (etwa die Geheim- und Intimsphäre, die Empfindungs- und Gedankenwelt) im Sinne eines Gesetzesvorenthalts vor jeder eindringenden staatlichen Normierung (und dulden allenfalls eine umfriedende Schutzgesetzgebung). Grundrechte sind somit nur in Einzelfällen zur Bekämpfung der äußeren Übernormierung, d.h. zur partiellen Entgesetzlichung, geeignet. Wegen ihrer eingriffslimitierenden und ausrichtenden Funktion können sie aber sehr wohl der Abwehr innerer Übernormierung durch überdetaillierte Gesetze dienen.

Sonstige direkte Aussagen über das zulässige Höchstmaß an Normierung sind im Grundgesetz nicht enthalten ${ }^{53}$. Art. 72 Abs. 2 GG kennt zwar das Kriterium des Gesetzgebungsbedürfnisses, allerdings nur in der spezifischen föderalistischen Fragestellung der Kompetenzzuweisung zwischen Bund und Ländern. Der Verfassung lassen sich im übrigen leichter Verbote der Unternormierung (durch fehlende oder zu unbestimmte Gesetze) als allgemeine Reaktionen auf Übernormierungen entnehmen. Der Gesetzesvorbehalt sagt, wo der Gesetzgeber regeln muß, nicht, wo er regeln darf. Eine wie immer abzugrenzende Wesentlichkeitstheorie ist - so verlockend dies auch sein mag - nicht zu dem Satz umkehrbar, der Gesetzgeber dürfe nur Wesentliches regeln ${ }^{54}$. Freilich treffen den Gesetzgeber dort, wo er nicht handeln muß, erhöhte Legitimationslasten.

Weiterführen könnte die im Rechtsstaatsprinzip wurzelnde Vorstellung des rechten Maßes von Staatsaktivitäten ${ }^{55}$. Ein aus dem Übermaßverbot abgeleitetes allgemeines Übernormierungsverbot (mit den Geboten der Normierungsnotwendigkeit, -erforderlichkeit und -verhältnismäßigkeit $\left.{ }^{56}\right)$ könnte insbe-

${ }^{53}$ Auch subtile Klärungen der verfassungsrechtlichen Gesetzesbegriffe (dazu z.B. Roellecke, Der Begriff des Gesetzes und das Grundgesetz, 1969; Starck, Der Gesetzesbegriff des Grundgesetzes, 1970) ergeben kaum unmittelbare Verfassungsschranken der Übernormierung.

54 Vgl. aber Fleiner, in: Winkler/Schilcher, Gesetzgebung, 1981, S. 145; ferner Kirchhof, Anm. 42, S. 81.

${ }_{55}$ Siehe dazu etwa Böckenförde, Anm. 7, S. 83.

${ }_{56}$ Die Normierungsnotwendigkeit könnte eine Normierung verhindern, wenn bereits eine hinreichende Normierung vorliegt und die Normierungserforderlichkeit könnte Gesetze dort untersagen, wo eine Regelung durch rangniedrigere Rechtsakte ausreichend erscheint. Das Gebot der Normierungsverhältnismäßigkeit könnte den Erlaß eines Gesetzes dort verhindern, wo sie angesichts der Relevanz eines Sachregelungsproblems als offenkundig überflüssig erscheint. 
sondere den Erlaß überflüssiger Normen verbieten ${ }^{57}$. Dem könnte entsprechen, daß das Bundesverfassungsgericht den Einwand der Überflüssigkeit einer Norm unter Mißbrauchsgesichtspunkten prüft ${ }^{58}$. Wegen der Eingriffsorientiertheit des Übermaßverbots kann dieses zwar überflüssige Eingriffe verhindern ${ }^{59}$, versagt jedoch von vornherein bei nicht eingreifenden Normen. Vor allem aber kann das typischerweise am einzelnen Eingriff und an der einzelnen Gesetzesvorschrift ansetzende Übermaßverbot allenfalls - partiell - die innere Übernormierung steuern. Die äußere Übernormierung mit ihren flächendeckenden Freiheitsverlusten durch Regelungssummierung und Eingriffsaddition ${ }^{60}$ kann das Übermaßverbot dagegen kaum in den Griff bekommen.

Auch wenn somit ein allgemeines Übernormierungsverbot aus der Verfassung nicht ableitbar ist, bleiben Übernormierungen auch außerhalb der erwähnten Teilreaktionen des Übermaßverbots nicht ganz ohne verfassungsrechtlich relevante Konsequenz. Übernormierungen schaffen legalitätsgefährdende, vermindert verbindliche Rechtslagen ${ }^{61}$. Derartige geltungslabile Rechtslagen sind durchgängige, freilich bisher wenig erörterte allgemeine Erscheinungen der Rechtsordnung. Sie sind etwa in der Rückwirkungsrechtsprechung des Bundesverfassungsgerichts (z. B. bei unklarem, unpraktikablem, verworrenem oder systemwidrigen Recht, auf dessen Bestand gegenüber Rückwirkungen kein schutzwürdiges Vertrauen besteht ${ }^{62}$ ) oder bei alterndem Recht ${ }^{63}$ bzw. bei Recht kurz vor seinem Außerkrafttreten oder unmittelbar nach seinem Inkrafttreten ${ }^{64}$ deutlich geworden. Weil Übernormierungen vermindert verbindliche Rechtslagen schaffen, sind sie leichter rückwirkend beseitigbar. In krassen Fällen können sie sogarso bedauerlich dies auch aus prinzipiellen Gründen der Legalitätsgefährdung sein mag - sanktionsfrei oder doch sanktionsvermindert übertreten werden. Die vom Bundesverfassungsgericht bereits vorsichtig angesprochene grundsätzliche Mög-

${ }^{57}$ Als rechtspolitische Forderung bereits erhoben z.B. bei Jahrrei $\beta$, Anm. 13, S. 51; siehe auch Kloepfer, ZFU 1979, $148 \mathrm{f}$.

${ }_{58}$ Vgl. BVerfGE 13, 230 (234f.); kritisch zur Beseitigung überflüssiger Gesetze durch das Verfassungsgericht Ehmke, VVDStRL 20, 96.

${ }^{59}$ Siehe z.B. BVerfGE 17, 306 (313f.).

Bo $\mathrm{Zu}$ den Freiheitsverlusten durch Übernormierung etwa K. Lange, 1979, 535;

H. Jellinek, VuF 1978, 66; Leisner, DVBl. 1981, 851.

61 Kloepfer, ZfU 1979, 149.

62 Vgl. besonders BVerfGE 11, 64 (72f.); 13, 261 (272) sowie 19, 187 (197).

63 Dazu BVerfGE 34, 269 (288f.), in Anschluß an Kübler, JZ 1969, 645; vgl. auch Kloepfer, Vorwirkung von Gesetzen, 1974, S. $117 \mathrm{f}$.

${ }_{64}$ Kloepfer, Anm. 63, S. $117 \mathrm{f}$. 
lichkeit einer Anwendung der Strafrechtsfigur des unvermeidbaren Verbotsirrtums bei Übernormierungen ${ }^{65}$ ist nur die unterverfassungsrechtliche Umsetzung dieser bitteren allgemeinen Einsicht.

\section{Rechtsgrenzen von Gesetzesänderungen}

Gegen übermäßige Gesetzesänderungen könnte das Verfassungsrecht gewissermaßen als Kontinuitätsreserve rechtliche Barrieren bereithalten. Weil die Gesetzesänderung heute den Regelfall des Gesetzes darstell ${ }^{66}$, kann hier eine verfassungsrechtliche Begrenzung zur Vermeidung von Übernormierungen außerordentlich wirksam sein. Eine noch zu erarbeitende Verfassungsdogmatik der Gesetzesänderung kann sich also als ein juristischer Schlüssel für eine partielle Lösung des Übernormierungsproblems erweisen. Dabei sind aber verfassungsrechtliche Überzeichnungen von vornherein zu vermeiden, weil Gesetzesänderungen ohnehin bereits aus vielfältigen politischen und finanziellen Gründen erschwert sein können.

$\mathrm{Zu}$ den Gesetzesänderungen zählen nicht nur die eigentlichen Änderungsgesetze mit Änderungen von Einzelvorschriften, sondern auch die Gesamtänderungen durch neue Ersatzgesetze unter gleichzeitiger Aufhebung alten Rechts.

\section{a) Ausgangsposition}

Nach überkommener Auffassung wird das Vertrauen auf den künftigen Fortbestand von Rechtsnormen grundsätzlich nicht geschützt ${ }^{67}$. Führt man alle Argumente gegen eine mögliche Fortbestandsgarantie gegenüber der Gesetzgebung auf

${ }_{65}$ Vgl. die Andeutung im Beschluß vom 17. März 1978, RIW/AWD 1979, 132 (133), mit Anm. von Hüfler, wobei die Hauptproblematik freilich in einer Verweisungsproblematik bestand (s. dazu auch Krey, EWR 1981, 180); - allgemein zur Informationsproblematik in der Normenfülle Mayer-Maly, Rechtskenntnis und Gesetzesflut, 1969, bes. 13 ff.; Simitis, Informationskrise des Rechts und Datenverarbeitung, 1970, S. $9 \mathrm{ff}$., $15 \mathrm{ff}$.

${ }^{66}$ Mock, in: Winkler/Schilcher, Gesetzgebung, 1981, S. 167.

${ }^{67} \mathrm{Vgl}$. nur etwa BVerfGE 14, 76 (104); 27, 375 (386); 28, 66 (88); 38, 61 (83); grundlegend Leisner, Berber-Festschrift, 1973, S. $273 \mathrm{ff}$, der (S. 280 f.) zwischen dem gegenwartsbezogenen Geltungsvertrauen und dem - liier interessierenden - zukunftsbezogenen Kontinuitätsvertrauen unterscheidet; sowie Degenhart, Systemgerechtigkeit und Selbstbindung als Verfassungspostulat, 1976, S. $59 \mathrm{ff}$, $73 \mathrm{ff}$., $103 \mathrm{ff}$.; Kisker, VVDStRL 32, $176 \mathrm{ff}$., $189 \mathrm{ff}$;; Ossenbühl, DÓV 1972, $30 \mathrm{ff}$.; Püttner, VVDStRL 32, 216f;; Rhinow, Rechtsetzung und Methodik, 1979, S. $274 \mathrm{ff}$. 
ihren Kern zurück, so stehen die gewiß sehr wichtigen Zwecke der Erhaltung der Flexibilität der Rechtsordnung, der Abwehr legaler Erstarrung und - vor allem nach Neuwahlen - der Realisierung demokratischer Alternativen im Vordergrund ${ }^{68}$. Diese wichtigen Positionen haben sich freilich gegenüber der Erwägung zu behaupten, daß der Bürger in einer rechtlich intensiv geordneten Umwelt das bestehende (oder vorhersehbare) Recht prinzipiell in seinen Dispositionen berücksichtigen muß.

\section{b) Schutzansätze}

Ganz kann die herrschende Meinung ihren Standpunkt vom fehlenden Schutz des Fortbestandsvertrauens freilich nicht durchhalten, wenn gesteigerte Vertrauenspositionen auftauchen. So akzeptiert sie ausnahmsweise schutzwürdige Fortbestandslagen vor allem bei der unechten Rückwirkung ${ }^{69}$, bei den wohlerworbenen Rechtspositionen ${ }^{70}$, insbesondere des Beamtenrechts und des Sozialrechts ${ }^{71}$, sowie ansatzweise auch bei gesetzgebungsbezogenen Plangewährleistungsansprüchen $^{72}$. Das Recht des Gesetzgebers zur Änderung seiner Entscheidungen ${ }^{73}$ ist also wohl doch nicht unbegrenzt.

Ansätze zum erweiterten Schutz des Fortbestandsvertrauens $^{74}$ werden bei der unechten Rückwirkung erkennbar. Das von der Rechtsprechung hierbei gewählte Abgrenzungskriterium - der bereits in der Vergangenheit begründete rechtliche Tatbestand - müßte erweitert werden zum Schutz auch vorgezogener faktischer Dispositionen im Hinblick auf den künftigen Fortbestand von geltendem Recht (z.B. konkrete Investitionsvorbereitungen, Unternehmensgründungen, Berufsvorbereitungen etc.). Im übrigen überzeugt die krasse Gegenüberstellung von echter und unechter Rückwirkung ebensowenig ${ }^{75}$

${ }^{68}$ Allgemein zur ,Änderungs- und Verbesserungsfunktion“ des Gesetzes Pawlowski, Rechtstheorie, 1981, 15.

${ }^{69}$ Siehe dazu zuletzt Pieroth, Rückwirkung und Übergangsrecht, 1981, S. 36 ff., $60 \mathrm{ff}$., $79 \mathrm{ff}$., $84 \mathrm{ff}$., m.w.N.

${ }^{70}$ Siehe dazu vor allem Salzwedel, Die Verwaltung 1972, $11 \mathrm{ff}$.

71 Dazu zuletzt BVerfGE 53, 257 (289ff.); BVerfG, NJW 1982, 155 ff.; Badura, BSG-Festschrift, Bd. II, 1979, S. $673 \mathrm{ff} . ; 1 .$, ichneider, Der verfassungsrechtliche Schutz von Renten der Sozialversicherung, 1980.

${ }^{72}$ Hierzu jüngst Maurer, Allgemeines Verwaltungsrecht, 1980, S. $297 \mathrm{ff}$.

${ }^{73}$ Dazu - freilich relativierend - BVerfGE 48, 403 (415); Leisner, JZ 1977, 539.

74 Ausdrücklich ist eine Erweiterung auf das Fortbestandsvertrauen - bei befristeten Gesetzen - vorgesehen worden in BVerfGE 30, 392 (404) - dazu Kloepfer, Anm. 64, S. 98 FN 419 -; eingeschränkter BVerfGE 48, 403 (415).

${ }^{75}$ Kritisch auch Grabitz, DVBl. 1973, 677f.; Kloepfer, Anm. 64, S. 102f., m.w.N.; Pieroth, Anm. 69, S. 79 ff., 84 ff. 
wie die scharfe Kontrastierung von Rückwirkung und Fortwirkung. Hier liegen lediglich Stufungen des einheitlichen Problems gesetzgeberischer Kontinuitätsbindung vor. Außerdem wird die Intensität eines Kontinuitätsbruchs durch Gesetzesänderung als querschnittartiges Differenzierungskriterium bisher viel zu wenig beachtet ${ }^{76}$. Es kann z.B. sehr wohl sein, daß die echte Rückwirkung einer minimalen Änderung verfassungsrechtlich insgesamt unbedenklicher ist als die erhebliche Änderung bei der unechten Rückwirkung oder die krasse künftige Änderung als massiver Eingriff in den Fortbestand bisheriger Rechtslagen.

$\mathrm{Ob}$ der Gesetzgeber, wenn schon nicht zur Aufrechterhaltung seiner Normen, so doch wenigstens zur system- und konzeptionskonformen Weiterbildung der Rechtsordnung verpflichtet ist, erscheint bislang wenig geklärt. Erwägungen gesetzgeberischer Selbstbindung ${ }^{77}$ lassen sich noch am ehesten bei den planenden Programmgesetzen festmachen ${ }^{78}$, wie sie sich z. B. im Globallenkungs-, Haushaltsgrundsätze- und Haushaltsordnungsrecht ${ }^{79}$ sowie im Recht der kommunalen Neugliederung ${ }^{80}$ finden. Hier liegt Gesetzgebung über künftige, formal ranggleiche Gesetzgebung vor. Aber auch sonst kann ein Gesetz gewissermaßen über sich selbst hinausweisen, wenn es zwar nicht ein solches Programmgesetz, wohl aber ein programmatisches oder programmbestätigendes Gesetz darstellt, das ersichtlich nur ein Schritt innerhalb eines klar erkennbaren gesetzgeberischen Gesamtkonzepts ${ }^{81}$ ist (z.B. Umweltgesetze in Vollzug des Umweltprogramms der Bundesregierung ${ }^{82}$ ).

${ }^{76} \mathrm{Vgl}$. auch den Hinweis von Lerche, Ipsen-Festschrift, 1977, S. $441 \mathrm{f}$. daß allmähliche, schrittweise Änderungen verfassungsrechtlich leichter zu realisieren sind als zeitlich unmittelbare Veränderungen.

77 Vgl. für alle Degenhart, Anm. 67; ferner Ossenbühl, DÖV 1972, 31.

${ }^{78}$ Siehe dazu insbesondere Breuer, DVBl. 1970, $101 \mathrm{ff}$.; Quaritsch, Das parlamentslose Parlamentsgesetz, 1964, S. 23; vgl. ferner Degenhart, Anm. 67, S. 32 ff., $106 \mathrm{ff}$; - anders G. Müller, Anm. 12, S. 53 FN 164; Püttner, DÖV 1977, 322 ff.; T. Würtenberger, Anm. 35, S. $349 \mathrm{ff}$; - zu den spezifischen Eigenarten der Planungsgesetze Herzog, Allgemeine Staatslehre, 1971, S. $328 \mathrm{ff}$.; T. Würtenberger, Anm. 35, S. 195 ff. - zur Planbindung des Parlaments, Ossenbühl, 50. DJT, 1974, B 99 f.; M. Schröder, Anm. 25, S. 84 ff.; - gesetzgeberische Selbstbindungsansätze werden auch bei Selbstverpflichtungen zu Anpassungen (s. Anm. 97) deutlich,

${ }^{79}$ Fischer-Menshausen, in: v. Münch, Grundgesetz-Kommentar, Bd. 3, 1978, Art. 109 Rn. 17; anders Stern, in: Stern/Münch/Hansmeyer, Gesetz zur Förderung der Stabilität und des Wachstums der Wirtschaft, 2. Aufl. 1967, S. 68, 107, 145.

${ }^{80}$ Siehe etwa Degenhart, Anm. 67, S. 32 f., 106 f., m.w.N.

81 Zur ,klaren Gesetzgebungstendenz" als „Zukunftsversprechen“ Leisner, Anm. 67, S. 294.

${ }^{82}$ Vgl. hierzu Vitzthum, Anm. 45, S. 135 ff. 
Derartige legislative Selbstbindungserwägungen aus der Idee gesetzgeberischer Gesamtprogramme sind allerdings nur erste Annäherungen an das allgemeine Problem, ob und inwieweit die politische Gesetzgebungsmaxime der In-sich-Stimmigkeit der Rechtsordnung Verfassungskraft besitzt und z.B. Gebote gesetzgeberischer Systemgerechtigkeit ${ }^{83}$ trägt. Dabei muß insbesondere die etwaige Pflicht zur intranormativen Konsequenz innerhalb eines Gesetzes von der Pflicht zur internormativen Konsequenz zwischen Gesetzen unterschieden werden. Ein zeitlich gefärbter Ausschnitt aus dem Themenkreis internormativer Konsequenz ist nun die Frage nach einer Pflicht zur konzeptionskonformen Gesetzesänderung im Sinne einer kontinuitätswahrenden Gesetzesfortschreibung. Eine Legitimation für die in einer solchen Pflicht enthaltene Bindung künftiger gesetzgeberischer Entscheidungen läßt sich vorrangig darin finden, daß sich langfristige gesetzgeberische Regelungsprobleme - einschließlich der für die Rechtsordnung strukturbestimmenden Entscheidungen - dem relativ kurzen Takt der Legislaturperioden notwendigerweise entziehen. Dies beschreibt zugleich den Kernbereich möglicher Zukunftsbindungen des Gesetzgebers durch den Gesetzgeber. Un freilich die Realisierung demokratischer Alternativen nicht übermäßig zu erschweren, muß der gegenwärtige Gesetzgeber die Entscheidungsfreiheit des künftigen Gesetzgebers weitmöglichst schonen. Präjudizierungen durch Selbstbindungsansätze wie auch durch Schaffung oder Ermöglichung von nicht oder schwer veränderlichen Rechts- und Tatsachenlagen darf der Gesetzgeber nur im Falle der sachlichen Unvermeidbarkeit vornehmen.

\section{c) Gesetzesänderung und Widerruf von Verwaltungsakten}

In der Reibung zwischen dem Veränderungsinteresse des Gemeinwesens und dem Verharrungsinteresse des einzelnen, zwischen staatlicher Flexibilität und Vertrauensschutz, ähnelt das Problem der Gesetzesänderung - unter dem Aspekt der Gesetzesaufhebung - in Umrissen auch der Frage der Beseitigbarkeit von Verwaltungsakten. Freilich sind grundlegende Unterschiede unübersehbar. Zunächst handelt es sich bei der Frage des Fortbestands von Gesetzen regelmäßig nicht um

${ }^{83}$ Statt aller: Battis, Ipsen-Festschrift, 1977, S. 11 ff.; Degenhart, Anm. 67; Hoppe/Rengeling, Rechtsschutz bei der kommunalen Gebietsreform, 1973, S. 114 ff.; K. Lange, Die Verwaltung 1971, $259 \mathrm{ff}$.; Stüer, Funktionalreform und kommunale Selbstverwaltung, 1980, S. 152ff., 321 f.; T. Würtenberger, Anm. 35, S. 358 ff.; zur Strukturgerechtigkeit Lerche, DÖV 1961, $487 \mathrm{ff}$. 
individuelle Rechtsverhältnisse und besondere Vertrauenspositionen und auch nicht um Einzelentscheidungen, die in Bestandskraft erwachsen können. Zum anderen ist der für die Problematik der Beseitigung von Verwaltungsakten prägende Unterschied zwischen rechtmäßigen und rechtswidrigen Entscheidungen - zwischen Widerruf und Rücknahme - auf die Frage des Fortbestands des Gesetzes grundsätzlich nicht übertragbar, weil jedenfalls das inhaltlich rechtswidrige Gesetz grundsätzlich nichtig ist. Es kann deshalb insgesamt nicht darum gehen, eine Lehre des Gesetzeswiderrufs in einfacher Analogie zu der Lehre vom Widerruf von Verwaltungsakten zu entwickeln. Diese Konstruktion wäre einfach zu schlicht. Der demokratische Souverän ist kein gebundener Verwaltungsbeamter. Verfassungsbindung ist nicht Gesetzesbindung, Gesetzgebung ist nicht Verwaltung.

Gleichwohl sind weitere Zusammenhänge zwischen den Grundsätzen zum Widerruf von Verwaltungsakten und den Rechtsgrenzen der Gesetzesaufhebung unübersehbar ${ }^{84}$. Da der moderne Gesetzgeber bei seinen punktuell-maßnahmebezogenen Regelungen häufig relativ verwaltungsnah handelt, hat er sich auch verstärkt an wichtigen spezifisch rechtsstaatlichen Sicherungen gegenüber Verwaltungseingriffen zu orientieren (wenn auch nicht direkt diese zu befolgen). Vor allem aber: Wegen der Wechselbezüglichkeiten zwischen Verfassungsrecht und Unterverfassungsrecht ist die Verfassung maßgeblich auch abstrahiertes Unterverfassungsrecht ${ }^{85}$. Sie enthält differenziert nach ihren Schutzgehalten - wesentliche Aussagen des Unterverfassungsrechts unter Weglassung des Individuellen und Zufälligen eines Rechtsgebiets. In diesem Sinne lassen sich aus den verwaltungsrechtlichen Grundsätzen zum Widerruf von Verwaltungsakten folgende tragende Gehalte abstrahieren: Die Prinzipien der Rechtssicherheit, der Berechenbarkeit und des Vertrauensschutzes sind als maßgebliche Gegenpositionen bei der Veränderung staatlicher Entscheidungen zu berücksichtigen; Flexibilitäts- und Stabilitätsinteressen sind gerecht und schonend auszugleichen. Das so Abstrahierte ist nicht mehr verwaltungsrechtsspezifisch, sondern stellt allgemeines Verfassungsrecht dar, gilt also auch - in freilich materienspezifischer Weise - für das Problem der Gesetzesänderung, wobei die erweiterte Handlungsfreiheit des Gesetzgebers freilich stets mitbedacht werden muß.

${ }^{84} \mathrm{Vgl}$. auch den Ansatz bei Rhinow, Anm. 67, S. 275.

${ }_{85}$ In eine teilweise ähnliche Richtung weist auch die Sicht von Lerche, Werbung und Verfassung, 1967, S. $33 \mathrm{f}$.; ders., Maunz-Festgabe, 1971, S. $286 \mathrm{f}$. 
Ein solches „Lernen des Gesetzgebers von sich selbst" bei Erkundung der Verfassungsgrenzen von Gesetzesänderungen durch das Abstrahieren von unterverfassungsrechtlichen Regelungen über die Veränderbarkeit staatlicher Entscheidungen ist etwa auch im Bereich des Planungsänderungs-, Planungsfortschreibungs ${ }^{86}$ und Planungsschadensrechts ${ }^{87}$ vorstellbar. Die hier entwickelten Prinzipien liegen dem Fortbestandsproblem noch näher als die Lehre der Beseitigung von Verwaltungsakten, weil der Plan regelmäßig gesetzesähnlicher ist als der Verwaltungsakt und nicht selten sogar gesetzesförmig ergeht ${ }^{\text {Bg }}$.

\section{d) Gesetzesänderung und verfassungsgeschützte Kontinuität}

Weil es einen Rechtsstaat ohne eine gewisse rechtliche Beständigkeit nicht geben kann, ist die Kontinuität des Rechts auch ein verfassungsrechtliches Schutzgut ${ }^{89}$. Eine Gesetzesänderung belastet notwendigerweise dieses Verfassungsgut. Sie ist ja nicht nur die Aufhebung einer alten Vorschrift mit der gleichzeitigen Ersetzung durch eine neue, sondern vor allem Änderung, d.h. ein Kontinuitätseingriff. Ein solcher Eingriff in die verfassungsgeschützte Kontinuität darf nur unter Berücksichtigung des Übermaßverbots erfolgen ${ }^{90}$. Die hieraus ableitbaren Einzelgehalte der Änderungserforderlichkeit und der Änderungsverhältnismäßigkeit verbieten beliebige und unangemessene Kontinuitätsbrüche durch Gesetzesänderungen, zumal diese stets auch Gleichheitseingriffe sind ${ }^{91}$.

Prinzipiell ist ein die Gesetzgebung verstetigender schonender Ausgleich zwischen Beharrung und Veränderung bzw. zwischen den jeweils dahinterstehenden Interessen und Rechtsgütern vorzunehmen und so insgesamt Kontinuität im

86 Zur Notwendigkeit der Fortschreibung von Planungsgesetzen siehe etwa Herzog, Anm. 78, S. 329.

${ }_{87} \mathrm{Vgl}$. insbes. $\$ \$ 39$ jff. BBauG.

${ }_{88}$ T. Würtenberger, Anm. 35, S. $185 \mathrm{ff}$; zur Planung durch Gesetz zuletzt Badura, H.-Huber-Festschrift, 1981, S. $15 \mathrm{ff}$.

89 Zur Kontinuität als Verfassungsgut siehe Kloepfer, Anm. 63, S. 193 ff., 209 ff., m.w.N.; Lerche, DVBl. 1961, 488f.; Zippelius, Rechtsphilosophie, 1982, S. 162 ff.; - Zum Rechtsstaat als Form der Herstellung von Kontinuität Heller, Staatslehre, 1934, S. 267; Hesse, Smend-Festgabe, 1962, S. $82 \mathrm{f}$.

90 Kloepfer, DOV 1978, 232f., m.w.N.; siehe hierzu Pieroth, Anm. 69, S. 152f.; Änderungen ,in maßvollen Grenzen“ fordert BVerfGE 13, 274 (278) - allerdings für einen Fall der unechten Rückwirkung.

91 Siehe hierzu Dürig, in: Maunz/Dürig, Grundgesetz, Bd. I, Art. 3 I (1973), Rn. $200 \mathrm{ff}$; Kloepfer, DÖV 1978, $227 \mathrm{ff}$; ders., Anm. 9, S. 16f., mit Darlegung (S. 62 ff.) der Geltung des Übermaßverbotes für Gleichheitseingriffe. 
Wandel als Rechtsziel ${ }^{92}$ sicherzustellen. Dies ermöglicht und fordert zugleich weitere hier nur andeutbare Differenzierungen, z. B. zwischen belastenden und begünstigenden Änderungen oder solchen kurz nach dem Inkrafttreten eines Gesetzes oder länger danach. Mit zunehmendem Alter des Rechts mindert sich die Schutzwürdigkeit des Fortbestandsvertrauens. Weiter ist nach den verschiedenen Gesetzgebungsmaterien, nach dem Gewicht der beteiligten Kontinuitäts- und Flexibilitätsinteressen sowie nach etwaigen gesteigerten Kontinuitätspositionen (z.B. Besitzständen, befristeten Gesetzen bis zum Fristablauf etc.) zu unterscheiden. Zusätzliche Differenzierungen sind auch bezüglich der Existenz und Differenziertheit abfedernder Übergangsregelungen möglich, welche die vermeidbaren Härten von Kontinuitätsbrüchen kraft Verfassungsgebot auffangen müssen ${ }^{93}$.

\section{e) Arten der Gesetzesänderung}

Schließlich kann differenziert werden zwischen nur formellen Gesetzesänderungen (wort- und inhaltsgleiche Wiederholungen früheren Rechts), formellen und materiellen Gesetzesänderungen (Wort- und Inhaltsänderungen) bzw. nur materiellen Gesetzesänderungen (z.B. durch Veränderung von Gesetzesvoraussetzungen oder Verweisobjekten, ohne daß der Wortlaut des betreffenden Gesetzes angetastet wird ${ }^{94}$ ). Hinzu kommt die erwähnte Unterscheidung zwischen Einzeländerung und ersetzender Gesamtänderung; erstere ist gewöhnlich kontinuitätsschonender.

Von der inhaltlichen Änderungsintensität her ist typisierend vor allem zwischen richtungsumkehrenden (d.h. wertungsverändernden) und den weitaus häufigeren richtungsmodifizierenden Änderungen zu differenzieren ${ }^{95}$. Diese beiden Änderungsformen müssen ihrerseits unterschieden werden von den

\footnotetext{
92 Kloepfer, Anm. 63, S. 194.

${ }_{93}$ Zur gesetzgeberischen Pflicht zu Übergangsregelungen vgl. etwa BVerfGE 43, 242 (288) sowie Götz, BVerfG-Festgabe, Bd. II, 1976, S. 436 ff.; Kloepfer, DÖV 1978, 230 ff.; Pieroth, Anm. 69, S. 73 ff., 149 ff.; Salzwedel, Anm. 70, S. $20 \mathrm{f}$.

${ }_{94}$ Als Beispiel vgl. die in BVerfGE 37, 363 (383) angesprochenen (nur) materiellen Änderungen (der Tragweite und Bedeutung) von Regelungen des Verwaltungsverfahrens durch Änderungen des materiellen Rechts.

${ }_{95}$ Die Differenzierung von Burmeister, DÖV 1981, $508 \mathrm{f}$., zwischen ,reformeinschränkender" und ,korrektureinschränkender" Bindung an vorausgegangenem Tun (der Verwaltung) setzt ebenfalls an inhaltlichen Gehalten eines Kontinuitätsbruches an.
} 
reagierenden Anpassungsänderungen ${ }^{96}$, die Erscheinungen des allgemeinen Rechtsgedankens der Anpassung sind. Sie finden sich z.B. im Besoldungs-, Sozialversicherungs- und Steuerrecht ${ }^{97}$ in Form von Anpassungsgesetzen und -verordnungen. $\mathrm{Ob}$ sie den Namen der Anpassungsänderung tragen, ist für ihre Rechtsnatur unerheblich. Anpassungsänderungen sind besonders kontinuitätsbezogen und versuchen, die ursprüngliche gesetzliche Konzeption an neue rechtliche Umstände $^{98}$ und vor allem veränderte tatsächliche Außendaten anzupassen. Ihr Erlaß entspricht teilweise auch verfassungsstarken Anpassungsgeboten an den Gesetzgeber ${ }^{99}$.

Der Kontinuitätsbruch ist bei der Richtungsumkehr ersichtlich am stärksten und bei der Anpassungsänderung am geringsten. Die Flexibilitätsinteressen müssen also bei richtungsumkehrenden Gesetzen am gewichtigsten sein, bei den übrigen Änderungsformen dagegen geringer.

\section{Verbesserung der Gesetzesqualität}

\section{Verbesserung der gesetzgeberischen Entscheidungsfin- dung}

Die Verbesserung der Gesetzesqualität kann die Übernormierung insgesamt erträglicher machen, insbesondere korrigierende Gesetzesänderungen von vornherein vermeiden ${ }^{100}$. Was sind nun aber qualitativ gute Gesetze? Diese Schlüsselfrage des Gesetzgebungsstaates ist wegen der Unzahl und eventuellen Widersprüchlichkeit möglicher Qualitätskriterien abschließend nicht beantwortbar. Die hier vor allem von der Gesetzgebungswissenschaft entwickelten inhaltlichen Maß-

${ }_{96} \mathrm{Vgl}$. auch BVerfGE 54, 11 (37), wo die ,einfache und daher schnell zu verwirklichende Anpassung" der umfassenden Neuregelung gegenübergestellt wird. Zur Anpassung durch Gesetzesänderung vgl. z. B. auch Leisner, Anm. 67, S. 292.

97 Als Beispiele für Anpassungsgesetze: $\S 14$ BBesG - vgl. dazu zuletzt BVerfGE 56, 353 (361 ff.) - und $\S 579$, 1272 RVO; 49 AVG; Anpassungsverordnung: $\S 26$ II UStG.

98 Z.B. Anderungen höherrangigen Rechts (etwa EG-Recht, Verfassungsrecht einschließlich verfassungsgerichtliche Entscheidungen), aber auch Veränderungen gleichrangigen, inhaltlich verbundenen Rechts (Änderungen zur Einpassung in die Rechtsordnung - s. auch oben B III 3).

99 Siehe etwa Art. 106 IV S. 1 GG; - zur Nachbesserungspflicht des Gesetzgebers Anm. 109.

100 Zutreffend ist z.B. die Beobachtung von Weiß, DÖV 1978, 607, daß viele Gesetze bereits bei Verabschiedung als änderungsbedürftig betrachtet werden. 
stäbe klingen bislang häufig wie Tugendkataloge des Gesetzgebers und haben überwiegend keine Verfassungskraft. Ähnliches gilt von den ministeriellen Gesetzgebungsrichtlinien ${ }^{101}$.

\section{Ausgangsposition}

Zur Hebung der Gesetzesqualität sind insbesondere operationalisierbare Verbesserungen einer sachkundigen gesetzgeberischen Entscheidungsfindung möglich und notwendig, ohne daß dies in die ausgedehnten Forderungen einer umfassenden Gesetzesplanung münden müßte.

Bei der demokratischen Gesetzgebung mit ihrem typischen - hauptsächlich durch das Zusammenspiel von Exekutive und Legislative im Gesetzgebungsverfahren organisierten Ausgleich zwischen Sachverstand und Konsensfähigkeit können grundsätzlich nur Minimalgebote einer sachkundigen Entscheidungsfindung als Verfassungspostulate anerkannt werden. Die Abgeordneten sind - und so falsch ist das nicht regelmäßig keine Sachverständigen für gesetzliche Sachregelungsmaterien, sondern Experten des politisch Machbaren. Sie trifft keine Verfassungspflicht zur optimalen Methodik der Gesetzgebung ${ }^{102}$, sondern lediglich eine behutsam zu umreißende Pflicht zu einer von wesentlichen Fehlern freien Gesetzesmethodik.

Eine grundsätzliche Schwierigkeit für die Entwicklung einschlägiger verfassungsrechtlicher Standards besteht darin, daß die - wegen der Präjudizierungswirkung politisch so wichtige - vorparlamentarische Phase der Gesetzesentstehung vom Grundgesetz direkt nicht geregelt wird. Seine Vorschriften über das Gesetzgebungsverfahren setzen erst dann ein, wenn in aller Regel die wesentlichen politischen Vorentscheidungen durch internationale oder interföderative Absprachen, durch das „Aushandeln“ politischer Lösungen zwischen der Regierung und gesellschaftlichen Gruppen, durch Parteitags- oder Koalitionsbeschlüsse oder aber insbesondere durch Entscheidungen der gesetzesvorbereitenden Exekutive be-

101 Dazu z.B. Kindermann, Ministerielle Richtlinien der Gesetzestechnik, 1979; Lachmayer, in: Winkler/Schilcher, Gesetzgebung, 1981, S. 213 ff., sowie die Beiträge von Kindermann, Adamovich, Holzinger und Lachmayer, in: Ohlinger, Methodik der Gesetzgebung, 1982, S. $211 \mathrm{ff}$., $232 \mathrm{ff}$., $239 \mathrm{ff}$., $250 \mathrm{ff}$.

102 So aber Schwerdtfeger, Ipsen-Festschrift, 1977, S. 173ff.; gegen ihn Schlaich, VVDStRL 39, 109; teilweise auch Stern, Anm. 13, S. 645; - zur Praxis des BVerfG Benda, Grundrechtswidrige Gesetze, 1979, S. $21 \mathrm{ff}$. 
reits gefallen sind ${ }^{103}$. Angesichts dieses grundgesetzlichen Regelungsdefizits bezüglich der Gesetzgebungsvorbereitung sind Gesetzgebung und Wissenschaft zur stärkeren rechtlichen Durchdringung dieser Phase aufgerufen ${ }^{104}$. Insbesondere werden - trotz aller Schwierigkeiten der rechtlichen Faßbarkeit des Politischen - verfassungsrechtliche Mindeststandards für eine rationale gesetzgeberische Entscheidung um so wichtiger.

\section{Verbesserung gesetzgeberischer Diagnose und Prognose}

Ein wesentlicher Zweck solcher verfassungsrechtlichen Anforderungen an die gesetzgeberische Entscheidungsfindung ist die Sicherung der materiellen Verfassungsmäßigkeit eines Gesetzes. Daher sind solche Verfassungsregeln für die Entscheidungsfindung auch von den Verfassungsanforderungen an den Inhalt eines fertigen Gesetzes her zu entwickeln. Aus materiellen Geeignetheits- und Erforderlichkeitsprinzipien lassen sich so - freilich nicht immer leicht abgrenzbare Pflichten des Gesetzgebers zur hinlänglichen Tatsachenermittlung oder (nachrangig) zur rationalen Prognose ${ }^{105}$ ableiten. Nach Erlaß eines Gesetzes wandeln sich diese Pflichten in eine laufende Erfolgskontrollpflicht des Gesetzgebers ${ }^{106}$.

Wie - und durch wen - der Gesetzgeber sich sein Entscheidungswissen verschafft, $z$. B. durch - zugleich konsensfördern$\mathrm{de}$-Anhörungen, bleibt ihm überlassen ${ }^{107}$. Ob er seinen Erkun-

103 Siehe dazu etwa Scheuner, Anm. 23, S. 136; T. Würtenberger, Anm. 35, S. 152; vgl. in diesem Zusammenhang etwa auch die Gegenüberstellung von formellem und materiellem Gesetzgeber z.B. bei Maihofer, Anm. 26, S. 20ff.; Winkler, in: Winkler/Schilcher, Gesetzgebung, 1981, S. $125 \mathrm{ff}$.

$104 \mathrm{Vgl}$. etwa auch die Forderungen von Eichenberger, Anm. 31, S. $321 \mathrm{f}$; Stern, Anm. 13, S. 643.

105 Zur gesetzgeberischen Tatsachenfeststellung und Prognose statt aller: Breuer, Der Staat 1971, $21 \mathrm{ff}$; Goerlich, JR 1977, $91 \mathrm{ff}$.; Kloepfer, NJW 1971, 1585 ff.; Pestalozza, NJW 1981, 2083; Schwerdtfeger, Anm. 102, S. $178 \mathrm{ff}$.; Seetzen, NJW 1975, 429 ff.; - zur einschlägigen Kontrolle durch das BVerfG: Ossenbühl, BVerfG-Festgabe, Bd. I, 1976, S. 459ff.; Philippi, Tatsachenfeststellungen des Bundesverfassungsgerichts, 1971; Schuppert, Die verfassungsgerichtliche Kontrolle der Auswärtigen Gewalt, 1973, S. 167ff.; Thierfelder, Jur. Anal. 1970, 879ff; — zuletzt BVerfGE 49, 89 (131 ff.); 50, 290 (323f.); BVerfG, NJW 1981, 2107 (2108).

106 Siehe auch Pestalozza, NJW 1981, 2085; sowie jetzt auch BVerfGE 55, 274 (308); - zur Evaluierung von Gesetzen etwa Amelung, ZStW 92 (1980), $30 \mathrm{ff}$; Hellstern/Wollmann, ZfParl. 1980, 547ff.; Noll, Anm. 31, S. $146 \mathrm{ff}$.

$107 \mathrm{Vgl}$. auch BVerfGE 36, 321 (330). 
dungspflichten im konkreten Fall nachgekommen ist, wird sich vielfach der Schilderung der gesetzgeberischen Entscheidungsfindung (z.B. durch Ausschußberichte, Begründungen etc.) entnehmen lassen. Auf jeden Fall dürften gänzlich fehlende, evident unvollständige oder ersichtlich unzutreffende Tatsachenfeststellungen bzw. deutlich irrationale Prognosen zu einem fehlerhaften gesetzgeberischen Entscheidungsverfahren führen. Rechtsfolge muß dabei nicht immer die Nichtigkeit eines Gesetzes sein ${ }^{108}$, sondern kann auch in bloßen Aufhebungs-, Korrektur- und Nachbesserungspflichten ${ }^{109}$ bestehen.

\section{Gesetzgebungsexperimente}

\section{Abgrenzung}

Wichtige und zunehmend beliebtere Hilfsmittel der gesetzgeberischen Ermittlung und Prognose sind Gesetzgebungsexperimente ${ }^{110}$, die sich etwa im Ausbildungs- ${ }^{111}$, Medien- ${ }^{112}$ und

${ }^{108}$ Siehe auch die Konzeption für Verfahrensfehler der Gesetzgebung von Schwerdtfeger, Anm. 102, S. 178, $186 \mathrm{f}$.; grundsätzlich anders etwa Papier, Der verfahrensfehlerhafte Staatsakt, 1973, S. $21 \mathrm{ff}$.; Pestalozza, „Formenmißbrauch“ des Staates, 1973 , S. $158 \mathrm{ff}$.

${ }_{109}$ Zur Nachbesserungspflicht des Gesetzgebers: BVerfGE 25, 1 (12f.); 49, 89 (130, 132); 50, 290 (332f); 55, 274 (308, 317); 56, 54 (78ff.); BVerfG, NJW 1981,.2107 (2109).

110 Allgemein hierzu Hopt, JZ 1972, $68 \mathrm{ff}$; Kloepfer, DÖV 1978, 226; ders., in: K. Vogel, Grundrechtsverständnis und Normenkontrolle, 1979, S. 86; Steinberg, Der Staat 1976, 191; - kritisch zu Gesetzgebungsexperimenten z.B. Leisner, DVB1. 1981, 855; Pestalozza, NJW 1981, 2084; Winkler, Anm. 103, S. 102f., 133; allgemein zum experimentellen Denken in der Jurisprudenz Beutel, Die Experimentelle Rechtswissenschaft, 1971; Ryffel, Rechtssoziologie, 1974, S. 43ff.; Zippelius, H.-Huber-Festschrift, 1981, S. $143 \mathrm{ff}$.

${ }_{111}$ Dazu Ossenbühl, Verfassungsrechtliche Probleme der Kooperativen Schule, 1977, S. 62f.; ders., Das elterliche Erziehungsrecht im Sinne des Grundgesetzes, 1981, S. 131 ff., m.w. N.; Pirson, Jahrreiß-Festschrift, 1974, S. 181 ff.; $I$. Richter, JZ 1978, 553 ff.; $H$. Säcker, RdJB 1972, 13 ff.; Stober, DÖV 1976, 521; - für die zahllosen Experimente im Bereich der akademischen Ausbildung vgl. z.B. die Erprobung der einstufigen Juristenausbildung nach $\$ 5 \mathrm{~b}$ DRiG; dazu E. Hirsch, JZ 1971, 286 ff.; Rupp, WissR 1973, $105 \mathrm{ff}$.

${ }_{112}$ Derzeit sind die Kabelfernseh-Pilotprojekte besonders interessant; - vgl. insbes. das rheinland-pfälzische Landesgesetz über einen Versuch mit Breitbandkabel vom 4. 12. 1980, GVBl. 229, und dazu bzw. zu den Entwürfen Fleck, VerwArch. 1980, 280ff.; Hoffmann-Riem, ZRP 1980, 31 ff.; Kloepfer, Anmerkungen zum Referentenentwurf eines rheinland-pfälzischen Landesgesetzes über die Durchführung eines Modellversuchs mit Breitbandkabel (Stand 11. 11. 1979), 1979, hekt.; Ricker, AfP 1980, 140 ff.; ders., NJW 1981, 849; Stock, Zur Theorie des Koordinationsrundfunks, 1981 , bes. S. 9 ff., 133 ff.; ders., Koordinationsrundfunk als Modellversuch, 1981; - zum Münchener Pilotprojekt siehe insbes. Schmitt Glaeser, Kabelkommunikation und Verfassung, 1979, passim, bes. S. $201 \mathrm{ff}$; allgemein auch Bullinger, Kommunikationsfreiheit im Strukturwandel der Telekommunikation, 1980, S. $107 \mathrm{ff}$. 
Wirtschaftsbereich ${ }^{113}$ finden und bisweilen auch mit dem himmelstürmenden Namen: Pilotprojekt geschmückt werden. Bezüglich der Gesetzgebungsexperimente ist zwischen den Experimentgesetzen (bei denen das Gesetz selbst erprobt wird) und den gesetzgeberischen Grundlagen für exekutive Experimente (Experimentierklauseln ${ }^{14}$ ) zu differenzieren. Im Modellversuchsgesetz verschwimmen häufig diese beiden Elemente der Gesetzeserprobung und der exekutiven Testermöglichung.

Das Gesetzgebungsexperiment ist von dem weiterentwickelten Normalgesetz zu unterscheiden ${ }^{115}$. Die immanente Verbesserbarkeit solcher „normalen“ Gesetze hat freilich zu dem Fehlschluß geführt, jedes Gesetz sei ein Experiment ${ }^{116}$. Das „normale" Gesetz ist zwar verbesser- und änderbar, soll aber wenigstens derzeit als richtig erkannte, begrenzt dauerhafte Lösungen anstreben. Das Gesetzgebungsexperiment entsteht dagegen aus einer Situation der Ungewißheit und ist auf Vorläufigkeit, auf Erprobung und Auswertung angelegt, wobei ein Scheitern möglich bleibt. Das schließt allerdings Zwischenformen etwa durch befristete Einstiegs- und Vorschaltgesetze ${ }^{17}$ nicht aus.

\section{Ursachen}

Ein Grund für die politische Attraktivität der Gesetzgebungsexperimente liegt darin, daß sie weiche und gebrochene politische Entscheidungen zulassen, die eine Gegnerschaft erschweren. Gesetzgebungsexperimente ermöglichen auf jeden Fall den Eindruck, daß politisch gehandelt wird, ohne daß wirklich etwas auf breiterer Ebene bewegt werden muß. Gesetzgebungsexperimente können Instrumente einer Taktik der langfristigen Durchsetzung (mit Hinarbeiten und Hoffnung auf den Testerfolg) oder entgegengesetzt der langfristigen Vermeidung von bestimmten politischen Entscheidungen (mit Anstreben und Erwarten des Testmißerfolgs) sein. Häufig ist das Gesetzgebungsexperiment der kleinste gemeinsame politi-

\footnotetext{
${ }_{113}$ Vgl. dazu Tettinger, Rechtsanwendung und gerichtliche Kontrolle im Wirtschaftsverwaltungsrecht, 1980, S. $298 \mathrm{ff}$.

${ }^{114}$ Siehe hierzu Häberle, Verfassung als öffentlicher Prozeß, 1978, S. 85 ff.; Tettinger, Anm. 113, S. 305.

115 So wohl auch Tettinger, Anm. 113, S. 300; - Normalgesetz und Gesetzgebungsexperiment unterscheiden sich etwa wie ein (verbesserbares) Serienfahrzeug und ein Testwagen.

${ }^{116}$ Statt aller Jahrreiß, Anm. 13, S. 5, 32, 33; Noll, Anm. 31, S. 96f.; ähnlich für die moderne Gesetzgebung Ossenbühl, Anm. 105, S. 511.

${ }_{117}$ Dazu Kloepfer, Anm. 63, bes. S. $201 \mathrm{f}$.
} 
sche Nenner, der überhaupt einen vorläufigen politischen Kompromiß ermöglicht. Im übrigen entspricht das Gesetzgebungsexperiment dem nicht ganz unproblematischen Trend zur Quasi-Verwissenschaftlichung der Politik: Gesetze nicht als Ergebnisse politischer Entscheidungen, sondern als scheinbare Konsequenzen angeblich erwiesener sozialer Notwendigkeiten. Auf jeden Fall entlastet das Gesetzgebungsexperiment den Gesetzgeber politisch, wenn dieser ein geglücktes Experiment vorweisen kann.

\section{Verfassungsrechtliche Voraussetzungen}

Wenig ausgeleuchtet ist bisher die Frage, wann ein Gesetzgebungsexperiment evtl. verfassungsrechtlich verboten oder umgekehrt geboten ist. Gesetzgebungsexperimente gefährden die Rechtssicherheit, sind bisweilen auch normative Experimente mit Menschen und deshalb keineswegs beliebig einführbar. Bei rechtsbewußtseinssensiblen Gerechtigkeitsgesetzen (wie z. B. dem Strafgesetz) und bei Gesetzen mit Dauertatbeständen ${ }^{118}$ (etwa den Beamtengesetzen) sind Gesetzgebungsexperimente regelmäßig politisch und rechtlich problematischer als bei Maßnahmegesetzen. Der hohe Verfassungs- und Rechtsrang der durch Gesetzgebungsexperimente möglicherweise gefährdeten Rechtsgüter kann entsprechende gesetzgeberische Versuche $u$. U. ganz untersagen ${ }^{119}$. Gerade im so versuchsfreudigen Ausbildungsbereich sind aus rechtlicher Sicht Experimente nur zurückhaltend durchzuführen, weil es hier auch um die experimentelle Gefährdung von Lebenschancen gehen kann. Zur Vermeidung von Regelungen im Zustand völliger tatsächlicher Ungewißheit können - als Ausfluß der gesetzgeberischen Erkundungs- und Prognosepflicht ${ }^{10}-u m$ gekehrt aber auch Verwaltungs- oder Gesetzgebungsexperimente geboten sein ${ }^{121}$, bevor es zu umfassenden gesetzgeberischen Regelungen kommt, z.B. bei breiter Einführung neuer

${ }_{118}$ Zur Experimentierfeindlichkeit von Dauergesetzen vgl. insbes. Ossenbühl, Anm. 105; ders., Verfassungsrechtliche Probleme der Kooperativen Schule, 1977, S. 62, der hier eine schrittweise Gesetzgebung fordert; folgend Tettinger, Anm. 113, S. 302 f.

119 BVerfGE 39, 1 (60).

${ }_{120}$ Siehe dazu Anm. 105; - speziell auch im Hinblick auf Gesetzgebungsexperimente Schmitt Glaeser, Anm. 112, S. 160 ff., 174f., 208.

${ }_{121}$ Dazu etwa Ossenbühl, Verfassungsrechtliche Probleme der Kooperativen Schule, 1977, S. 59 ff.; - eine gesetzgeberische Pflicht zum Gesetzgebungsexperiment begründet nicht unbedingt einen Anspruch des Bürgers auf Durchführung eines Gesetzgebungsexperiments. 
Techniken. Gesetzgebungsexperimente ausschließlich zur experimentellen Erprobung der Gesetzesakzeptanz sind nicht unproblematisch, weil sie potentielle Rechtsbrüche zu Bestandteilen der Versuchsanordnung machen und damit den Verlust gesetzgeberischer Verbindlichkeit in Kauf nehmen. Sie dürfen jedenfalls nicht zu funktionsverschiebenden, quasiplebiszitären Annahmeverfahren von Gesetzen führen.

Besonders wichtig sind die verfassungsrechtlichen Voraussetzungen und Rahmenbedingungen für die Einführung und Ausgestaltung derartiger Gesetzgebungsexperimente. Testvoraussetzungen sind neben der grundsätzlichen Legitimität und Testbarkeit des Testziels das Testbedürfnis, die Testgeeignetheit und die Testerforderlichkeit. Ein Testbedürfnis liegt nicht vor, wenn verwertbare Erfahrungen im Inland (insbesondere in einem Bundesland) bzw. - soweit vergleichbar - im Ausland vorliegen ${ }^{122}$. Die Testgeeignetheit ${ }^{123}$ fragt danach, ob die erstrebten Erkenntnisse überhaupt durch die angestrebten Tests erreichbar sind. Testerforderlichkeit liegt nicht vor, wenn geringer dimensionierte Tests oder sogar bloße Modellrechnungen bzw. Planspiele etc. ${ }^{124}$ zur Ermittlung der zu testenden Ergebnisse im wesentlichen ausreichen ${ }^{125}$. Das Gebot der Testverhältnismäßigkeit ist verletzt, wenn die durch den Versuch verursachten Gefahren und möglichen Schäden außer Verhältnis zu den durch den Test voraussichtlich zu erreichenden Erkenntnissen stehen würden.

Notwendige Voraussetzung für Gesetzgebungsexperimente ist die Noch-Nicht-Abgeschlossenheit der politischen Willensbildung vor einem Test, um den Mißbrauch der Form des Gesetzgebungsexperiments zu rein taktischen Zwecken weitmöglichst zu verhindern. Der Test ist zu befristen ${ }^{126}$ sowie realitätsnah ${ }^{127}$ zu gestalten und durchzuführen. Er muß ergebnisof-

122 Siehe auch Hoffmann-Riem, ZRP 1980, 32; Hopt, JZ 1972, 69 f.; Pestalozza, NJW 1981, 2084.

${ }^{123}$ Zu dieser Forderung Hoffmann-Riem, ZRP 1980, 32; Stock, Zur Theorie des Koordinationsrundfunks, 1981, S. 141.

${ }_{124}$ Dazu etwa Hellstern/Wollmann, ZfParl. 1980, 550; Hopt, in: EDV und Recht, Bd. 4, 1972, S. 33 ff.; ders., JZ 1972, 72 ff.; Triffterer, Schröder-Festschrift, 1978, S. $514,519 \mathrm{f}$.

${ }^{125}$ Sind Tests auf freiwilliger Ebene möglich, widersprächen zwangsweise Tests dem Gebot der Testerforderlichkeit; vgl. auch die Argumentationsrichtung in BVerfGE 34, 165 (199); zur Freiwilligkeit bei Ausbildungsversuchen Häberle, Anm. 114, S. 86; Ossenbühl, Das elterliche Erziehungsrecht im Sinne des Grundgesetzes, 1981, S. 131 ff; ; H. Säcker, RdJB 1972, 16.

${ }^{126}$ Zum weitergehenden Verbot des ständigen Experimentierens Stern/Püttner, Grundfragen zur Verwaltungsreform im Stadtumland, 2. Aufl. 1969, S. 26; Stüer, Anm. 83, S. 154 FN 51, 379 FN 762.

${ }^{127}$ Kloepfer, Anm. 112, S. 1; - jedenfalls evident realitätsfremde Gesetzgebungsexperimente sind verfassungswidrig. 
fen $\operatorname{sein}^{128}$, d.h. eine Ergebnispräjudizierung durch Versuchsanordnung vermeiden und darf deshalb grundsätzlich keine dauerhaft irreversiblen Rechts- und Sachlagen schaffen $^{129}$. Wesentliche Rahmenbedingungen sind außerdem Vorkehrungen für sachverständige und objektive Auswertungen von Experimenten (insbesondere durch weisungsfreie Kommissionen ${ }^{130}$ ) sowie Vorsorge- und Auffangregelungen für das Testende (zur Vermeidung unzumutbarer Testopfer für die Beteiligten). Bereits begonnene befristete Gesetzesexperimente dürfen nicht ohne triftigen Grund vorzeitig abgebrochen werden $^{131}$. Es ist schließlich ein Gebot legislatorischer In-sichKonsequenz, daß der Gesetzgeber bei der Entscheidung über seine endgültige Maßnahme die Ergebnisse des von ihm selbst vorgesehenen Experiments hinreichend berücksichtigt.

Ungeklärt ist bislang die Frage, ob - und gegebenenfalls inwieweit - Gesetzgebungsexperimente in gelockerter Verfassungsbindung stattfinden können ${ }^{132}$. Grundsätzlich gibt es keine verfassungsfreien Räume für Gesetzgebungsexperimente. Die Grundrechtsbindung sowie die Einhaltung der Gesetzgebungszuständigkeiten und des Gesetzgebungsverfahrens sind unabdingbar. Auch hinsichtlich der durch den Vorbehalt des Gesetzes verfassungsrechtlich gebotenen Gesetzesform sind kaum Lockerungen möglich ${ }^{133}$. Die verbreitete Praxis, Gesetzesentwürfe vorwirkend als Verwaltungsrichtlinien zu erproben ${ }^{134}$, ist also grundsätzlich nur zulässig, wenn dies mit dem Vorbehalt des Gesetzes vereinbar ist ${ }^{135}$. Gesetzliche Er-

${ }_{128} K l o e p f e r$, Anm. 112, S. 1; - eine ,weichenstellende Funktion“ eines Gesetzgebungsexperiments, wie sie Schmitt Glaeser, Anm. 112, S. 36 f., 209, für ein Pilotprojekt diagnostiziert, wäre verfassungsrechtlich bedenklich, wenn und weil mit der Testeinrichtung bereits eine Präjudizierung für die Dauerlösung angestrebt würde.

${ }_{129}$ Zum Irreversibilitätsverbot Stock, Anm. 123, S. 142; siehe auch Hopt. JZ 1972,70 .

130 Kloepfer, Anm. 112, S. $1 \mathrm{f}$.

131 Vgl. dazu auch Ossenbühl, Anm. 125, S. $131 \mathrm{f}$.

132 Wohl ablehnend etwa Hoffmann-Riem, ZRP 1980, 32; Schmitt Glaeser, Anm. 112, S. 207, 227; Stock, Anm. 123, S. 142; ders., Koordinationsrundfunk im Modellversuch, 1981, S. 167 ff., m.w.N.; teilweise eher bejahend wohl Häberle. Anm. 114, S. $86 \mathrm{f}$.

${ }^{133} \mathrm{Zur}$ gesetzlichen Ermächtigung für Schulversuche vgl. Oppermann, 51. DJT, 1976, C 56; Pirson, Anm. 111, S. $192 \mathrm{ff}$.; H. Säcker, RdJB 1972, $13 \mathrm{ff}$; Stober, DÖV 1976, 518ff.; - zur gesetzlichen Ermächtigung von Versuchen für privaten Rundfunk jetzt BVerfG, NJW 1981, 1774 (1777).

$134 \mathrm{Zu}$ Gesetzesentwürfen als Verwaltungsrichtlinien Kloepfer, Anm. 63, S. 23, 123, 208, 209.

${ }^{135}$ Was eine Voranwendung künftiger -- hochwahrscheinlich in Kraft tretender - rückwirkender Gesetze nicht ausschließt; Kloepfer, Anm. 63, S. $120 \mathrm{ff}$. 
mächtigungen zu Experimenten müssen Zweck und Ausmaß des Tests sowie seine Rahmenbedingungen festlegen. Allerdings werden die rechtsstaatlichen Vorhersehbarkeits- und Bestimmbarkeitsgebote und die gesetzgeberischen Ermittlungs- und Prognosepflichten bei Gesetzesexperimenten relativiert. Dies deshalb, weil Experimente gerade Ungewisses erproben und begleitende, fortschreibend-anpassende Testveränderungen je nach Teststand möglich sein sollen. Auch das Geeignetheitsgebot kann bei Gesetzgebungsexperimenten nicht in gewohntem Umfange verfassungsrechtlich gelten; sehr wohl ist aber - wie erwähnt - Testgeeignetheit zu fordern. Diese testbezogenen Lockerungen einiger wesentlicher allgemeiner Verfassungsbindungen erweisen - ebenso wie die spezifischen verfassungsrechtlichen Testvoraussetzungen - den eigenen juristischen Sinn und Charakter des Gesetzgebungsexperiments, das so zu einer neuen, selbständigen Rechtsfigur wird.

\section{Ausblick}

Insgesamt ist die heutige Situation der Gesetzgebung in der Bundesrepublik Deutschland verbesserungsfähig. Den Beruf unserer Zeit zur Gesetzgebung grundsätzlich zu verneinen, wäre falsch und in einem angreifbaren Sinne theoretisch, denn es wird und muß - auch konzeptionell - weiter geregelt werden. Der Traum vom einfachen und ursprünglichen Gesetz wird angesichts der Kompliziertheit heutiger Regelungsprobleme ein solcher bleiben müssen. Vor einem naiven Aussteigertum aus einer differenzierten Rechtsordnung sei nachdrücklich gewarnt. Eine Reduzierung der Vielzahl von Gesetzen und Gesetzesänderungen, eine Verbesserung der Gesetzesqualität und eine Rückgewinnung gesetzgeberischer Distanz, das alles kann gewiß zur Stärkung und Konsolidierung des Rechtsstaates beitragen. Für politische Untergangsvisionen und rechtsstaatliche Endzeitobsessionen wegen des $\mathrm{Zu}$ standes unserer Gesetzgebung gibt es weder Anlaß noch Legitimation. Gesetz und Rechtsstaat sind fordernde Formulierungen auch in die Zukunft. 
Leitsätze des 2. Mitberichterstatters über:

\section{Gesetzgebung im Rechtsstaat}

1. Dem Rechtsstaat als Staatsform der Distanz entspricht das Gesetz als Instrument zur Erstellung von freiheits- und gerechtigkeitssichernder Distanz. Die Gesetzgebung der Gegenwart ist gekennzeichnet durch den Verlust an rechtsstaatlicher und demokratischer Distanz.

2. Die u.a. hierdurch verursachte äußere und innere Übernormierung bringt beträchtliche Nachteile für den Bürger, die Rechtsanwendung und den Gesetzgeber, über die freilich die Vorteile einer Vergesetzlichung nicht vergessen werden dürfen.

3. Ursachen der Übernormierung sind vor allem die Ausdehnung der Staatsaufgaben, der Gebrauch des Gesetzes und des Gesetzgebungsverfahrens als Mittel der politischen Auseinandersetzung sowie institutionelle Gründe. Demgegenüber treten rechtliche Gründe zurück. Als Ursache der Normerzeugung verdrängt der derivative Gesetzesänderungsvorbehalt heute zunehmend den Gesetzesvorbehalt, dessen innere Grenzen zudem wenig beachtet werden.

4. Die Rückgewinnung gesetzgeberischer Distanz, Rechtsbereinigungen und eine Beschränkung auf das wirklich Normierbare können zum Abbau der Übernormierung beitragen. Eine Entlastung des Gesetzgebers kann auch durch private Rechtsetzung erfolgen, die in staatliches Recht freilich nur aufgrund einer konkreten Rezeptionsentscheidung des Staates übernommen werden darf.

5. Rechtliche Abhilfemöglichkeiten gegen die Übernormierungen müssen Freiheits- und Gerechtigkeitsgefährdungen durch distanzarme Gesetze ausgleichen. Das Übermaßverbot kann gegen die innere Übernormierung bei eingreifenden Gesetzen aktiviert werden. Es trägt aber kein allgemeines Übernormierungsverbot.

6. a) Demgegenüber sind allgemeine Verfassungsgrenzen von Gesetzesänderungen auch außerhalb bisheriger Ansätze (unechte Rückwirkung, Besitzstandsschutz etc.) erkennbar. An programmerstellende und -bestätigende Gesetze können Erwägungen einer gesetzgeberischen Selbstbindung anknüpfen. 
b) Bei langfristigen Regelungsproblemen trifft den Gesetzgeber die Pflicht zur kontinuitätswahrenden Gesetzesfortschreibung. Präjudizierungen des künftigen Gesetzgebers darf der gegenwärtige Gesetzgeber nur im Falle sachlicher Unvermeidbarkeit vornehmen.

c) Die aus den verwaltungsrechtlichen Grundsätzen des Widerrufs von Verwaltungsakten abstrahierbaren Verfassungsgehalte (insbes. das Gebot des gerechten und schonenden Ausgleichs von Flexibilitätsinteressen und Stabilitätsinteressen) sind prinzipiell - unter Beachtung der gesetzgeberischen Entscheidungsfreiheit - auch auf Gesetzesänderungen übertragbar.

d) Kontinuitätseingriffe durch - vielfältig differenzierbare - Gesetzesänderungen sind an das Übermaßverbot gebunden. Deshalb erweisen sich beliebige, nicht erforderliche undhinsichtlich der Intensität eines Kontinuitätsbruchs - unangemessene Gesetzesänderungen als unzulässig.

7. Zur Hebung der Gesetzesqualität sind Verbesserungen der gesetzgeberischen Entscheidungsfindung notwendig. Aus dem Verfassungsrecht können insoweit jedoch nur Mindeststandards abgeleitet werden. Dies gilt etwa für die Verfassungspflicht des Gesetzgebers zur Ermittlung der für seine Entscheidung erheblichen Tatsachen bzw. zur rationalen Prognose.

8. Das Gesetzgebungsexperiment stellt eine eigenständige Rechtsfigur dar. Seine Durchführung kann verfassungsrechtlich geboten, aber auch verboten sein. Verfassungsrechtliche Anforderungen an Gesetzgebungsexperimente sind u.a. das Testbedürfnis, die Testgeeignetheit, Testerforderlichkeit und Testverhältnismäßigkeit sowie die Ergebnisoffenheit, Umkehrbarkeit und Befristung von Tests. Der Gesetzgeber muß eine objektive Testbewertung sichern und evtl. Auffangregelungen für das Testende vorsehen. Lockerungen von allgemeinen Verfassungsbindungen sind bei Gesetzgebungsexperimenten nur ausnahmsweise bezüglich rechtsstaatlicher Bestimmbarkeitsund Geeignetheitsgebote feststellbar. 


\section{Aussprache und Schlußworte Gesetzgebung im Rechtsstaat}

Vorsitzender (Martens): Sehr verehrte Frau Kollegin, sehr geehrte Herren Kollegen!

Ich begrüße Sie zur Aussprache über den ersten Beratungsgegenstand. Eine trennscharfe Gliederung der zahlreichen Aspekte unseres Themas erschien während unserer Vorüberlegungen in der Mittagspause nicht möglich. Erfahrungsgemäß sprengen auch die Diskussionsbeiträge der Mitglieder gelegentlich alle Versuche einer Kanalisierung. In Übereinstimmung mit den Referenten möchte ich Ihnen deshalb nur eine ganz grobmaschige Strukturierung unserer Diskussion in zwei Abschnitte vorschlagen. Wir sollten in einem ersten Abschnitt sprechen über den verfassungsrechtlichen und den verfassungstheoretischen Rahmen rechtsstaatlicher Gesetzgebung, und wir sollten uns dann im zweiten Teil zuwenden den Therapien zur Besserung - ich will nicht von Heilung sprechen eines von den Referenten einmütig als kritisch diagnostizierten Zustandes heutiger Gesetzgebung. Ich gehe davon aus, daß in diese beiden Abschnitte sich alles das, was Sie zu sagen wünschen, nahtlos einfügen lassen wird. Ich möchte Sie dann, um die Diskussion zu eröffnen, um Ihre Wortmeldungen zu dem ersten Abschnitt unseres Themas bitten und, sofern Sie den Wunsch haben, unmittelbar auf einen vorangehenden Diskussionsredner zu erwidern, das durch das Heben beider Hände zu signalisieren. Ich bin von verschiedenen Seiten eben heftig kritisiert worden dafür, daß von Anfang an eine Redezeitbegrenzung von vier Minuten vorgesehen worden ist. Ich nehme diese Kritik zur Kenntnis, kann allerdings nur darauf hinweisen, daß jeder, der länger redet, anderen - wie ich meine - gleichberechtigten Kollegen, die Gelegenheit nimmt, sich hier zu äußern. Ich kann nur, wie im letzten Jahr in Innsbruck auch, an Ihre Fairne $\beta$ appellieren; mehr kann ich nicht tun, und mehr will ich nicht tun. Herr Kaiser, Sie hatten sich gemeldet, bitte schön.

Kaiser: Dem Vorstand und den Referenten ist zu danken, daß sie uns mit zentralen Ordnungs- und Handlungsproblemen des Staates der Industriegesellschaft befaßt haben. Der 
Gesetzesbegriff - so scheint mir - erweist sich wieder einmal als Schlüsselbegriff, wie schon gelegentlich in der Geschichte der Verfassungsdogmatik. Meine ausdrückliche Zustimmung gilt auch Stil und Form der Darstellung, von der (wenn ich das hinzufügen darf) zu hoffen ist, daß sie sich im Druck nicht zu Kompendien auswachsen, sondern den sympathischen Essaystil bewahren wird.

Bei der ansprechenden Originalität der drei Referate mag es kühn erscheinen, nach Gemeinsamkeiten zu suchen. Eine Reihe der in den Referaten behandelten Fragestellungen - auch Infragestellungen - lädt meines Erachtens dennoch dazu ein. In Anlehnung an die, wie ich meine, zutreffende Bemerkung von Herrn Kloepfer über das Abstand erzeugende juristische Denken möchte ich eine Gemeinsamkeit der Referate in der Distanz zum Rechtspositivismus sehen, zu dem vom Rechtspositivismus geschaffenen Begriff des Gesetzes, dessen Rationalität verhältnismäßig nahe steht $\mathrm{zu}$ den Vorstellungen vom Gesetz als ratio scripta; die Leistung des Rechtspositivismus sollte in unserer Rechtsdogmatik freilich ebensowenig verloren gehen, wie auch moderne Gesetzgebung immer noch eine gewisse Nähe zum Gesetz als ratio scripta bewahren möge.

Die Distanz der Referate zum Rechtspositivismus wird meines Erachtens einmal sichtbar in den wertmaterialen Akzentuierungen bei Herrn Eichenberger. Darauf könnte man breit eingehen. Ich möchte mich aber einem anderen Merkmal der Distanzierung vom Rechtspositivismus zuwenden, nämlich der Auffassung vom Gesetz als Instrument für alle möglichen Politiken. Herr Kloepfer hat ja das Gesetz auch als Experiment bezeichnet und hat dieses zu einer eigenständigen Rechtsfigur gesteigert. Vieles davon scheint mir ebenso mutig wie neu. Seine Beispiele halte ich für überzeugend.

Es gibt einen Sektor der Gesetzesproduktion, wo die Instrumentalität des Gesetzes besonders deutlich hervortritt: Das ist die Steuerung der Märkte für Getreide und für andere Agrarprodukte durch europäische Gesetze, nämlich durch die Verordnungen der EG. Nicht zu Unrecht hat Herr Novak gewußt, wo er Beispiele für absurde Gesetzesregelungen finden kann, und darin ist ihm zuzustimmen. Hier geht die Instrumentalität des Gesetzes bis in die Banalität einer alltäglichen Steuerung von Märkten. Und ich meine, in diesem Sektor der Gesetzesproduktion ist der früher - und ja auch heute noch zum Teil perhorreszierte Begriff des motorisierten Gesetzgebers keineswegs mehr ein Widerspruch zu dieser Funktion des Gesetzes, sondern eine logische Resultante des Gesetzes als eines Instrumentes der Steuerung. 
Gesetzgebungsverfahren - das ist meine letzte Bemerkung - vieles spricht sicher für eine gesetzliche Regelung, wie sie in Erwägung gezogen worden ist unter dem Eindruck der schweizerischen Erfahrungen. Nichtsdestoweniger scheint mir gerade die immer wieder zu beobachtende Verselbständigung des Gesetzgebungsverfahrens, für das Herr Kloepfer Beispiele gegeben hat, dafür zu sprechen, daß das Verfahren unbeschadet geschriebener Normierungen immer vor allem die Kunst des Juristen bleiben wird.

Vorsitzender: Vielen Dank, Herr Kaiser, für diese einführenden Bemerkungen in die Problematik. Der nächste Redner ist Herr Hans Schneider.

Hans Schneider: Die drei Referate haben, so meine ich, ein eindrucksvolles Bild von der Rolle der Gesetzgebung und des Gesetzes im modernen Rechtsstaat der drei betrachteten Länder geboten, von Ländern mit einer modernen Industriegesellschaft. Dabei scheint mir zu kurz gekommen zu sein der Umstand - weil ja von der rechtsstaatlichen Seite geblickt worden ist - daß es sich bei den Staaten um bundesstaatliche Systeme handelt. So ist bei unserem - die Bundesrepublik Deutschland angehenden - Gesetzgebungsverfahren gar nicht erwähnt worden: die Rolle des Bundesrates und damit die Rolle der Länderbürokratien. Das verstärkt gerade im Sinne von dem, was Herr Eichenberger vorgetragen hat, die Präponderanz der Exekutive. Ich glaube übrigens, daß das Bild von der Gesetzgebungspraxis in der Bundesrepublik für die letzten fünfzehn Jahre insofern einer Ergänzung bedarf, als politische Vorgaben auch für die Exekutive bestehen, nämlich durch den Umstand, daß wir eine Koalitionsregierung haben. Die Ministerialreferenten wissen schon, was ihr Minister und was das Kabinett wünscht. Selbst wenn sie noch keine verbindliche Weisung bekommen haben, können sie die Richtung abschätzen, wie parlamentarische Mehrheiten für ein Vorhaben zu gewinnen wären.

Das Zweite ist: man müßte in bezug auf die Gesetze noch stärker differenzieren: einmal nach Maßnahmegesetzen, die kurz aufgeblitzt sind, und nach Rechtsgesetzen, die also mehr auf Bewahrung und dauernde Stabilisierung ausgerichtet sind, aber auch nach Planungsgesetzen. Ob die „Experimentiergesetze" eine selbständige Kategorie bilden, wage ich zu bezweifeln. Dann müßte man auch einbeziehen das, was man sonst „,nur formelle Gesetze" nennt. Ich meine, daß der Begriff „Rechtsnorm“ nicht bloß generelle Regelungen betrifft (abstrakte Regeln), sondern auch Feststellungen grundlegender 
Art einschließt, so daß also der Rechtsnormbegriff und demgemäß der Begriff des Gesetzes für meinen Geschmack auch in der modernen Zeit die sogen. nur-formellen-Gesetze umfaßt. Schließlich müßte man auch noch bei den Änderungsgesetzen und den in ihrem Gefolge erscheinenden flankierenden gesetzlichen Maßnahmen - das ist ja meistens eine Fülle von Änderungen - und weiter bei denjenigen Gesetzen, die europäische Richtlinien in nationales Recht umsetzen (in der Bundesrepublik oft durch Rechtsverordnung dank einer gesetzlichen Ermächtigung) verschiedene Differenzierungen vorgesehen.

Ich halte es für richtig, daß Herr Kloepfer versucht hat, gegenüber dem Drang nach ständiger Änderung einige, auch verfassungsrechtliche Schranken zu ziehen, insbesondere weil, wie Herr Pieroth in seiner Habilitationsschrift überzeugend dargetan hat, die Unterscheidung zwischen echten und unechten rückwirkenden Gesetzen ein Gegenstand ist, den der Gesetzgeber manipulieren kann durch die Art der technischen Gestaltung, deren er sich bedient.

v. Simson: Nichts kann schöner sein, wenn man etwas reparieren will, als einen guten Handwerkskasten vorgesetzt zu bekommen. Und ich denke, in der Hinsicht ist das Referat von Herrn Eichenberger wirklich von wundervoller Gediegenheit gewesen. Trotzdem glaube ich, an einer Stelle noch eine Lücke zu sehen, die wir irgendwie ausfüllen müßten. Eugen Huber, wie Herr Eichenberger erwähnt hat, spricht von soziologischen Realien, in Beziehung auf welche die Gesetzgebung gesehen werden müßte, und zu den heutigen soziologischen Realien ist hinzugetreten, als etwas, was früher niemals zweifelhaft war, jetzt aber zweifelhaft zu werden beginnt, daß Teile der Bevölkerung und auch Teile der Verwaltung ein Auswahlprinzip walten lassen dahingehend, welche Gesetze sie als für sich für verbindlich ansehen, welche Gesetze erzwungen, welche befolgt werden sollen und welche nicht. Wir haben heute eine Situation, in der die Bindung an das Gesetz dem Verhältnismäßigkeitsprinzip unterworfen zu werden scheint. Man vergißt aber leicht, daß das Verhältnismäßigkeitsprinzip sich manipulieren läßt. Ich kann in der Tat 3000 Menschen aufbringen und es so unangenehm machen für die Verwaltung, daß keiner mehr wagt, ein unzweifelhaft geltendes Gesetz noch weiter zu erzwingen, daß er sogar als rückständig, als inhuman oder als hoffnungslos reaktionär bezeichnet wird, wenn er das tut. Das ist heute eine ganz große Gefahr für die Stellung der Gesetzgebung im Rechtsstaat.

Ich möchte hier nichts weiter tun, als dieses Thema einmal in unser Bewußtsein zu rufen und zu sagen, daß die Staatsrechts- 
lehrer nicht länger an dieser soziologischen Realität vorbeigehen können. Sie müssen sich überlegen, was daraus folgt, wenn der Rechtsstaat nicht allmählich wieder ein Staat des Rechts des Stärkeren werden soll.

Püttner: Mir ist als Gemeinsamkeit der Referate aufgefallen die Frage nach den Anforderungen, die an den Gesetzgeber gestellt werden, mit anderen Worten die Frage nach der Qualität der Gesetze und der Gesetzgebung (beides ist etwas Verschiedenes). Ich muß aber sagen, daß ich aus allen drei Referaten leider ein gewisses Unbehagen mitgenommen habe; ich weiß nicht, ob es uns gelingen wird, die Qualität von Gesetzen wirklich $\mathrm{zu}$ beurteilen. Können wir einteilen in gute und schlechte Gesetze? Können wir ein bestimmtes Gesetz oder vielleicht auch einen Gesamtzusammenhang von Gesetzen in einer bestimmten Situation insgesamt als qualitativ hochstehend, mittelwertig oder minderwertig einstufen? Möglicherweise kommt es - und Herr v. Simson hat das schon angedeutet - auch auf die Zeit und sozialen Umstände an. Ein bestimmtes Gesetz kann möglicherweise unter bestimmten Umständen seine Funktion voll erfüllen und damit (trotz sprachlicher Holprigkeit) ein gutes Gesetz sein; es kann aber möglicherweise in anderem Zusammenhang, wenn es seine Funktion nicht erfüllt, trotz glanzvoller Formulierung insgesamt ein schlechtes Gesetz sein. Oder sehe ich die Dinge falsch? Ich möchte diese Frage hier dahingestellt sein lassen, aber eines hinzufügen: Wenn man sich selbst an die Aufgabe heranwagt, ein Gesetz zu formulieren (ich hatte dieses Vergnügen kürzlich im Zusammenhang mit dem Schulrecht), dann erfährt man die Schwierigkeiten. Nichts ist schauervoller, als wenn man selbst zur Feder greifen muß, um ein Gesetz zu entwerfen. Wer das noch nicht getan hat, möge über mich also nicht den Stab brechen; und ich möchte eigentlich auch für den Gesetzgeber, für den vielgeschmähten, eine Lanze brechen und wage zu behaupten, daß die heutigen Gesetze nicht alle schlechter sind als die früheren Gesetze. Wenn man einmal den Maßstab der Weitschweifigkeit oder der Relevanz anlegen würde, so würde man in der Preußischen Gesetzessammlung oder sogar im "Heiligen" ALR so manche Stelle finden, die man als verbesserungsbedürftig empfinden könnte. Ich bin mir deshalb auch nicht ganz sicher, Herr Kloepfer, ob wir so unbedingt und pointiert von Übernormierung sprechen sollen, ob dieses Urteil nicht $\mathrm{zu}$ relativieren ist, hier und da Übernormierung, vielleicht hier und da auch nicht.

Interessiert hat mich, Herr Novak, das Verhältnis Gesetz und Verordnung. Auch hierzu nur eine ganz kurze Anmerkung: 
Mir scheint, daß die Frage, ob Gesetzgebung oder Verordnungsgebung gewählt wird, in der Praxis doch oft einen sehr großen Unterschied macht. Im Schulrecht etwa (ich muß immer auf dieses Beispiel zurückkommen) ist es ein Unterschied, ob eine inhaltlich sehr brisante Regelung öffentlich vorgelegt und einige Monate im Parlament beraten werden muß (dann kann man sich immerhin zu Wort melden), oder ob pünktlich zwei Tage nach Beginn der Sommerferien durch eine Schubladenverordnung vollendete Tatsachen geschaffen werden. Ich möchte also darauf aufmerksam machen, daß die Abgrenzung Gesetz und Verordnung nicht nur von theoretischen Gesichtspunkten, sondern gerade auch von diesen Umständen her beurteilt werden müßte. Gefreut hat mich dann noch, Herr Kloepfer, daß Sie die Distanz des Gesetzes hervorgehoben haben; ich sehe darin eine Beerdigung des Prinzips der Bürgernähe, das ja sonst immer betont wird, und freue mich, daß dies hier so öffentlich bekundet worden ist.

Grimm: Ich habe den Eindruck gewonnen, als stünde hinter Herrn Kloepfers Referat, auf das ich mich hauptsächlich beziehe, ein deutlicher Politikaffekt. Dieser Eindruck stellte sich bereits ein, als Herr Kloepfer, im Gegensatz zu den beiden anderen Referenten, die heutige Gesetzesfülle weniger auf strukturelle und insofern kaum beeinflußbare als auf politische und also prinzipiell veränderbare Faktoren zurückführte. Das halte ich nicht für richtig, ohne es in diesem Zusammenhang näher ausführen zu wollen. Mit Blick auf den Politikaffekt scheint mir aber eine der Begründungen des Referenten interessant. Er sieht die Ursache der Gesetzesfülle zum großen Teil darin, daß das Gesetz heute nicht mehr als Rechtsgesetz verstanden, sondern als politisches Lenkungsmittel benützt würde. Der Gegensatz zwischen dem Rechtsgesetz, das nur eine vorgegebene Gerechtigkeit positiviert, und dem Gesetz als politischem Instrument ist uns aus der Geschichte bekannt und wurde in der Geschichte vorwiegend zur Zurückdrängung politischer Rechtsetzungsbefugnisse eingesetzt. Solange damit die Rechtsetzungsbefugnisse absoluter Herrscher gemeint waren, mag das unsere Sympathie genießen. Wir müssen uns aber vor Augen halten, daß damit heute die Rechtsetzungsbefugnis des demokratischen Gesetzgebers zurückgedrängt wird, und insofern schiene es mir wichtig, Herrn Kloepfers Referat auf seine demokratische Verlustliste hin zu befragen. Der Eindruck eines Politikaffekts verstärkte sich noch im späteren Teil des Referats, wo Herr Kloepfer aus dem Übermaßverbot allerlei einschränkende Konsequenzen für den Gesetzgeber zog, von denen ich ohne weiteres einräume, daß sie 
als Maßstäbe guter Gesetzgebung meine uneingeschränkte Befürwortung hätten. Eine andere Frage ist, ob es sich um verfassungsrechtliche Maßstäbe handelt. Betrachtet man sie als verfassungsrechtliche Maßstäbe, so wird die Verfassung auf ihre rechtsstaatliche Komponente verengt, während die demokratische Komponente unberücksichtigt bleibt. Verfassung tritt nur noch als Einbindung von Politik und nicht zumindest auch als Ermöglichung von Politik in Erscheinung, und der Gesetzgeber findet sich auf der Stufe der Verwaltung wieder. Allein unter dieser Voraussetzung kann man, glaube ich, zu der Annahme kommen, daß jeder Gesetzesbestandteil, der hinter ein rechtsstaatliches Maximum zurückfällt, schon deswegen verfassungswidrig sei. Im übrigen, und das ist mein letztes Wort, damit ich die Zeit nicht überschreite, trügt wohl auch die Hoffnung von Herrn Kloepfer, auf diese Weise Politik stärker einbinden zu können. Man darf ja nicht vergessen, daß jede zusätzliche verfassungsrechtliche Einbindung des Gesetzgebers auf der anderen Seite als Kompetenzgewinn des Bundesverfassungsgerichts $\mathrm{zu}$ Buche schlägt, so daß es in Wirklichkeit nicht zu einer Eliminierung von Politik, sondern zu einer Verlagerung von Politik kommt, und zwar auf ein Organ, das, demokratisch gesehen, zumindest prekärer ist als der Gesetzgeber. Aber an dieser Stelle breche ich ab, denn damit bin ich wieder bei demjenigen Beitrag angelangt, den ich vor einem Jahr in Innsbruck geleistet habe.

Badura: Seit der Französischen Revolution ist das Gesetz der zentrale Begriff unseres Faches, und man kann vielleicht ohne besondere Übertreibung sagen, daß das Staatsrecht als Wissenschaft durch den Gesetzesbegriff der Französischen Revolution entstanden ist, und daß auch Freiheit und die Institutionen des Verfassungsstaates ohne diesen Begriff des Gesetzes gar nicht definiert werden können. Herr Eichenberger hat heute sein Referat ausdrücklich - und vielleicht die beiden anderen Referenten unausdrücklich - auf die These gestellt, daß wir es mit einem neuen Gesetzes- und Gesetzgebungsstaat zu tun hätten, und das Wort „neu“ steht in Anführungszeichen. Es ist offenbar der Staat, der durch demokratische und soziale Bedingungen charakterisiert ist und über den wir heute in der Beleuchtung gehört haben, daß sich dadurch Gesetzgebung und die Rolle des Gesetzes vielleicht geändert haben. Vielleicht ist sogar die These so zu sehen, daß eben in dem „,neuen“ Gesetzgebungsstaat die Staatsrechtswissenschaft und der Verfassungsstaat eigentlich nicht mehr auf den Eckstein des Gesetzesbegriffes gegründet werden können. Wenn das so wäre, würde in der Tat das, was wir heute gehört haben, der 
Versuch sein, von dieser Seite her die Folgerungen sowohl für die Institutionen wie auch für die Begriffe des Staatsrechtes zu suchen oder neu zu finden: Etwa wenn Herr Eichenberger hingewiesen hat darauf, daß die Gesetzgebung eine "beengte“ Funktion sei, daß wir nicht ausgehen können von der Vorstellung einer Art Omnipotenz und Nullsituation, wo der Gesetzgeber durch sein Fiat Entscheidungen treffen könnte, daß die Leistungsfähigkeit des Gesetzgebers usw. begrenzt sei, daß wir es im Vorfeld der parlamentarischen Entscheidung mit einem konsensualen Aushandeln der Gesetzgebung zu tun hätten. Das mögen Mosaiksteine sein für eine neue Lehre von Gesetz und Gesetzgebungsstaat. Ich glaube aber, und ich würde das jedenfalls behaupten, daß auch dieser neue Gesetzesund Gesetzgebungsstaat nach wie vor im Gesetz seinen Grundbegriff hat und daß ein Abgesang auf Gesetz und Gesetzgebung nicht richtig wäre, weder vom wissenschaftlichen, noch vom verfassungsrechtlichen, noch vom faktischen Standpunkt aus.

Wenn der Versuch gemacht wird, mit Hilfe von Postulaten wie "Notwendigkeit" von gesetzgeberischen Vorhaben oder dem Gebot, daß alle wichtigen Fragen eines Stoffes durch Gesetz geregelt werden sollen, der sogenannten Normenflut Herr zu werden, möchte ich einwenden, daß es sich dabei überwiegend um rein politische Maximen handelt. Ich glaube deshalb, daß die Rechtsprechung des Verfassungsgerichtes, soweit sie von der „Wesentlichkeit“ einer Materie ausgeht, nur insoweit auf justiziablen Kriterien beruht, als rechtlich faßbar ist, als sie aus rechtsstaatlichen Grundsätzen sich ableitet. Soweit dagegen von demokratischen oder politischen Gesichtspunkten die Rede ist, würde ich meinen, daß es sich um rein politische Maximen handelt. Das Gericht darf dem Parlament nicht die Entscheidung darüber wegnehmen, was eine „wichtige" Frage sei oder was denn gesetzgeberisch zu regeln eigentlich „notwendig“ sei. Das sind zentrale Fragen der Staatsraison, die nicht in die Entscheidung eines Gerichtes übergehen können. Vielleicht darf ich Herrn Eichenberger unter These 7 und Herrn Novak unter These 4 so verstehen, daß dieser Punkt dort berührt ist.

Der Gesetzgebungsstaat hat erstaunlicherweise insoweit zum Richterstaat geführt, als das Übermaß der Gesetzgebung zur Unklarheit der Rechtsordnung, zur mangelhaften Berechenbarkeit der Rechtsordnung und zu beträchtlichen Lücken der gesetzlich bestimmten Rechtsordnung geführt hat, die nur noch mit Hilfe der Verfassung gedeckt werden können, so daß der Anschein entstehen kann, wie wenn in die Mängel des 
Gesetzgebungsstaates der Richterstaat eintreten würde. Das ist allerdings nur eine scheinbare Rolle, die hier dem Gericht zuwächst und es ändert sich an der Grundgegebenheit dadurch nichts, daß die entscheidende Vollmacht in der Hand der Parteien im Parlament liegt. Die Lehre von Gesetz und Gesetzgebungsstaat ist im Kern also eine Lehre des Parlamentarismus, auch des parlamentarischen Regierungssystems, wie Herr Eichenberger in seiner letzten These dargelegt hat, und damit unter den heutigen Bedingungen letzten Endes des Parteienstaates.

Denninger: Ein paar Randbemerkungen zur Diagnose in dieser ersten Runde. Vielleicht ist es noch nicht allgemein bekannt, daß die Klage über die Normenflut uralt ist. Sie können sie nachweisen bei Leon Battista Alberti in der zweiten Hälfte des 15. Jahrhunderts mit hochaktuellen Wendungen. Sie können sie genauso nachweisen bei John Stuart Mill im 19. Jahrhundert, der schon über das pausenlose Rotieren einer wahnsinnig gewordenen Gesetzgebungsmaschinerie klagt, also in der Zeit des guten alten bügerlich-liberalen Rechtsstaats. Ich möchte auch behaupten, daß man zu beliebigen anderen Zeiten diese Klage über die Normenflut entdecken könnte, wenn man etwas nachbohrt. Das bringt mich dazu, und ich fühle mich durch die Referate in dieser Auffassung bestärkt, daß man hier das Problem der Quantität vielleicht zunächst einmal ausklammern sollte und sich ganz dem Problem der Qualität widmen sollte. Und wenn man das tut, dann müßte man zunächst einmal den Gesetzgebungsprozeß analysieren, sowohl nach seinen gesellschaftlichen wie nach seinen verfassungsrechtlichen Rahmenbedingungen. Ich bin - hier kann ich an das anknüpfen, was Herr Schneider eben bemerkt hat auch skeptisch hinsichtlich einer allzu krassen Unterscheidung zwischen Experimentgesetzen oder Testgesetzen, die sich natürlich rechtstechnisch etwas anders darstellen als normale Gesetze, und diesen letzteren; das ist, Herr Kloepfer, unbestritten. Aber hinsichtlich der Gesamtfunktion und Anlage, meine ich, tragen heute sehr viele Gesetze den Charakter von Versuchen in der Weise, $\mathrm{da} \beta$ sie eben versuchen, auf gesellschaftliche Probleme, die neu oder in neuer Gestalt aufgetaucht sind, eine neue Antwort zu geben. Deswegen sollte man vielleicht auch den Gesetzgebungsprozeß unter dem Stichwort „Trial and Error" oder „Versuch und Irrtum“ einmal analysieren. Ich habe das Gefühl, daß das im parlamentarischen Verfahren bis zu dem Punkt trägt, an dem dieser Proze $\beta$ vorzeitig abgebrochen wird. Oder etwas anders gesagt: $\mathrm{Zu}$ - 
nächst wird ein relativ einfaches, politisch artikuliertes Bedürfnis festgestellt; bei der Ausarbeitung zeigt sich dann die volle Komplexität der Rahmenbedingungen; nun wird aber die Sache nicht bis zu der endgültigen einfachen Klärung vorangetrieben, sondern man bleibt bei der Entscheidung praktisch in dieser Fülle, in dieser Komplexität von Alternativen und Einzelheiten stecken und sieht dann vor lauter Bäumen den Wald nicht mehr. Was wäre also zu tun? Die Diagnose bringt unvermeidlich den Ausblick auf Therapie mit sich. Vielleicht darf ich das gleich kurz anfügen: Herr Eichenberger hat sehr stark und - ich meine - sehr dankenswerterweise auf die Präparativverfahren hingewiesen. Nicht so stark wurde betont, und das darf ich hier vielleicht nachholen, die Notwendigkeit einer Vollzugskontrolle. Die Parlamente sollen sich doch einmal der Wirkungskontrolle ihrer Normen stärker annehmen, als das bisher geschehen ist. Man wird nämlich dann das Problem eines Vollzugsdefizits häufig vielleicht in der Weise lösen - ganz einfach - , daß man das Gesetz abschafft und nicht etwa die Verwaltung mit nun wieder neuen Gesetzen behelligen. Ich habe es sehr begrüßt - das als letzte, vielleicht generelle Bemerkung - , daß die Thematik heute morgen nicht so sehr unter institutionellem Gesichtspunkt, sondern auch unter zunächst primär funktionalem und normtheoretischem Gesichtspunkt angepackt wurde. Ich halte das in dieser Situation für vollkommen richtig. Wenn das so ist, dann wird man auch nicht so sehr auf die Kompetenzverteilung zwischen Exekutive, wobei ja noch gar nicht genauer definiert wurde, was damit im einzelnen gemeint ist, und Legislative, sprich Parlament, abzuheben haben, sondern man wird ganz stark nach dem Verhältnis zwischen Ministerialverwaltung qua Regierung oder Regierungshilfe und ausführender Verwaltung fragen müssen; und man wird eben dann Erscheinungen notieren müssen, wie die, daß das Gesetz im Ministerium schon wieder geändert wird, während unten die Vollzugserlasse noch nicht heraus sind und noch nicht bekannt geworden sind. Welche Konsequenzen das für eine geordnete rechtsstaatliche Verwaltung hat, liegt, meine ich, auf der Hand.

Roellecke: Ich möchte mich in konstruktiver Kritik versuchen und bitte deshalb um Nachsicht, wenn ich die Gliederung der Diskussion überschreite.

Ich habe bei allen drei Referaten eine Analyse des Rechtsstaates vermißt. Nach meiner Meinung genügt es nicht zu sagen, Rechtsstaat ist das, was wir haben. 
Herr Kloepfer hat für die Staatsanalyse allerdings zwei Stichworte angeboten: Distanz und Nähe, und er hat versucht, den Unterschied zwischen Rechtsstaat und Sozialstaat an diesen Stichworten zu verdeutlichen. In seinen weiteren Ausführungen hat er aber von den beiden Stichworten keinen Gebrauch mehr gemacht. Vielmehr hat er es unternommen, die Gesetzgebungspraxis über das Begriffspaar „Flexibilität und Stabilität" zu analysieren. Das zeigt für meinen Geschmack, daß Distanz und Nähe wahrscheinlich untaugliche Katalysatoren sind.

Ich meine, es hängt vom Rechtsstaatsbegriff $a b$, wie man die derzeitige Gesetzgebung einschätzt und welche Möglichkeiten man sieht, sie zu verbessern. Deshalb wage ich es, Ihnen - mit allen Vorbehalten - einen Rechtsstaatsbegriff anzubieten, der das Gesetzgebungsproblem strukturieren könnte. Dieser Begriff lautet: Ein Rechtsstaat ist ein Staat, der Rechtsänderungen durch Recht steuert.

Auf der Basis dieses Begriffes würde sich das Problem „Gesetzgebung im Rechtsstaat" in die Frage verwandeln: Wie bewirkt das Recht es, Rechtsänderungen zu steuern? Die von allen Referenten beklagte "Normenflut" wäre dann ein Zeichen dafür, daß die Steuerungskapazität des Rechtes nicht mehr ausreicht. Dafür gibt es auch einen Beleg aus der Gesetzgebungsdiskussion. Das ist die Wesentlichkeitstheorie, die ich nicht für eine Theorie, sondern für eine Fehlstelle in der Verfassungsdogmatik halte. Die entscheidende Frage würde also lauten: Wie läßt sich die Steuerungskapazität des Rechtes, insbesondere des Verfassungsrechtes, verbessern?

Bisher hat die Dogmatik immer nur gefragt: Wie können wir die Durchsetzung des Rechtes, des Gesetzes, verbessern? Herr Eichenberger hat nun dankenswerterweise - ich halte das für einen echten Gewinn - darauf hingewiesen, daß man beide Seiten, sowohl die Vorbereitung wie die Durchsetzung des Gesetzes, betrachten müsse. Mit dem Schlagwort von Souveränität des Parlamentes ist dieser Forderung nicht Genüge getan.

Freilich, wenn man beide Seiten (und insbesondere die Seite der Gesetzesvorbereitung) verbessern will, dann erscheint es nicht besonders erfolgversprechend, wiederum nur mit Rechtsregeln zu arbeiten. Denn offenbar hat das bisherige Recht nicht ausgereicht, das Auftauchen der Gesetzgebungsschwierigkeiten zu verhindern. Man müßte deshalb nicht nur die rechtlichen, sondern auch die sozialen Voraussetzungen moderner Gesetzgebung überprüfen. Allerdings tauchen dann neue Probleme auf. Um das an einer These von Herrn Kloepfer 
zu demonstrieren: Wenn die Übernormierung, also die Gesetzesflut, auch dadurch verursacht wird, daß es zu viele Leute gibt, die im Gesetzgebungsverfahren arbeiten, dann könnte man schließen: Wenn man die Gesetzgebungsflut eindämmen will, muß man die Gesetzgebungskapazität verringern, zum Beispiel die Ministerien halbieren. Oder man könnte erwägen, das Einbringungsrecht der Bundesregierung und des Bundesrates zu beschneiden. Wir sind uns wahrscheinlich einig, daß solche Maßnahmen vielleicht effektiv, aber unangenehm wären, weil wir befürchten müßten, daß eine rigorose Einschränkung der Gesetzgebungskapazität auch die Regelung von Sachproblemen ausschließt, die geregelt werden sollten. Das heißt, das neue Problem wäre die Gewährleistung einer sachangemessenen Problemlösungskapazität.

Ich muß gestehen, auch ich kenne das Normalmaß nicht, auf das die Gesetzesflut einzudämmen wäre. Solange ich aber das Normalmaß nicht kenne, halte ich mich lieber an das Prinzip des ,muddling through“.

Häberle: Herr Vorsitzender, verehrte Kollegen!

Ich möchte mich zum ersten Gliederungspunkt auf zwei Probleme konzentrieren: Erstens auf die Frage, welche verfassungsstaatlichen Aufgaben die parlamentarische Gesetzgebung in der pluralistischen Demokratie und im sozialen Rechtsstaat einer Industriegesellschaft hat, und zweitens: Wessen Werk ist eigentlich das Parlamentsgesetz, wenn man sein Zustandekommen realistisch sieht und dessen Pluralismus erkennt? Zunächst zum ersten Punkt: Hier sollten wir die Zeitdimension einführen; Herr Kloepfer hat dies in Leitsatz 8 überzeugend getan, insofern er der "Gesetzgebung auf Zeit" einen eigenen Rang zumißt. Gesetzgebung ist in der pluralistischen Demokratie doch auch Verarbeitung sozialen Wandels, kompromißhafte Lösung sozialer Konflikte in der Zeitdimension. Hier kommt die politische, demokratische Seite ins Spiel, auf die Herr Badura und andere Vorredner schon zu sprechen kamen. Im übrigen ist Herrn Eichenberger zuzustimmen, insofern er der Gesetzgebung - differenziert je nach Sachbereich - die Aufgabe der Verwirklichung der Grundrechte, auch nach der Verfahrensseite hin zugewiesen hat, also den Rechtsschutz. Ich erinnere an die Aufgabe der Schlichtung der Konflikte zwischen öffentlichen und privaten Interessen, bekannt als Gemeinwohlauftrag der Legislative, an die Realisierung des sozialen Rechtsstaates usw. Hinzu treten Gerechtigkeitsmomente, die auch bei Herrn Eichenberger mehr oder weniger versteckt ins Spiel kamen. In bestimmten Bereichen ist Gesetzgebung auch heute nicht bloß ein formales Verfahren in 
möglichst großer Transparenz und Öffentlichkeit. Vielmehr sollten wir vorletzte, mitunter letzte Gerechtigkeitswertungen i.S. inhaltlicher und verfahrensorientierter Direktiven im Blick behalten, differenziert nach Lebensbereichen und Gesetzestypen.

Ein Wort zum zweiten Punkt, zu den pluralistischen Faktoren und Impulsen im Blick auf Gesetzgebung als Proze $\beta$ weit vor dem und über das Parlament hinaus. Herr Eichenberger hat eindrucksvoll die „Präparativphase“ herausgearbeitet. Wir müßten sie nach formellen und informellen Vorgängen und Mitwirkenden aufschlüsseln und etwa rechtssoziologisch die gesetzgebungspolitische Frage nach dem „Regelungsbedarf" stellen. Besitzen wir Instrumente um festzustellen, ob ein Regelungsbedarf für eine gesetzliche Normierung vorliegt oder nicht? Dies diente der Eindämmung der Normenflut. Einflußreich wird eine Fülle von formalisierten und informellen Faktoren und Impulsen wie Wissenschaft, private Entwürfe oder öffentliche Meinung: für den Entstehungsprozeß des Gesetzes einerseits, den Vollzugsproze $\beta$ andererseits, Herr Denninger hat die Vollzugsforschung schon erwähnt. Erweiternd hinzufügen möchte ich die Nachbereitungsphase. Das Gesetz ist ja auch hier nicht nur das Werk des „formalen“ Gesetzgebers, des Parlaments. Sobald das Gesetz verkündet ist, wird es von einer Vielzahl von gestaltenden Faktoren interpretiert: das Gesetz entgleitet dem Gesetzgeber, unbeschadet möglicher Novellen als Nach- und Vorbereitung. Wir sollten hier, Herr Eichenberger, nicht nur die Exekutive sehen, die Sie für den Vorbereitungsprozeß mit Grund herausgestellt haben. In der Nachbereitungsphase hat wesentlich die Rechtsprechung das Wort und die Arbeit, besonders auch in Gestalt von Appelljudikatur. Es gibt nicht nur verfassungsgerichtliche Appellentscheidungen mit Aufträgen für den Gesetzgeber, etwa zum „Nachfassen“, vorbehaltlich seiner soziologischen Grenzen. Es gibt "Anstoßjudikatur" auch beim BAG und beim BGH, jüngst etwa im Datenschutzrecht. - Herrn Kloepfers bürgerfernen Schlüsselbegriff der „Distanz“ möchte ich im übrigen nicht übernehmen. Da er in Trier als Tagungsleiter und Referent indes ein „Platzhirsch" ist, wage ich keinen weiteren Widerspruch (Heiterkeit). Indes haben mich alle drei Referenten, auch Herr Novak, beeindruckt durch ihren Mittelweg: Ihr Bild der heutigen Gesetzgebung hält sich in der Mitte zwischen Kritik und Zustimmung. Das moderne Gesetz wird nicht verteufelt i.S. von Verfalltheorien, es wird aber auch nicht einfach unkritisch hingenommen. Vielmehr werden Wege gesucht im Blick auf eine möglicherweise bessere verfassungsstaatliche 
Gesetzgebung, die zugleich der Normalität einer pluralistischen Demokratie und ihren Anforderungen gerecht wird.

Burmeister: Die Referenten mögen es mir nachsehen, wenn ich mich zustimmender Bemerkungen zur Analyse der Gegenwartslage der Gesetzgebung im Rechtsstaat enthalte, sondern mich hier auf einen zusätzlichen Aspekt beschränke: Namentlich die von Herrn Kloepfer aufgezeigten Grenzen der Gesetzesänderung, die heute - darin ist der Gegenwartsanalyse von Herrn Kloepfer zuzustimmen -, im Mittelpunkt der Diskussion um den Auftrag der gesetzgebenden Gewalt stehen, sind alle geprägt von einem Gesetzesbegriff, der - Herr Badura hat darauf hingewiesen - auf die Französische Revolution zurückgeht. Dieser Gesetzesbegriff ist wesenhaft geprägt durch seinen Bezug auf den staatlichen Außenrechtskreis, durch seinen Individualbezug. D. h. vom Gesetzesbegriff her erfaßt sind im Grunde nur jene Regelungen, die im Sinn der klassischen Trennung von rechtserfülltem staatlichem Außenbereich und rechtsfreiem Innenbereich Gegenstände der Außenbeziehungen zum Individuum regeln. Dementsprechend sind auch alle rechtsstaatlichen Kautelen, die wir bislang entwickelt haben und die auf Kontinuitätswahrung angelegt sind, in erster Linie auf Individualrechtsschutz angelegte Kautelen. Nicht dagegen ist berücksichtigt, daß durch die Erstreckung des Gesetzesvorbehaltes auf den binnenstaatlichen Organisationsbereich gewissermaßen ein neuer Typus von Gesetzen geschaffen worden ist, die allein staatsgerichtet sind und nur die Regelung der Kompetenzen staatlicher Untergliederungen zum Gegenstand haben. Ein Schlüsselbeispiel für diesen neuen Typus von Organisationsgesetzen sind die Gebietsreformgesetze. Bei ihnen hat sich denn auch sehr schnell herausgestellt, daß die kontinuitätswahrenden Kautelen andere sind als die im klassisch rechtsstaatlichen Instrumentarium angelegten Elemente wie Übermaßverbot, Erforderlichkeit, Geeignetheit, Voraussehbarkeit und dergleichen mehr. Jedenfalls scheint es mir wichtig zu sein, sich bei der notwendigen Kompromißlösung zwischen rechtsstaatlicher Kontinuität und angemessener Flexibilität zu vergegenwärtigen, daß wir es eben nicht mehr mit einem einheitlichen außenrechtsbezogenen Gesetzesbegriff zu tun haben, sondern mit zwei grundverschiedenen Typen von in die Form des Gesetzes eingebundenen staatlichen Regelungen: nämlich einerseits den außenbezogenen Organisationsregelungen und andererseits den innenbezogenen Organisationsregelungen. Es scheint mir notwendig zu sein, klarzustellen, daß die Frage der Veränderbarkeit beider Gesetzestypen 
nach grundsätzlich verschiedenartigen Kategorien $\mathrm{zu}$ beantworten ist.

Schwabe: Bei dem, was ich sagen wollte, hat mir Herr Grimm schon vorgegriffen, so daß ich mich kurz fassen kann und nur noch eine Bitte äußern kann an Herrn Kloepfer, eine Bitte um etwas Veranschaulichung, sofern er aus der Vorbereitung seines Referates über Material verfügt. Wir sind ja, glaube ich, in der Tat permanent in der Gefahr, daß wir bei diesen und ähnlichen Beratungsgegenständen politologische Maximen verfassungsrechtlich einkleiden und dann leicht überfordern. Die Frage ist dann, glaube ich, konkret immer die, ob sich mit jenen Maßstäben, die Sie, Herr Kloepfer, uns skizziert haben und ich glaube, es sind überwiegend neue Maßstäbe gewesen -, ob sich damit in plausibler Weise verfassungsrechtlich arbeiten, das heißt judizieren läßt. Voriges Jahr sind die Referenten zum Thema der Steuergesetzgebung - ich glaube mit Recht - gefragt worden, ob die von ihnen entwickelten Maßstäbe in einem bestimmten konkreten Fall zur Verfassungswidrigkeit führen würden. Herr Kirchhof hat dann zum Schluß ein oder zwei Beispiele beigebracht, und meine entscheidende Frage an Sie wäre, ob Ihnen Anschauungsbeispiele begegnet sind, bei denen Sie sagen könnten, hier wäre es praktizierbar und hier wäre es überzeugend, wenn da mit meinen Maßstäben das Bundesverfassungsgericht mal dazwischen gefahren wäre.

Schäffer: Es ist heute schon mehrfach die Frage nach den Gemeinsamkeiten der Referate angeklungen. Mir will scheinen, daß ein unausgesprochener Grundkonsens der Referate und auch der Diskussion darin besteht, daß bei der Frage nach der Optimierung oder Verbesserung der Qualität der Gesetze keine einschneidenden Änderungen in den Grundstrukturen des demokratisch-parlamentarischen Verfassungsstaates westlicher Prägung erörtert werden können, sondern daß wir uns im wesentlichen in systemimmanenten Überlegungen bewegen müssen. Auf dieser Grundlage ein paar Bemerkungen, zunächst zu dem glänzenden Referat von Herrn Eichenberger. Herr Eichenberger, Sie haben in besonders anschaulicher und differenzierter Weise das Übergewicht oder eine Quasimonopolstellung der Exekutive insbesondere auf dem Gebiet der präparativen Phase der Gesetzgebung herausgearbeitet und gemeint, es gäbe hierzu eigentlich gar keine Alternative. Hier möchte ich einen kleinen Zweifel anmelden und zu überlegen geben, ob es nicht denkbar wäre, durch die Installierung eines 
- wenn auch kleinen - Hilfsdienstes der Gesetzgebung, ein gewisses Gegenüber und Gegengewicht hierzu zu schaffen. Als besonders wohltuend habe ich in Ihrem Referat empfunden, daß Sie das Selbstbewußtsein und die Selbstverantwortlichkeit des Parlaments als einen wesentlich bestimmenden Faktor in der politischen Willensbildung im Wege der Gesetzgebung hervorgehoben haben. Als ganz entscheidend haben Sie die Weichenstellungen in der präparativen Phase bezeichnet und aufgezeigt, welche Verbesserungsmöglichkeiten sich hier anbieten. Sie haben von einer Normierung der Normierung gesprochen, allerdings offengelassen, welche Stufe eine solche Normierung einnehmen müßte. Diese Frage hängt aber, wie ich glaube, unausweichlich mit der Frage der Sanktionierung oder der Kontrolle, insbesondere eben nicht der Selbst-, sondern der Fremdkontrolle solcher Normierungen zusammen. Letzten Endes stellt sich die Frage, ob dies auch eine Basis der Normenkontrolle sein müßte oder könnte. Eine Frage, der wir nicht ausweichen können, und ich möchte in diesem Zusammenhang vor einer Überdehnung von Verfassungspflichten und Kontrollmaßstäben warnen. Zum einen, weil die Durchnormierung von Vorfeldern nach den Erfahrungen der Organisationssoziologie nur dazu führen kann, daß neue Vorfelder eröffnet werden; man wird eben dann neue Vorfelder für politische Verhandlungen finden, etwas, das sicher nicht im Sinne der Erfinder sein kann. Und zum anderen gilt die grundsätzliche Überlegung, daß eben letzten Endes der Gesetzgeber die entscheidende politische und staatsleitende Funktion hat, und daß hier die inhaltlichen Normierungen nicht bis ins Letzte getrieben werden können. Zum Schluß noch eine Frage an Herrn Kloepfer: Sie haben in Ihrem Referat insbesondere die möglichen Präjudizierungen eines künftigen Gesetzgebers verpönt. Ich habe die These nicht recht verstanden. Man kann sie vielleicht verfassungspolitisch diskutieren. Mich würde interessieren, wie Sie diese These als eine meßbare Verfassungspflicht begründen? Danke.

Rauschning: In der Vereinigung der Deutschen Staatsrechtslehrer halte ich es für eine legitime Argumentationsebene, auch von der Staatslehre her zu argumentieren, und ich meine nicht, daß wir unsere Diskussion darauf beschränken können, Maßstäbe fürs Bundesverfassungsgericht an den Gesetzgeber zu diskutieren; und insofern habe ich insbesondere die Ausführungen gerade zur Staatslehre bei Herrn Eichenberger und auch die Kunstlehren, die in den anderen Referaten dann angeboten oder behandelt wurden, als eine besondere Bereicherung empfunden, und ich meine nicht, daß wir nur 
nach Maßstäben über Nichtigkeit oder Nichtnichtigkeit suchen sollten.

Wielinger: Ich spreche nicht nur als Mitglied dieser Vereinigung, sondern auch als einer jener Beamten, die in der Gesetzgebungsvorbereitung tätig sind; in Österreich „Legisten“ genannt. Ich bin in einer Landesverwaltung der Leiter des Verfassungsdienstes. Das hat nichts mit dem Verfassungsschutz zu tun; der Verfassungsdienst ist mit der Gesetzgebungsvorbereitung und der verfassungsrechtlichen Beratung der Regierung befaßt. Auf Bundesebene gibt es den Verfassungsdienst im Bundeskanzleramt. Sie werden verstehen, daß ich aus dieser Position eine spezifische Sicht von manchem, was hier gesagt worden ist, habe. Erlauben Sie mir daher einige Bemerkungen:

Zunächst zu der in allen Referaten angesprochenen Gesetzgebungslehre. Es wäre für die Vorbereitung von Gesetzen sehr schön, wenn es so etwas wie eine Gesetzgebungslehre gäbe; ich meine allerdings, das wird es nur im Sinne einer Lehre, die die Gesetzestechnik verbessern hilft, und einer Rechtstatsachenforschung geben können. Eine Gesetzgebungslehre, die den Inhalt der Gesetze zum Gegenstand hat, wird es meines Erachtens - und damit deklariere ich meine methodologische Position - nicht geben können, weil die Formulierung von Sollenssätzen stets nur Aufgabe von Rechtserzeugungsorganen, nie aber eine Aufgabe der Wissenschaft sein kann.

Zum Thema Gesetzesflut möchte ich folgendes anmerken: Hans Kelsen hat in der ersten Auflage von ,Wesen und Wert der Demokratie" gesagt, er meine, in einem wohlgeordneten Staatswesen werde es nur da und dort einiger Korrekturen an der bestehenden Ordnung bedürfen. In der zweiten Auflage hat er das schon nicht mehr gesagt. Da war die in der Zeit nach dem Ersten Weltkrieg relativ weit verbreitete euphorische Meinung, Bürokratie und Gesetzesflut könnten überwunden werden, schon verflogen. Ich meine, wir sollten uns der Erkenntnis, daß die Zahl der Rechtsvorschriften nicht wesentlich reduziert werden kann, nicht verschließen. Herr Eichenberger hat gefordert, es möge nur wirklich Normierbares normiert werden und hat in diesem Zusammenhang immer wieder vom richtigen Recht gesprochen. Ich bitte, zu explizieren, was darunter verstanden werden könnte. Denn zu wissen, was das richtige Recht ist, wäre für den Legisten sehr schön. In der Praxis erleben wir nämlich, daß das tatsächlich gesetzte Recht das Ergebnis eines oft recht obskuren und mitunter dem Freistilringen ähnlichen politischen Prozesses ist. 
Was die Durchsetzung des Rechts anlangt, erlaube ich mir einen historischen Hinweis: In Österreich war es nach 1862 nicht möglich, die Besetzung des Parlamentes durch Ungarn durchzusetzen; und die Grundrechte, die 1867 beschlossen worden sind, waren, was die Bestimmungen über religiöse Freiheitsrechte anlangt, in Tirol bis 1938 - oder wenn man die österreichische Rechtsordnung in Betracht zieht, bis $1945-$ praktisch nicht anwendbar. Das soll zeigen, daß dieses Problem keineswegs neu ist, soll aber nicht heißen, daß man ihm gegenüber resignieren soll. Gerade bei der Gesetzesvorbereitung muß man die Anwendbarkeit immer im Blick haben. Man darf sich keineswegs mit inhaltsleeren Alibigesetzen begnügen. Auf diesem Gebiet ist allerdings eine bedenkliche Entwicklung im Gange: Immer mehr findet leeres pathetisches Gerede in Gesetze Eingang. Dies schwächt die Glaubwürdigkeit des demokratischen Gesetzgebers und damit letztlich die Position des demokratischen Rechtsstaates.

Nun noch eine abschließende Bemerkung zu Herrn Kloepfer. Was die Frage der Änderung von Gesetzen anlangt, teile ich die Meinung von Herrn Grimm. Wie in einem demokratischen Staat dem von der Mehrheit legitimierten Gesetzgeber das Recht zur Gesetzesänderung beschnitten werden sollte, ist mir nicht klar. Was das Gesetz als Experiment anlangt, schließe ich mich der Ansicht von Herrn Denninger an. Für Gesetze mit Experimentcharakter gibt es wieder ein schönes historisches Beispiel aus Österreich: Es gab vor dem ABGB das westgalizische Gesetzbuch, das ausdrücklich als Experiment bezeichnet wurde.

Lerche: Auch eine kleine sozusagen legistische Frage an Herrn Kloepfer, ohne damit zum Ausdruck zu bringen, daß ich das für Jägerlatein halte (Gelächter), was Sie uns berichtet haben. In Ihrer bekannten Organisationstatkraft haben Sie ja nicht nur die Rechtsfigur des Experimentiergesetzes entwikkelt, sondern, wenn ich recht sehe, eine ganze Experimentierlehre. Auch das Bundesverfassungsgericht hat in jüngster Zeit - wenn wir etwa an die Rundfunkentscheidung denken dazu einiges beigesteuert, so etwa den Satz, daß sogar Versuche, wenn sie Wesentliches enthalten, der Gesetzesform bedürfen - wobei interessanterweise gewisse Einschränkungen aus der Kalkarentscheidung nicht mehr auftauchen. Darüber sind Sie aber hinausgegangen und haben ein ganzes Gespinst von einzelnen Rechtsregeln und Rechtsaussagen auf dieses Experimentierfeld gelegt - gewissermaßen so als eine Art Test auf Akzeptanz -. Ich frage mich, ob hier nicht tatsächlich zu viel verrechtlicht worden ist? Wie kommt man damit im 
einzelnen in der Praxis durch? Sie sagen zum Beispiel: „Möglichst keine vollendeten Tatsachen", möglichst Testerforderlichkeit, Geeignetheit und dergleichen. Sie nehmen als Beispiel etwa die Pilotprojekte auch im Medienbereich. Diese Pilotprojekte im Medienbereich müssen gerade - wenn sie überhaupt sinnvoll sein sollen - unter Umständen so aussehen, daß gewisse vollendete Tatsachen geschaffen werden. Etwa dann, wenn nicht anders herausgebracht werden kann, ob "Schäden" (Schäden in Anführungszeichen) erzeugt werden. Ohne ein solches Inkaufnehmen von nicht unabsehbaren, aber doch absehbaren Schäden ist ein derartiges Experimentiergesetz in sich selbst nicht recht sinnvoll. Ich glaube, daß das nicht nur eine Erscheinung dieser Pilotprojekte im Medienbereich ist, sondern eine allgemeinere Erscheinung, die schon in Frage stellt, ob wir in der Tat ein solches ganzes Gitter von einzelnen rechtlichen Aussagen über diesen Bereich des Experimentiergesetzes wirklich drüber fallen lassen sollen.

Dagtoglou: Die Rechtsfigur des Gesetzgebungsexperiments ist auf sehr viel Interesse gestoßen. Tatsächlich ist der Begriff sehr fraglich und mindestens schillernd. Es ist bereits wiederholt gesagt worden, daß gewissermaßen jedes Gesetz oder jedes zweite Gesetz ein Experiment ist, zumal in unserer Zeit des ständigen Wandels und des permanenten Zweifels. Aber wie sollte man eigentlich und wann kann man ein Gesetz als Experiment betrachten? Soll sich ein jedes Gesetz sagen, daß es ein Experiment ist? Ist ein Experimentgesetz nur das, was sich ausdrücklich als Experiment bezeichnet? Dann soll man auch weiter unterscheiden. Ich meine: Worin liegt eigentlich nun der experimentelle Charakter eines Gesetzes? Im Gegenstand selbst oder in der örtlichen oder in der zeitlichen Begrenzung? Die meisten Fragen betreffen natürlich die Zulässigkeit. Diese hängt zunächst einmal von der Kategorie dieses Experimentgesetzes ab. Am wenigsten Bedenken entstehen bei Gesetzen, die einfach eine zusätzliche Option eröffnen, sagen wir, die Möglichkeit einer einstufigen Juristenausbildung zu der bestehenden zweistufigen. Dann kann jeder wählen. Da gibt es wohl keine Bedenken. Aber bereits darin besteht schon ein Zweifel, der etwas anderes betrifft, nämlich was man vielleicht Irreversibilitätsverbot nennen könnte. Zunächst einmal kann man sagen, für die Betroffenen ist ein Gesetz oft immer irreversibel. Wer die einstufige Juristenausbildung durchgemacht hat, kann sie ja wohl nicht wiederholen, das ist praktisch nicht zumutbar. Dann gibt es ja ganze Bereiche, wo praktisch alles irreversibel ist, zum Beispiel im Baurecht. Wie kann man also Grenzen ziehen? Wenn freilich der Gesetzgeber einen Gegen- 
stand überhaupt nicht oder nur bis zu einem gewissen Maße regeln darf, darf er sich wohl auch auf kein Gesetzexperiment einlassen.

Vorsitzender: Danke schön, Herr Dagtoglou. Direkte Erwiderung von Herrn Hans-Peter Schneider.

H.-P. Schneider: Eigentlich keine Erwiderung, sondern eine kurze Ergänzung. Wer aus einem Bundesland kommt, das seit nunmehr dreißig Jahren mit einer „vorläufigen Verfassung“ lebt, das „Vorschaltgesetze“ im Hochschulrecht kennt, und wer von einer Universität kommt, die nicht bloß die einstufige Juristenausbildung erprobt, sondern auch selbst nur eine, ,vorläufige Grundordnung" besitzt, hat überhaupt keine Probleme mit „Experimentiergesetzen“, weil er weiß, daß solche Gesetze oft langlebiger sind als Gesetze, die nicht so bezeichnet werden. Deshalb bin ich der Meinung, wir sollten den Begriff des „Experimentiergesetzes“ als verfassungsrechtliche Kategorie verabschieden, weil diese Gesetze den gleichen Maßstäben unterliegen müssen wie alle übrigen Gesetze auch. Man kann ein Gesetz nicht deswegen für weniger verfassungswidrig erklären, nur weil es auf eine bestimmte, statt auf unbestimmte Zeit gelten soll und der Erprobung neuer Erkenntnisse dient. Art. 3 Abs. 1 GG läßt beispielsweise mit dem Schutz legislativer "Gestaltungsfreiheit" und dem Evidenzmaßstab auch da genügend Spielraum für differenzierende Lösungen, wo der Gesetzgeber vor einer endgültigen Regelung glaubt, noch weitere praktische Erfahrungen sammeln zu müssen.

Doehring: Mir ist in den drei Referaten etwas zu kurz gekommen, was Herr $v$. Simson schon angedeutet hat, und ich möchte das nochmals zum Ausdruck bringen und unterstreichen. Wir haben gesprochen, und die Referenten haben gesprochen von guten und schlechten Gesetzen und guter und schlechter Gesetzesherstellung, und mich bewegt dabei die Sorge um den Verlust der Autorität des Gesetzes. Dieser Verlust kann natürlich auch auf schlechter Gesetzesherstellung beruhen. Aber ich glaube, der Autoritätsverlust des Gesetzes - wenn er vorhanden ist, und ich meine, ihn zu sehen -, liegt vielleicht in erster Linie doch an einem Mangel an Gesetzestreue der Exekutive selbst; ich würde auch nicht einmal die Gerichtsbarkeit gänzlich von diesem Vorwurf ausschließen wollen, denn ich sehe, wie weich die Gesetze gehandhabt werden. Nun, dieser Effekt wird vielleicht dadurch verstärkt, daß, wie Herr Eichenberger sagt, die Gesetze ihren wahren Urheber letztlich nicht in der Legislative, sondern in der Exekutive haben, und 
das leitet über zu der Frage: Nimmt die Dignität des Gesetzes nicht auch dann ab, wenn die klassische Trennung der Gewalten abnimmt? Das aber ist natürlich ein Dilemma oder - man mag es auch begrüßen - ein Faktum unserer parlamentarischen Demokratie. Wenn zwischen Parlamentsmehrheit und Exekutive im Grunde kein Spannungsverhältnis mehr besteht, wird das Gesetzesprodukt sicherlich disponibler für die Exekutive, weil keine rechte Kontrolle einsetzt. Wir haben auch im Europarecht keine strikte Gesetzestreue. Viele Vorschriften des Europarechts werden von den Mitgliedstaaten doch auch nicht gerade vorbildlich angewendet. Vielleicht liegt das daran, daß die klassische Art der Gewaltenteilung, die für die europäischen Gemeinschaften nicht passen mag, dort auch nicht stattfindet. Aber dieser Mangel, wenn er der parlamentarischen Demokratie immanent sein sollte, ist natürlich im Rahmen des bestehenden Grundgesetzes wohl nicht abzuwenden. Wir hatten Systeme, die auch nicht funktionierten, wobei vielleicht andere Gründe wesentlich waren. Es sei erinnert an Schwierigkeiten der Weimarer Verfassung oder der Verfassungen der USA und Frankreichs. Die gegenseitige Kontrolle der Gewalten war immer ein nützliches Regulativ. Für den Staatsbürger, wenn er eine Norm beachten soll und wenn die Verwaltung ihm mitteilt, was er darf und was er nicht darf, ist es sicherlich nicht so wichtig, ob die anordnende Verwaltung sich auf eine Vorschrift des Europarechts, auf eine Rechtsverordnung oder auf ein formelles Gesetz beruft; der Staatsbürger weiß jedenfalls, wie er sich verhalten soll. Vielleicht sind für ihn, den Staatsbürger, unsere subtilen Unterscheidungen der Gesetzesarten nicht so wichtig, wie es auch heute noch eine starke Kontrolle im System der klassischen Gewaltenteilung wäre. Das ist natürlich eine rechtspolitische Frage, und ich bin mir darüber im klaren, daß unser Grundgesetz die von mir vermißte Spannung selbst aufgehoben hat.

Frowein: Erlauben Sie mir, zunächst mit zwei ausländischen Beispielen den Beleg zu versuchen, daß die rechtsstaatliche Funktion des Gesetzes, die Herr Eichenberger ja zu Anfang sehr stark herausgestellt hat, noch immer höchst aktuell ist. In dem Urteil eines britischen Gerichts, das sich mit der Frage zu beschäftigen hatte, ob die Tatsache, daß in Großbritannien Telefone ohne gesetzliche Grundlage abgehört werden, zu einer Rechtswidrigkeit führt, hat das sehr angesehene, damit befaßte Gericht gesagt, in England gelte der Grundsatz, daß das, was gesetzlich nicht verboten sei, erlaubt sei. Deswegen also könnten Telefone abgehört werden. Wir mögen darüber lächeln. Wenn wir aber uns dem Problem stellen, wie wir mit der Affäre 
Traube zurechtgekommen sind, stellt sich in meinen Augen sehr wohl die Frage, ob diese Aktualität nicht weiter auch uns als Vereinigung beschäftigen muß. Hier haben ja alle politischen Kräfte in der Bundesrepublik Deutschland gemeinsam gesagt: „Wir können, wir wollen, wir dürfen kein Gesetz machen." Trotzdem wissen Sie alle, und das ist durch Untersuchungsausschüsse belegt worden, daß Abhörmaßnehmen weiter stattfinden.

Meine zweite Bemerkung bezieht sich auf einen italienischen Fall: In Italien gibt es eine gesetzliche Regelung, die es ermöglicht, Personen einen Zwangswohnsitz in einer Gemeinde zuzuweisen. Die Exekutive stellte sich auf den Standpunkt, das bedeute, daß auch der Zwangswohnsitz in einem Teil einer Gemeinde zugewiesen werden könne. Die Gerichte stützten das. Daraufhin ging die Exekutive dazu über, Leuten einen Zwangswohnsitz auf einem $1 \times 2 \mathrm{~km}$ großen Gelände einer Insel zuzuweisen, auf dem sich 4 Gebäude befanden und im übrigen natürlich eine entsprechende Polizeistation eingerichtet war. Hier scheint sich mir das interessante und weiter aktuelle Problem zu zeigen, daß die Bestimmtheit der Gesetzgebung und die Determinierung des exekutiven Verhaltens ein Problem ist, dem wir uns wieder widmen müssen.

Schließlich eine letzte, ganz kurze Bemerkung, vielleicht etwas übergreifend in den zweiten Teil: Herr Eichenberger hat an einer Stelle die Funktion des französischen Conseil d'Etat in seiner Begutachtungsfunktion erwähnt und wohl auch die Frage gestellt, ob man an ähnliche Verfahren zur Verbesserung der Gesetzgebungstechnik denken könnte. Man sollte auch darauf hinweisen, da $\beta$ im angelsächsischen Bereich das System der sogenannten parliamentary draftsmen etwas ist, was wir nicht kennen: unabhängig gestellte hochrangige Beamte, deren besondere Kompetenz es ist, Gesetzgebung auf die rechtstechnische Qualität hin zu begutachten und vorzubereiten. Ich weiß nicht, ob wir nicht hierüber weiter nachdenken müßten.

Vorsitzender: Vielen Dank, Herr Frowein. Herr Bull, bitte direkt dazu.

Bull: Ich bitte um Verzeihung, wenn ich interveniere. Herr Frowein, Ihre Behauptung, daß in der Bundesrepublik weiter abgehört werde in einer Weise wie im Fall Traube, das heißt unter Eindringen in die Wohnung, unter Verletzung des Art. 13 GG, ist geradezu sensationell zu nennen und muß uns alle aufrühren. Ich kenne solche Fälle nicht. Ich wei $\beta$ natürlich, daß wir ein Abhörgesetz haben - und Sie wissen es alle - und 
daß danach verfahren wird, da 3 aber dieses Gesetz das Eindringen in Wohnungen eben nicht rechtfertigt. Sie haben sich berufen auf den Untersuchungsausschuß in der Abhöraffäre Strauß-Scharnagl, wo die Minderheit im Ausschuß in der Tat gesagt hat, wir brauchten ein Gesetz, das diese Möglichkeit eröffnet, die Mehrheit dies jedoch nicht für richtig gehalten hat. Ich meine, gerade in diesem Fall zeigt sich doch die ganze Dramatik und Gewichtigkeit der Gesetzgebungsnotwendigkeit. Das englische Beispiel imponiert mir nicht. Ich meine, der Staat kann sich nicht Eingriffsbefugnisse selbst zuweisen - gerade in so heiklen, so schwierigen, so tief eingreifenden Bereichen - ohne gesetzliche Grundlagen. Hier liegt ein ganz wesentlicher Regelungsauftrag für den Gesetzgeber, und hier müssen wir durch die Diskussion hindurch, so schwierig und emotionsbeladen sie auch sein mag, und wir müssen gerade deswegen hindurch, damit das, was einige hier als angeblichen Verlust an Autorität des Rechtes, des Gesetzes, des Staates diagnostiziert haben, nicht wirklich eintritt. Ich meine, die Gefahr ist da. Die Darstellung wird oft überzogen, aber es kann ja doch dahin kommen, daß dem Staat keiner mehr traut, wenn solche Dinge nicht irgendwann einmal öffentlich diskutiert und dann geregelt werden. Wir können doch stolz darauf sein, daß wir ein Gesetz zu Artikel 10 GG haben, das Schranken setzt. Wir müssen auf diesem Wege weitergehen.

Vorsitzender: Danke schön, Herr Bull. Sie werden Verständnis dafür haben, daß ich Herrn Frowein zur Klarstellung kurz die Gelegenheit der Erwiderung gebe.

Frowein: Nur, um Mißverständnisse auszuräumen, die offenbar leider entstanden sind. Ich hatte das englische Beispiel genannt, und ich hatte gehofft, klar zu sein, um deutlich zu machen, wie aktuell dieser Wert des Gesetzes ist und selbstverständlich nicht, weil ich mich dem Urteil des High Courts anschließen wollte, sondern eigentlich in einer Deutschen Staatsrechtslehrervereinigung der Auffassung war, da $\beta$ das nicht mißverstanden werden konnte. Was ich weiter sagen wollte zu dem Problem des Abhörens, Herr Bull, um da auch Mißverständnisse auszuschließen: ich habe mich in der Tat bezogen auf die Untersuchungsausschußberichte, aus denen klar wird, daß Abhörverfahren ohne Eindringen in die Wohnung in größerem Umfang vorgenommen worden sind und alles dafür spricht, daß unter gegebenen Umständen ähnliche Abhörmethoden in der Bundesrepublik Deutschland angewendet werden. Mein Petitum war: hier muß das Gesetz her, genau das Gesetz, das wir zu Artikel 10 GG erfreulicherweise in der 
Bundesrepublik haben, mit dem ich in Straßburg, wie Sie wissen, und der Gerichtshof in Straßburg in letzter Instanz auch befaßt waren. Mein Petitum war gerade, sich nicht dabei zu beruhigen, daß wir solche Verfahren unter Berufung auf den strafrechtlichen Notstand etwa im Rechtsstaat und Gesetzesstaat auf die Dauer als akzeptabel ansehen.

Mußgnug: Ich will mich kurz fassen: Herr Kloepfer, Sie haben die „Kontinuität des Gesetzes“ in den Mittelpunkt Ihres Referats gerückt und sie, wenn ich Sie richtig verstanden habe, zum verfassungsrechtlichen Postulat erhoben. Meines Erachtens sind Sie damit in einen kaum zu überbrückenden Widerspruch zu dem Grundsatz der parlamentarischen Diskontinuität geraten, der den Gesetzgeber von jeder Kontinuitätspflicht gerade freizeichnet. Daran zu rütteln, halte ich für falsch. Es gehört zu den Grundlagen der Demokratie, daß die Wählerschaft dem Parlament zugleich mit der Abwahl der bisherigen Mehrheit den Befehl zur legislativen Kursänderung und damit zum Kontinuitätsbruch erteilen kann. Zu Beginn Ihres Referats haben Sie das auch klargestellt und einige Taktiken geschildert, mit denen der moderne Gesetzgeber den legislativen Richtungswechsel zu behindern versucht. Diese Taktiken haben Sie, wie ich finde, mit Recht kritisiert. Was Sie in diesem Zusammenhang vorgetragen haben, hat mich mehr überzeugt, als Ihr Plädoyer für die Kontinuität der Gesetze. Denn mit einem Kontinuitätsschutz für solche Gesetze, die dazu geführt haben, daß die Parlamentsmehrheit, die sie zu verantworten hat, abgewählt worden ist, kann ich mich nicht anfreunden. Er beschwört die Gefahr herauf, daß politisch abgehalfterte Gesetze nur deshalb aufrechterhalten bleiben, weil ihre längst in der Versenkung verschwundenen Väter nicht wahrhaben wollen, daß die Verfassung auch ihren Nachfolgern die gleiche politische Gestaltungsfreiheit gewährt, die sie für sich in Anspruch genommen haben. Wenn ich an die Gruppenuniversität denke, so ist mir der Kontinuitätsbruch jedenfalls weit lieber, als das Kontinuitätsdenken derer, die zwar selbst nicht mehr recht daran glauben, mit ihr das Richtige getroffen zu haben, sie aber als sakrosankt ausgeben, weil sie existiert und es bequemer ist, bei ihr stehenzubleiben, als aus ihrem Versagen die naheliegenden Konsequenzen zu ziehen.

Starck: Gestatten Sie mir zunächst zu dem schönen so faktenreichen und gedankenreichen Vortrag von Herrn Eichenberger zwei Bemerkungen aus deutscher Sicht zum Problem der Qualität der Gesetze: Herr Eichenberger hat zu Recht auf 
die Gefahren für die Qualität des Gesetzes hingewiesen, die im Gesetzgebungsverfahren stecken. Es ist heute schon in der Diskussion vermerkt worden, daß wir in Deutschland außer dem Bundestag noch den Bundesrat haben, der an der Gesetzgebung beteiligt ist; aber auch der Vermittlungsausschuß kann - gerade wenn ein großer politischer Kompromiß erforderlich ist - bewirken, daß das Gesetz an innerer Stimmigkeit verliert und dadurch einen Qualitätsverlust erleidet. - Eine weitere Bemerkung zum Stichwort "Qualität der Gesetze": Herr Eichenberger hat uns wieder ins Bewußtsein gerückt, daß die Ministerialbürokratie den Inhalt des Gesetzes zu verantworten hat. Die Ministerialbürokratie ist aber auch zuständig für den Inhalt der Rechtsverordnungen. Wird nun z.B. ein Schulgesetz entworfen, so hat dieses Schulgesetz zum Schluß 120 Paragraphen, nicht etwa, weil für die Materie, die im Schulrecht unter Gesetzesvorbehalt steht, 120 Paragraphen nötig sind, sondern weil die Grenze zwischen dem, was im Gesetz geregelt werden muß, und dem, was in einer späteren Verordnung geregelt werden kann, unklar ist und z.T. bewußt verwischt wird. Die Ministerialbürokratie, die den Inhalt des Gesetzes entwirft und für die Verordnungen zuständig ist, hat ein Interesse daran, möglichst viel ins Gesetz zu packen, ungeachtet der verfassungsrechtlichen Notwendigkeit. Der zweite Grund liegt in einer verfassungsrechtlichen Unsicherheit: Wie weit wirkt eigentlich der Art. 80 des Grundgesetzes? Es gibt in der Rechtsprechung des Bundesverfassungsgerichts dazu keine klare Linie; deshalb neigt die Ministerialbürokratie dazu, möglichst viel in das Gesetz selbst hineinzupacken und sich nicht später auf Verordnungen zu verlassen.

Ich bin damit schon zu einem zweiten Aspekt der Vorträge gekommen, zu dem ich kurz sprechen möchte. Herr Novak hat gesagt, vor einigen Jahren hätte man in unserer Vereinigung für die Ausdehnung des Gesetzesvorbehalts plädiert, jetzt müsse man die Zeche dafür bezahlen. Herr Novak, wenn Sie damit zum Ausdruck bringen wollen, daß auch die Beratungen innerhalb der Vereinigung unter dem Zeitgeist stehen, will und kann ich Ihnen im allgemeinen nicht widersprechen. Aber worum ging es denn vor einigen Jahren? Vor einigen Jahren standen wir vor der Situation, daß wir etwa für die Massensubventionen keine Gesetze hatten (Ipsen und Zacher 1966, VVDStRL 25), daß das Schulrecht ein gesetzesleerer Raum war (Evers und $F u ß 1964$, VVDStRL 23), daß die Durchführung des Strafvollzugs mit wesentlichen Eingriffen keine gesetzliche Grundlage hatte (Starck, ZRP 1969, 147). Die damaligen Tendenzen sind also nicht nur verständlich, sondern es war 
unsere Aufgabe, den Gesetzesvorbehalt auszuarbeiten und zu zeigen, wie weit der Gesetzesvorbehalt reicht. Herr Kloepfer hat nun heute in umgekehrter Kampfrichtung versucht, verfassungsrechtliche Grenzen für die Gesetzgebung aufzustellen. Ich möchte nicht wiederholen, was hierzu schon gesagt worden ist. Ich glaube nicht, daß diese Grenzen weit reichen und daß mit diesen Grenzen viel anzufangen ist, selbst wenn sich an der einen oder anderen Stelle, etwa im Schulrecht, ein Normierungsverbot ausmachen läßt (Starck, DÖV 1979, 271). Und ich habe auch Bedenken, daß hier zu viel aus der Verfassung herausgelesen wird mit der Folge, daß das Bundesverfassungsgericht $\mathrm{zu}$ einer Gesetzesverhinderungsinstitution ausgebaut wird. Vielmehr ist anzuknüpfen an den fruchtbaren Gedanken von Herrn Kloepfer zum Stichwort „Gesetzgebungslehre“. Der Gesetzgebungslehre müßten wir Staatsrechtler uns wieder verstärkt zuwenden, und zwar muß es um eine Gesetzgebungslehre im modernen Gewand gehen. Wir können gewiß an den klassischen Gesetzesbegriff anknüpfen, der eine ganze Fülle von Gesetzgebungslehre enthält. Dann müssen wir wieder Wert legen auf die Adäquanz von Gesetzgebungsverfahren und Gesetzesinhalt. Das Verfahren in dem Gesetze entstehen, ist nicht dafür da, Kleinigkeiten, Details und Dinge zu regeln, die morgen schon wieder überholt sind. Schließlich muß an die Arbeitskapazität des Gesetzgebers gedacht werden. Dieser Gesichtspunkt ist heute noch gar nicht zum Ausdruck gekommen. Der Gesetzgeber muß angemessene Zeit haben, um vernünftig zu regeln; auch die Kompromisse im Vermittlungsausschuß brauchen Zeit, wenn sie die Qualität des Gesetzes nicht vermindern sollen. Hier liegen also ganz wichtige Grenzen für die Gesetze in unserem Staat. Alles das zusammengenommen unter dem Stichwort „Gesetzgebungslehre“ könnte durchaus zu einer Stabilisierung des Gesetzes führen.

Kirn: Mich hat an dem Referat von Herrn Kloepfer besonders ein Begriff interessiert, der mir in philosophischer Hinsicht sehr fruchtbar zu sein scheint. Er kam gleich in seinem ersten Satz vor: der Begriff der „Distanz". Mir scheint eine Erneuerung der Staats- und Rechtsphilosophie nur unter dem Gesichtspunkt denkbar, daß so lange wie möglich die Frage festgehalten wird: Wo und wie setzen wir die richtige Distanz? Und da kann ich in vielen Punkten dem Referat von Herrn Kloepfer zustimmen, vor allem hinsichtlich eines weiteren Begriffes, den ich noch einmal in Erinnerung rufen möchte. Herr Kloepfer sprach von ,angemessener Entfeinerung" des Rechts, was mir eine besonders gelungene Begriffsbildung im Sinne 
der Distanzierung zu sein scheint, weil sie die logische Kategorie des „Maßes“ enthält. Um den Gegenbegriff zur ,,angemessenen Entfeinerung", nämlich den angemessenen Normierungsgrad des Rechts ging es auch schon in der Kontroverse Savigny/Thibaut und Hegels Stellungnahme zu dieser Kontroverse, die ich ganz kurz referieren will. Sie wissen, 1814 hat Thibaut ein Zivilgesetzbuch für Deutschland vorgeschlagen. Savigny hat ihm widersprochen mit seiner Schrift „Vom Begriff unserer Zeit für Gesetzgebung und Rechtswissenschaft". Hegel hat sich in $\$ \S 211,212$ der "Rechtsphilosophie“ auf die Seite Thibauts gestellt mit dem Argument, daß Savignys Forderungen maßlos seien, weil dieser von dem Grundsatz ausging: Wir können noch nicht ein Zivilgesetzbuch machen, wir müssen erst alle Rechtsnormen wissenschaftlich vorklären. Und Hegel hat damit eigentlich die Übernormierung auf einer sogar noch weiter gedachten Ebene angesprochen, indem er die Überszientifizierung als eine Gefahr erkannt hat, eine Gefahr, deren wir uns alle bewußt sein müssen, denn wir wirken an der Übernormierung mit durch Überszientifizierung der vielen Rechtsnormen, die erlassen werden. Wir machen noch mehr Aufsätze und Kommentare daraus, und das sind ja alles wiederum kleine Normbildungen. Für Hegel war mit der Übernormierung und der Überszientifizierung der Staatsbegriff selbst angesprochen und gefährdet. Ich bin leider in dem Zwang der vier Minuten und muß deswegen meine These aufs äußerste abstrahieren. Sie wird Ihnen so nicht gefallen, aber philosophisch gesehen war Savigny für Hegel ein Verfassungsfeind durch Überszientifizierung des Rechts. Hegel hat Savigny den Staatsbegriff entgegengestellt, der in folgendem Satz zusammengefaßt ist - schon beim frühen Hegel - :,Der Staat ist die machthabende Allgemeinheit als Quelle allen Rechts."Diese Formel ist wichtig und bedeutsam, und ich finde, man muß sie auch ganz deutlich dem gegenüberstellen, was Herr Roellecke als Rechtsstaatsdefinition hier gegeben hat. Er hat gesagt: „Der Staat ist ein System, das Rechtsänderungen durch Recht steuert." Also Sie sehen, in der Formel von Roellecke fehlt das Moment der Distanz. Es steuert sich das Recht unmittelbar durch das Recht, und das kann im Grunde genommen auch ein Computer. Deswegen habe ich vom philosophischen Gesichtspunkt her eben an diese Formel die Frage zu richten, ob es nicht langfristig die Entmenschlichung des Rechts in unserem Denken bewirkt, wenn man sagt, der Rechtsstaat ist ein System, das Rechtsänderungen durch Recht steuert, und nicht hinzufügt, daß das eine praktische Betriebsformel ist, die noch der philosophischen Relativierung bedarf. In Hegels Formel: 
„Der Staat ist machthabende Allgemeinheit als Quelle allen Rechts", sehen Sie ein Moment der Idealität der Staatsgewalt, das als Gegenpol gesetzt ist zu der rechtlichen Steuerung und Normierung, die natürlich auch drin ist. Aber Sie haben eben die Polarität, es sind zwei Gesichtspunkte, und das Moment der Idealität, das hier hinzukommt, das ist für Hegel die Staatssouveränität. Die Staatssouveränität ist tot - heute für uns, das muß ich den Referaten entnehmen -; denn zwischen Staatssouveränität und Gesetzgebung müßte zweifellos ein Zusammenhang hergestellt werden, und wenn er nicht ausgesprochen wird in drei Referaten, die sich mit der Gesetzgebung beschäftigen, dann muß ich daraus die Schlußfolgerung ziehen: Also halten die Referenten die Staatssouveränität für einen toten Begriff, nicht mehr für den Zentralbegriff der Staatslehre. Ich bin auch dieser Ansicht. Aber die Frage ist: Was folgt daraus? Muß nicht - und das ist mein letzter Gesichtspunkt - in dem, was früher mit Staatssouveränität gemeint war, das Element der Idealität erhalten bleiben? Können wir uns das erlauben, daß wir mitsamt der Staatssouveränität auch das, was da an ideeller Übereinstimmung zwischen Mensch und Gemeinschaft, an sozialbildender Kraft auch der Großgruppe gesetzt war, können wir das einfach über Bord werfen und heute nur noch über Gesetzgebung sprechen und den Staat auslassen? Ich glaube, daß wir da auf einer falschen Linie liegen.

Staff: Herr Kirn, ich möchte das Zeitmoment nicht ganz in Vergessenheit geraten lassen. Ich freue mich, daß in der Bundeswehrhochschule Philosophie so intensiv betrieben wird. Aber wir können unmöglich die Argumente, die Savigny bewogen haben, gegen Thibaut anzutreten, bzw. Hegels Staatsverständnis jetzt in unmittelbaren Zusammenhang setzen mit der Problematik, die sich derzeit - insbesondere hinsichtlich der staatlichen Souveränität und einer demokratischen Gesetzgebung - für unseren Rechtsstaat ergibt. Das möchte ich nur kurz hinzufügen, damit der historische Zusammenhang, in dem die hier aufgeworfenen Fragen zu sehen sind, nicht völlig aus dem Blickfeld gerät.

Vorsitzender: Herr Kaiser möchte unmittelbar erwidern.

Kaiser: Dem möchte ich, verehrte gnädige Frau, nur den einen Satz des Widerspruchs, wenn Sie erlauben, entgegensetzen: daß jede Staatslehre, und insbesondere das, was doch immerhin eindrucksvoll als Souveränitätslehre hier entwickelt 
wurde, schlicht vor der Notwendigkeit steht, Grundlagen in der allgemeinen Philosophie zu suchen; und gibt es eine größere als die des deutschen Idealismus?

Vorsitzender: Danke schön, Herr Kaiser. Mit Herrn Bachof nähern wir uns wieder der Erde, glaube ich.

Bachof: Gestatten Sie noch eine verspätete Bemerkung zu Herrn Burmeister; ich hatte mich vorhin nicht schnell genug gemeldet.

Herr Burmeister will scharf unterscheiden zwischen zwei Kategorien von Gesetzen: solchen des Außenrechtskreises mit Individualrechtsschutz, und solchen des Innenrechtskreises, Organisationsnormen vor allem, ohne Individualrechtsschutz. Abgesehen davon, daß mir bisher nicht einsichtig ist, welche Konsequenzen daraus für die Gesetzgebung zu ziehen wären, glaube ich nicht, daß man so unterscheiden kann. Gerade das von Herrn Burmeister gebrachte Beispiel der Kommunalreform scheint mir zu zeigen, daß man diesen Bereich nicht einfach als Innenrechtskreis verorten kann. Gemeinden und Staat können Opponenten sein, die Gemeinden genießen kraft der Selbstverwaltungsgarantie Rechtsschutz. Sie werden sagen: Nun, das ist kein Individualrechtsschutz, das ist eben Rechtsschutz der Gemeinde, betrifft also den Organisationsbereich. So mag man es formal betrachten können. Politischsoziologisch gesehen ist das aber anders. Die Gemeinden treten hier nicht nur als „Organisation Gemeinde" auf, sondern, mindestens auch, als Wahrer der gebündelten Interessen - ich möchte sogar sagen: der Rechte - ihrer Bürger. Nichts zeigt das so deutlich, als daß bei keinen anderen Verfassungsprozessen der Publikumsandrang, nämlich seitens der betroffenen Bürger, so stark war und ist als bei Prozessen über Maßnahmen der Gebietsreform. Entsprechendes gilt für andere Organisationsakte; ob das Gesetze oder Verordnungen oder Verwaltungsakte sind, spielt keine entscheidende Rolle. Nehmen Sie z.B. Schulorganisationsgesetze oder -verordnungen oder, was wir jetzt gerade in Baden-Württemberg hatten, die Auflösung pädagogischer Hochschulen durch ein Gesetz: Da sind nicht nur die Organisationen als solche betroffen, da handelt es sich nicht nur um Innenrecht; da sind vielmehr die Bürger, die Studenten, die Professoren, das ganze Personal mitbetroffen. - Ich meine also, jene scharfe Abgrenzung von Außen- und Innenrecht kann man nicht machen. Ich habe schon Zweifel, ob es Gesetze gibt, die wirklich nur den Außenrechtskreis betreffen; mittelbar wirken sie sich immer auch irgendwie auf die Staatsorganisation aus. Umgekehrt jedenfalls, Gesetze, die 
nur den Innenrechtskreis betreffen und die nicht mehr oder minder zugleich auch eine Bürgerbetroffenheit auslösen, die gibt es meiner Ansicht nach nicht.

Erichsen: Wir sehen uns einer Trilogie der Fragen gegenüber: Was darf der Gesetzgeber, was muß der Gesetzgeber und was darf der Gesetzgeber nicht? Ich möchte mich zunächst dem letztgenannten Aspekt zuwenden. In diesem Zusammenhang stellt sich u.a. einmal das Problem der Unterscheidung von Staatsaufgaben und solchen Aufgaben, die der Selbstregulierung der Gesellschaft unterliegen. Zum anderen stoßen wir auf einen Befund, den Herr Kloepfer heute morgen unter dem Stichwort ,Verwaltungsvorbehalt" angesprochen hat. Mich interessiert, ob es diesen Verwaltungsvorbehalt überhaupt gibt und wie er gegebenenfalls näher zu definieren ist.

Herr Kloepfer, Sie haben in Ihrem Referat die mangelnde Distanz des Gesetzgebers beklagt. Ich bin nicht ganz sicher, ob in Ihren Ausführungen nicht insofern eine gewisse Gegenläufigkeit zu verzeichnen ist, als Sie andererseits den Gesetzgeber in eine normative Steuerungsdichte hineinstellen, die jener gleichkommt, die für die Verwaltung gilt. Mir scheint es symptomatisch zu sein, daß in Ihrem Leitsatz $6 \mathrm{c}$ im Hinblick auf die Frage der Gesetzesänderung Überlegungen zum Widerruf von Verwaltungsakten aufscheinen. Wenn Sie in dieser Art und Weise den Gesetzgeber an den Zügel legen, dann wird wohl in der Tat das herauskommen, was hier schon in einigen Beiträgen beschworen worden ist, daß nämlich die politische Dimension der Gesetzgebung sehr nachhaltig beschnitten wird. Diese normative Verdichtung, die Sie vor uns entwickelt haben, ist zumal - wie mir scheint - doch teilweise von sehr postulatorischem Charakter. Sie gehen zwar von einigen uns vertrauten Maximen wie etwa dem Übermaßverbot aus, aber ich habe doch Zweifel, ob das alles so aus der Verfassung entwickelt werden kann, wie Sie es getan haben. Manches scheint mir auch nur in einem neuen Gewande daherzukommen. So hat mich bei allen drei Referenten des heutigen Vormittags überrascht, daß der Grundsatz der Subsidiarität doch wohl in der Sache vergegenwärtigt, aber jedenfalls ausdrücklich nicht angesprochen worden ist. Danke schön.

Tomuschat: Das Gesetz ist von mehreren Rednern bereits auf seine Ursprünge in der Französischen Revolution zurückgeführt worden. Es war von Anfang an ambivalent. Die Erklärung von 1789 sieht es einerseits als Garantie der Freiheit des Bürgers an; andererseits ist sie sich bewußt, daß das Gesetz 
diese Freiheit beschneiden kann. In den Anfängen der Bundesrepublik hat man das Gesetz in der Lehre zunächst stärker als Eingriff und als Schranke gesehen, bis dann Herr Häberle uns belehrt hat, daß es auch als Entfaltung von Freiheit verstanden werden kann. Heute scheint allgemein das Pendel zurückzuschwingen. Das Gesetz wird eher als Last, als Druck empfunden. Obwohl Herr Grimm bei Herrn Kloepfer einen antipolitischen, ja antidemokratischen Affekt diagnostiziert hat, kann man vielleicht doch einen gemeinsamen Nenner finden: Denn was den gegenwärtigen Klagen zugrunde liegt, ist das Gefühl, daß es sich nicht eigentlich um demokratisches Recht handele, um Bürgerrecht, sondern eher um Recht von Bürokraten für Bürokraten. Das rührt an Grundfesten der Demokratie. Haben wir es überhaupt noch mit einer funktionierenden Demokratie zu tun, wenn sich das Gesetz so sehr in Apparaten verkrustet und von dem Bürger nicht mehr verstanden werden kann? Es ist dies eine zunächst beängstigende Erscheinung, die aber auch gewisse undramatische Züge aufweist. Manche Rechtsakte wenden sich ihrer Natur nach nur an Bürokraten und beschneiden nicht eigentlich die Freiheit des Bürgers. In dieser Hinsicht, so meine ich, sind die bereits angeführten EG-Agrarmarktverordnungen gar nicht so sehr kritikwürdig, denn sie richten sich an einen engen Kreis von Betroffenen, an die Exporteure und Importeure, und rühren nicht grundsätzlich an Freiheitspositionen. Auf der anderen Seite gibt es aber auch jenes undurchsichtige Recht, das von Bürokraten gemacht wird und tatsächlich den Bürger betrifft, wo der Bürger aber gar nicht wei $\beta$, in welcher Weise es eigentlich um seine Sache geht. Wenn, wie so häufig, in undurchschaubarer Weise Vorteile verliehen und Nachteile auferlegt werden, stehen so grundlegende Axiome wie Freiheit und Gleichheit auf dem Spiel.

Lassen Sie mich noch ganz kurz einen zweiten Punkt anführen: Im Mittelalter war jedes Gesetz ein „Testgesetz“: Man wußte nicht, ob die Gesetze überhaupt jemals durchgeführt werden, es gab keine amtlichen Gesetzessammlungen, jedes Gesetz lief mehr oder weniger auf einen Versuch hinaus. Vor allem das 19. Jahrhundert führte zu einer ungeheuren Effektivierung des Gesetzes. Seine Verfestigung als Handlungsinstrument lief parallel zum Aufsteigen des Beamtenstaates. Heute scheint die Grenze der Verarbeitungskapazität erreicht zu sein, und es besteht die Gefahr, daß der Gesetzeserlaß wiederum generell zum bloßen Experiment gerät, weil nämlich nicht mehr bekannt ist, in welcher Weise der Gesetzesakt überhaupt zu wirken vermag. 
Vorsitzender: Danke schön, Herr Tomuschat. Ich möchtejetzt zum Schluß des ersten Teils den Referenten Gelegenheit zu einem „Zwischenwort" geben, wobei ich darum bitte - Sie werden Verständnis dafür haben -, daß der Ausdruck „Wort“ nicht wörtlich zu nehmen ist. Zunächst Herr Eichenberger bitte.

Eichenberger: Nur kurz: Ich bin sehr dankbar für die Äußerungen von Herrn Badura. Er hat hier klärend deutend gewirkt, und ich gehe völlig einig mit seinen Ausführungen, die eine Bestätigung und Klärung dafür bringen, was ich auszuführen versucht habe. Herrn Doehring, darf ich kurz hinweisen darauf, daß in der Tat die Dignität der Gesetzgebung leidet, wenn auf diese Weise die Exekutive tätig wird; aber wir müssen auf der anderen Seite, was Herr Starck betont hat, unterstreichen, wie sehr es der Exekutive gleichgültig wird, ob sie nun in Gesetzesform auftritt oder in der Verordnungsform. Sie hat das eine $\mathrm{Mal}$ etwas größere Leiden zu durchstehen, bis sie den endgültigen Entscheid auf dem Tische hat, und das andere Mal hat sie hausintern unter Umständen größere Widerstände zu überwinden, bis sie den Verordnungstext endlich durchgebracht hat. Bemerkenswert ist aber, wie die Ressorts interessiert werden, Gesetze für das eigene Haus zu haben, weil sie sich auf diese Weise verfestigen und stabilisieren können, nicht zuletzt gegenüber ihren Konkurrenzressorts. Darf ich die Ausführungen von Herrn Wielinger in bezug auf das richtige Recht streifen: Sie werden nicht erwarten, daß wir hier über dieses Thema uns einläßlich aussprechen können. Ich möchte einfach hervorheben, daß es für die heutige Gesetzgebung wieder zu einem Zentralbegriff wird. Dabei dürfen wir mit Ruhe und Fug anknüpfen an Stammler, wir dürfen einmal übernehmen, was Walther Burckhardt dazu ausgeführt hat, was Hans Ryffel dazu zu explizieren versuchte oder was aus dem Zivilrechtsbereich von Karl Larenz vorgetragen wird: Es sind auf alle Fälle die Gerechtigkeitsbezüge und die freiheitsrelevanten Konnexe aufzugreifen und einzubringen. Das ist nun auch ein Hinweis darauf, was Herr Püttner angedeutet hat. Ja, was ist denn jetzt ein gutes Gesetz? Da würde ich doch meinen, es kommt auf die gegenwärtige Deutung an; wenn Sie also mit Nietzsche reden, es kommt auf die „Jetztzeit“ an. Auf die Qualitätsforderung der legislativen Richtlinien, die heute geboren werden, aber sollten endlich auch wir Staatsrechtswissenschaftler uns besinnen und dieses Thema nicht einfach länger den Technikern und Philologen in den Händen belassen. Die sind freilich durchaus nötig, die wird man hinzuziehen, die soll man hören; aber es sind nicht die zentralen Leute. Wir sollten aber auch nicht die Privatrechtler oder gar die Strafrechtler in dieser Thematik 
allein fungieren lassen. Die tun auch ihr Werk und sind respektabel; aber wir wären es auch. Und wir sollten den Mut haben, in dieser Hinsicht aufzutreten und an die Entwicklung heranzugehen. Was das gute Gesetz der Gegenwart ausmacht, da sind wir bis jetzt vor allem im Verwaltungsrechtsbereich die Antwort schuldig geblieben. Und insofern würde ich Herrn Starck sehr nachhaltig unterstützen; die Wissenschaft hat hier eine Verpflichtung, ob sie das jetzt als Gesetzgebungslehre anschreibt oder anderswie, das ist völlig gleichgültig. Es kommt aber darauf an, daß wir uns angesprochen fühlen. Noch eine Bemerkung zu Herrn Schäffer: Hilfsdienste der Gesetzgebung, die können wir schon aktivieren. Die USA haben hier recht erfreuliche Erfolge zu verzeichnen. Die Bundesrepublik, die einen so vielversprechenden Anfang genommen hatte, hat dann aber die interessante Veränderung erfahren, daß dieser Hilfsdienst lediglich noch für die Opposition zur Verfügung steht und man nicht wagt, ihn anzugehen, sobald die Präparation in einiger Vertraulichkeit vor sich gehen soll. In der Schweiz ist dieser Hilfsdienst zwar sehr rudimentär ausgebaut, man könnte ihn aber von außen verstärken. Doch die Praxis zeigt, daß man über kurz oder lang jeweils gleichwohl die Verwaltung mit ihrem enormen Wissen holen muß, das den Hilfsdiensten nicht zur Verfügung steht, wenn sie nicht eine gleichwertige Wissenskapazität aufbauen wollen. Zur Frage: In welche Stufe gehören die Richtlinien? Da würde ich, was in den Voten zum Ausdruck gekommen ist, ebenfalls angelegentlich raten, nicht allzu rasch voranzugehen, sondern sie zunächst einmal entwickeln und später fragen, in welche Stufe wir sie zu setzen haben. Auf alle Fälle den Richter nicht zu früh holen. Das würde ich auch gegenüber Herrn Häberle unterstreichen. Die Disziplinierung der Gesetzgebung durch den Richter ist mit aller Zurückhaltung zu betrachten. Es ist nicht die Funktion des Richters, diese Tätigkeit, gerade diese Funktion des Staates in der vollen Breite nochmals aufzunehmen bzw. steuernd auch den methodischen Aufbau der Rechtsordnung zu lenken, wenn wir nicht in den Richterstaat nach Marcic übergehen wollen.

Novak: Ich möchte versuchen, das hier schon mehrfach apostrophierte Übermaßverbot auch für meine Zwischenwortmeldung gelten zu lassen, und das sehr umfangreiche Paket von Interventionen nur stückweise aufschnüren, soweit ich persönlich angesprochen worden bin. Zunächst, Herr Starck, war mein Hinweis auf frühere Verhandlungen dieser Vereinigung durchaus nicht kritisch gemeint. Es war der Zug der Zeit, damals gesetzliche Freiräume zu entdecken und eine Vertie- 
fung und Ausweitung des Gesetzesvorbehalts voranzutreiben - nicht nur in Deutschland; das gilt auch für die österreichische Lehre. Die Meinungen waren allerdings immer geteilt. Schon in den Beratungen über Verwaltung durch Subventionen etwa oder über Verwaltung und Schule haben sich auch gegenteilige Auffassungen gezeigt; und man könnte heute bis zu einem gewissen Grad von einer späten Rechtfertigung sprechen.

Herr Püttner, zu Ihrer Frage Gesetz oder Verordnung, namentlich was das Schulrecht betrifft: Freilich, es ist nicht gleichgültig, ob Recht durch formelles Gesetz oder durch Verordnung geschaffen wird. Mein Ansatzpunkt im Referat war die Vorstellung einer Entlastung des Gesetzgebers. Sicherlich nicht einer Preisgabe jener Normierungen, die im Sinne der „Wesentlichkeitstheorie" oder, um es so auszudrücken, im Sinne dieser flexiblen Faustregel, die die Judikatur entwickelt hat, dem Parlament vorbehalten bleiben müssen. Worum es geht, ist, im Gesetz auf Vorschriften technischer Art zu verzichten - "technisch" natürlich nicht in der engeren Bedeutung des Wortes genommen. Gemeint sind Bestimmungen, die, nach welchen Kriterien immer bemessen, nicht als politisch ,wesentlich" oder wichtig zu betrachten sind. Wobei sich gewiß die Maßstäbe auch in der Zeit ändern können. Ein zweites: Man wird diesen Vorschlag nicht verallgemeinern dürfen; das liegt auf der Hand. Die reine Durchführungsverordnung behält ihrèn Platz. Es muß sachspezifisch differenziert werden. Ich habe ein Beispiel ausıder jüngeren österreichischen Rechtsentwicklung genannt, das in weiterem Umfang für das Wirtschaftsrecht stehen kann. Auch an den Planungsbereich ist $\mathrm{zu}$ denken. Dagegen besteht im traditionellen Polizeirecht für eine grundsätzliche Änderung wohl kein Anlaß. Schließlich konkret zum Schulrecht: In diesem Zusammenhang stellt sich nicht bloß die Frage nach Gesetz oder Verordnung, sondern auch jene nach Regelung überhaupt oder Nichtregelung. Ich darf nochmals das Schülervertretungs-Gesetz erwähnen, das im heurigen Jahr in Österreich ergangen ist. Dazu dann selbstverständlich eine Verordnung; denn man muß ja auch für die Wahl der Schülerbeiräte Vorsorge treffen. Und zuletzt ist, ähnlich der bewußten Rektorswahl in Wien, über die Nominierung des Vorsitzenden des Bundes-Schülerbeirates bereits der Streit entbrannt. Was kaum überraschen kann, weil die Bestimmungen - noch immer oder gerade jetzt - unklar und lückenhaft sind. Ich glaube - und das wäre ein Beispiel, wie es in der Diskussion gefordert wurde - , daß die ganze Regelung schlicht überflüssig ist. Mitreden durften die Schüler schon 
bisher; auch ohne Gesetz. Und das Mitreden, das ihnen nun kraft Gesetzes gestattet ist, hilft ihnen nicht. Letzten Endes ist das ein Problem des österreichischen Verfassungsrechtes, des fehlenden Bezuges zu den Grundrechten und ihrer Verwirklichung. Die Auseinandersetzung um das Elternrecht etwa haben wir in Österreich noch nicht gehabt; sie ist bei der derzeitigen Situation unserer Grundrechtsordnung auch kaum zu erwarten. Das Gesetz dient als Ersatzbefriedigung.

Herr Badura, mit dem Stichwort Gesetzesstaat und Richterstaat ist zweifellos eine ernste Frage angeschnitten. Der Gedanke, durch verstärkte Verordnungs- oder Ermessensdelegationen Regelungsbefugnisse von der Ebene der formellen Gesetzgebung auf die Vollziehung zu verlagern, bedeutet zusätzliche Verantwortung für die Verwaltung und in weiterer Folge zusätzliche Verantwortung und Inanspruchnahme für die Gerichtsbarkeit; für das Verfassungsgericht, die Verwaltungsgerichte und - was Österreich anlangt, wenn man an den Bereich der leistenden Verwaltung denkt - auch für die Fachgerichte. Das trifft den Kern. In der Literatur zu unserem Themenkreis wurde dazu gesagt: Beides kann man nicht haben. Entlastung des Gesetzgebers bei gleichzeitiger Entlastung der Verwaltung und der Justiz, das ist unmöglich. Dem stimme ich zu. Kleine Schritte sind anzustreben; sie sind auch gangbar. Eine große Lösung sehe ich nicht. Sie könnte höchstens in eine Reihe frommer Wünsche ausmünden: Nach einem Gesetzgeber, der von sich aus Zurückhaltung übt; nach Parteien und Verbänden, die eine maßvolle Politik an den Tag legen, und nach Bürgern, die weniger anspruchsbewußt und streitsüchtig wären.

Kloepfer: Auf die naturkundlichen Bemerkungen von Herrn Häberle eingehend möchte ich sagen, die ganze Diskussion war bisher ein sehr pikantes Wild-Gericht. Ich möchte, da ich sehr häufig angesprochen worden bin, versuchen, nach Themen zu antworten. Sicherlich ist es schwierig, in einem Referat sozusagen alles anzusprechen. Manches ist nur mit einem Halbsatz gesagt worden. Entgegen der Bemerkung von Herrn Schneider, der Bundesstaat sei in den Referaten zu kurz gekommen, taucht dieser in meinem Referat unter dem Aspekt auf, daß die dezentralisierte Rechtserzeugung ein Grund der Übernormierung ist.

Die eher politisch ansetzenden Diskussionsbeiträge - insbesondere von Herrn Grimm - lassen für meine Begriffe eine etwas altertümliche Vorstellung von der Verfassung erkennen, nämlich die Verfassung unter einen Politikvorbehalt zu stellen. Darüber sollten wir hinaus sein, und wenn das Thema 
heißt: „Gesetzgebung im Rechtsstaat" geht es natürlich vorrangig um die Entwicklung der spezifisch rechtsstaatlichen Aussagen. Dazu: Ich würde mich mißverstanden fühlen, wenn meine Darlegungen der verfassungsrechtlichen Begrenzungen der Gesetzgebung nun nicht gesehen würden als die Postulierung von bloßen Minimalstandards. Die Verfassung - ich habe das auch mehrfach im Referat gesagt - kann nur solche Mindeststandards bereithalten, und hier allerdings meine ich, steht die Verfassung nicht unter Politikvorbehalt, sondern die Politik unter Verfassungsvorbehalt.

Zur Frage der Distanz: Manche haben ja Distanz von diesem Distanzverständnis gesucht. Es ist sicherlich nicht leicht, eine solche Vorstellung in einer kompakten Weise darzustellen. Ich glaube aber gleichwohl, daß dieses Vorstellungsbild der Verfassung, das sich sicherlich nicht zu wohlfeilen Formeln eignet, es doch ermöglicht, verschiedene, bisher sehr unterschiedlich gesehene Punkte zusammenzufassen. Ich habe eine Fülle von Beispielen gebracht, so daß ich mich hier, glaube ich, im einzelnen nicht wiederholen muß. Erwähnt sei nur etwa die Verbindung der verfahrensmäßigen Distanz durch ein gestuftes Gesetzgebungsverfahren und der inhaltlichen Distanz durch die Notwendigkeit der Mehrheitsfindung und dergleichen. Ich meine, daß die Vorstellung der Distanz einen neuen Ansatz bietet, die verschiedenen Verfassungsanforderungen an die Gesetzgebung zu deuten und Verbindungen zwischen ihnen zu suchen und aufzufinden.

Ich bin in diesem Zusammenhang von Herrn Erichsen auf einen angeblichen Widerspruch hingewiesen worden, einerseits Distanz, andererseits sozusagen Bindung an die Widerrufslehre - etwas verkürzt gesagt. Nur meine ich, daß die prinzipielle Trennung, die möglicherweise einer solchen Kritik zugrundeliegt, nämlich Verfassungsrecht und Verwaltungsrecht als zwar inhaltlich irgendwie verbundene, aber letztlich doch stets in verschiedenen Lehrbüchern abgehandelte, also säuberlich zu trennende Rechtsgebiete zu sehen, so meines Erachtens nicht zutrifft. Mein Lehrer Fritz Werner hat das eindrucksvolle Wort vom Verwaltungsrecht als konkretisiertes Verfassungsrecht geprägt. Ich meine, diese Vorstellung kann man weiterzeichnen im Hinblick darauf, daß das Verfassungsrecht und das Unterverfassungsrecht sich in Wechselbezüglichkeiten befinden, so daß man aus unterverfassungsrechtlichem Rechtsstoff verfassungsrechtliche Aussagen abstrahieren kann. Allerdings muß man dies behutsam tun, und ich hatte versucht, im Referat darzulegen, daß man dies nun bitte nicht im Sinne einer einfachen Analogie machen sollte. Aber 
die Vorstellung, daß Flexibilitätsinteressen und Stabilitätsinteressen gerecht und schonend auszugleichen seien - zugegebenermaßen dann immer noch eine sehr weite Formel -, ist doch etwas, was das Verfassungsrecht aus dem Unterverfassungsrecht abstrahiert, wobei dann diese Aussage sicherlich in die Wechselbezüglichkeit zwischen beiden Rechtslagen eintritt.

Herr Erichsen hat mich nach dem Verwaltungsvorbehalt gefragt. Ich meine, daß dies eine bisher zu wenig problematisierte Vorstellung in unserem Verfassungsrecht ist. Ein aktuelles Beispiel bietet etwa das Chemikaliengesetz. Das Chemikaliengesetz enthält sehr differenzierte Regelungen darüber, was passiert, wenn plötzlich von einem Stoff Gefahren ausgehen. Grundsätzlich ist ja dort nur ein Anmeldeverfahren vorgesehen. Aber was geschieht eigentlich nach dem Chemikaliengesetz, wenn ein Stoff sich plötzlich als gefährlich für den Menschen erweist (bzw. erweisen kann)? Dann hat das Chemikaliengesetz eine gestufte Regelung geschaffen, daß nämlich zunächst einmal vorläufig die Verwaltung eingreifen darf (§23II), dann der Verordnungsgeber ohne Zustimmung des Bundesrats ( $\$ 17 \mathrm{II}$ ) und dann der Verordnungsgeber mit Zustimmung des Bundesrats ( $\$ 17$ I Nr. 1). Ich meine, hier erkennt man schon: Wenn so schnell gehandelt werden muß, daß der Gesetzgeber einfach nicht mehr handeln kann, weil eben jedes Gesetzgebungsverfahren dauert - beim Chemikaliengesetz geht es freilich um einen Dispens von Verordnungsverfahren und sodann vom Erfordernis der Bundesratszustimmung -oder auch wenn ein Rechtsverordnungsverfahren, eine Bundesratszustimmung einfach zu lange für eine effektive Gefahrenbekämpfung dauern, dann in der Tat ist der erste Zugriff hier bei der Verwaltung, allerdings, muß ich sagen, aufgrund einer notwendigen, vorher erteilten allgemeinen gesetzlichen Ermächtigung. Hier zeigt sich meines Erachtens, daß z.B. aus Zeitgründen, also aus Praktikabilitätsgründen, ein verfassungsstarker Verwaltungsvorbehalt bestehen kann. Dies ließe sich nun in vielen Beispielen illustrieren, aber dann würden wir jetzt gar nicht mehr in der Diskussion weiterkommen.

Die Zeitgemäßheit und -abhängigkeit von Gesetzen, die mehrfach angesprochen worden sind, würde ich aus meiner grundsätzlichen Sichtweise in diesem Bereich nachdrücklich unterschreiben. Ich glaube, daß die Gesetze altern, daß sie zunächst sehr gut sein und dann durch veränderte äußere Umstände ihren Wert verlieren können. Hierbei können die im Referat angesprochenen Anpassungsgebote der Verfassung bedeutsam werden. 
Die Vorbereitungsphase bei der Gesetzgebung ist im wesentlichen in der Tat ein "schwarzes Loch" im verfassungsrechtlichen Universum - dunkel und die Energien benachbarter Verfassungsbestimmungen in sich aufzehrend. Dem müßte man sicherlich noch sehr viel grundsätzlicher und ausführlicher nachgehen. Das berührt sich mit manchen Diskussionspunkten im Hinblick auf den Problemaspekt: formeller und materieller Gesetzgeber. Wer ist eigentlich wirklich Gesetzgeber? Da unsere ganze Verfassungsdogmatik zum Gesetzgebungsverfahren sozusagen weitgehend umgewichtet oder gar materiell verändert werden kann, je nachdem was sich in dieser Vorbereitungsphase abspielt, halte ich an meinem Standpunkt fest, daß den Gesetzgeber zum Beispiel eine Pflicht zu einer von wesentlichen Fehlern freien Gesetzesmethodik trifft - mit allen Fernwirkungen gewissermaßen in dieses „schwarze Loch“ hinein.

Die notwendige Nachbereitung im Gesetzgebungsverfahren hatte ich - wenngleich auch notwendigerweise nur kurz angesprochen. Ich meine schon, daß dies etwa über die Rechtsbereinigungen oder über die weiteren Erforderlichkeitsprüfungen - die „Noch-Erforderlichkeitsprüfung“ hatte ich ja erwähnt - institutionalisiert werden könnte.

Zur Diskontinuität: Den Gegensatz von kontinuitätsbezogenen Begrenzungen von Änderungsgesetzen und der notwendigen Ermöglichung demokratischer Alternativen habe ich in meinem Referat behandelt. Ich habe gerade die notwendige Freiheit des künftigen Gesetzgebers als Gegenpol angesehen für die Entwicklung verfassungsrechtlicher Standards der gesetzgeberischen Kontinuität, um dann natürlich auch lediglich $\mathrm{zu}$ verfassungsrechtlichen Minimalstandards zu kommen, weil natürlich jede verfassungsrechtliche Erschwerung von Gesetzesänderungen unmittelbar auf den nächsten Gesetzgeber zielt. Und hier habe ich versucht, zwei Eingrenzungen zu entwickeln: Erstens kann die Legitimation zur Bindung künftiger Gesetzgeber nur darin bestehen, daß langfristige Sachverhalte gesetzlich geregelt werden, die sich gerade dem relativ kurzen Takt von Legislaturperioden entziehen. Dieser Widerspruch, daß der Gesetzgeber einen langfristigen Sachverhalt normieren muß, obwohl er formell nur regelmäßig vier Jahre zur Rechtsetzung legitimiert ist, führt zweitens zu dem Gedanken, daß er eben in diesen Fällen möglichst die künftigen Entscheidungen des Gesetzgebers schonen muß, also nicht mehr als notwendig präjudizieren darf. Aber insgesamt glaube ich, daß man an dem Grundgedanken, daß der Gesetzgeber über die Legislaturperiode hinaus regeln muß und es deshalb bestimm- 
ter eingrenzender verfassungsrechtlicher Standards bedarf, nicht vorbeigehen kann.

Ich bin nach Beispielen befragt worden. Ich glaube, für die Kontinuitätsproblematik bieten z. B. der Ausbildungsbereich, der Umweltschutzbereich, der Kindergeldbereich manches Anschauungsmaterial.

Zur Abgrenzung des Gesetzgebungsexperiments vom normalen Gesetz: Es sind ja hier sehr verschiedene Thesen vertreten worden. Eine der wesentlichen Thesen war: Das Gesetzgebungsexperiment läßt sich gar nicht abgrenzen, weil jedes Gesetz gewissermaßen experimentellen Charakter hat. Dazu muß ich bemerken, daß ich diese Auffassung für gewisse Teile der Gesetzgebung vielleicht als politische Bewertung nachvollziehen könnte, nicht aber in einem Rechtssinne. Ich meine, daß das Gesetzgebungsexperiment als eigene Rechtsfigur in der Tat nur dann legitimiert ist, wenn diese spezifische Rechtsfolgen nach sich zieht. Diese spezifischen Rechtsfolgen bestehen aus meiner Sicht in zwei Richtungen. Nämlich einmal in den von Herrn Lerche als Gespinst betrachteten vielfältigen Anforderungen der Verfassung an die Testerforderlichkeit, Testgeeignetheit etc. Auf der anderen Seite besteht die spezifische Rechtsfolge des Gesetzgebungsexperiments - und deswegen ist dieses natürlich eine mit Vorsicht $z u$ genießende Angelegenheit - darin, daß das Geeignetheitsprinzip eben für dieses Gesetz selbst nicht in gewohnter Weise gelten kann (weshalb dem Gebot der Testgeeignetheit besondere Aufmerksamkeit zukommt). Das Experiment soll ja gerade Ungewisses erproben. Hier erweist sich der Versuch einer gewissen Ausbalancierung der durch Gesetzgebungsexperimente verursachten Verluste von allgemeinen Verfassungssicherungen auf der einen Seite mit verstärkten, spezifischen verfassungsrechtlichen Anforderungen an diese Tests auf der anderen Seite als unentbehrlich. Zu meinen, das Gesetzgebungsexperiment sei kein eigenständiges Gebilde oder kein eigenständiger Topos unserer Wissenschaft, halte ich für falsch. Es ist meines Erachtens nicht richtig, etwa ein Modellversuchsgesetz oder ein Pilotprojekt in den Medienbereichen hinsichtlich ihrer grundsätzlichen normativen Qualität gleichzusetzen z.B. mit dem Bürgerlichen Gesetzbuch. Das sind zwei völlig verschiedene Typen von Gesetzen. Das gibt mir noch die Möglichkeit, daran zu erinnern, daß man natürlich über die Gesetzestypen vielfältig noch weiter hätte differenzieren können. Aber dazu fehlte leider die Zeit. Ich meine, das Gesetzgebungsexperiment muß wegen seiner spezifischen Rechtsfolgen und wegen seiner besonderen Gefährlichkeit für bestimmte Verfassungs- 
gehalte auch verfassungsrechtlich spezifisch eingegrenzt werden, und ich würde es für fatal halten, wenn sich die Ansicht durchsetzen würde, jedes Gesetz sei ein Experiment. Das Bundesverfassungsgericht hat etwa gesagt, wenn der Gesetzgeber zum ersten Mal ein neues Gebiet regele, dann seien die ihn treffenden Pflichten zur Ermittlung und Prognose sowie die Bindungen an die Geeignetheit weniger intensiv als bei sonstigen Gesetzen in bereits durchnormierten Bereichen. Ich meine, hier zeigen sich bedenkliche breitflächige Gefährdungen wichtiger verfassungsrechtlicher Prinzipien (z. B. der Erforderlichkeit, der Geeignetheit sowie der gesetzgeberischen Ermittlungspflicht), wobei in dieser Rechtsprechung freilich derartige Gefährdungen nicht durch zusätzliche Verfassungssicherungen kompensiert werden. Diesen Aufweichungen verfassungsrechtlicher Standards zur Gewinnung einschlägiger gesetzgeberischer Erfahrungen kann dadurch begegnet werden, daß eine engumgrenzte Rechtsfigur des Gesetzgebungsexperiments mit spezifischen Sicherungen und Rechtsfolgen für notwendige Tests bereitgestellt wird.

Nun zum Argument von Herrn Lerche zur fehlenden Umkehrbarkeit bei Experimenten, wonach es unerläßlich sei, daß Gesetzgebungsexperimente vollendete Tatsachen schafften. Gewiß ist es z.B. unvermeidlich, daß der im Rahmen des Gesetzgebungsexperiments der einstufigen Juristenausbildung Ausgebildete eben nun ein einstufig ausgebildeter Jurist ist; das kann man nicht umkehren. Ich wäre mißverstanden worden, wenn man sozusagen in jedem Fall der Beendigung eines Gesetzgebungsexperiments gewissermaßen totale $\mathrm{Na}$ turalrestitution fordern würde. Das geht natürlich nicht. Meine Forderung geht dahin, daß ich eine grundsätzliche Umkehrbarkeit bei Gesetzgebungsexperimenten anstrebe. Ich möchte nicht, daß man sagt: Das Gesetzgebungsexperiment ist da, davon können wir jetzt nicht mehr weg, also müssen wir die endgültige Lösung nach dem Muster des Gesetzgebungsexperiments machen. Daß Schäden oder jedenfalls Beeinträchtigungen durch Gesetzgebungsexperimente möglich sind, meine ich, habe ich dadurch zum Ausdruck gebracht, daß ich vom Gesetzgeber fordere, Testopfer auszugleichen. Aber ein solcher Ausgleich von Testschäden setzt natürlich voraus, daß überhaupt erst mal solche entstehen.

Vorsitzender: Danke schön, Herr Kloepfer. Auf der Liste der Interessenten für den zweiten Teil stehen zehn Namen. Ich entziehe mich der weiteren Verantwortung dafür, daß alle zu Wort kommen, dadurch, daß ich das Schicksal der Kollegen am Ende der Liste in die Hand der Kollegen an deren Spitze 
lege. Und ich weiß, Herr Zacher, das Schicksal ist bei Ihnen gut aufgehoben. (Heiterkeit). Bitte.

Zacher: Zunächst eine beruhigende Bemerkung zur Normenflut. Sie scheint noch nicht sehr schlimm zu sein. Wenn ich sehe, daß wir immer noch die Freiheit haben, ohne jede gesetzliche Regelung das Wort „Distanz" als „distance“ auszusprechen oder „distance“ auch als „Distanz“ zu schreiben, so beruhigt mich das ungemein.

Nun, ein kleiner Nachtrag zum diagnostischen Teil der Abhandlung. Ich meine - das ist mehrfach gefallen - wir müßten einen Kreislauf an Autoritätsverlust registrieren: nämlich die Zunahme von Gesetzen hat mit der Abnahme der Amtsautorität zu tun. Die Entscheidung des Lehrers wird nicht mehr akzeptiert, wenn er sich nicht auf das Gesetz berufen kann. Also bekommt er ein Gesetz. Der nächste Schritt ist, daß auch die Entscheidung des Gesetzes nicht mehr akzeptiert wird. Wir haben es also nicht nur mit einer Gesetzeskrise, sondern schlechthin auch mit einer Autoritätskrise zu tun.

Nun zum therapeutischen Teil. Da habe ich zunächst eine Frage an Herrn Fromont. Vielleicht könnte er uns sagen, wie in Frankreich die Erfahrungen mit dem Conseil d'Etat sind, ob er ein Instrument ist, um uns weiterzuhelfen. Seine große Tradition werden wir allerdings durch Transplantation nicht in unser System hereinholen können.

Nun aber zu dem eigentlichen Punkt: Ich glaube, die zentrale therapeutische Aufgabe jenseits marginaler Möglichkeiten durch institutionelle Vorkehrungen ist die systematische Wiederentdeckung und Aufbereitung der Vielfalt der Steuerungsmechanismen. Wir haben ja seit der französisischen Revolution nicht nur, wie Peter Badura so klar hervorgehoben hat, den Zentralbegriff des Gesetzes entdeckt und kultiviert sondern dies hat sich in einer Entwicklung vollzogen, die auf eine DreiBereiche-Gleichung hinauslief: Recht $=$ Geset $z=$ Zuständigkeitsbereich des Richters. Das deutete sich zunächst nur an, hat sich dann das ganze 19. Jahrhundert hindurch nach und nach geklärt, noch in unser Jahrhundert hinein unvollkommen realisiert, bis wir nach 1945 diese Gleichung geradezu gewitterartig postuliert und perfekt realisiert haben. Von daher muß ich davor warnen, zu erwarten daß - und da muß ich Kritik an den Referaten üben, vor allem, wenn ich recht sehe, an dem von Herrn Kloepfer, aber auch, glaube ich, an dem von Herrn Eichenberger - die Beruhigung von den Richtern kommen könne. Nein, die Richter waren es ja weitgehend, die den Gesetzgeber hineingetrieben haben in diese Situation, die wir jetzt haben. Aber mehr noch: Die Richter, die Parlamentarier 
in der Legislative, die Exekutive, die die Gesetze vorbereitet, und wir als Öffentlichrechtler, wir alle haben uns in die Hand gearbeitet, denn es war unser aller Kompetenz, die wir damit ausgeweitet haben. Wo Recht war, da waren wir kompetent, da hatten wir mitzureden. Und ich glaube, diese Psychologie darf man bei der ganzen Entwicklung, die wir erlebt haben, nicht verkennen. Was wir nun vor uns haben, ist eine ganz gewaltige Schizophrenie. Wir haben den großen Vordergrund der Universalität, der Allmacht, der Allgegenwart des Gesetzes - „das Gesetz kann alles" - , und im schwer überschaubaren Hintergrund haben wir verschiedenste Bereiche einer evidenten Ohnmacht des Gesetzes, auch einer ignorierten Ohnmacht des Gesetzes. Wir haben Bereiche der evidenten Ohnmacht des Gesetzes, z. B. im Tarifbereich, im ganzen Bereich der Gewerkschaftsmacht, wo nur der Richter noch Rechtsmacht darstellen kann, nicht der Gesetzgeber. Wir haben noch nicht wahrgenommene Bereiche der Ohnmacht des Gesetzes, in welche die Steuerungsmechanismen des Rechts gar nicht eindringen können, wo schon als Steuerung etwa Ausbildung mehr hilft als Recht das exekutiert wird, was gelernt worden ist, nicht das, was angeordnet worden ist. Es ist ja das Elend des ganzen Übermaßes an Schulrecht, daß man nicht einfach einem Lehrer, nachdem er Jahre in der Praxis war, verordnen kann: „So, aber jetzt ab morgen so." Da kann er nicht einfach umlernen. Da ist ferner der ganze Bereich der Sozialarbeit. Hier endet die Macht des Rechts; wie personale Dienste zu erbringen sind, läßt sich erklären, im Kern aber nicht anordnen. Dies sind nur Beispiele. Wir stehen also an Grenzen, die durch die Doktrin der Allgegenwart und Allmacht des Gesetzes zu sehr überdeckt werden. Und ich würde meinen, daß es in der Tat uns obliegt, diese Grenzen systematisch aufzuspüren, und zwar nicht mit dem Repertoire der Vergangenheit, wo es etwa geheißen hat „Was ist Hausgut der Verwaltung?" usw., sondern nun mit einer Systematik, die einer Dienstleistungsgesellschaft, einem Sozialstaat, einem Dienstleistungsstaat gerecht wird. Wir haben lange genug - einige Jahrzehnte hindurch - Gesetzgebern und Richtern vorgeredet, daß das Recht überall hineinregieren muß. Und wir sind es, glaube ich, nun dem System schuldig, da $\beta$ wir auch dazu beitragen, Wege zur Repluralisierung, und zwar zu einer geordneten Repluralisierung unseres Rechtssystems, zu finden.

Meyer: Herr Kloepfer, Sie haben sicherlich recht in der Feststellung, daß die Verfassung nicht unter Politikvorbehalt steht. Aber Ihre Auslegung der Verfassung wird man sicher darauf befragen dürfen, wie sie mit dem Demokratieprinzip zu 
vereinbaren ist. Der Rechtsstaat als Distanzstaat ist Ihre Erfindung, nicht eine Erfindung des Grundgesetzes. Hätten Sie nämlich recht, dann wären die Volksentscheide in den Ländern wegen Art. 28 GG grundgesetzwidrig, weil sie rechtsstaatswidrig wären; denn es gibt keinen Typ von distanzloserem Gesetz als den Volksentscheid. Ein zweiter Punkt: Sie haben die Behauptung aufgestellt, wir hätten eine Übernormierung; diese Behauptung haben sie freilich selbst glänzend widerlegt. Sie haben nämlich gesagt, die Gesetzesflut sei eine Änderungsflut. Dann aber geht es gar nicht um die Erweiterung der Gesetzesmasse, sondern lediglich um eine Veränderung. Und schon sind wir beim alten Thema: Wie steht es mit dem status quo, wie steht es mit dem Bestands- oder Vertrauensschutz? einem Thema, das wir schon in Mannheim behandelt haben und morgen wahrscheinlich wieder behandeln werden - dank der „kontinuitätswahrenden“ Arbeit dieses Vorstandes! Was im übrigen die Kontinuitätswahrung angeht, so darf ich auf Frankreich oder England verweisen. Dort nimmt man keinerlei Rücksicht darauf, was die vorangegangene Regierung gemacht hat, führt vielmehr ohne Hemmung gravierende Änderungen durch Gesetz ein. Sie haben die These der Übernormierung aber nicht nur durch den Hinweis auf den bloßen Änderungscharakter widerlegt, sondern auch dadurch, daß Sie gesagt haben, was wir brauchen, ist eine Verdünnung des Rechts oder der Gesetze. Wenn Sie aber die Gesetze ausdünnen, bleiben die ausgedünnten Stellen nicht etwa rechtsfrei, es fließt vielmehr Verfassungsrecht hinein, das wir wiederum auszulegen haben. Die Folge ist nur eine Kompetenzverlagerung vom Gesetzgeber auf uns oder in der Konsequenz zu den Gerichten oder zum Bundesverfassungsgericht. Ein dritter Punkt: Was die Präparationsphase der Gesetzgebung angeht, so gibt es eine rudimentäre Regelung im deutschen Recht, nämlich in der gemeinsamen Geschäftsordnung der Bundesministerien. Ich bin unsicher, inwieweit man diese erweitern könnte, möchte aber auf folgendes Dilemma hinweisen. Die Gesetzgebungsarbeit geschieht in den zuständigen Ressorts. Wenn man die Gesetzgebungsvorbereitung aus diesem Subsystem der Regierung herausnimmt, würde die Regierung in ihrer Gliederung selbst berührt, was um so schwieriger ist, als unsere Parlamente sich mittlerweile dieser Regierungseinteilung angeschlossen haben, da die Parlamentsausschüsse den einzelnen Ministerien zugeordnet sind. Dies hat zur Konsequenz, daß das Interessenpotential voll hinter jedem Gesetz steht, nämlich einmal über das Ressort und zum anderen über den jeweiligen Ausschuß, und die Frage stellt sich, durch 
welche Stelle noch irgendeine neutralisierende Wirkung gewährleistet werden könnte - sicherlich nicht durch einen Verfassungsdienst. Zum Schluß: Den Umweg, Herr Kloepfer, über die Regelungen des Vertrauensschutzes beim Widerruf halte ich für kurios; denn diese Regeln sind just aus der Verfassung abgeleitet worden. Wenn Sie dieselben Regeln auf die Gesetzgebung anwenden wollen, können Sie sie unmittelbar aus der Verfassung holen.

Vogel: Herr Kloepfer: Vertrauensschutz beim Kindergeld scheint mir ein nicht ganz angemessener Gedanke. Gewissermaßen ein Plangewährleistungsanspruch für Familienplanung? Das geht doch wohl zu weit. Herr Novak Ihnen danke ich herzlich für die Klarstellung, daß Sie nicht haben sagen wollen, in dieser Vereinigung sei stets für die Ausweitung des Gesetzesvorbehalts plädiert worden. Ich weiß mich in diesem Dank mit Herrn Herzog einig. Jetzt aber zu etwas anderem:

Mit den Referenten stimme ich darin überein, daß wir, ausgehend von einer Phase des Normenhungers über eine Zeit der Normenvöllerei inzwischen zu einem Zustand gekommen sind, in dem uns Menge und (mangelnde) Qualität der Normen schwer auf dem Magen liegen. Ich möchte hier auf die Kosten dieses Gesetzgebungsstils hinweisen - nicht auf die ,politischen", sondern die ganz realen Kosten, auch nicht etwa nur auf die Kosten jener Leistungsgesetze, die wir inzwischen alle paar Jahre einmal durch Haushaltssicherungsgesetze zurückzustutzen gewohnt sind, sondern vor allem auf die durch die Fülle der Gesetze ständig wachsenden Verwaltungsausgaben (im Sinne des Art. 104a Abs. 5 GG und ein wenig darüber hinaus: einschließlich der Kosten der Vermehrung des Beamtenapparats zum Vollzug der Gesetze, und auch der Richterstellen). Die Finanzgerichtsbarkeit gibt ein deutliches Beispiel dafür, wie schlechte Gesetzgebung immer mehr Richterstellen erforderlich macht und dennoch die Gerichte mit der Prozeßlawine nicht Schritt halten können; für die Verwaltung gilt Entsprechendes. Wir stehen inzwischen an einer Stelle, an der die Grenzen der Möglichkeit, den Vollzug solcher Gesetzgebung überhaupt noch zu finanzieren, in Sichtweite liegen; ich kann dafür unmittelbar auf unsere Innsbrucker Beratungen verweisen. Herr Kloepfer hat, wie ich meine zu Recht, darauf hingewiesen, daß unsere Gesetze heute zum Teil überhaupt nur noch symbolischen Charakter haben. Nehmen wir nur das Stabilitäts- und Wachstumsgesetz: es ist ja doch auffallend, daß ziemlich genau seit dem Erlaß dieses Gesetzes uns zunächst nach und nach die Stabilität abhanden gekommen ist und inzwischen auch schon das Wachstum. 
Indes gerade an dieser Stelle erwächst aus dem Leiden auch ein starker Anreiz zur Therapie. Denn der Gesetzgeber hat offenbar nur noch zwei Möglichkeiten: entweder weiterzumachen wie bisher - dann wachsen die Vollzugsdefizite, und wir bekommen maghrebinische Zustände, in denen Gesetze mit einem gewissen Augenzwinkern erlassen werden, von vornherein schon in dem Bewußtsein, daß man sie nicht wird vollziehen können. Oder der Gesetzgeber ringt sich, was freilich derzeit nicht sehr wahrscheinlich ist, dazu durch, seine Gesetzesproduktion auf ein Maß zurückzuschneiden, in dem sie vollziehbar bleibt. „Wo aber Gefahr ist, wächst das Rettende auch" - das ist Hölderlin. Wir stehen an einem Scheideweg: es kommt jetzt nur darauf an, jenes „Rettende" auch zu ergreifen.

Stern: Im ersten Teil der Diskussion ist mit Recht darauf hingewiesen worden, da $\beta$ das Thema Gesetzesmalaise und ihre Abhilfe kein neues Thema ist. Aber das entscheidend Neue unter dem Blickpunkt, unter dem wir es heute behandeln, ist, daß wir es unter verfassungsrechtlichen Gesichtspunkten erörtern müssen, das heißt unter der Existenz - ich will es einmal so ausdrücken - eines Gesetzes auch für den Gesetzgeber. Unter diesem Blickpunkt sehe ich mit Herrn Eichenberger, mit Herrn Starck und gegen Herrn Wielinger die Frage einer Gesetzgebungslehre als ein ganz wichtiges, verfassungsrechtliches Postulat. Ich bedauere es, daß wir Kollegen des Staatsrechts, dies zu verwirklichen, leider weithin den Methodikern und den Damen und Herren der allgemeinen Rechtslehre überlassen haben. Wir sollten in diese Dinge einsteigen und könnten dadurch auch manches bewältigen. Beispielsweise sind vorhin die Geschäftsordnungen erwähnt worden. Ich appelliere da auch an meine eigene Brust: In der Enquêtekommission Verfassungsreform haben wir es versäumt, dieses Thema so gebührend zu behandeln, wie es notwendig gewesen wäre, vielleicht deshalb, weil uns die Abgeordneten und die Ministerialbeamten deutlich gemacht haben, man müsse dies allein unter dem Gesichtspunkt der Gesetzesberatung sehen.

Welche Abhilfen sind denkbar? Herr Eichenberger hat vor allen Dingen darauf hingewiesen, daß man in der Frage der Gesetzgebungspräparation Verbesserungen schaffen kann. Das richtet sich in erster Linie an die Regierung und den Apparat, der ihr zur Verfügung steht. In der Tat ein wichtiges Postulat, hier eine Anlaß- und Motivprüfung anzustellen, und zwar sehr viel sorgfältiger, als sie derzeit geschieht. Ich halte es für verhängnisvoll, wenn man die Deckblätter von Gesetzge- 
bungsentwürfen liest und dort bei den Bemerkungen „Kosten“ meistens vermerkt findet: „keine“. . . oder sie sind auf andere Beteiligte - sei es Länder, Gemeinden oder sonst jemand - überwälzt. Oder wenn man die Bemerkung antrifft: "Alternativen: keine"; das ist absolut unzureichend und das ist insonderheit für den Abgeordneten unbefriedigend. Daher muß er sich ja den Sachverstand von Interessenverbänden und Gesetzgebungshilfsdiensten und dergleichen beschaffen.

Ich glaube, Herr Kloepfer, um jetzt Ihr Wort Distanz distance aufzugreifen, hier liegt doch ein wichtiges Moment, wieder zu erkennen, daß die Regierung als gemeinwohlverpflichtet eine gewisse Unabhängigkeit auch gegenüber den sie tragenden Parteien und sonstigen Gruppierungen $\mathrm{zu}$ wahren hat. Vielleicht dachten Sie da auch an die Idee des freien Mandats, das ebenfalls eine Rolle spielt.

Zweiter Vorschlag - Gesetzgebungsverfahren: Ich möchte hier noch einmal anknüpfen an die Unterscheidung, die wiederholt gemacht worden ist, von den Rechtsgesetzen als jenen Gesetzen, die maßgebend sind für die grundlegenden Lebensordnungen, nennen wir es einmal so, und jenen Gesetzen, die wir als Maßnahmegesetze, Zweckgesetze, Programmgesetze, Plangesetze usw. bezeichnet haben. Vielleicht sollte ein Ansatz gefunden werden, im Gesetzgebungsverfahren für diese verschiedenen Arten von Gesetzen auch gewisse prozedurale Unterschiede zu machen.

En passant: Ich bedauere es, daß wir in der Staatsrechtswissenschaft den Kampf gegen das Maßnahmegesetz so schnell aufgegeben haben und nicht vielleicht daran gedacht haben, ob aus Art. 19 Abs. 1 des Grundgesetzes nicht doch etwas herauszuholen ist. Es wäre meiner Meinung nach darüber noch einmal nachzudenken.

Schließlich könnte man, und das klingt bei Herrn Frowein und bei Herrn Zacher an, noch einmal die Frage aufwerfen: Sollte es nicht eine Institution geben, die vielleicht am Ende des Gesetzgebungsverfahrens noch einmal eine Überprüfung durchführt, und zwar nicht bloß auf Gesetzestechnik, sondern auch auf gewisse besondere Stimmigkeiten - In-Sich-Stimmigkeiten - in der Rechtsordnung? Ich weiß, daß der Art. 113 des Grundgesetzes auf einem anderen Bereich für die Regierung existiert; er wurde zwar fast nie angewendet, aber immerhin ist hier ein Vorbild eines gewissen Vorbehalts vorhanden, ehe ein Gesetz inkrafttritt.

Endlich - dritte Stufe - Gerichte sind ja wiederholt angesprochen worden: Ich kann mich mit dem Hinweis begnügen, den auch Herr Zacher aufgestellt hat. Hier sind gewisse Inter- 
dependenzen, Wechselbezüglichkeiten zwischen dem Thema Gesetzesstaat - Richterstaat vorhanden. Nur am Rande: Bei der verfassungskonformen Auslegung und Rechtsfortbildung - all das, was ebenfalls hier eine Rolle spielte - sollte man überlegen, ob nicht gerade diese Tendenz, ein fehlerhaftes Gesetz, ein nicht-richtiges Gesetz im Sinne von Herrn Eichenberger, wirklich unter allen Umständen aufrechtzuerhalten, aufgegeben werden sollte.

Letztlich Thema „Regelungslast“, „Wesentlichkeitstheorie“: Ich habe Sorge, daß hier manchmal das Kinde mit dem Bade ausgeschüttet wird. Das Schulrecht als typisches Beispiel ist hier allzu oft genannt worden.

Gestatten Sie mir an dieser Stelle noch eine Intervention zur Frage im ersten Teil mit der Kontroverse zwischen Herrn Kloepfer und Herrn Grimm. Herr Kloepfer, ich habe Sie doch richtig so verstanden: Es ging Ihnen nicht bloß um irgendwelche verfassungsrechtliche Postulate, sondern in einem höheren Sinne um das verfassungsstaatliche Anliegen schlechthin. Das ist mehr als das Verfassungsrecht, da gehört doch noch eine ganze Auslegungsreihe mit hinein, etwas, was wir vielleicht einmal im Sinne eines allgemeinen Verfassungsrechts, allgemeiner Prinzipien, zu entwickeln versuchen, und unter diesem Gesichtspunkt, Herr Grimm, meine ich, daß in den Anforderungen, die Herr Kloepfer aufgestellt hat, sicher mehr drin steckt, als Sie meinen. Denn gerade mit „Systemgerechtigkeit, Vertrauensschutz" sind doch allgemeine Begriffe verbunden, die zwar nicht ausdrücklich in der Verfassung stehen, aber aus Verfassungsprinzipien herausgeholt werden. Hier finde ich, daß einige von den verfassungsrechtlichen Geboten, die Herr Kloepfer aufgestellt hat, außerordentlich bedeutsam sind. Sicher müssen wir in dieser Hinsicht über vieles noch nachdenken. So freue ich mich, daß Sie den Begriff ,Übermaßverbot" aufgegriffen und damit dargetan haben, daß es Ihnen um mehr geht als nur um den Verhältnismäßigkeitsgrundsatz für die Eingriffsverwaltung.

Was ist schließlich die Quintessenz? Herr Eichenberger hat mit Recht gesagt: „Legistisches Können und politisches Maß, richtiges Recht, Gerechtigkeitsidee.“ Da liegen Grundaufträge an die heutigen Rechtsetzungsorgane. Der Beruf unserer Zeit zur Gesetzgebung, um Savigny/Thibaut wieder aufzugreifen, hängt von der Qualität unserer Gesetzgebungsorgane - und zwar aller Beteiligten am Gesetzgebungsverfahren - ab, und das ist nicht nur ein Postulat, das wir als Staatsrechtler auch an uns zu richten haben, sondern hier ist in vollem Umfange jeder einzelne, jeder Bürger, gefordert. 
Schuppert: Ich möchte nur zwei kleine Anmerkungen machen zu den Therapievorschlägen von Herrn Kloepfer. Punkt eins: Das Übernormierungsverbot. Ich frage mich, welche Rechtsqualität dieses Übernormierungsverbot eigentlich haben soll. Soll das ein verfassungsrechtliches Verbot sein mit der Konsequenz, daß es im Wege der Verfassungsbeschwerde über den Umweg von Artikel 2 gerügt werden kann? Ich wäre gespannt darauf, das Gesicht von Herrn Benda zu sehen, wenn die erste Verfassungsbeschwerde auf den Tisch kommt, mit der schlichten Begründung „Verstoß gegen das Übernormierungsverbot"(Kloepfer VVDStRL,S.68ff.).Ich glaubenicht, daß das ein Verfassungsgebot ist. Wenn es unterhalb der verfassungsrechtlichen Ebene liegt, dann möchte es möglicherweise so eine Art Obliegenheit des Gesetzgebers sein, und ich glaube, Herr Stern, in der Tat nur im Sinne einer Deckblattveränderungspflicht, indem zu den Rubriken Kosten und Alternativen „keine“ hinzukommt: „Erforderlichkeit: Siehe Gesetzesbegründung.“ $\mathrm{Da} ß$ es sich hier nicht um eine hochrangige Rechtspflicht handelt, scheint mir auch dadurch nahezuliegen, daß dieses Postulat in allen Parteiprogrammen vorkommt ebenso wie das Postulat, gegen die Staatsverschuldung vorzugehen oder die Bürokratieauswüchse zu kappen. Wenn Sie mir, Herr Vorsitzender, gestatten, mich in der Sprache des Politikers zu üben, so würde ich sagen: „Das Übernormierungsverbot ist eine politische Gemeinschaftsaufgabe aller Demokraten." Jetzt zu dem zweiten Punkt: der Distance. Ein schicker Begriff, wie ich eigentlich finde, aber ich weiß nicht, ob er nicht überfrachtet ist, und möchte gerne zu den Therapievorschlägen von Herrn Kloepfer Stellung nehmen. Er hat gesagt - unter anderem - , man könne dem Übernormierungsverbot dadurch Rechnung tragen und auch eine größere Distance dadurch herstellen, daß man den Bereich der quasigesellschaftlichen Rechtsetzung erweitert. Das halte ich für einen wenig tauglichen Weg, denn gerade die quasi-gesellschaftliche Rechtsetzung ist ja die distancelose Rechtsetzung par excellence. Denn wenn wir eine ganz einfache verwaltungswissenschaftliche Erkenntnis bemühen, daß nämlich Körperschaften, die so konstruiert sind, daß sie die Interessen ihrer Mitglieder bündeln, als interessenvertretende Körperschaften - jetzt etwas ketzerisch gesprochen - nichts anderes sind als „Interessenverbände im öffentlich-rechtlichen Gewande“, dann darf man sich nicht wundern, wenn sie die Rechtsprobleme in der engen Perspektive des Berufsstandes sehen; und wir sollten doch nicht die guten Erkenntnisse der Facharztentscheidung des Bundesverfassungsgerichts wieder verges- 
sen. Da hat der erste Senat des Bundesverfassungsgerichts in dankenswerter Weise den Gesetzesvorbehalt in der Weise aktualisiert, daß er gesagt hat, wir müssen ein Kontrollgesetz haben, um gerade zu vermeiden, da $\beta$ ein Berufsstand allein über die Regelungsprobleme in eigener Regie entscheidet. Das ist also ein Gesichtspunkt gerade für mehr Gesetze. Und jetzt ein letzter kleiner Gesichtspunkt, mit dem ich schon - wenn Sie mir erlauben, Herr Vorsitzender - etwas überleiten möchte auf den morgigen Tag: Herr Kloepfer hat gesagt, Distance würde auch dadurch geschaffen, daß man Gesetzgebung und Gesetzesvollzug abkoppelt. Ich glaube, daß es ein falscher Weg wäre, Distancegewinn dadurch zu erzielen, daß der Gesetzgeber sich auf die Normierung von unbestimmten Rechtsbegriffen beschränkt und dadurch politische Konsense möglich macht und damit alles auf die Vollzugsebene der Verwaltung verschiebt. Denn dadurch treten Distanceverluste bei der Verwaltung ein. Es handelt sich mit anderen Worten um eine kommunizierende Röhre. Man kann nicht einen Distancegewinn bei der Gesetzgebung dadurch erkaufen, daß man die Verwaltung auf der Vollzugsebene - wie wir es im Umweltschutz ja erleben können -, in eine enge Klientelbeziehung zwingt und sie dadurch nötigt, Interessenaushandlungsprozesse ohne Distance wahrzunehmen. Aber ich will nicht vorgreifen auf den nächsten Tag.

Vorsitzender: Danke schön, Herr Schuppert. Wir müssen hier die Diskussion leider abbrechen. Die Zeit drängt angesichts unseres Abendprogramms, das pünktlich beginnen muß, so sehr, daß ich nur noch die Referenten bitten kann, möglichst kurze Schlußworte zu sprechen. Zunächst Herr Kloepfer bitte.

Kloepfer: Ich stimme Herrn Zacher zu, daß die Vielfalt der staatlichen Steuerungsmechanismen dazu beitragen kann, die Übernormierung zu beseitigen.

Der Beitrag von Herrn Meyer ist, glaube ich, zum Teil auf eine unzulässige Vereinfachung zurückzuführen. Das Distanzgesetz, die Distanzvorstellung sind ja hier sozusagen nicht als eine über Artikel 79 Abs. 3 Grundgesetz hinausgehende Bestimmung angesehen worden. Natürlich haben wir bei Formen der direkten Demokratie, zum Beispiel etwa beim Volksentscheid, die Distanz zwischen Repräsentierten und Repräsentanten nicht mehr. Wir haben hier aber ein anderes Modell, (inhaltliche) Distanz zu erzeugen. Normalerweise sind nämlich die zur Abstimmung gestellten Fragen recht allgemein und notwendig verkürzt. Nur allgemeine - meistens auf einen Satz $\mathrm{zu}$ bringende - Postulate, nicht aber detaillierte Einzelrege- 
lungen sind in der Regel politisch volksentscheidungsfähig, so daß auf diese Weise inhaltliche Distanz geschaffen werden kann.

Herr Meyer meinte zu Unrecht, daß die Übernormierung deshalb nicht bestünde, weil heute die meisten Gesetze bloße Gesetzesänderungen seien. Dies verkennt zweierlei. Erstens ist natürlich auch ein Aspekt der Übernormierung die Tatsache, daß ständig ein neues Sicheinstellen der Rechtsunterworfenen auf neue Gesetzesänderungen erforderlich wird. Die Vielfalt der Gesetzesänderungen ist eine typische Erscheinung der Übernormierung. Aber die scheinbar schlüssige Argumentation von Herrn Meyer, die Gesetzesänderung ersetze ja stets gewissermaßen nur, führe aber nicht zu einer absoluten Vergrößerung des Normenbestandes, ist ja regelmäßig unrichtig, wenn man sich die Gesetzesänderungen in der Praxis anschaut. Die Gesetzesänderung wird sehr häufig dazu benutzt, bisherige Regelungen zu korrigieren, zu präzisieren und bislang nicht erfaßte Randbereiche durchzunormieren. Man muß einmal mehrere ursprüngliche Gesetze und Gesetzesänderungen nebeneinander halten. Da kommt im Ergebnis fast immer erheblich mehr raus als aufgehoben wird, so daß also auch die Gesetzesänderungen selbst den Normenbestand regelmäßig insgesamt ansteigen lassen, von Überleitungsvorschriften jetzt einmal ganz abgesehen. Dies hängt eben damit zusammen, da $ß$ die Gesetzesänderung normalerweise mit dem Anspruch auftritt, eine Gesetzesverbesserung zu sein; und der Gesetzgeber meint meistens, das Gesetz dadurch verbessern zu können, daß er jetzt noch detaillierter regelt, noch bestehende Lücken füllt usw. Ich halte es schließlich historisch nicht für richtig, daß die Widerrufslehre aus der Verfassung entwickelt worden sei.

$\mathrm{Zu}$ den Einwänden von Herrn Schuppert: Herr Schuppert, ich darf Sie nur auf Satz 3 meiner These 5 hinweisen. Sie haben hier ja mit Nachdruck darauf hingewiesen, daß es kein allgemeines Übernormierungsverbot gebe. Sie haben dabei vorgegeben, meine Thesen zu widerlegen; nur steht Ihr Einwand leider fast wörtlich bereits in meinen Thesen, auf die ich deshalb nochmals verweisen darf. Die Frage der jetzt auch von Ihnen festgestellten Distanzlosigkeit der privaten Rechtsetzung habe ich in meinem Referat bereits zum Anla 3 genommen, mehrere Sätze auf die Frage zu verwenden, wie dabei die in der Tat bestehende Distanzarmut von den formulierenden Interessen beseitigt werden kann. Meine Folgerung: Der Staat kann hier auf Kontrolle nicht ganz verzichten, sondern er muß versuchen, etwa durch ausgewogene Beteiligung der normierenden Interessen und dergleichen eine Mindestdistanz herzu- 
stellen. In dem Augenblick, wo es - z.B. bei der staatlichen Rezeption privater Normen - um staatliche Rechtsetzung geht, werden diese Distanzgehalte noch verschärft, und deshalb bedarf es dann stets einer konkreten, rechtsstaatlich gebundenen, distanzierten Rezeptionsentscheidung, so daß ich mich auch hier im Ergebnis bestätigt fühle.

Die grundsätzliche Frage, die sich am Ende stellt, ist meines Erachtens die, ob die hier mehrfach — insbesondere von Herrn Doehring - angesprochene drängende Problematik des Autoritätsverlusts des Rechts eigentlich wirklich vorrangig erklärbar ist mit der Übernormierung. Es wäre wohl zu leicht, wollte man sagen, wir haben zu viele Gesetze und meinetwegen auch zu schlechte Gesetze und vor allem deshalb komme es zu einem Autoritätsverlust des Rechts. Im Grunde würde dadurch das Phänomen der Rechtsmüdigkeit oder gar der Rechtsfeindschaft entpolitisiert. Ich glaube, es handelt sich bei der verbreiteten Rechtsanimosität vor allem um ein politisches Problem, was sicherlich auch, jedoch nicht vorrangig im Phänomen der Übernormierung wurzelt. Aber um über die komplexen Ursachen dieser Unbeliebtheit des Rechts umfassend und differenziert nachzudenken, bedürfte es sicherlich einer neuen Tagung unserer Vereinigung. Ich meine, und damit möchte ich schließen, daß das Recht auch in der pluralistischen Demokratie mehr ist als ein nur unverbindliches Handlungsangebot an den Bürger. Die Gesetzesbindung des Bürgers wieder zu verstärken, ist gerade heute ein wesentliches Anliegen des Rechtsstaats.

Novak: Auch ich stehe jetzt unter dem Druck, aus den zahlreichen Diskussionsbeiträgen auszuwählen. Ich bitte, das nicht als Wertung meinerseits zu betrachten, sondern als reine Willkür. Ich möchte an zwei Wortmeldungen anknüpfen. Einerseits hat Herr Zacher, und eben auch Herr Kloepfer, die Aufdeckung der Vielfalt an möglichen Steuerungsmechanismen angeregt. Andererseits wurde das Bedenken zum Ausdruck gebracht, daß eine „Ausdünnung“ der gesetzlichen Regelung durch Richterspruch aufgefüllt wird; und - wir können weitergehen - auch aufgefüllt wird durch Ausübung privater oder verbandlicher Rechtssetzungs- und Quasi-Rechtssetzungsmacht. Diese unterschiedliche Sicht, die mehrfach angeklungen ist, zeigt, daß unsere Thematik ganz natürlich eine politische Seite hat. Es wird allerdings notwendig sein, zwischen dem rechtspolitischen und dem gesellschaftspolitischen Aspekt zu trennen. Auf das gesellschaftspolitische Problem soll nicht eingegangen werden; das wurde auch im Rahmen der Aussprache grundsätzlich vermieden. Wir würden hier 
zwangsläufig in eine neue Frontstellung zwischen Rechtsstaat und Sozialstaat geraten. Die Beschränkung auf die rechtspolitische Frage mag wiederum insofern unbefriedigend sein, als sie nur kleine Schritte und bescheidene Lösungen erlaubt. Ich glaube freilich, daß auch unter diesem Gesichtspunkt der Gedanke gesellschaftlicher Selbststeuerung durchaus seinen Platz haben kann. Ich erinnere an Regelungen, wie sie aus der österreichischen ebenso wie aus der deutschen Rechtsordnung vertraut sind, die etwa im Baurecht oder Wasserrecht der gütlichen Einigung der Parteien Vorrang geben vor der Entscheidung der Behörde. Sicherlich kein großer Wurf im Sinn eines Subsidiaritätsprinzips, aber doch ein Ansatz dazu. Vielleicht müßte der Weg realistischerweise wirklich so aussehen, daß man die einzelnen Rechtsgebiete durchforstet und mit Verbesserungen dieser Art zu einer Vereinfachung des Gesetzes und einer Entlastung des Gesetzgebers gelangt. Daß daneben die Postulate der Gesetzestechnik und der Gesetzgebungslehre beherzigenswert sind, ist unbestritten. Nur möchte ich für die Rechtslage in Österreich ein Fragezeichen hinter die These setzen, daß die Forderungen der Gesetzgebungslehre in mehr oder minder weitem Umfang aus dem Verfassungsrecht abgeleitet werden können. Das mag an unserer Verfassung liegen - Herr Kloepfer hat diesbezüglich von einem altertümlichen Verfassungsverständnis gesprochen. Zugegeben, wie sollte es anders sein; die österreichische Bundesverfassung ist eben alt und reformbedürftig. Immerhin, das Bewußtsein dafür und das Bemühen um Fortentwicklungen ist in Literatur und Rechtsprechung deutlich im Wachsen begriffen.

Meine sehr geehrten Damen und Herren Kollegen, es ist Brauch, daß auch der Referent sich am Ende der Diskussion bei Ihnen bedankt. Ich möchte das in einer Form tun, die dem behandelten Gegenstand angemessen ist. Es gibt in den weitläufigen Auseinandersetzungen um die Gesetzesflut viele hübsche Bilder. Eines davon lautet, daß das Gesetz heutzutage oftmals einem "Schuß ins Dunkle“ gleicht. Nun, ich meine, auch ein Referat vor diesem Forum ist in gewisser Weise ein Schuß ins Dunkle. Ich möchte die Hoffnung aussprechen, daß dieser Schuß nicht ganz daneben gegangen ist. Ich glaube, das der Aussprache entnehmen zu dürfen, und danke Ihnen dafür sehr herzlich.

Eichenberger: Ich beschränke mich auf zwei Punkte. Das erste, ich darf nochmals an das Thema der heutigen Tagung erinnern: „Gesetzgebung im Rechtsstaat.“ Mir scheint, daß wir Anla $\beta$ haben, Idee und Begriff des Rechtsstaates wieder in Erwägung zu ziehen, nicht um die Werte in Frage zu stellen, 
aus denen der Rechtsstaat emporwächst, bei weitem nicht, gerade nicht, sondern um voranzukommen, den Rechtsstaat für die Gegenwart aufzubereiten. Insbesondere geht es darum, die Idee konkret genug fortzuführen. Das Unbehagen an der Gesetzgebung ist auch ein unbewältigtes Thema zeitgemäßer Rechtsstaatlichkeit. Eine zweite Bemerkung, woran ich anknüpfen darf an Herrn Stern und Herrn Starck insbesondere: Wir, die Staatsrechtswissenschaftler, sind aufgefordert, mindestens an einem Ort keine Distanz zu wahren, unsere Distanz aufzugeben, nämlich unsere vornehme Distanz zur realen Gesetzgebung, und uns bewußt zu sein, daß bei der Gesetzgebung und beim Bemühen um Gesetzgebung auf richtiges Recht hin auch unsere Sache betrieben wird.

Vorsitzender: Meine Dame, meine Herren! Ich möchte ihnen abschließend für die faire, lebhafte und intensive Diskussion danken. Die wesentlichen Voraussetzungen für diese Diskussion haben unsere Referenten in - wie ich glaube sagen zu dürfen - hervorragender Weise geschaffen. Dafür gebührt ihnen unser aller Dank, den ich hier noch einmal wiederholen möchte. Damit ist die Sitzung geschlossen. 
